\title{
The effect of driving conditions and ambient temperature on particulate matter emission rates and size distributions from light duty gasoline-electric hybrid vehicles
}

\author{
By \\ Martha Christenson, B.Sc. Eng \\ A thesis submitted to the Faculty of Graduate Studies and Research \\ in partial fulfillment of the requirements for the degree of \\ Master of Applied Science \\ in \\ Environmental Engineering ${ }^{*}$ \\ Department of Civil and Environmental Engineering \\ Carleton University \\ Ottawa, Ontario \\ Canada
}

\footnotetext{
${ }^{*}$ The Master of Applied Science in Environmental Engineering Program is a joint program with the University of Ottawa administered by the Ottawa-Carleton Institute for Environmental Engineering
}

CCopyright, 2007 


$\begin{array}{ll}\begin{array}{l}\text { Library and } \\ \text { Archives Canada }\end{array} & \begin{array}{l}\text { Bibliothèque et } \\ \text { Archives Canada }\end{array} \\ \begin{array}{l}\text { Published Heritage } \\ \text { Branch }\end{array} & \begin{array}{l}\text { Direction du } \\ \text { Patrimoine de l'édition }\end{array} \\ \begin{array}{l}\text { 395 Wellington Street } \\ \text { Ottawa ON K1A 0N4 }\end{array} & \begin{array}{l}\text { 395, rue Wellington } \\ \text { Ottana ON K1A ON4 } \\ \text { Canada Oa }\end{array}\end{array}$

Your file Votre référence ISBN: 978-0-494-26985-5 Ourfile Notre référence ISBN: 978-0-494-26985-5

NOTICE:

The author has granted a nonexclusive license allowing Library and Archives Canada to reproduce, publish, archive, preserve, conserve, communicate to the public by telecommunication or on the Internet, loan, distribute and sell theses worldwide, for commercial or noncommercial purposes, in microform, paper, electronic and/or any other formats.

The author retains copyright ownership and moral rights in this thesis. Neither the thesis nor substantial extracts from it may be printed or otherwise reproduced without the author's permission.
AVIS:

L'auteur a accordé une licence non exclusive permettant à la Bibliothèque et Archives Canada de reproduire, publier, archiver, sauvegarder, conserver, transmettre au public par télécommunication ou par l'Internet, prêter, distribuer et vendre des thèses partout dans le monde, à des fins commerciales ou autres, sur support microforme, papier, électronique et/ou autres formats.

L'auteur conserve la propriété du droit d'auteur et des droits moraux qui protège cette thèse. $\mathrm{Ni}$ la thèse ni des extraits substantiels de celle-ci ne doivent être imprimés ou autrement reproduits sans son autorisation.
In compliance with the Canadian

Privacy Act some supporting forms may have been removed from this thesis.

While these forms may be included in the document page count, their removal does not represent any loss of content from the thesis.
Conformément à la loi canadienne sur la protection de la vie privée, quelques formulaires secondaires ont été enlevés de cette thèse.

Bien que ces formulaires aient inclus dans la pagination, il n'y aura aucun contenu manquant. 
The undersigned hereby recommend to the Faculty of Graduate Studies and Research acceptance of the thesis entitled

\title{
The effect of driving conditions and ambient temperature on particulate matter emission rates and size distributions from light duty gasoline-electric hybrid vehicles
}

\author{
Submitted by \\ Martha Christenson, B.Sc. Eng \\ in partial fulfillment \\ of the requirements for the degree of
}

Master of Applied Science

Deniz Karman, Thesis Co-Supervisor

Lisa Graham, Thesis Co-Supervisor

Gil Hartley, Chair, Department of Civil and Environmental Engineering

Carleton University

Ottawa, Ontario, Canada

2007 


\begin{abstract}
Particulate matter (PM) is an air pollutant known to cause reduced visibility, climate perturbations, and serious health problems when introduced into the human respiratory system. PM emissions from motor vehicles have properties that are known to negatively impact human health. The hybrid-electric vehicle (HEV) has been gaining widespread acceptance and has the potential to reduce emissions through reduced fuel consumption. In this study, PM number and mass emission rates, organic and elemental carbon compositions, and number-based size distributions were measured from four HEVs and one small conventional vehicle over five driving cycles at $20^{\circ} \mathrm{C}$ and $-18^{\circ} \mathrm{C}$. Vehicles were also tested at steady-state speeds of 40 and $80 \mathrm{~km} / \mathrm{h}$. Testing took place at the Emissions Research and Measurement Division of Environment Canada using conventional chassis dynamometer procedures. The patterns and trends observed could be taken into account when developing new PM modelling approaches.
\end{abstract}




\section{Acknowledgements}

I gratefully acknowledge the work of Lisa Graham, who is Senior Chemist at the Science and Technology Branch of Environment Canada and my co-supervisor. She initiated the light duty hybrid project long before I was involved, was paramount in over-seeing the project, and was an invaluable source of information and advice during all phases of this thesis.

I am also grateful to my co-supervisor Dr. Deniz Karman, professor in the Civil and Environmental Engineering Department at Carleton University. He provided valuable help, advice, and information throughout my thesis work, and was responsible for connecting me with the light duty hybrid project.

This work could not have been done without the efforts of the staff at the Emissions Research and Measurement Division (ERMD) of Environment Canada including drivers, sampling technicians, and chemical technologists. I gratefully acknowledge their crucial contribution to the project and my thesis.

I would also like to acknowledge the valuable work of Aaron Loiselle, a graduate student working on a parallel thesis related to the light duty hybrid vehicle project, who also worked on many of the data files used in this project.

Finally, I am thankful to Kirk Sutherland for important programming help which made the data analysis phase of this project much faster than it would otherwise have been. 
Funding for this project was provided by:

Natural Sciences and Engineering Research Council of Canada (NSERC)

Climate Change Technology and Innovation Initiative

Program for Energy Research and Development

Vehicles were provided by Transport Canada's Advanced Technology Vehicle Program. 


\section{Table of Contents}

ABSTRACT III

ACKNOWLEDGEMENTS IV

LIST OF TABLES $\mathbf{X}$

LIST OF FIGURES XI

\subsection{INTRODUCTION} 1

2.1 Particle Properties

2.2 PARTICLE FORMATION IN SPARK-IGNITION ENGINES

2.3 PARTICle Measurement ANd ChaRACTERIZATION

2.4 PM EMISSION REgulation AND CONTROL FOR MOBILE SOURCES

2.5 TRENDS IN PM EMISSIONS FROM SI VEHICLES

2.5.1 STEADY-STATE, TRANSIENT, AND DRIVING CYCLE BEHAVIOUR

2.5.2 ENGINE START-UP AND SHUT-DOWN

2.5.3 COLD AMBIENT TEMPERATURES

2.5.4 VEHICLE TECHNOLOGY

3.1 HYBRID CONTROL STRATEGIES 
3.4 SPECIFIC VEHICLES STUDIED

3.4.1 FORD ESCAPE HYBRID (2005) 33

3.4.2 TOYOTA PRIUS (2004) 34

3.4.3 HONDA CIVIC HYBRID (2003) 34

3.4.4 HONDA INSIGHT (2000)

3.4.5 GASOLINE SMART CABRIO (2002) 35

$\begin{array}{ll}\text { 3.5 FUTURE TRENDS } & 36\end{array}$

\begin{tabular}{lr} 
4.0 EXPERIMENTAL METHODOLOGY & 37 \\
\hline
\end{tabular}

$\begin{array}{ll}\text { 4.1 VEHICLE CONDITION } & 38\end{array}$

$\begin{array}{ll}\text { 4.2 CHASSIS DYNAMOMETER OPERATION } & 40\end{array}$

4.3 DRIVING CYCLES AND EMisSion DATA 41

$\begin{array}{lll}\text { 4.3.1 LA4 } & 43\end{array}$

$\begin{array}{ll}\text { 4.3.2 LA92 } & 45\end{array}$

4.3.3 HIGHWAY FUEL ECONOMY TEST (HWFET) 46

4.3.4 NEW YORK CITY CYCLE (NYCC) $\quad 47$

4.3.5 US06 SUPPLEMENTAL FEDERAL TEST PROCEDURE (US06-SFTP) 48

4.3.6 STEADY-STATE TESTS (SS40, SS80)

4.4 SAMPLing Methodology

4.4.1 DILUTION TUNNEL AND EJECTOR DILUTER 52

4.4.2 ELECTRICAL LOW PRESSURE IMPACTOR (ELPI)

4.4.3 CONDENSATION PARTiCle COUNTER (CPC) 56

4.4.4 CYCLONES AND FILTERS $\quad 58$

4.4.5 GAS ANALYSIS 
$\begin{array}{ll}\text { 5.1 DILUTION FACTOR } & 65\end{array}$

5.2 MODAL EMISSION RATES FROM ELPI AND CPC DATA

5.3 INTEGRATED EMISSION RATE FROM CPC AND ELPI

5.4 PM2.5 MASs EMission RATE

5.5 OC-EC MASS EMISSION RATE

$\begin{array}{ll}\text { 5.6 FUEL CONSUMPTION } & 78\end{array}$

$\begin{array}{ll}\text { 5.7 Net EnERgy Change VARIANCE } & 80\end{array}$

\begin{tabular}{lr} 
6.0 RESULTS AND DISCUSSION & 83 \\
\hline
\end{tabular}

6.1 The Transient Nature of Particulate Matter Emissions

$\begin{array}{ll}\text { 6.1.1 STEADY-STATE OPERATION } & 84\end{array}$

6.1.2 ACCELERATION, DECELERATION, IDLE, ENGINE-OFF 90

$\begin{array}{ll}\text { 6.1.3 START-UP } & 103\end{array}$

$\begin{array}{ll}\text { 6.1.4 COLD-START } & 105\end{array}$

6.2 INTEGRATED EMISSION RATES

6.2.1 NET ENERGY CHANGE VARIANCE AND EMISSION RATE 111

$\begin{array}{ll}\text { 6.2.2 STEADY-STATE EMISSION RATES } & 114\end{array}$

6.2.3 IMPACT OF DRIVING CYCLE ON EMISSION RATE $\quad 118$

6.2.4 IMPACT OF DRIVING CYCLE ON SIZE DISTRIBUTION 129

6.2.5 IMPACT OF COLD-START ON EMISSION RATE $\quad 138$

6.2.6 IMPACT OF COLD-START ON SIZE DISTRIBUTION

viii 


\section{List of Tables}

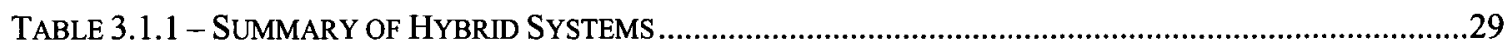

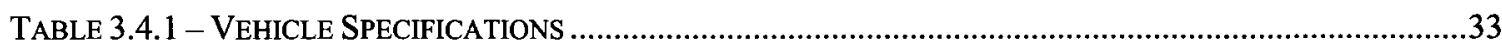

TABLE 4.1.1 - VEHICLE KILOMETRES TRAVELLED AT THE END OF TESTING ................................................38

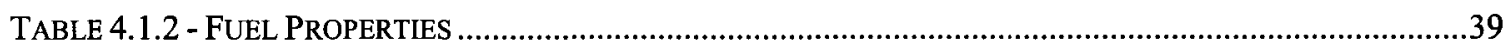

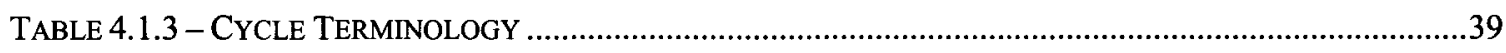

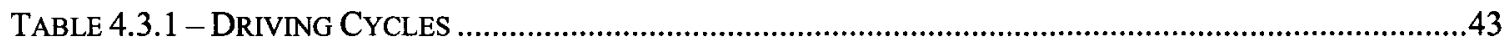

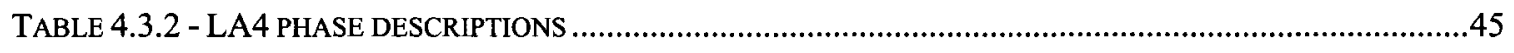

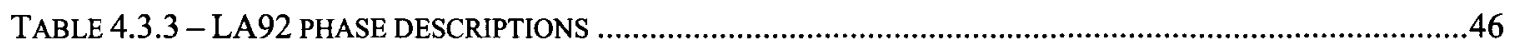

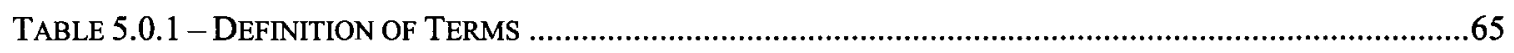

TABLE 5.2.1 - Condensation Particle Counter Specifications ......................................................70

TABLE 5.2.2 - NOMINAL IMPACTOR SPECIFICATIONS FOR 10LPM ELPI ....................................................71

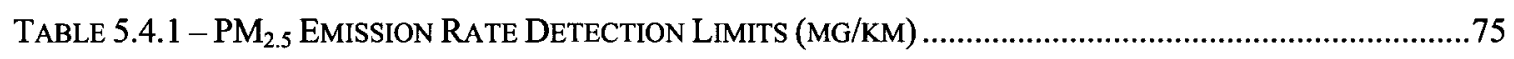

TABLE 5.5.1 - OC-EC EMISSION RATE DETECTION LIMITS (MG/KM) ......................................................78

TABLE 6.2.1 -TESTS WITH ABSOLUTE NEC GREATER THAN 1\% .......................................................112

TABLE 6.2.2 - RATIO OF US06 AND HWFET NUMBER EMISSION RATES $\left(\mathrm{KM}^{-1}\right)$ TO 80KM/H STEADY-STATE

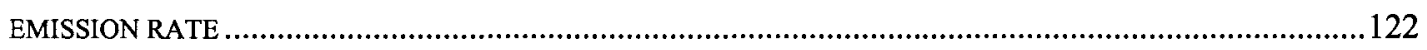

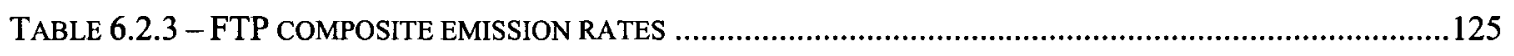

TABLE 6.2.4 - RATIO OF COLD-START TO HOT-START EMISSION RATES .......................................................139 


\section{List of Figures}

FIGURE 2.1.1 - IDEALIZED ATMOSPHERIC PM SURFACE AREA DISTRIBUTION SHOWING PRINCIPAL MODES, SOURCES OF MASS, AND PROCESSES INVOLVED IN MASS TRANSFER AND REMOVAL

FIGURE 2.1.2 - TYPICAL DIESEL ENGINE EXHAUST PARTICLE SIZE DISTRIBUTION

FIGURE 3.1.1 - SCHEMATIC OF HONDA IMA SYSTEM

FIGURE 3.1.2 - SCHEMATIC OF TOYOTA HSD SYSTEM 28

Figure 4.2.1 - SMART ON CHASSIS DYNAMOMETER

FIGURE 4.2.2 - CIVIC ON CHASSIS DYNAMOMETER 41

FIGURE 4.3.1 - LA4 TEST CYCLE

$\begin{array}{ll}\text { FIGURE 4.3.2 - LA92 DRIVING CYCLE } & 45\end{array}$

FIGURE 4.3.3 - HIGHWAY FUEL ECONOMY TEST (HWFET)

FIGURE 4.3.4 - NEW YoRK CITY CYCLE (NYCC)

FIGURE 4.3.5 - US06 SUPPLEMENTAL FTP

FIgURE 4.4.1 - EXHaUSt SAmPLING SChEMATIC

$\begin{array}{ll}\text { FIGURE 4.4.2 - SAMPLING SYSTEM } & 52\end{array}$

$\begin{array}{ll}\text { FIGURE 4.4.3 - EJECTOR DILUTER } & 53\end{array}$

Figure 4.4.4 - Diagram OF THE EleCtrical Low PRESSURE IMPACTOR 55

FiguRe 4.4.5 - CONDENSATION PARTICLE COUNTER 57

FIGURE 4.4.6 - FLOW DIAGRAM FOR CONDENSATION PARTICLE COUNTER

FIGURE 4.4.7 - DIAGRAM OF PM PM $_{2.5}$ MASS COLLECTION

FIGURE 4.4.8-CYCLONE SCHEMATIC $\quad 61$

FIGURE 4.4.9 - URG CYCLONE AND FILTER PACK

$\begin{array}{ll}\text { Figure 4.4.10 - SNAP-ON DIAGNOSTICS SCANNER } & 63\end{array}$

$\begin{array}{ll}\text { FIGURE 4.4.11 - MULTIMETER } & 64\end{array}$

FIGURE 6.1.1 - VARIATION OF PARTICLE EMISSION RATES FOR STEADY-STATE OPERATION OF THE SMART 88

FIGURE 6.1.2 - VARIATION OF PARTICLE EMISSION RATES FOR STEADY-STATE OPERATION OF THE PRIUS $\quad 88$

FIGURE 6.1.3 - VARIATION OF PARTICLE EMISSION RATES FOR STEADY-STATE OPERATION OF THE ESCAPE 89

$\mathrm{xi}$

Reproduced with permission of the copyright owner. Further reproduction prohibited without permission. 
FIGURE 6.1.4 - VARIATION OF PARTICLE EMISSION RATES FOR STEADY-STATE OPERATION OF THE CIVIC 89

FIGURE 6.1.5 - VARIATION OF PARTICLE EMISSION RATES FOR STEADY-STATE OPERATION OF THE INSIGHT 90 FIGURE 6.1.6 - EXAMPLE TRANSIENT EMISSIONS FROM A SMALL CONVENTIONAL GASOLINE VEHICLE: SMART ON THE NYCC* 2 AT $20^{\circ} \mathrm{C} \quad 94$

FigURE 6.1.7 - EXAMPLE TRANSIENT EMISSIONS FROM A VEHICLE FEATURING THE HYBRID SYNERGY DRIVE SYSTEM: FORD ESCAPE HYBRID ON THE NYCC*2 AT $20^{\circ} \mathrm{C}$

FIGURE 6.1.8 - EXAMPLE TRANSIENT EMISSIONS FROM A VEHICLE FEATURING THE INTEGRATED MOTOR ASSIST SYSTEM: CIVIC ON THE NYCC* 2 AT $20^{\circ} \mathrm{C}$

FIGURE 6.1.9 - EXAMPLE TRANSIENT EMISSIONS FROM A SMALL CONVENTIONAL GASOLINE VEHICLE: SMART ON THE NYCC*2 AT $-18^{\circ} \mathrm{C}$

FIGURE 6.1.10 - EXAMPLE TRANSIENT EMISSIONS FROM A VEHICLE FEATURING THE HYBRID SYNERGY DRIVE SYSTEM: FORD ESCAPE HYBRID ON THE NYCC* 2 AT $-18^{\circ} \mathrm{C} \quad 98$

FIGURE 6.1.11 - EXAMPLE TRANSIENT EMISSIONS FROM A VEHICLE FEATURING THE INTEGRATED MOTOR ASSIST SYSTEM: CIVIC ON THE NYCC* 2 AT $-18^{\circ} \mathrm{C}$

FIGURE 6.1.12 - EXAMPLE TRANSIENT NUMBER-WEIGHTED SIZE DISTRIBUTION FOR THE PRIUS ON THE $\begin{array}{ll}\mathrm{NYCC} * 2 \mathrm{AT} 20^{\circ} \mathrm{C} & 102\end{array}$

FIGURE 6.1.13 - EXAMPLE TRANSIENT NUMBER-WEIGHTED SIZE DISTRIBUTION FOR THE PRIUS ON THE $\begin{array}{lr}\text { NYCC } & 2 \text { AT }-18^{\circ} \mathrm{C} \\ & 102\end{array}$

FIGURE 6.1.14 - EXAMPLE OF START-UP EMISSIONS: SMART DURING THE FIRST 250S OF THE NYCC AT $20^{\circ} \mathrm{C}$

FiguRe 6.1.15 - EXAMPLE OF HEV START-UP EMISSIONS: PRIUS ON THE LA4HS AT - $18^{\circ} \mathrm{C}$

FIGURE 6.1.16 - PARTICLE NUMBER EMISSIONS (CPC) FOR THE SMART ON THE FIRST 500S OF THE COLD- AND $\begin{array}{ll}\text { HOT-START LA4 AT } 20^{\circ} \mathrm{C} & 106\end{array}$

FIGURE 6.1.17 - PARTICLE NUMBER EMISSIONS (CPC) FOR THE CIVIC ON THE FIRST 500S OF THE COLD- AND $\begin{array}{ll}\text { HOT-START LA4 AT } 20^{\circ} \mathrm{C} & 107\end{array}$

FIGURE 6.1.18 - PARTICLE NUMBER EMISSIONS (CPC) FOR THE ESCAPE ON THE FIRST 500S OF THE COLD$\begin{array}{lr}\text { AND HOT-START LA4 AT } 20^{\circ} \mathrm{C} & 108\end{array}$ 
FIGURE 6.1.19 - PARTICLE NUMBER EMISSIONS (CPC) FOR THE ESCAPE ON THE FIRST 500S OF THE COLDAND HOT-START LA4 AT $-18^{\circ} \mathrm{C}$

FIGURE 6.1.20 - SECOND-BY-SECOND PARTICLE NUMBER BY SIZE (ELPI) MEASURED FOR THE SMART ON THE $\begin{array}{ll}\text { LA4 AT } 20^{\circ} \mathrm{C} \text { HOT-START AND }-18^{\circ} \mathrm{C} \text { COLD-START } & 110\end{array}$

FIGURE 6.2.1 - EXAMPLE STATE-OF-CHARGE CORRECTION: THE ESCAPE ON THE LA4 AT - $18^{\circ} \mathrm{C} \quad 114$

FIGURE 6.2.2 - INTEGRATED STEADY-STATE EMISSION RATES \pm 1 STANDARD DEVIATION AT $20^{\circ} \mathrm{C} \quad 116$

FIGURE 6.2.3 - INTEGRATED STEADY-STATE EMISSION RATES \pm 1 STANDARD DEVIATION AT $-18^{\circ} \mathrm{C} \quad 116$

FIGURE 6.2.4 - INTEGRATED STEADY-STATE EMISSION RATES \pm UNCERTAINTY AT $20^{\circ} \mathrm{C}$

FIGURE 6.2.5 - INTEGRATED STEADY-STATE EMISSION RATES \pm UNCERTAINTY AT $-18^{\circ} \mathrm{C}$

FIGURE 6.2.6 - AVERAGE PM NUMBER EMISSION RATES \pm 1 STANDARD DEVIATION AT $20^{\circ} \mathrm{C}$ : IMPACT OF $\begin{array}{ll}\text { DRIVING CYCLE } & 121\end{array}$

FigURE 6.2.7 - AVERAGE PM NUMBER EMISSION RATES \pm 1 STANDARD DEVIATION AT $-18^{\circ} \mathrm{C}$ : IMPACT OF $\begin{array}{ll}\text { DRIVING CYCLE } & 121\end{array}$

FIGURE 6.2.8 - AVERAGE TOTAL PM 2.5 MASS EMISSION RATES \pm 1 STANDARD DEVIATION AT 20 ${ }^{\circ} \mathrm{C}$ : IMPACT OF $\begin{array}{ll}\text { DRIVING CYCLE } & 124\end{array}$

FIGURE 6.2.9 - AVERAGE TOTAL PM 2.5 MASS EMISSION RATES \pm 1 STANDARD DEVIATION AT $-18^{\circ} \mathrm{C}$ : IMPACT OF DRIVING CYCLE

FIGURE 6.2.10 - AVERAGE ORGANIC AND ELEMENTAL CARBON EMISSION RATES \pm 1 STANDARD DEVIATION AT $20^{\circ} \mathrm{C}$ : IMPACT OF DRIVING CYCLE $\quad 128$

FIGURE 6.2.11 - AVERAGE ORGANIC AND ELEMENTAL CARBON EMISSION RATES \pm 1 STANDARD DEVIATION AT $-18^{\circ} \mathrm{C}$ : IMPACT OF DRIVING CYCLE

FIGURE 6.2.12 - AVERAGE INTEGRATED NUMBER-WEIGHTED SIZE DISTRIBUTION FOR THE SMART AT $20^{\circ} \mathrm{C}$ : IMPACT OF DRIVING CYCLE

FIGURE 6.2.13 - AVERAGE INTEGRATED NUMBER-WEIGHTED SIZE DISTRIBUTION FOR THE SMART AT $-18^{\circ} \mathrm{C}$ : IMPACT OF DRIVING CYCLE

FIGURE 6.2.14 - AVERAGE INTEGRATED NUMBER-WEIGHTED SIZE DISTRIBUTION FOR THE PRIUS AT $20^{\circ} \mathrm{C}$ : IMPACT OF DRIVING CYCLE

xiii 
FIGURE 6.2.15 - AVERAGE INTEGRATED NUMBER-WEIGHTED SIZE DISTRIBUTION FOR THE PRIUS AT $-18^{\circ} \mathrm{C}$ : IMPACT OF DRIVING CYCLE

FIGURE 6.2.16 - AVERAGE INTEGRATED NUMBER-WEIGHTED SIZE DISTRIBUTION FOR THE ESCAPE AT $20^{\circ} \mathrm{C}$ : IMPACT OF DRIVING CYCLE

FIGURE 6.2.17 - AVERAGE INTEGRATED NUMBER-WEIGHTED SIZE DISTRIBUTION FOR THE ESCAPE AT $-18^{\circ} \mathrm{C}$ : IMPACT OF DRIVING CYCLE

FIGURE 6.2.18 - AVERAGE INTEGRATED NUMBER-WEIGHTED SIZE DISTRIBUTION FOR THE CIVIC AT $20^{\circ} \mathrm{C}$ : IMPACT OF DRIVING CYCLE

FIGURE 6.2.19 - AVERAGE INTEGRATED NUMBER-WEIGHTED SIZE DISTRIBUTION FOR THE CIVIC AT $-18^{\circ} \mathrm{C}$ : IMPACT OF DRIVING CYCLE

FIGURE 6.2.20 - AVERAGE INTEGRATED NUMBER-WEIGHTED SIZE DISTRIBUTION FOR THE INSIGHT AT 200C: IMPACT OF DRIVING CYCLE

FIGURE 6.2.21 - AVERAGE INTEGRATED NUMBER-WEIGHTED SIZE DISTRIBUTION FOR THE INSIGHT AT $-18^{\circ} \mathrm{C}$ : IMPACT OF DRIVING CYCLE

FIGURE 6.2.22 - AVERAGE PM NUMBER EMISSION RATES \pm 1 STANDARD DEVIATION AT $20^{\circ} \mathrm{C}:$ IMPACT OF COLD-START

FIGURE 6.2.23 - AVERAGE PM NUMBER EMISSION RATES \pm 1 STANDARD DEVIATION AT $-18^{\circ} \mathrm{C}$ : IMPACT OF COLD-START

FigURE 6.2.24 - AVERAGE $\mathrm{PM}_{2.5}$ MASS EMISSION RATES \pm 1 STANDARD DEVIATION AT 20 $0^{\circ} \mathrm{C}$ : IMPACT OF COLD-START

FIGURE 6.2.25 - AVERAGE PM $_{2.5}$ MASS EMISSION RATES \pm 1 STANDARD DEVIATION AT $-18^{\circ} \mathrm{C}$ : IMPACT OF COLD-START

FIGURE 6.2.26 - AVERAGE ORGANIC AND ELEMENTAL CARBON MASS EMISSION RATES \pm 1 STANDARD DEVIATION AT $20^{\circ} \mathrm{C}$ : IMPACT OF COLD-START

FIGURE 6.2.27 - AVERAGE ORGANIC AND ELEMENTAL CARBON MASS EMISSION RATES \pm 1 STANDARD DEVIATION AT $-18^{\circ} \mathrm{C}$ : IMPACT OF COLD-START

FIGURE 6.2.28 - AVERAGE INTEGRATED NUMBER-WEIGHTED SIZE DISTRIBUTION FOR THE SMART AT $20^{\circ} \mathrm{C}$ : IMPACT OF COLD-START 
FIGURE 6.2.29 - AVERAGE INTEGRATED NUMBER-WEIGHTED SIZE DISTRIBUTION FOR THE SMART AT $-18^{\circ} \mathrm{C}$ :

IMPACT OF COLD-START

FIGURE 6.2.30 - AVERAGE INTEGRATED NUMBER-WEIGHTED SIZE DISTRIBUTION FOR THE PRIUS AT $20^{\circ} \mathrm{C}$ : IMPACT OF COLD-START

FIGURE 6.2.32 - AVERAGE INTEGRATED NUMBER-WEIGHTED SIZE DISTRIBUTION FOR THE ESCAPE AT $20^{\circ} \mathrm{C}$ : IMPACT OF COLD-START

FIGURE 6.2.34 - AVERAGE INTEGRATED NUMBER-WEIGHTED SIZE DISTRIBUTION FOR THE CIVIC AT $20^{\circ} \mathrm{C}$ : IMPACT OF COLD-START

FIGURE 6.2.36 - AVERAGE INTEGRATED NUMBER-WEIGHTED SIZE DISTRIBUTION FOR THE INSIGHT AT $20^{\circ} \mathrm{C}$ : IMPACT OF COLD-START

FIGURE 6.2.37 - AVERAGE INTEGRATED NUMBER-WEIGHTED SIZE DISTRIBUTION FOR THE INSIGHT AT $-18^{\circ} \mathrm{C}$ : 


\subsection{Introduction}

Air pollution continues to be a major problem in Canada and worldwide. It is a threat to our health, our environment, and our economy. While many air pollutants are gases, this study focuses on small airborne solid or liquid particles generally referred to as particulate matter (PM) or aerosols. PM is known to cause reduced visibility and climate perturbations, and is a major component of what we know as "smog". In addition, PM can cause serious health problems when introduced into the human respiratory system. Many epidemiological studies from all over the world have linked high ambient levels of PM to increased mortality, exacerbation of asthma, chronic bronchitis, respiratory tract infections, ischaemic heart disease, and stroke (Pope, Dockery, \& Schwartz, 1995; Pope \& Dockery, 2006; Saldiva et al., 1995)

Particles may vary in chemical composition and size. These factors affect the environmental and health impacts of PM. For instance, depth of penetration and deposition in the lung are highly dependent on particle size (Brain \& Valberg, 1979). PM is often classified as coarse $\left(\leq 10 \mu \mathrm{m}\right.$ in diameter, $\left.\mathrm{PM}_{10}\right)$, fine $(\leq 2.5 \mu \mathrm{m}$ in diameter, $\mathrm{PM}_{2.5}$ ), ultrafine ( $\leq 100 \mathrm{~nm}$ in diameter), and nanoparticles $(\leq 50 \mathrm{~nm}$ in diameter). Ultrafine particles in particular have been linked to many of the health effects listed above (Delfino, Sioutas, \& Malik, 2005; Salvi \& Holgate, 1999; Sydbom et al., 2001). Ambient PM is currently measured in terms of mass concentrations. For example, the Canada Wide Standard for $\mathrm{PM}_{2.5}$ adopted in recent years targets a $24 \mathrm{hr}$ average value of $30 \mu \mathrm{g} / \mathrm{m}^{3}$ (Canadian Council of Ministers of the Environment, 2000). Emission regulations are also based on mass emission rates; in the case of transportation sources 
regulations are in terms of mass emitted per distance travelled or mass emitted per energy delivered. However, because the smallest particles contribute relatively little to total particle mass, and are potentially the most hazardous, researchers have begun to focus on particle number concentrations and size distributions.

The size and chemical composition of PM varies depending on its source. PM can originate from both natural sources and human activities. PM from natural sources such as windblown soil and volcanic dust is typically coarse, although some fine particles such as ash from forest fires and PM formed from chemicals released by vegetation are also of natural origin. Anthropogenic PM spans all size ranges and includes coarse particles such as those arising from road dust and construction sites, as well as fine, ultrafine, and nanoparticles such as those from fossil fuel burning in power plants, industry, and motor vehicles. PM from motor vehicles is typically in the lower size ranges and can be coated by a mixture of toxic chemicals.

Vehicle exhaust is composed of a complex mixture of many components including toxic gaseous pollutants, particulate matter, and greenhouse gases (GHGs). According to Environment Canada's emission inventories, in 2002 the transportation sector was responsible for emitting $76 \%$ of carbon monoxide $(\mathrm{CO}), 55 \%$ of nitrogen oxides $\left(\mathrm{NO}_{\mathrm{x}}\right)$, $32 \%$ of volatile organic compounds (VOCs), $25 \%$ of $\mathrm{CO}_{2}$ equivalent greenhouse gases (GHGs), and $17 \%$ of PM mass with diameter $\leq 2.5 \mu \mathrm{m}$ in Canada (totals do not include open source emissions) (Environment Canada, 2006a; Environment Canada, 2006b). Ambient levels of PM from motor vehicles are expected to be highest in urban centres 
where traffic is most dense, and where human exposure is mostly likely to occur. Due to the air pollution caused by motor vehicle emissions, along with growing concern over the availability of oil, a great deal of effort has gone into lowering vehicle emissions and fuel consumption.

One method for reducing emissions is to reduce the need for motorized transportation by encouraging walking, bicycling, telecommuting, and teleconferencing. Changes to infrastructure (improved bicycle paths and transit facilities), and the design of urban areas that are more compact and mixed so that homes, workplaces and services are close together would favour more efficient modes of transportation. Unfortunately, Canadians have grown increasingly dependent on automobiles. The current dependency leads to a vicious cycle as demand for more roadways increases and people expect to live in lowdensity housing developments away from cities. Increased costs to provide transit service to areas outside the city core hinder transit service growth, leading to lower transit use, and higher dependency on the automobile. Despite air pollution issues and rising fuel costs, passenger-kilometres travelled in Canada by cars remained relatively constant between 1990 and 2004, while at the same time passenger-kilometres travelled by light trucks, including sport utility vehicles (SUVs), increased by an average of $6 \%$ per year (Office of Energy Efficiency, Natural Resources Canada and Statistics Canada, 2006). It is unlikely that Canadians will be giving up this mode of transportation in the near future.

Another option for reducing emissions is the development of advanced technologies. The federal government has been gradually implementing more stringent emissions standards 
for new vehicles and will continue to do so. Vehicle manufacturers are developing new technologies to meet these standards and exceed them as the market demands. One such technology, the gasoline-electric hybrid vehicle, has already gained widespread acceptance. Hybrids accounted for $1.2 \%$ of the vehicles sold in North America in 2005, or approximately 200,000 vehicles (Greywitt \& Tews, 2005). The 2006 model year offerings in North America include hybrid vehicles by Toyota, Honda, Ford, GM, Mercury, and Lexus. Toyota expects $25 \%$ of its American sales to be hybrids by the end of the decade. There are also government incentives to purchase these vehicles. For instance, in British Columbia and Ontario residents can get a rebate of up to $\$ 2,000$, and in PEI up to $\$ 3,000$. Considering the growing popularity of hybrid vehicles, it is important to understand what kind of impacts they may have on environmental and health issues.

Hybrid electric vehicles (HEVs) often have low emissions compared to their conventional counterparts primarily due to reduced fuel consumption. This is achieved in a variety of ways. Internal combustion engines (ICEs) run most efficiently in a narrow range of torque and speeds. By using an electric motor and battery to assist during hill climbing and acceleration, the ICE can be downsized and optimized to run mainly at those points where it is most efficient. The ICE in HEVs can be shut off to avoid idling and some HEVs can be propelled at low speeds by electric power alone. Hybrids also usually employ regenerative braking to capture energy as electrical power that would otherwise be lost during braking as frictional heat. Considering the complexity of hybrid operation along with that of PM formation and growth, it is difficult to predict the 
transient nature of HEV PM emission characteristics and the overall effect on PM emission rates.

This thesis was undertaken in the context of an Environment Canada project to look at GHG emissions from engines and vehicles with advanced emission control technologies under the Climate Change Technology \& Innovation (CCT\&I), Transportation R\&D program. Four commercially available light-duty gasoline-electric hybrid vehicles and one small conventional gasoline engine vehicle had been chosen to evaluate the impacts of these new technologies on $\mathrm{CO}_{2}, \mathrm{CH}_{4}$ and $\mathrm{N}_{2} \mathrm{O}$ emissions. The project also provided an opportunity for evaluating the effects of these technologies on criteria air contaminant emissions $\left(\mathrm{CO}, \mathrm{NO}_{\mathrm{x}}, \mathrm{THC}, \mathrm{PM}\right)$ and in particular for a detailed evaluation of PM emissions. An overall assessment of the transportation sector's contribution to atmospheric PM in Canada is one of the topics of interest for the Federal Government Program on Energy Research and Development (PERD). The detailed study reported in this thesis of particulate emissions in terms of their number and mass emission rates as well as their size distributions is of direct relevance to our understanding of the nature of this contribution. To date, no other study has provided a detailed evaluation of PM number emission rates and size distributions from gasoline-electric hybrid vehicles.

Given the context above, the objectives of the research undertaken for this thesis are:

i) Determine the effect of driving conditions and ambient temperature on the following from commercially available hybrid vehicle technologies: 
a. Number emission rates and number-based size distributions of PM

b. $\mathbf{P M}_{2.5}$ mass emission rates and the nature of carbon emissions

ii) Identify any patterns and trends that may be used in improving the quantification of PM emissions from hybrid vehicles in emission factor models.

To this end, vehicles were tested on a chassis dynamometer at the Emissions Research and Measurement Division (ERMD) of Environment Canada. As part of this larger project I was responsible for analysis of PM results including assimilation of data from different instruments, performing necessary calculations, graphing the data, quality assurance/quality control, interpreting the results, and drawing conclusions. Also, I did preliminary analysis of gaseous emissions and fuel economy for tests prior to April 2006. The gaseous emissions measured during this project are the subject of a parallel thesis. Along with the laboratory staff at Environment Canada, I participated in vehicle testing and emissions sampling. I usually dealt with hybrid battery monitoring equipment, but became familiar with all relevant laboratory activities.

The remaining chapters will deal with the necessary background, detail the experimental methodology and data analysis, present the results and discuss their significance, and finally provide the conclusions of the study. Chapter 2 is a review of PM emissions from motor vehicles including their properties, their formation mechanisms, how they are currently measured, characterized, regulated, and controlled, and the kinds of trends that are expected of PM emissions from gasoline vehicles. Chapter 3 is a review of hybrid 
technology and the issues associated with hybrid vehicle emissions analysis and reporting. It also includes a description of the vehicles studied. Chapter 4 describes the experimental methodology that was used to examine particle emissions including test conditions, driving cycles, and sampling methodology. Chapter 5 details the data analysis undertaken to determine emission rates and account for hybrid battery energy changes. Chapter 6 presents the results and includes a discussion. Finally, the conclusions are stated in Chapter 7.

\subsection{Review of PM Emissions from Motor Vehicles}

Particulate matter from internal combustion engines, the focus of this study, is made primarily of fine carbonaceous particles coated in a mixture of various toxic chemicals. Primary PM is emitted directly into the atmosphere from its source and can be coarse or fine. Secondary PM is formed in the atmosphere from particle precursor gases, including nitric oxide and nitrogen dioxide $\left(\mathrm{NO}_{\mathrm{x}}\right)$, sulphur dioxide $\left(\mathrm{SO}_{2}\right)$, volatile organic compounds (VOCs), and ammonia $\left(\mathrm{NH}_{3}\right)$. Secondary particles are mostly in the fine category.

While diesel engines emit more particulate matter on a fleet average $\mathrm{g} / \mathrm{km}$ basis than gasoline engines and have been studied quite extensively for this reason, PM from gasoline vehicles has recently been gaining attention. The total number of vehicle kilometres travelled by gasoline engines greatly exceeds that of diesel engines, especially in urban centres (Kayes \& Hochgreb, 1998) and on weekends (Kittelson, Watts, Johnson, Schauer, \& Lawson, 2006/8). Gasoline vehicles emit a higher proportion of nanoparticles than do diesel vehicles (Maricq, Podsiadlik, \& Chase, 1999a; Rickeard, Bateman, Kwon, 
McAughey, \& Dickens, 1996), and the relative contribution of light-duty vehicles to road-side number emissions has been shown to increase for nanoparticles (Kittelson, Watts, Johnson, \& Schauer et al., 2006/8). Ultrafine and nanoparticles have higher alveolar deposition efficiencies and are more closely linked to negative health effects than are larger particles. In addition, diesel particulate filters exist which are highly efficient at capturing PM from diesel exhaust, while such filters are not used on gasoline vehicles. For these reasons, PM emissions from spark-ignition (SI) engines deserve attention.

\subsection{Particle Properties}

The environmental impact of PM is dependent on various particle properties. The climate relevant properties of aerosols include their ability to absorb and scatter light, their hygroscopicity, their size, and their shape. The main PM properties determining their impact on human health include atmospheric concentration (particularly number concentration as opposed to mass concentration), size distribution, and chemical composition. The current study focuses primarily on particle number concentrations and size distributions. Mass emission rates and carbon composition were also measured and will be discussed.

The terminology used to describe particle size can be confusing as definitions vary depending on the research area (ie. health effects, ambient measurement, emissions measurement). Figure 2.1 shows the idealized atmospheric aerosol size distribution (Whitby \& Cantrell, 1975). The distribution is generally trimodal and lognormal in form. Mechanisms such as heterogeneous nucleation, condensation, and coagulation transfer 
aerosol mass from one size range to another. The nuclei mode is the smallest size range and contains particles between 0.001 and $0.08 \mu \mathrm{m}$ in diameter. It consists of primary particles emitted by sources such as combustion engines and secondary particles formed by coagulation of primary particles to form chain aggregates. The accumulation mode, which includes particles between 0.1 and $1 \mu \mathrm{m}$, contains particles emitted by sources such as combustion engines as well as secondary particles transferred from the nuclei range through condensation and coagulation. The largest of the three modes is referred to as the coarse aerosol size range and consists of particles 1.0 to approximately $40 \mu \mathrm{m}$ in diameter. These particles are generally formed through mechanical process such as grinding and bulk material handling. There is very little exchange of particle mass between this mode and the two smaller modes.

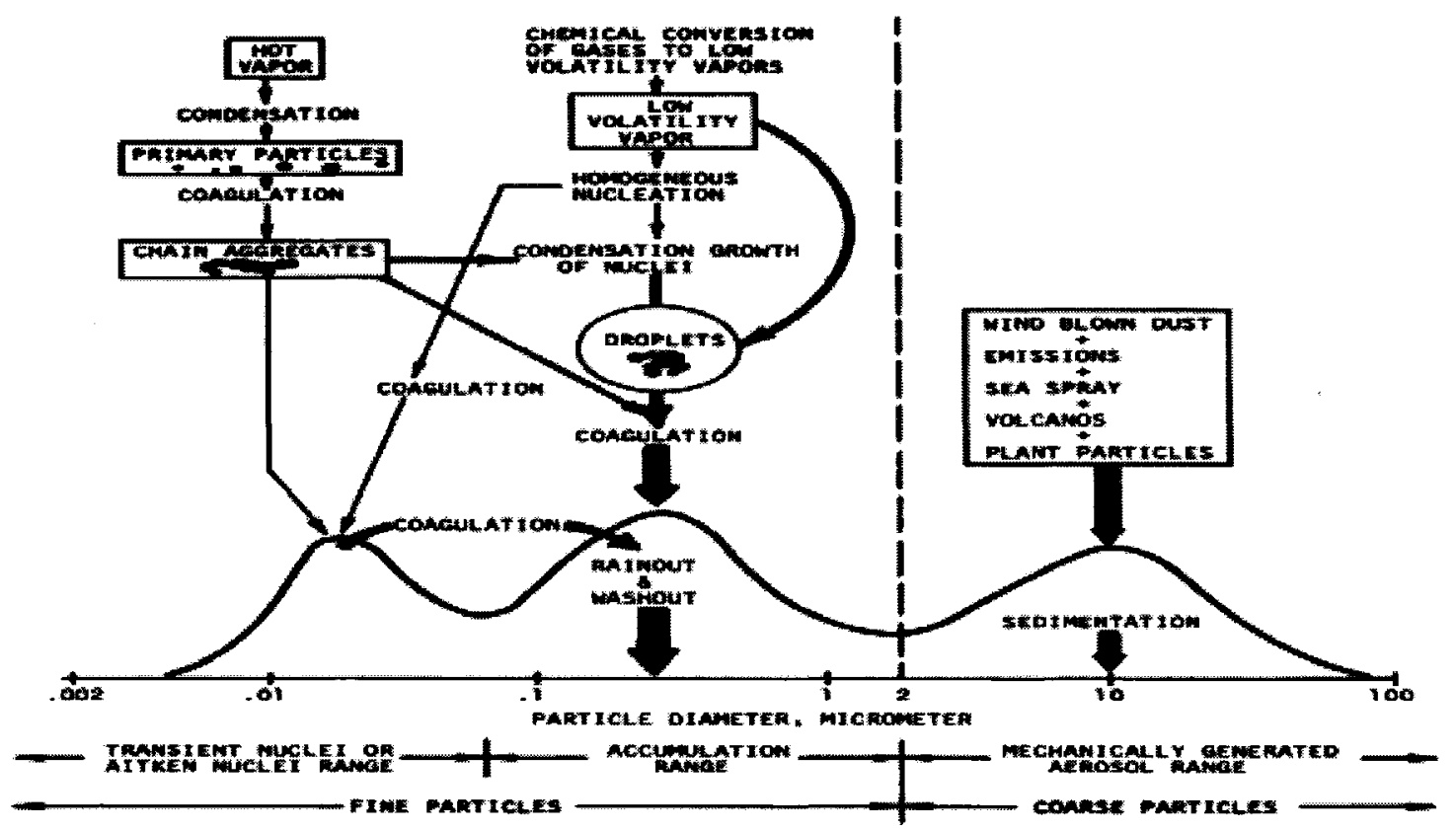

Figure 2.1.1 - Idealized atmospheric PM surface area distribution showing principal modes, sources of mass, and processes involved in mass transfer and removal (Whitby \& Cantrell, 1975) 
As with the atmospheric particle size distribution, the size distribution of exhaust aerosols is generally trimodal and lognormal in form. A typical diesel engine exhaust PM size distribution showing number and mass weightings as well as alveolar deposition efficiency is given in Figure 2.1.2 (Kittelson, 1998). Particle emissions in exhaust are classified as coarse $(\leq 10 \mu \mathrm{m}$ in diameter $)$, fine $(\leq 2.5 \mu \mathrm{m}$ in diameter $)$, ultrafine $(\leq 100 \mathrm{~nm}$ in diameter), and nanoparticles ( $\leq 50 \mathrm{~nm}$ in diameter). The size of measured particulate matter is represented with a subscript indicating the upper cutoff size in micrometers. For instance, fine particulate matter is $\mathrm{PM}_{2.5}$ and ultrafine $\mathrm{PM}$ is $\mathrm{PM}_{0.1}$. These definitions are used throughout this study. The smallest particle mode in engine exhaust, nuclei mode $(0.005-0.05 \mu \mathrm{m}$ diameter), usually consists of volatile organic and sulphur compounds that form during dilution and cooling and may also contain some solid carbon and metal compounds (ash). This mode usually contains $1-20 \%$ of particle mass and more than $90 \%$ of particle number. Most of the particle mass is found in the accumulation mode $(0.1-$ $0.3 \mu \mathrm{m}$ diameter), which consists of carbonaceous agglomerates and associated adsorbed materials. The coarse mode represents $5-20 \%$ of particle mass and consists of accumulation mode particles that were deposited on cylinder and exhaust systems and later reentrained. While PM emissions from SI engines have not been examined as extensively as those of diesel engines, size distributions in previous studies have tended to be asymmetric and have smaller mean diameters compared to diesel engines (Harris \& Maricq, 2001), although at least one study found SI vehicle PM size distributions to be similar to modern heavy-duty diesel engines (Kittelson, Watts, Johnson, \& Schauer et al., 2006/8). 


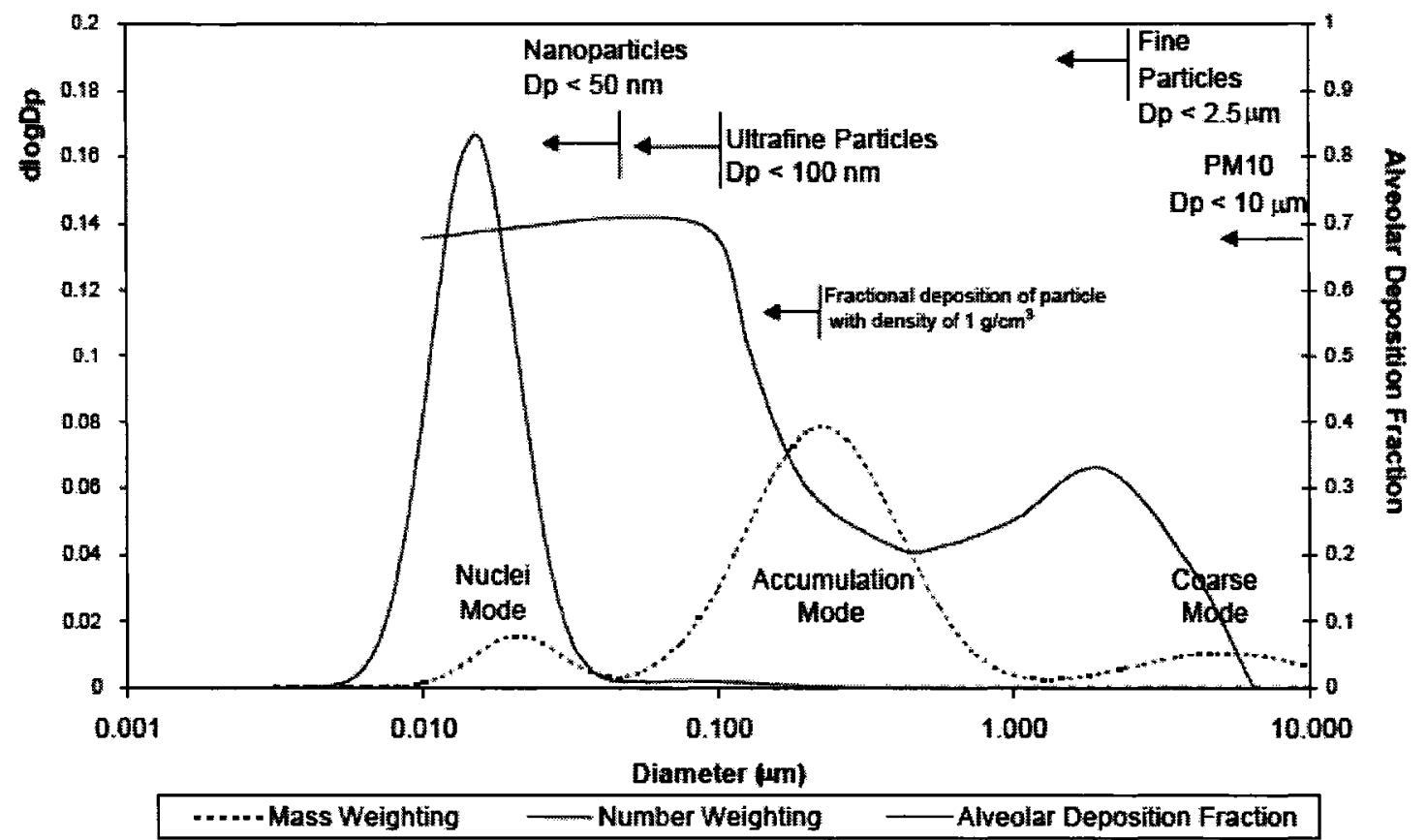

Figure 2.1.2 - Typical diesel engine exhaust particle size distribution (Kittelson, 1998)

Particle size influences the atmospheric residence time, optical properties, surface area (ability to participate in atmospheric chemistry), and health effects of particles. Residence time is longest (about 1 week) for particles with diameters between 0.1 and 10um (Kittelson, 1998). Larger particles are removed by settling, and smaller particles by coagulation and deposition. Light scattering is strongly dependent on particle size and shape and is a maximum for particles a few tenths of a micron in diameter (Scherrer \& Kittelson, 1982). Finally, pulmonary deposition efficiency increases with decreasing particle size, and studies have shown that the correlation between health effects and atmospheric particle concentration is improved when fine particle concentration is considered as opposed to $\mathrm{PM}_{10}$ concentration (Pope et al., 1995). 
As seen in Figure 2.1.2, by number almost all of the particles emitted by both diesel and gasoline engines are in the nuclei mode range. By mass, these particles represent only a small proportion of PM emissions, and this highlights the importance of measuring particle number emissions as well as, or instead of, particle mass emissions. Although these nuclei mode particles are quickly removed from the atmosphere by diffusion and coagulation (a characteristic distance of $90 \mathrm{~m}$ and time of 30s downwind of roadways has been observed for nanoparticles $<10 \mathrm{~nm}$ ), it is important to note that an estimated $50 \%$ of PM exposure takes place on or near roadways while commuting (Kittelson et al., 2005).

PM can also be characterized based on its carbon composition. Atmospheric carbon is classified as organic, elemental, or carbonate $\left(\mathrm{CO}_{3}{ }^{-}\right)$. Organic carbon (OC) is carbon associated with organic compounds. Primary OC is emitted directly into the atmosphere, while secondary OC forms through the atmospheric oxidation of volatile organic compounds (VOCs). Organic carbon is emitted from internal combustion engines as unburned fuel. It is associated with over-fueling. Elemental carbon is formed during the combustion of hydrocarbons and is nonvolatile at ambient temperatures. It is associated with hard operation (hard accelerations, high speeds) of IC engines. Carbonate carbon exists in mineral dusts and is not related to combustion.

\subsection{Particle Formation in Spark-Ignition Engines}

It is important to understand the mechanisms that lead to nucleation, oxidation, and growth of PM in spark ignition (SI) engine exhaust. In order to gain insight into these processes Kayes and Hochgreb (Kayes \& Hochgreb, 1999a; Kayes \& Hochgreb, 1999b; Kayes \& Hochgreb, 1999) undertook a combined experimental and modeling study. Two 
port fuel injection (PFI) spark ignition engines were studied on an engine dynamometer, and a scanning mobility particle sizer (SMPS) was used to measure PM number concentration and size distribution. It was found that nucleation of PM in SI engines depends on temperature and the availability of fuel rich regions, particle precursors such as liquid fuel, and products of incomplete fuel combustion. The absence of solid material in the exhaust to absorb semivolatile material forces nucleation and nanoparticle formation. Oxidation of PM depends on the availability of oxygen and on the temperature. Growth is determined by the amount of hydrocarbons (HCs) available to adsorb/absorb onto particle surfaces, the amount of surface area for this to take place on, and the number of particles which can readily coagulate to cause growth.

Engine operating conditions affecting PM nucleation, oxidation, and growth include fuelair equivalence ratio, engine speed, engine load, fuel injection timing, exhaust gas recirculation, and spark timing.

The equivalence ratio $(\Phi)$ is the ratio of engine fuel/air ratio to the chemically correct (stoichiometric) fuel/air ratio. Minimum PM number concentrations have been found to occur at or within $10 \%$ of stoichiometric $(\Phi=1.0)$ and increased number emissions were observed at rich or lean $\Phi$ (Kayes \& Hochgreb, 1999a). Lean and rich fuel/air ratios also lead to larger particles, with the smallest particles observed at the stoichiometric fuel/air ratio. In the same study, PM number concentration was found to increase monotonically as engine load increased. No trends were observed in PM size as a function of engine load. 
A rise and fall in PM number concentration has been observed with increasing engine speed between 1500 and 2500 rpm (Kayes \& Hochgreb, 1999a). This was true when tested at three different load conditions. In the same study, no trends were observed in particle size as a function of engine speed.

\subsection{Particle Measurement and Characterization}

Particle emissions must be measured and characterized to determine if emission sources are in compliance with regulations, to determine impacts of these sources on air quality, and to gain information for use in the design of emission control strategies and devices.

Particle emissions from mobile sources can be measured on-road, or in a laboratory setting. On-road measurement can be done using chase experiments during which a chase vehicle equipped with PM measurement equipment follows the test vehicle. This method offers the advantage of ensuring real-world driving and dilution conditions. Unfortunately, this method offers poor day-to-day repeatability because atmospheric conditions (temperature, wind, humidity etc.) are uncontrolled, and it also brings up numerous safety issues at high speeds (Kittelson, Watts, Johnson, \& Schauer et al., 2006/8). It is therefore unacceptable as a regulatory tool. In a laboratory setting, conditions can be more adequately controlled. Tests can be carried out on a chassis or engine dynamometer in a test cell with controlled temperature and humidity. The dilution process can also be carefully controlled. Driving schedules have been developed to represent real-world driving (discussed in Chapter 4), and studies have been done to 
compare real-world and laboratory results (Kittelson, Watts, \& Johnson, 2006/8; D. B. Kittelson, Watts, Johnson, \& Schauer et al., 2006/8).

The dilution and sampling process for measurement of particulate matter in a laboratory setting is very important as it can affect the dynamics of particle nucleation and growth. The dilution and sampling system can affect the measured aerosol through particle-wall interactions, and through particle dynamics and transformations that occur during dilution and cooling. Particle-wall interactions can be minimized by the use of metal sample lines (to avoid electrostatic build-up), by insulating and heating sample lines (to avoid large differences in temperature between lines and exhaust gas), by keeping sample lines short (to reduce diffusional deposition) and by avoiding sharp turns (to reduce inertial impaction) (Kittelson, Arnold, \& Watts, 1999).

Because of the strong effect of atmospheric dilution on exhaust temperature, current U.S. EPA emissions testing guidelines require that the temperature be below $190^{\circ} \mathrm{C}$ in the primary mixing zone, and below $52^{\circ} \mathrm{C}$ at the filter face. This constrains the minimum dilution ratio to approximately 10:1 depending on the temperature of the exhaust gas. Additional dilution is usually needed for aerosol instruments that require lower particle concentrations. There are no set guidelines for the amount of dilution at each step or the residence times of exhaust at each dilution ratio value.

Particles can be characterized based on mass concentration, number concentration, size distribution, light absorption and scattering coefficients, surface area, and composition. 
The instruments most frequently used for particle characterization were summarized by Kittelson et al. 1999. The instruments used in the current study include the condensation particle counter (CPC) which measures real-time particle number concentration, and the electrical low pressure impactor (ELPI) which measures real-time number-weighted particle size distributions. In addition, cyclones and filters were used to measure particle mass concentration with an upper cut-off size of $2.5 \mu \mathrm{m}$, and the organic and elemental carbon composition of particles. The instruments and methods are described in detail in Chapter 4.

The fraction of organic and elemental carbon present in combustion related PM samples can provide information on the specific mechanism of PM formation. Quartz fired filters (QFFs) are typically used to collect OC and EC. Thermo-optical methods can be used to determine the OC and EC loading on QFFs. OC is associated with fuel rich operation while $\mathrm{EC}$ is linked to hard accelerations.

After having determined signature vehicle particle compositions and size distributions, chemical mass balance models such as CMB8 can be used for source apportionment (ie. to determine the contribution of vehicle exhaust to ambient air particle concentrations). In addition, models such as MOBILE6.2 can be used to estimate fleet emission rates under a range of conditions. This program requires inputs including external conditions such as temperature and humidity; fleet characteristics such as vehicle age distribution, mileage accumulation, and diesel fractions; vehicle activity including starts per day, starts by hour of the day, trip length, and soak time between starts; fuel specifications; and the presence 
of inspection and maintenance programs or regulation and control measures. Emission inventories can then be prepared based on a given set of input parameters.

\subsection{PM Emission Regulation and Control for Mobile Sources}

Diesel vehicle PM regulations in North America, Japan, and most of Europe are currently based on particle mass with cut-off sizes of 10 and $2.5 \mu \mathrm{m}\left(\mathrm{PM}_{10}\right.$ and $\left.\mathrm{PM}_{2.5}\right)$. Mass may, however, not be the best indicator of PM health effects. For example, as discussed earlier, smaller particles are known to have more severe health impacts than larger particles. A large number of small particles may not contribute significantly to the mass concentration in exhaust. Thus, knowledge of PM number concentrations may be more important than knowledge of PM mass concentrations.

While the U.S. will continue to regulate vehicle engine exhaust based on mass (Environmental Protection Agency, 1997), an EU program (GRPE PMP under the auspices of the UNECE WP29/GRPE group) to develop new standards based on number concentrations and size distributions has been underway since 2001 (Swiss EPA and DOT, 2002; United Nations Economic Commission for Europe, 2002). These standards may apply to gasoline vehicles as well as diesel vehicles. In Canada, standards for 2004 and later model year light-duty vehicles, light-duty trucks, and medium-duty passenger vehicles are harmonized with U.S. standards (Canadian Federal Government, 2002).

As PM regulations grow tighter, vehicle manufacturers are developing appropriate technologies for controlling emissions. SI engine PM emissions may be reduced by minimizing the factors involved in the formation of PM (described in section 2.2). This 
strategy, however, must be used carefully to ensure that the reduction in PM emissions does not come with a penalty in other emissions or fuel economy.

Another tactic for the control of PM emissions is the use of after-treatment technology. Two examples of after-treatment technology for diesel vehicles are the diesel particulate filter (DPF) and diesel oxidation catalyst (DOC). The purpose of the DOC is to reduce the organic fraction of particulate matter. Organic carbon, which comes from the incomplete combustion of fuel and lubricants in the engine, is oxidized to $\mathrm{CO}_{2}$ and water by the DOC. The catalyst also reduces $\mathrm{CO}$ and $\mathrm{HC}$ emissions in the exhaust stream. Almost all diesel vehicles have oxidation catalysts.

Most diesel particulate filters are wall-flow systems. In this type of system alternating channels of a honeycomb structure are blocked at one end forcing the exhaust gases to flow through the walls into the adjacent cell to exit. PM is captured on the walls. The honeycomb structure is coated with a catalyst that continuously oxidizes the collected PM at high exhaust temperatures. The DPF can have a total PM mass removal efficiency of $80 \%$ or higher depending on the fuel sulphur content. The DPF may, however, promote nanoparticle formation under certain conditions. The removal of accumulation mode particles which would otherwise be involved in sulphuric acid scavenging leaves sulphuric acid free to nucleate and form nanoparticles. The DPF is currently only used as a retrofit device and only if mandated by a local jurisdiction. In 2007, all new heavy-duty diesel vehicles will require a DPF to meet the new emission standards. 
After-treatment technologies for SI vehicles have not traditionally focused on PM removal. The three-way catalytic converter, which is used on all newer model gasoline vehicles, features both reduction and oxidation catalysts and is meant to lower $\mathrm{NO}_{\mathrm{X}}, \mathrm{HC}$, and $\mathrm{CO}$ emissions. The effect of the catalytic converter on PM emissions has been tested in several studies. In one such study (Kayes \& Hochgreb, 1999b), a gasoline engine was operated with a platinum-rhodium three-way catalytic converter or a section of stainless steel tubing between the manifold and muffler. Differences in PM number concentration and size with and without the catalytic converter were statistically insignificant. The theoretical expectation is that the catalyst would reduce particle size since it oxidizes HCs that contribute to growth via adsorption/absorption. The results do not support this theory. It was suggested that perhaps mechanisms such as coagulation or surface reactions are intensified by the flow and temperature conditions in the catalyst.

In another experiment (Maricq, Chase, Xu, \& Podsiadlik, 2002), particle number concentrations and size distributions were measured in the exhaust of two gasoline vehicles equipped with either a catalytic converter or a blank monolith. The use of a blank monolith meant that the difference between tests indicated the ability of the catalyst to oxidatively remove PM without removal due to mechanical filtration or changes in exhaust flow patterns. Tests showed that particle number emissions were less than two times higher without the catalyst. This is a minimal effect in comparison to the high removal rates of other pollutants achieved by the catalyst. Catalyst effects on PM size distribution were also small or insignificant. 
In a third study (Kim et al., 2001), two gasoline vehicles were tested with PM collected before and after the catalytic converter. In this study, a clear difference in size distribution was observed with $71 \%$ of the particles passing through the catalytic converter having a diameter less than $100 \mathrm{~nm}$, compared to only $21 \%$ with diameters less than $100 \mathrm{~nm}$ ahead of the catalytic converter.

The differing results in these three studies show that the effect of the catalytic converter on PM size distribution deserves further study. A possible explanation for the differing results is the variation in experimental method. For testing without a catalytic converter, one study used a section of stainless steel pipe, one study used a blank monolith, and one study sampled before and after the catalytic converter. These differences could affect the exhaust flow pattern, and sampling before and after the converter could result in differences due to sampling technique.

If the catalytic converter is important in PM emissions, fuel sulphur (a catalytic converter poison) could also affect PM emissions. In another experiment (Maricq et al., 2002), the effect of fuel sulphur on PM emissions was examined using two light-duty trucks and a passenger car, each equipped with a three-way catalytic converter. Starting with California reformulated gasoline containing $35 \mathrm{ppm}$ sulphur as the base fuel, the sulphur level was raised to $350 \mathrm{ppm}$ and $600 \mathrm{ppm}$. While the increased fuel sulphur content resulted in higher emissions of $\mathrm{HC}, \mathrm{CO}$ and $\mathrm{NOx}$, presumably due to sulphur storage on the catalyst causing decreased catalyst efficiency, PM number concentration and size distribution were unaffected by the fuel sulphur. 
To date, particulate matter emission regulation has had little to no effect on gasoline vehicles because PM mass emissions from these vehicles are well below requirements. As such, control technologies have not been developed specifically for gasoline vehicles. Because particle number concentrations and size distributions are now known to be important particle properties in terms of health and environmental effects, new control technologies may need to be developed for gasoline vehicles.

\subsection{Trends in PM Emissions from SI Vehicles}

Because the current study is the first to measure particle number and size distributions from gasoline-electric hybrid vehicles, it is difficult to compare results from this study with those from previous experiments. Nonetheless, general trends in particle emissions that are expected of SI vehicles and engines are discussed in the following sections.

\subsubsection{Steady-State, Transient, and Driving Cycle Behaviour}

Steady-state PM number emission rates have been quite low during chassis dynamometer tests (Kasper et al., 2005), with higher number emissions occurring during high speed cruise compared to low speed (Kittelson, Watts, Johnson, \& Schauer et al., 2006/8). During at least one on-road study of SI vehicles, researchers were unable to measure a significant particle signature above background at highway cruise conditions (Kittelson, Watts, Johnson, \& Schauer et al., 2006/8). Conversely, both on-road and laboratory studies have reported relatively high number emission rates for vehicles during periods of acceleration (Kasper et al., 2005; Kayes, Hochgreb, Maricq, Podsiadlik, \& Chase, 2000; 
Kittelson, Watts, Johnson, \& Schauer et al., 2006/8; Maricq, Podsiadlik, \& Chase, 1999a).

As mentioned earlier, many real-world driving cycles have been designed to capture the transient nature of vehicle emissions in a laboratory setting. The 3-phase FTP-75 (Federal Test Procedure) is one such cycle. It is currently used to determine city fuel economy and compliance with criteria emissions standards in North America. It consists of three phases: cold-start, hot-stabilized, and hot-start. The cold-start phase includes engine startup at ambient temperature and is 8.4 minutes long. It covers a distance of $5.8 \mathrm{~km}$ and the maximum speed reached is $91.1 \mathrm{~km} / \mathrm{h}$. Phase 2 , the hot-stabilized phase, follows immediately after phase 1 and covers a distance of $6.2 \mathrm{~km}$ in $14.4 \mathrm{~min}$. It has a maximum speed of $55.1 \mathrm{~km} / \mathrm{h}$. Phase 3 , the hot-start, follows the same speed-time trace as phase 1 , but the engine is warm at start-up. Another driving cycle, the US06, was designed to supplement the FTP and represent an aggressive high-speed style of driving. The US06 and LA4 (the first two phases of the FTP-75) were used in the current study, and both are described in detail in Chapter 4.

In one study of driving cycle emissions (Maricq, Podsiadlik, \& Chase, 1999b), vehicles were tested at steady-state, on the FTP-75 (Federal Test Procedure), and on the US06. Particulate matter number emissions during the US06 drive cycle were found to be higher than those of the FTP phase 3 (hot-start) and lower than those of the FTP phase 1 (coldstart). The US06 emissions are greater than those of FTP phase 3 because of the more aggressive accelerations and higher speeds represented in this cycle compared to the FTP 
cycle. During phase 3 of the FTP, the fuel/air ratio remains relatively constant around stoichiometric while the US06 drive cycle produces highly variable and often rich fuel/air ratios which differ by vehicle as different strategies for responding to high power demands are implemented. As discussed earlier, a rich or lean fuel/air ratio results in higher PM number emissions. Cold-start emissions (phase 1) are generally high and are discussed in section 2.5.2.

Driving cycle was also shown to influence particle size. Higher nanoparticle number concentrations were observed in vehicle exhaust during the US06 driving cycle compared to phase 3 of the FTP. During the US06 $60 \%$ of particles had diameters less than $50 \mathrm{~nm}$. This indicates that aggressive driving (high speeds, high acceleration, high deceleration) can result in smaller PM sizes.

\subsubsection{Engine Start-up and Shut-down}

PM emissions measured in controlled start-up experiments on an engine dynamometer have shown a peak at engine start-up followed by a period of relatively constant or drifting PM emissions. When fuel injection and ignition are shut off, PM emissions peak briefly and then rapidly decay to low levels (Kayes, Liu, \& Hochgreb, 1999).

The peak in PM emissions observed upon start-up reflects a higher load experienced by the engine to overcome its own inertia, higher engine speeds associated with cold idling, variation from stoichiometric air/fuel ratio, and cooler intake port and valve temperatures, all of which are known to result in PM formation. 
Cold-start refers to vehicle start-up when the engine and emission control technologies are at ambient temperature (as in phase 1 of the FTP). Several studies on chassis dynamometers have shown that particle number and mass emissions from SI vehicles are increased during cold-start. In addition, mean sizes of particles emitted during cold-start were higher than those emitted during stabilized transient operation. This size difference may occur because cooler temperatures result in more $\mathrm{HC}$ condensation onto particle surfaces thus enhancing particle growth (Kittelson, Watts, Johnson, \& Schauer et al., 2006/8; Maricq, Podsiadlik, \& Chase, 1999b).

\subsubsection{Cold Ambient Temperatures}

The increased PM emissions observed during cold-start are magnified at low ambient temperatures. In one study, average ratios of $0^{\circ} \mathrm{C}$ cold-start to $28^{\circ} \mathrm{C}$ hot-start emissions were 3.3 for number concentrations measured by a condensation particle counter (CPC), 7.6 for filter masses, and 22 for volume measured by the scanning mobility particle sizer (SMPS) (Kittelson, Watts, Johnson, \& Schauer et al., 2006/8). In the same experiments, elemental carbon was a major contributor to mass emissions averaging $64 \%$ and $34 \%$ of mass emissions for cold-cold and hot-start cycles respectively. Particle size was also affected by temperature; higher accumulation mode number concentrations and mass emissions were observed during cold-start tests

Particulate matter number concentrations and size distributions were examined with respect to ambient temperature in another recent study (Mathis, Mohr, \& Forss, 2005). Particle emissions were measured in the exhaust of five modern vehicles for two realworld driving cycles at $-20,-7$ and $23^{\circ} \mathrm{C}$ ambient temperatures. For port fuel injected 
(PFI) spark ignition vehicles, particle number and active surface area during cold-start were especially high at low ambient temperatures. Particle number emissions were increased in the diameter size range from 100 to $300 \mathrm{~nm}$ when the ambient temperature was decreased from -7 to $-20^{\circ} \mathrm{C}$. The shape of the number-weighted size distribution for the direct injection spark ignition (DISI) vehicle studied was not affected by ambient temperature. In the same study, no significant effect of ambient temperature on PM emission was observed for warmed up engines.

In the fleet emission rate model MOBILE6.2 ambient temperature has no effect on direct PM emissions and is only used in modeling emissions of some PM precursors (Environmental Protection Agency, 2004).

\subsubsection{Vehicle Technology}

Higher mileage gasoline vehicles have been shown to emit a higher number of nuclei mode particles compared to lower mileage vehicles. Low mileage vehicles produced lower number emissions, but exhibited a greater relative increase in emissions during cold-start tests at $0^{\circ} \mathrm{C}$ (Kittelson, Watts, Johnson, \& Schauer et al., 2006/8).

In a study of advanced technology light duty vehicles (Graham, 2005), diesel and gasoline direct injection (DISI) vehicles had higher $\mathrm{PM}_{2.5}$ mass emissions than conventional port fuel injection (PFI) vehicles. In the same study, a Toyota Prius (gasoline-electric hybrid) had the lowest PM emissions. 
Finally, in another study three gasoline vehicles (two PFI and one DISI) emitted higher PM number concentrations than a CI engine equipped with a diesel particle filter (DPF) (Mathis et al., 2005). This stresses the growing importance of understanding and studying SI engine PM emissions.

\subsection{Review of Hybrid Electric Vehicle Technology}

Hybrid electric vehicles (HEVs) combine an energy conversion unit, such as a combustion engine or fuel cell, and an electric motor powered by an energy storage device, such as a battery unit or ultra-capacitor. This study focuses primarily on commercially available models of light duty gasoline-electric hybrids, which use a conventional gasoline engine and a battery powered electric motor. Compared to conventional vehicles (CVs), hybrids offer some combination of better fuel economy and/or improved performance. Through a reduction in fuel consumption and the use of other emission control features, some of the lowest emission ratings of vehicles on the road today belong to HEVs.

\subsection{Hybrid Control Strategies}

There are several different approaches to HEV control and operation. The two configurations covered in this study are the Integrated Motor Assist (IMA), developed by Honda, and the Hybrid Synergy Drive (HSD), developed by Toyota and licensed to Ford.

Honda's IMA system (Figure 3.1.1) employs a crankshaft-mounted motor/generator to achieve hybrid functionality. The engine provides most of the vehicle's power, and the electric assist is used when needed for acceleration and passing. When cruising at 
highway speeds, the electric motor can be run in reverse (as a generator), in order to charge the battery using excess energy from the engine. The motor also acts as a generator during braking, converting energy from the wheels into electricity to charge the battery. When the vehicle is stopped, the engine can shut off altogether to avoid wasted “idling” energy. The battery can provide energy required to power vehicle accessories. This type of system is often referred to as a "mild" hybrid.

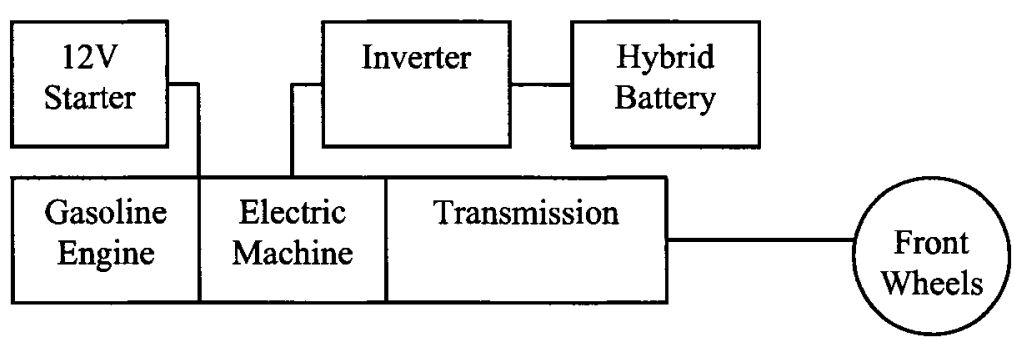

Figure 3.1.1 - Schematic of Honda IMA system (Husted, 2003)

The second hybrid design considered in this study is the Hybrid Synergy Drive (HSD). This system was originally developed by Toyota, and is licensed to Ford. The HSD uses a combination of series and parallel configurations. Unlike the IMA, the HSD has both an electric motor and a generator which can be used simultaneously in a series configuration. Unlike a simple series configuration, however, the HSD has the ability to drive the wheels using both the electric motor and the engine in parallel or using either one or the other. Because of the many possible driving modes, the HSD system is quite complex. The generator can use excess power from the engine to generate electricity to charge the battery or to directly drive the motor. At the same time, the motor can use electricity from either the battery or the generator to assist the engine during accelerations and at highway cruising speeds. Similar to the IMA design, the HSD uses regenerative braking to capture energy that would otherwise be lost during braking, and it shuts off the 
engine at stops and uses the hybrid battery to power vehicle accessories. For initial acceleration, slow speed driving, and driving in reverse, the HSD is able to drive the vehicle using electric power alone, a feature which is not possible with the IMA system. During all-electric drive the engine remains off and energy from the battery is used to drive the electric motor which in turn powers the wheels. This type of system is often referred to as a "full" hybrid.

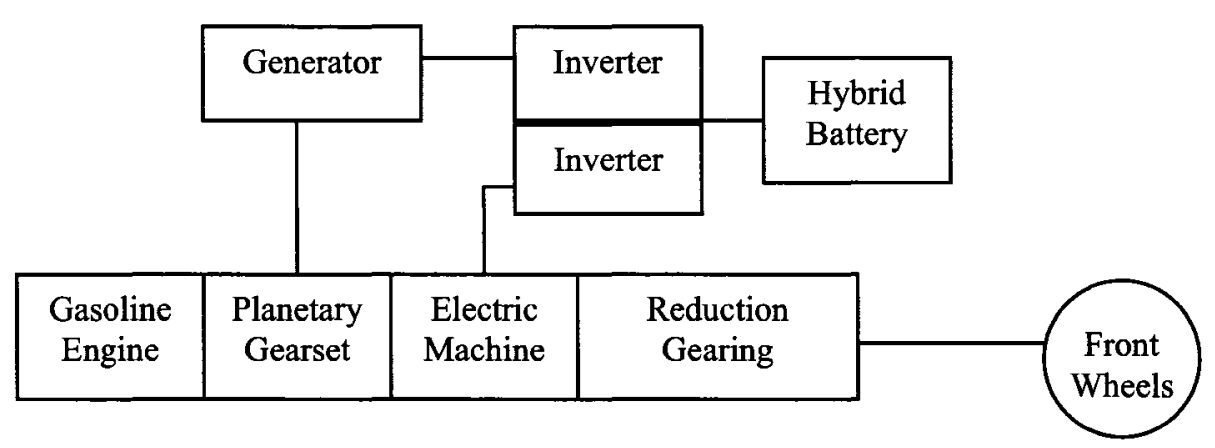

Figure 3.1.2 - Schematic of Toyota HSD system (Husted, 2003)

A third design, often referred to as the micro hybrid, merely shuts down the engine during stops to avoid idling emissions and fuel consumption. It uses electric motors to drive accessories but not the wheels. This type of hybrid was not considered in this study, and has only recently been commercially available in some new GM vehicle models.

Table 3.1.1 contains a summary of hybrid vehicle operation under conditions of acceleration, cruise, deceleration, and stop. The most obvious difference between the IMA and HSD systems is the ability of the HSD to run in electric mode at low speeds.

It is important to note that the use of the electric motor depends on energy availability from the battery. If the battery reaches a minimum state of charge for the given 
conditions, the system controller may require that the engine continue to run during stops and low speed operation.

Table 3.1.1 - Summary of Hybrid Systems

\begin{tabular}{|c|c|c|}
\hline & $\begin{array}{l}\text { Hybrid Synergy Drive } \\
\text { (HSD)* }\end{array}$ & $\begin{array}{l}\text { Integrated Motor Assist } \\
(\text { (IMA) }\end{array}$ \\
\hline Acceleration & Electric assist & Electric assist \\
\hline Cruise & $\begin{array}{c}\text { low speeds }(<40 \mathrm{~km} / \mathrm{h}) \text { : } \\
\text { all-electric drive } \\
\text { high speeds: gasoline } \\
\text { engine powers the } \\
\text { vehicle and excess } \\
\text { energy charges the } \\
\text { battery }\end{array}$ & $\begin{array}{l}\text { gasoline engine powers } \\
\text { the vehicle and excess } \\
\text { energy charges the battery }\end{array}$ \\
\hline Deceleration & regenerative braking & regenerative braking \\
\hline Stop & engine off & engine off \\
\hline
\end{tabular}

\subsection{Hybrid Vehicles and Emissions}

Hybrid electric vehicles often have low emissions compared to their conventional counterparts as evidenced by excellent California Air Resources Board (CARB) emission ratings such as ULEV (ultra-low emissions vehicle), SULEV (super ultra-low emissions vehicle) and/or AT-PZEV (advanced technology partial zero emissions vehicle). CARB emissions standards are among the most stringent in the world. Hybrid vehicles achieve low emissions primarily through reduced fuel consumption. This reduced fuel consumption is achieved in a variety of ways.

Internal combustion engines (ICEs) run most efficiently in a narrow range of torque and speeds. Conventional vehicles use their maximum power rating only about $1 \%$ of the time. The large engine required for this adds weight and is less efficient at average operating speeds than a smaller engine would be. By using an electric motor and battery 
to assist during hill climbing and acceleration, engineers are able to downsize the ICE, and optimize it to run mainly at those points where it is most efficient. In addition, the ICE in HEVs can actually be shut off to avoid idling. The HSD system goes one step further allowing the ICE to be shut off at low propulsion speeds, further enabling it to operate within the narrow range of torque and speeds at which it is most efficient.

Hybrid vehicles are also able to save energy when running accessories. Conventional vehicles typically run power draining systems such as air-conditioning, power steering, oil pump etc., directly off the gasoline engine. In a hybrid vehicle these components are highly efficient electric versions run off the large hybrid battery.

Most hybrids, including those of this study, employ regenerative braking to capture energy as electrical power that would otherwise be lost during braking as frictional heat. A generator (or electric motor operated in reverse) can convert torque created by slowing a moving vehicle into electricity to be stored in a battery. The greatest opportunity for braking regeneration occurs during stop and go traffic as well as in hilly country, making the fuel savings afforded by HEVs highly dependent on driving conditions. Currently, available hybrid vehicles are able to capture about half of the total braking energy.

Hybrid vehicle technology could affect PM emissions in several ways. Because PM is only emitted when combustion is occurring, it is expected that the idle-off feature will prevent PM emissions during portions of driving cycles where the vehicle is stopped. In the case of vehicles employing the HSD system, all-electric operation should prevent PM 
emissions at low speeds. In addition, the electric assistance during accelerations, when PM emissions are highest as discussed in Chapter 2, may be an advantage in terms of PM emissions. Particle emissions may, however, increase during engine start-up and shutdown, and at low engine temperatures. Thus, the start-stop cycles of the engine may have an effect on PM emissions. Considering the complexity of hybrid operation along with that of PM formation and growth, it is difficult to predict the transient nature of HEV PM emission characteristics and the overall effect on PM emission rates.

Currently, the fleet emission rate model MOBILE6.2 does not have any input parameters that are specific to hybrid vehicles. One purpose of this study is to determine whether or not such parameters may be needed. It is clear that some parameters, including those related to engine starts and idling emissions may need to be adapted to HEVs.

\subsection{Special Hybrid Testing Procedures}

One difficulty encountered when testing HEVs as opposed to conventional vehicles, is that the change in battery state of charge (SOC) may vary from test to test and this means that emissions measured during one test may not accurately reflect the true performance of the vehicle. HEV emissions and fuel consumption may be higher or lower depending on how much battery charging or discharging occurred during a particular test run. In order to test HEVs on the same "level playing field" as conventional vehicles, battery state of charge must be monitored during testing, and taken into consideration when reporting emission rates and fuel consumption. For HEVs, the CARB testing procedures (California Environmental Protection Agency, Air Resources Board, 1999) define a state of charge net change tolerance of $\pm 1 \%$. If, over a given emissions test, the SOC net 
change is outside of this range, test data are not accepted and the test must be repeated. Unfortunately, this method of HEV testing may require a large number of tests in the interest of obtaining just a few that are acceptable.

The Society of Automotive Engineers (SAE) has published recommended practices for testing HEV emissions and fuel economy (Society of Automotive Engineers, 1995; Society of Automotive Engineers, 2002). SAE suggests that multiple tests be performed and used to derive a linear relationship between emission rates (or fuel consumption) and net energy change (NEC) variance for a given vehicle and driving cycle so that emission rates corresponding to a $0 \% \mathrm{NEC}$ variance may be reported. The definitions and calculations pertinent to this method are detailed in Chapter 5. The SAE method allows an NEC variance of $\pm 5 \%$, and thus fewer test results are discarded compared to the CARB method. The assumption of a linear relationship between emission rate and NEC variance is, however, somewhat questionable. The validity of this assumption will be discussed in Chapter 6 along with the results of this study.

\subsection{Specific Vehicles Studied}

The hybrid vehicles tested include the 2005 Ford Escape Hybrid, 2004 Toyota Prius, 2003 Honda Civic Hybrid, and the 2000 Honda Insight. The 2002 Smart Cabrio was also included as a small conventional gasoline engine vehicle. All vehicles were obtained through Transport Canada. Vehicle specifications are listed in Table 3.3.1. All of the vehicles tested were gasoline fuelled, and had 3-way catalysts. All of the hybrids employed regenerative braking. 
Table 3.4.1 - Vehicle Specifications (Transport Canada, 2005)

\begin{tabular}{|c|c|c|c|c|c|}
\hline & $\begin{array}{c}\text { Toyota Prius } \\
\text { (2004) }\end{array}$ & $\begin{array}{c}\text { Smart Cabrio } \\
(2002)\end{array}$ & $\begin{array}{c}\text { Ford Escape } \\
(\mathbf{2 0 0 5 )}\end{array}$ & $\begin{array}{c}\text { Honda Civic } \\
\text { (2003) }\end{array}$ & $\begin{array}{c}\text { Honda Insight } \\
\text { (2000) }\end{array}$ \\
\hline Hybrid System & $\begin{array}{l}\text { Hybrid Synergy } \\
\text { Drive (HSD) }\end{array}$ & NA & $\begin{array}{l}\text { Hybrid Synergy } \\
\text { Drive (HSD) }\end{array}$ & $\begin{array}{c}\text { Integrated } \\
\text { Motor Assist } \\
\text { (IMA) } \\
\end{array}$ & $\begin{array}{c}\text { Integrated } \\
\text { Motor Assist } \\
\text { (IMA) } \\
\end{array}$ \\
\hline $\begin{array}{l}\text { Curb Weight } \\
\text { (kg) }\end{array}$ & 1313 & 730 & 1720 & 1245 & 856 \\
\hline Engine & $\begin{array}{l}\text { inline 4-cylinder } \\
\text { multi-port fuel } \\
\text { injection (MPFI) }\end{array}$ & $\begin{array}{l}\text { inline 3-cylinder } \\
\text { turbocharged } \\
\text { multi-port fuel } \\
\text { injection (MPFI) }\end{array}$ & $\begin{array}{l}\text { inline 4-cylinder } \\
\text { multi-port fuel } \\
\text { injection (MPFI) }\end{array}$ & $\begin{array}{l}\text { inline 4-cylinder } \\
\text { multi-port fuel } \\
\text { injection (MPFI) }\end{array}$ & $\begin{array}{l}\text { inline 3-cylinder } \\
\text { multi-port fuel } \\
\text { injection (MPFI) }\end{array}$ \\
\hline $\begin{array}{l}\text { Displacement } \\
\text { (cc) }\end{array}$ & 1497 & 599 & 2300 & 1339 & 996 \\
\hline $\begin{array}{l}\text { Power } \\
(\mathrm{kW} @ \mathrm{rpm})\end{array}$ & $57 @ 5000$ & $\begin{array}{c}40 \\
\text { (rpm unknown) }\end{array}$ & $99 @ 6000$ & $63 @ 5700$ & $50 @ 5700$ \\
\hline $\begin{array}{l}\text { Torque } \\
\text { (Nm@, rpm) }\end{array}$ & $111 @ 4200$ & $80 @ 2000-4500$ & $168 @ 4250$ & $118 @ 3300$ & 90 \\
\hline Motor & $\begin{array}{l}\text { permanent } \\
\text { magnet AC }\end{array}$ & & $\begin{array}{l}\text { permanent } \\
\text { magnet } \mathrm{AC}\end{array}$ & $\begin{array}{l}\text { permanent } \\
\text { magnet } A C\end{array}$ & $\begin{array}{l}\text { permanent } \\
\text { magnet } \mathrm{AC}\end{array}$ \\
\hline $\begin{array}{l}\text { Power } \\
(\mathrm{kW} @ \mathrm{rpm})\end{array}$ & $50 @ 1200-1540$ & NA & $70 @ 3000-5000$ & $10 @ 0-5700$ & $10 @ 5700$ \\
\hline $\begin{array}{l}\text { Torque } \\
\text { (Nm @ rpm) }\end{array}$ & $\begin{array}{l}400 @ 0- \\
1200 \mathrm{rpm}\end{array}$ & & not available & $62 @ 0-1000$ & 34 \\
\hline $\begin{array}{l}\text { Combined } \\
\text { Power } \\
\text { (kW@ @ rpm) }\end{array}$ & $82 @ 5000$ & $\begin{array}{c}40 \\
\text { (rpm unknown) }\end{array}$ & $116 @ 6000$ & $69 @ 5700$ & $54.4 @ 5700$ \\
\hline Hybrid Battery & $\begin{array}{l}\text { NiMH (nickel } \\
\text { metal hydride) }\end{array}$ & & $\begin{array}{l}\text { NiMH (nickel } \\
\text { metal hydride) }\end{array}$ & $\begin{array}{l}\text { NiMH (nickel } \\
\text { metal hydride) }\end{array}$ & $\begin{array}{l}\text { NiMH (nickel } \\
\text { metal hydride) }\end{array}$ \\
\hline Capacity (Ah) & 6.5 & NA & 6 & 6 & 6 \\
\hline $\begin{array}{l}\text { Nominal } \\
\text { Voltage (V) }\end{array}$ & 201.6 & & 330 & 144 & 144 \\
\hline Transmission & $\begin{array}{c}\text { ECVT } \\
\text { (electronic } \\
\text { continuously } \\
\text { variable) }\end{array}$ & $\begin{array}{l}\text { 6-speed } \\
\text { automatic }\end{array}$ & $\begin{array}{c}\text { ECVT } \\
\text { (electronic } \\
\text { continuously } \\
\text { variable) }\end{array}$ & $\begin{array}{c}\text { ECVT } \\
\text { (electronic } \\
\text { continuously } \\
\text { variable) }\end{array}$ & 5-speed manual \\
\hline $\begin{array}{l}\text { NRCAN fuel } \\
\text { economy rating } \\
\text { (City/Hwy) } \\
(\mathbf{L} / 100 \mathrm{~km}) \\
\end{array}$ & $4.0 / 4.2$ & $\begin{array}{c}4.9 / 3.8 \\
\text { (manufacturer's } \\
\text { rating) }\end{array}$ & $6.6 / 7.0$ & $4.9 / 4.6$ & $3.9 / 3.2$ \\
\hline $\begin{array}{l}\text { conventional } \\
\text { NRCAN fuel } \\
\text { economy rating } \\
\text { (City/Hwy) } \\
(\mathrm{L} / 100 \mathrm{~km}) \\
\end{array}$ & $\begin{array}{c}2004 \text { Toyota } \\
\text { Corolla } \\
7.1 / 5.3\end{array}$ & NA & $\begin{array}{l}2005 \text { Ford } \\
\text { Escape } \\
9.7 / 7.3\end{array}$ & $\begin{array}{c}2003 \text { Honda } \\
\text { Civic } \\
7.5 / 5.7\end{array}$ & NA \\
\hline $\begin{array}{l}\text { CARB } \\
\text { emissions } \\
\text { rating } \\
\end{array}$ & $\begin{array}{l}\text { SULEV } \\
\text { AT-PZEV }\end{array}$ & NA & $\begin{array}{l}\text { SULEV } \\
\text { AT-PZEV }\end{array}$ & $\begin{array}{l}\text { SULEV } \\
\text { AT-PZEV }\end{array}$ & ULEV \\
\hline
\end{tabular}

\subsubsection{Ford Escape Hybrid (2005)}

The 2005 Ford Escape Hybrid was the first full hybrid vehicle produced in North

America. It was also the first gasoline-electric sport utility vehicle (SUV) to be mass 
produced. The full hybrid system enables the Escape to run using its gasoline engine, electric power, or both (HSD system). The vehicle used in this study was front-wheel drive for purposes of testing on the chassis dynamometer, but the Escape Hybrid is also available in four-wheel drive. The overall acceleration and performance of the hybrid model was engineered to be on par with that of the $200 \mathrm{hp} \mathrm{V}-6$ conventional Escape. Compared to the other vehicles tested, the Escape was heaviest, had the largest engine, and had the highest fuel consumption rating.

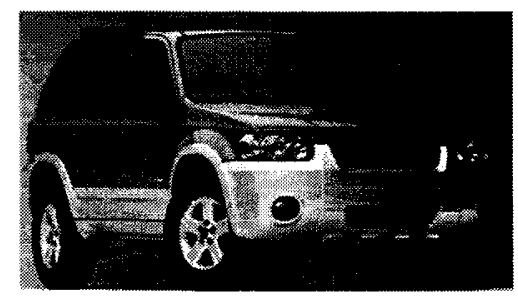

\subsubsection{Toyota Prius (2004)}

The Toyota Prius, a midsize sedan, is currently the number one selling hybrid vehicle in North America. Like the Ford Escape, it employs the HSD system and can run using its gasoline engine, electric power, or both.

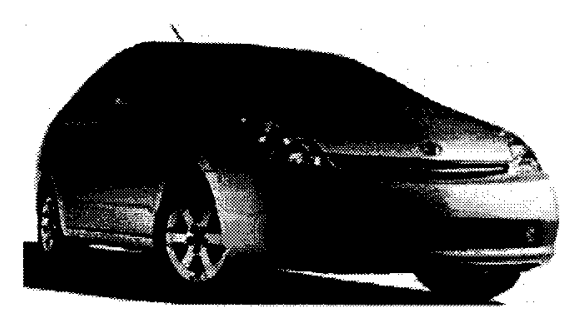

\subsubsection{Honda Civic Hybrid (2003)}

The Honda Civic Hybrid, a compact car, uses the IMA system which has many of the features of the HSD system but the electric motor cannot power the vehicle alone. It is lighter than either the Prius or Escape, and has a smaller engine. 


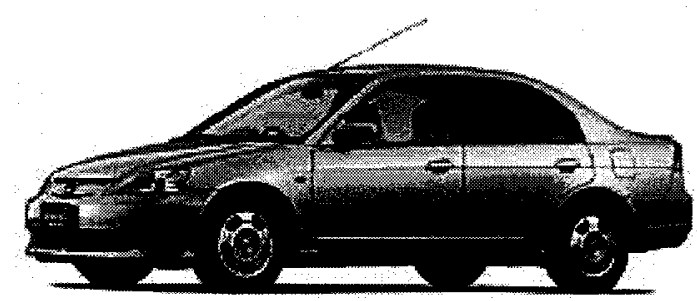

\subsubsection{Honda Insight (2000)}

The Honda Insight, a two-seater, is the smallest of the hybrid vehicles tested. Like the Civic, it uses the IMA system. This particular model was actually the first commercially available HEV in North America when it was introduced in 1999. Unlike the other hybrids tested, it has a five-speed manual transmission instead of a continuously variable transmission. It is distinguished by its small size and aerodynamic tear-drop shape. The Insight has a top speed of only $180 \mathrm{~km} / \mathrm{h}$.

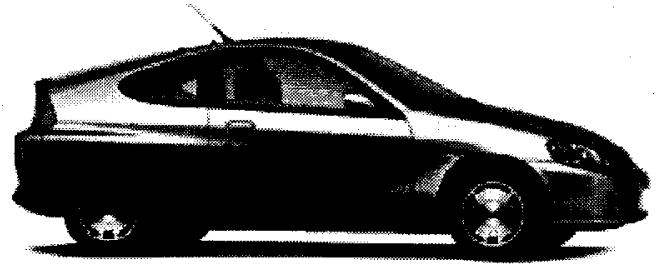

\subsubsection{Gasoline Smart Cabrio (2002)}

Only the diesel version of the Smart Cabrio is currently sold in North America, but a gasoline version was obtained for this study to represent a comparably low emission alternative to the hybrid system. The Smart Cabrio, weighing in at approximately half the weight of the Toyota Prius, was the lightest vehicle tested. It also had the smallest engine. Despite these advantages, its fuel consumption rating is comparable to that of the Honda Civic Hybrid. The vehicle has a top speed of only $135 \mathrm{~km} / \mathrm{h}$. 


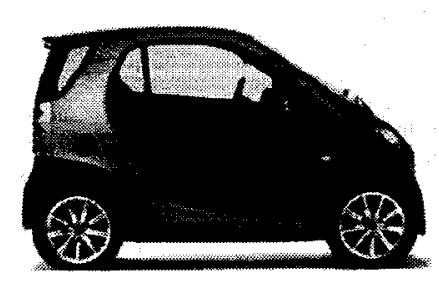

\subsection{Future Trends}

Most experts agree that the car of the future will be an HEV of some kind. All-electric vehicles are limited by the energy density of electric batteries, which has been slowly improving but is unlikely to ever equal that of liquid or gaseous fuels. For this reason it is likely that on-board energy conversion units will continue to play a significant role, and will be combined with energy storage devices in an HEV configuration. The internal combustion engine is expected to continue to play an important role in on-board energy conversion in the near future, with increasing use of alternative fuels such as ethanol, biodiesel, or natural gas. Fuel cells may also have potential for on-board energy conversion.

As far as HEV technology goes, plug-in-hybrids may be the next wave of commercially available advanced technology vehicles. These vehicles, which are fully functional in either electric or hybrid mode, have the potential to offer large emissions and oil savings, depending on the source of electricity. Another advantage of these vehicles is that they could offer a market for off-peak power from local utility plants, thus helping utilities with load balancing. In 2005 DaimlerChrysler brought out the first plug-in hybrid prototype vehicles built by a major automaker. 
Of course, in order to determine the true environmental impact of any technology, a full life-cycle analysis must be done. While the current study focuses on only one stage in the emission producing life of vehicles and fuel, there are certainly other considerations. One major environmental concern associated with the HEV lifecycle is the disposal of HEV batteries. The nickel metal hydride $(\mathrm{NiMH})$ batteries used in HEVs are under warranty for eight to ten years. While the components of these batteries are not as toxic as those of conventional lead acid or nickel cadmium batteries, the challenge of collecting and recycling these batteries will be important in the coming years.

\subsection{Experimental Methodology}

Experiments were carried out using the chassis dynamometer testing facility at the Environmental Technology Centre (ETC) of Environment Canada, 335 River Rd., Ottawa, ON. Currently, no standard method exists for sampling and dilution for particle number and size distribution measurements. The usual approach, however, is to use methods designed for gaseous measurements. The chassis dynamometer procedures used for emissions testing are detailed in the U.S. EPA Federal Code of Regulations, Schedule 40 Part 86. This standard protocol was used in order to facilitate comparison with other studies.

The five vehicles discussed in Chapter 3 were driven over five transient driving cycles representing various real-world driving conditions, and subjected to steady-state driving at $40 \mathrm{~km} / \mathrm{h}$ and $80 \mathrm{~km} / \mathrm{h}$. Experiments were performed at ambient temperatures of $20^{\circ} \mathrm{C}$ and $-18^{\circ} \mathrm{C}$ in order to represent typical summer and winter temperatures in Canada. For each test, the exhaust was diluted, collected, and sampled for $\mathrm{PM}_{2.5}$ mass emissions, 
organic and elemental carbon mass emissions, criteria gaseous emissions $\left(\mathrm{CO}, \mathrm{NO}_{\mathrm{x}}\right.$, THC, NMHC, NMOG), and green house gas emissions $\left(\mathrm{CO}_{2}, \mathrm{~N}_{2} \mathrm{O}, \mathrm{CH}_{4}\right)$. Transient (second by second) sampling was carried out for gaseous emissions $\left(\mathrm{CO}_{2}, \mathrm{CO}, \mathrm{NO}_{\mathrm{x}}\right.$, THC), as well as for particle number emissions using the condensation particle counter (CPC) and particle size distributions using the electrical low pressure impactor (ELPI). The hybrid battery state of charge (SOC) was continuously monitored on the Civic and Insight, while the charging current (CC) was recorded for the Prius and Escape. Each combination of vehicle, cycle, and temperature was evaluated at least twice.

\subsection{Vehicle Condition}

Information on vehicle condition was recorded for each test in a "Chain of Custody Vehicle Test Information Log". These logs are available at the ETC. Conditions monitored include odometer reading at start and end of each test, tire pressure, and fuel quantity.

The vehicles were provided by Transport Canada. They had accumulated the kilometres shown in Table 4.1.1 at the end of testing. Tire pressure was checked on each day of testing and was set to the recommended value for the particular dynamometer. The lubricants used were those recommended by the manufacturer. The regenerative braking systems were enabled where applicable. Vehicle components, including hybrid batteries, were aged with the vehicle.

Table 4.1.1 - Vehicle kilometres travelled at the end of testing

\begin{tabular}{|c|c|c|c|c|}
\hline $\begin{array}{c}\text { Toyota } \\
\text { Prius }\end{array}$ & $\begin{array}{c}\text { Smart } \\
\text { Cabrio }\end{array}$ & $\begin{array}{c}\text { Ford } \\
\text { Escape }\end{array}$ & $\begin{array}{c}\text { Honda } \\
\text { Civic }\end{array}$ & $\begin{array}{c}\text { Honda } \\
\text { Insight }\end{array}$ \\
\hline 5564 & 16300 & 8977 & 8670 & 23348 \\
\hline
\end{tabular}


The vehicles' fuel was exchanged according to the ETC standard operating procedure.

Tier 2 certification fuel was used for testing at $20^{\circ} \mathrm{C}$ and commercial winter grade fuel was used for testing at $-18^{\circ} \mathrm{C}$. Properties of these fuels are summarized in Table 4.1.2.

Table 4.1.2 - Fuel Properties

\begin{tabular}{|l|l|l|l|l|c|}
\hline Fuel & $\begin{array}{l}\text { Carbon } \\
\text { Fraction }\end{array}$ & BTU/lb & $\begin{array}{l}\text { Specific } \\
\text { Gravity }\end{array}$ & $\begin{array}{l}\text { Oxygen } \\
\text { Fraction }\end{array}$ & $\begin{array}{l}\text { Sulphur } \\
\text { (ppm) }\end{array}$ \\
\hline Tier 2 & 0.8430 & 18132.0 & 0.7430 & 0.0178 & 37 \\
\hline Winter & 0.8590 & 18621.0 & 0.7237 & & 28 \\
\hline
\end{tabular}

After fuel exchange, the vehicle was driven over a preconditioning cycle. The fuel was then drained, the tank was refilled with test fuel, and the vehicle sat at test temperature with the engine off ("soaking") for 12-36 hours. After this, testing began with a cold-start (CS) cycle, followed by several hot-start (HS) or "no crank" cycles (see Table 4.1.3). The driving cycles are described in detail in Section 4.3. Each day at the end of testing the fuel was topped up as needed, and the vehicle was left to soak for 12-36 hours before another day of testing.

Table 4.1.3 - Cycle Terminology

\begin{tabular}{|c|l|c|}
\cline { 2 - 4 } \multicolumn{1}{c|}{} & \multicolumn{1}{c|}{ Description } & Cycles \\
\hline $\begin{array}{c}\text { Cold Start } \\
\text { (CS) }\end{array}$ & $\begin{array}{l}\text { Includes cold engine crank. The test is } \\
\text { performed after the vehicle has soaked at } \\
\text { test temperature for } 12-36 \text { hours, and thus } \\
\text { the engine and emission control } \\
\text { technologies are at ambient test cell } \\
\text { temperature. }\end{array}$ & LA4CS, LA92CS \\
\hline $\begin{array}{c}\text { Hot Start } \\
\text { (HS) }\end{array}$ & $\begin{array}{l}\text { Includes hot engine crank. The test is } \\
\text { performed after any other test plus a 20 } \\
\text { minute soak period. Engine and emission } \\
\text { control technologies are warm. }\end{array}$ & $\begin{array}{c}\text { LA4HS, LA92HS, } \\
\text { NYCC, US06 }\end{array}$ \\
\hline No Crank & $\begin{array}{l}\text { Engine crank is not included. Sampling } \\
\text { begins after a pre-cycle drive. Engine and } \\
\text { emission control technologies are warm. }\end{array}$ & HWFET, SS40, \\
SS80
\end{tabular}




\subsection{Chassis Dynamometer Operation}

A twin-roll 8.65" electric chassis dynamometer was used for the cold temperature testing and a single-roll 24" electric chassis dynamometer was used for warm temperature testing. The dynamometer was warmed-up at the beginning of each day of testing. At the start of a series of tests on a particular vehicle, the dynamometer was calibrated by running coast-downs to determine road load settings. The purpose of this procedure is to derive coefficients that define a speed vs. power curve that will be simulated by the chassis dynamometer for a particular test vehicle at a given inertia mass setting. This curve models on-road drive-train parasitic losses and aerodynamic losses for the specific vehicle. The inertia weight was selected from the manufacturer's information.

During testing, a professional driver operated the vehicles over the driving cycles. The rotating speed of the dynamometer roll was measured by a pulse counter, and this signal was converted to a linear speed which was displayed on a monitor as a cursor. The driver uses this cursor to follow a given speed-time trace. A fixed speed cooling fan was directed at the front of the vehicle in order to simulate on-road air flow conditions over the radiator. Dynamometer speed was continuously recorded and vehicle exhaust was collected via a transfer line connected to the tailpipe and leading to the constant volume sampler (CVS) tunnel (described in section 4.4.1). Charging current or state of charge was continuously recorded as described in Sections 4.4.6 and 4.4.7. Figures 4.2.1 and 4.2.2 show chassis dynamometer testing. 


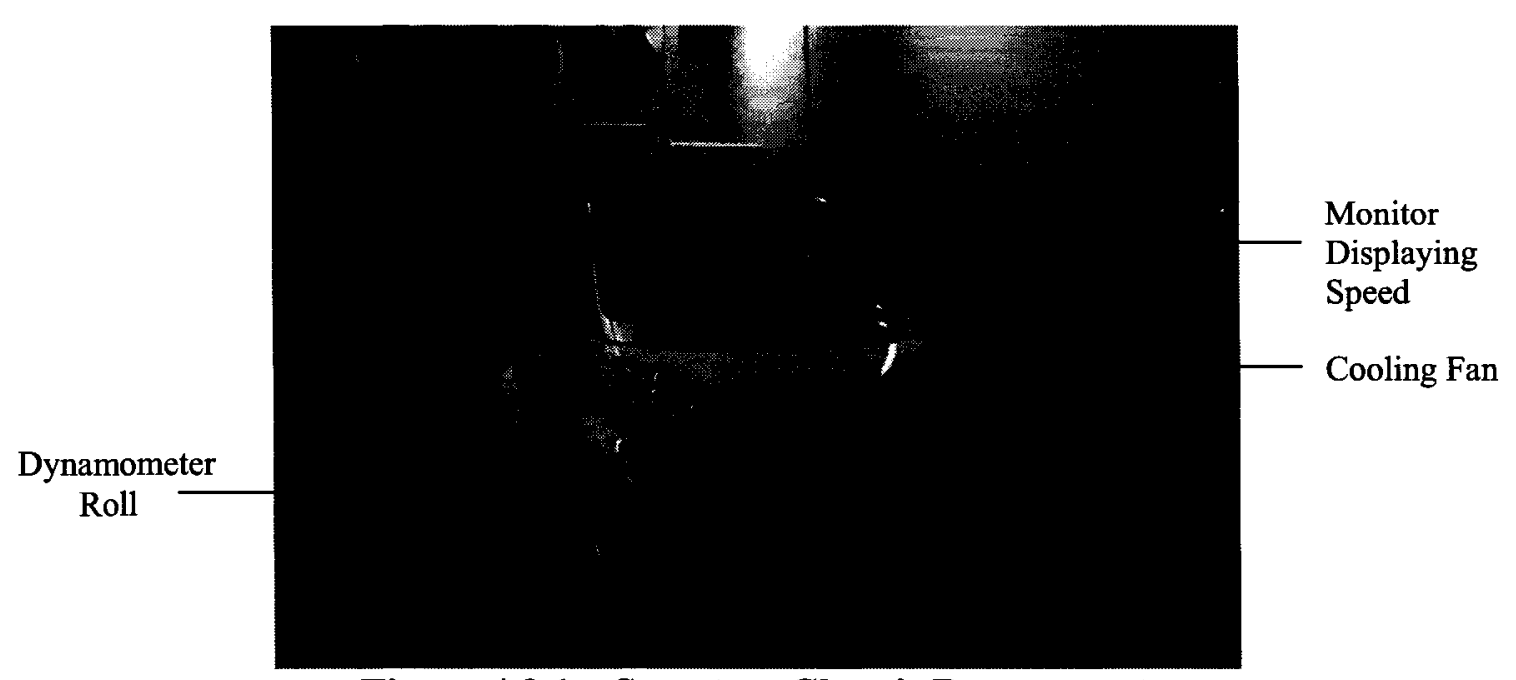

Figure 4.2.1 - Smart on Chassis Dynamometer

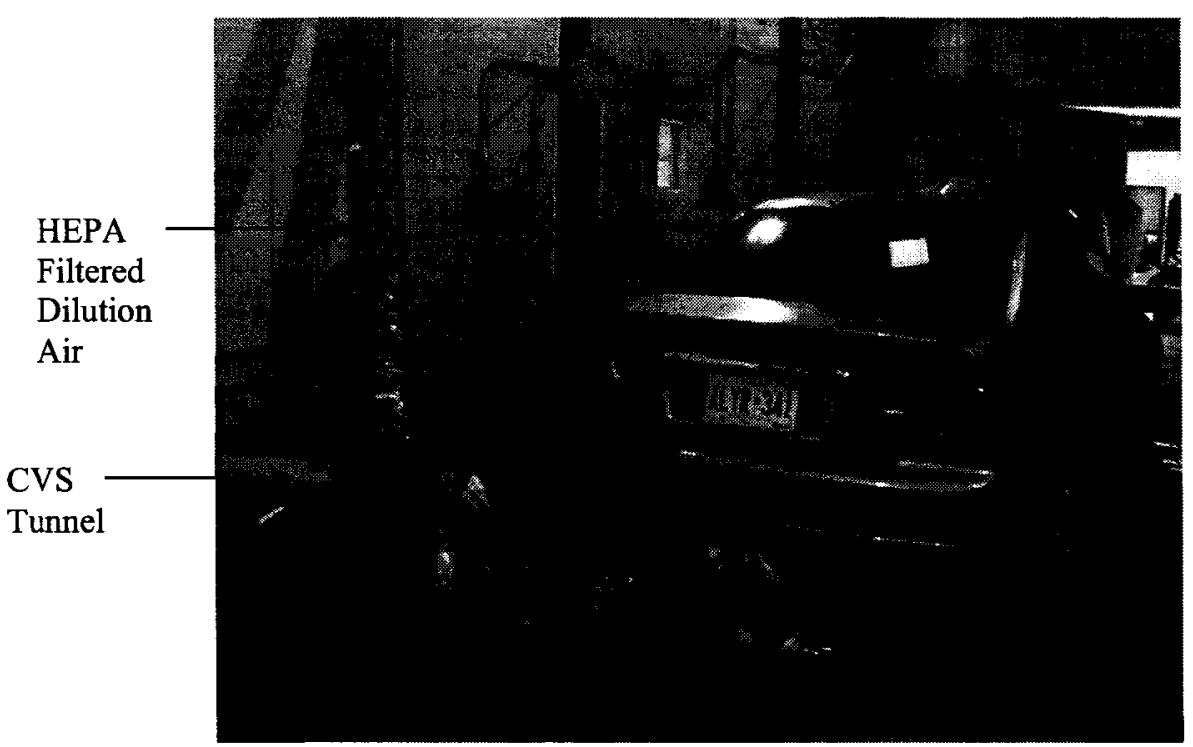

Figure 4.2.2 - Civic on Chassis Dynamometer

\subsection{Driving Cycles and Emission Data}

In order to observe the transient nature of hybrid vehicle emissions under various driving conditions, the vehicles were driven over five transient cycles. These cycles were designed to simulate non-demanding urban driving, more aggressive urban driving, congested urban driving, aggressive high speed driving, and highway driving. Two of the 
cycles were also designed to capture cold-start conditions. Steady-state tests at $40 \mathrm{~km} / \mathrm{h}$ and $80 \mathrm{~km} / \mathrm{h}$ were performed for comparison with the transient test results.

Transient (second by second) emissions data including particle number concentration, size distribution, $\mathrm{CO}_{2}, \mathrm{CO}, \mathrm{THC}$, and $\mathrm{NO}_{\mathrm{x}}$ were collected throughout each test. Particulate matter filters were used to obtain an integrated mass emission factor for each test. Exhaust samples were collected in bags and used to obtain integrated gaseous emission factors for each test, or phase within the test. Sampling methodology is described in Section 4.4. Cycle properties and data collection timings are summarized in Table 4.3.1, and detailed in the following sections. 
Table 4.3.1 - Driving Cycles

\begin{tabular}{|c|c|c|c|c|c|c|}
\hline $\begin{array}{c}\text { Test } \\
\text { Procedure }\end{array}$ & $\begin{array}{l}\text { Type of } \\
\text { driving }\end{array}$ & $\begin{array}{l}\text { Distance } \\
\text { (km) }\end{array}$ & $\begin{array}{l}\text { Time } \\
\text { (min) }\end{array}$ & $\begin{array}{l}\text { Average } \\
\text { Speed } \\
(\mathbf{k m} / \mathbf{h})\end{array}$ & $\begin{array}{l}\text { Maximum } \\
\text { Speed } \\
(\mathbf{k m} / \mathbf{h})\end{array}$ & $\begin{array}{c}\text { Integrated Data } \\
\text { Collection Timing } \\
\text { (Transient data } \\
\text { collected } \\
\text { continuously) } \\
\end{array}$ \\
\hline $\begin{array}{l}\text { Federal Test } \\
\text { Procedure } \\
\text { (LA4) }\end{array}$ & $\begin{array}{l}\text { Run as either a } \\
\text { cold or hot } \\
\text { start, transient, } \\
\text { non-aggressive }\end{array}$ & 12.1 & 22.8 & 31.5 & 91.2 & $\begin{array}{l}\text { Filter data collected } \\
\text { over entire test, bag } \\
\text { data collected twice } \\
\text { for each test (phases } \\
1 \text { and } 2 \text { ) }\end{array}$ \\
\hline $\begin{array}{l}\text { Unified Driving } \\
\text { Cycle (LA92) }\end{array}$ & $\begin{array}{l}\text { Run as either a } \\
\text { cold or hot } \\
\text { start, transient, } \\
\text { more aggressive } \\
\text { than LA4 }\end{array}$ & 15.8 & 23.9 & 39.6 & 107.0 & Same as LA4 \\
\hline $\begin{array}{c}\text { Highway Fuel } \\
\text { Economy Test } \\
\text { (HWFET) }\end{array}$ & $\begin{array}{l}\text { Hot, no engine } \\
\text { crank, highway } \\
\text { driving }\end{array}$ & 16.4 & 12.7 & 77.8 & 96.4 & $\begin{array}{l}\text { Collected over } \\
\text { entire test }\end{array}$ \\
\hline $\begin{array}{l}\text { New York City } \\
\text { Cycle (NYCC) }\end{array}$ & $\begin{array}{l}\text { Hot start, } \\
\text { congested urban } \\
\text { (gridlock) } \\
\text { driving }\end{array}$ & 1.9 & 10.0 & 11.4 & 44.6 & $\begin{array}{c}\text { Collected over } \\
\text { entire test, cycle } \\
\text { repeated twice } \\
\text { consecutively per } \\
\text { test } \\
\end{array}$ \\
\hline $\begin{array}{l}\text { Supplemental } \\
\text { FTP (US06) }\end{array}$ & $\begin{array}{l}\text { Hot start, } \\
\text { aggressive, } \\
\text { similar speeds } \\
\text { to HWFET but } \\
\text { more transients }\end{array}$ & 12.8 & 10.0 & 77.9 & 129.2 & Same as NYCC \\
\hline
\end{tabular}

\subsubsection{LA4}

The LA4 cycle used in this study is one of several existing emission test cycles derived from the speed-time trace shown in Figure 4.3.1. The cycle was developed by the U.S. EPA in the late 1960s and early 1970s based on "Los Angeles Route Four", a trip to and from the then headquarters of the Air Resources Board in Downtown Los Angeles. It is described in 40CFR Part 86, Appendix 1. It is sometimes called the "city" cycle, the urban dynamometer driving schedule (UDDS), or the Federal Test Procedure (FTP-72). In Sweden it is known as the A10 or constant volume sampler (CVS) cycle. In Australia 
it is referred to as the Australian Design Rules (ADR-27) cycle. The LA4 was used in this study to capture emissions representative of a non-demanding style of urban driving, to compare cold- and hot-start emissions, and because of its similarity to the 3-phase FTP75 which is currently used to determine city fuel economy, and compliance with criteria emissions standards in the U.S. and Canada.

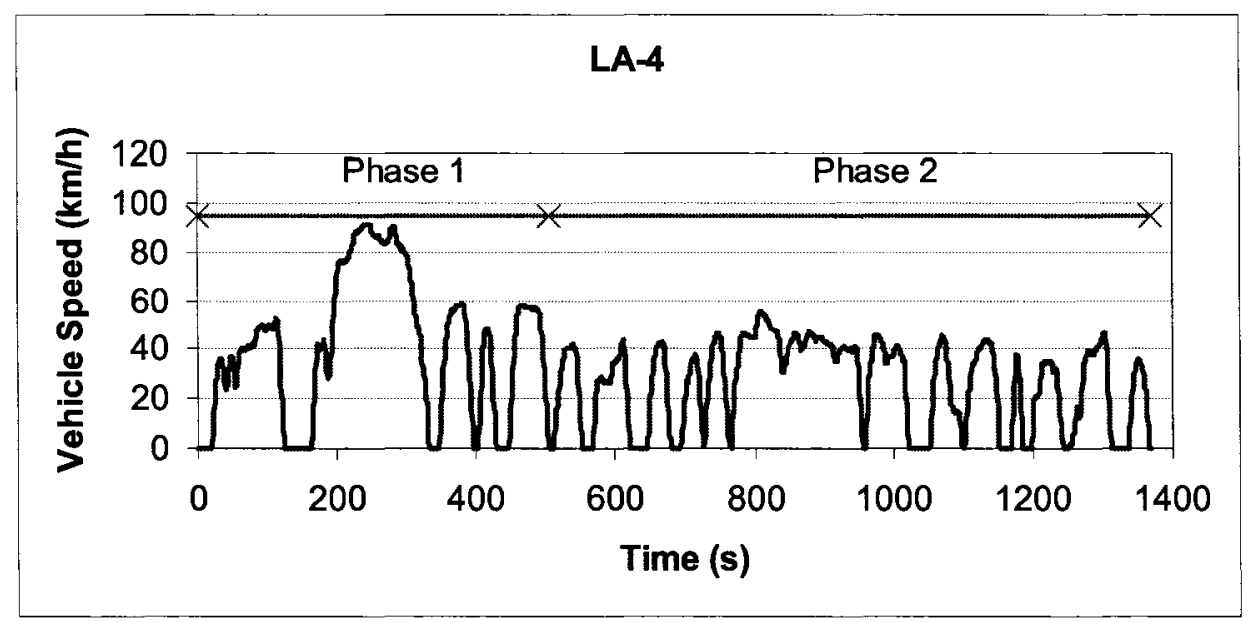

Figure 4.3.1 - LA4 Test Cycle

The phases of the LA4 are described in Table 4.3.2 and shown in Figure 4.3.1. This test was originally used as the federal test procedure, but over time it was demonstrated that emissions were the same during phase 2 and phase 4, and thus the FTP-75 was created by dropping phase 4 . In the current study, all 4 phases were run. This allowed filter data to be collected over a longer period of time (ie. phase $1+$ phase 2 , and phase $3+$ phase 4 ), and allowed hybrid vehicle performance to be better captured. The first LA4 was run as a cold start, followed by a 20 minute soak during which filters were changed, and then a second LA4 was run as a hot start. Exhaust bag data were collected for each phase of both tests. As with all tests, transient data were continuously collected, allowing integrated emission factors to be calculated over any portion of the test. Composite emission factors are calculated with the weightings shown in Table 4.3.2. 
Table 4.3.2 - LA4 phase descriptions

\begin{tabular}{|c|c|c|c|c|c|c|}
\hline & $\begin{array}{l}\text { Phase } \\
\text { has }\end{array}$ & $\begin{array}{l}\text { Distance } \\
\text { (km) }\end{array}$ & $\begin{array}{l}\text { Time } \\
\text { (min) }\end{array}$ & $\begin{array}{l}\text { Average } \\
\text { Speed } \\
(\mathbf{k m} / \mathbf{h})\end{array}$ & $\begin{array}{l}\text { Maximum } \\
\text { Speed } \\
(\mathrm{km} / \mathrm{h})\end{array}$ & $\begin{array}{l}\text { Composite } \\
\text { Weighting }\end{array}$ \\
\hline \multirow{2}{*}{$\frac{1}{2}$} & \multirow{2}{*}{ LA4CS } & 5.8 & 8.4 & 41.1 & 91.1 & \multirow{2}{*}{0.43} \\
\hline & & 6.2 & 14.4 & 25.8 & 55.1 & \\
\hline \multicolumn{7}{|c|}{20 minute soak } \\
\hline \multirow{2}{*}{\multicolumn{2}{|c|}{\begin{tabular}{l|l}
3 & LA4HS \\
4 &
\end{tabular}}} & \multicolumn{4}{|c|}{ Same as phase 1} & \multirow{2}{*}{0.57} \\
\hline & & \multicolumn{4}{|c|}{ Same as phase 2} & \\
\hline
\end{tabular}

\subsubsection{LA92}

The LA92 was developed by the California Air Resources Board in 1992 using a chase car with a forward looking laser to record driving patterns of randomly selected vehicles in the South Coast Air Basin. This cycle, shown in Figure 4.3.2, is meant to represent more realistic driving behaviour than the LA4. It includes higher speeds, fewer stops per kilometre, less idle time, and higher accelerations.

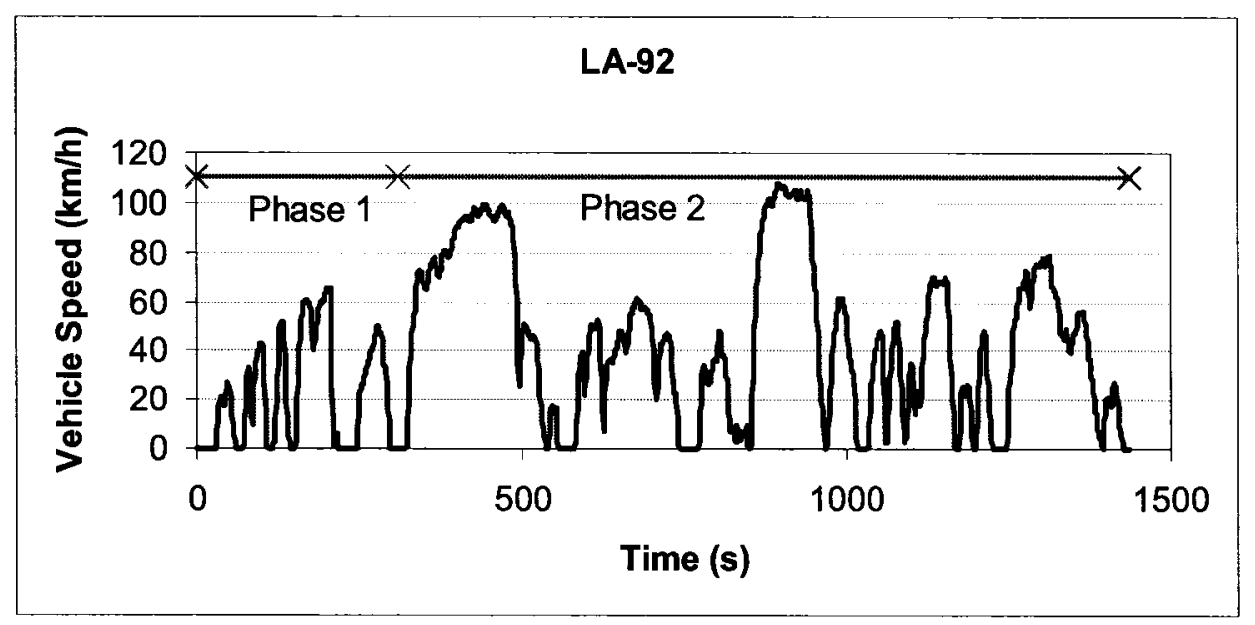

Figure 4.3.2 - LA92 Driving Cycle

As with the LA4, the LA92 emissions data was collected in 4 phases; these are described in Table 4.3.3 and shown in Figure 4.3.2. Two LA92 cycles were used, similar to the LA4. The first was run as a cold-start followed by a 20 minute soak during which PM 
filters were changed, and then a second LA92 was run as a hot start. Emissions were sampled as with the LA4.

Table 4.3.3 - LA92 phase descriptions

\begin{tabular}{|c|c|c|c|c|c|}
\hline & Phase & $\begin{array}{l}\text { Distance } \\
\text { (km) }\end{array}$ & $\begin{array}{l}\text { Time } \\
\text { (min) }\end{array}$ & $\begin{array}{l}\text { Average } \\
\text { Speed } \\
(\mathbf{k m} / \mathbf{h})\end{array}$ & $\begin{array}{l}\text { Maximum } \\
\text { Speed } \\
(\mathbf{k m} / \mathbf{h})\end{array}$ \\
\hline 1 & \multirow{2}{*}{ LA92CS } & 1.9 & 5.2 & 22.1 & 66 \\
\hline 2 & & 13.9 & 18.7 & 44.4 & 107 \\
\hline \multicolumn{6}{|c|}{20 minute soak } \\
\hline 3 & \multirow{2}{*}{ LA92HS } & \multicolumn{4}{|c|}{ Same as phase 1} \\
\hline 4 & & \multicolumn{4}{|c|}{ Same as phase 2} \\
\hline
\end{tabular}

\subsubsection{Highway Fuel Economy Test (HWFET)}

The highway fuel economy test (HWFET), sometimes referred to as the highway fuel consumption test (HWFCT) or highway fuel economy driving schedule (HWFEDS), is described in 40 CFR Part 600, Appendix 1. It was developed by the U.S. EPA for use in determining the highway fuel economy rating of light duty vehicles. It was used in this study to simulate free flow highway driving and because of its current use as a regulatory test. The HWFET has a maximum speed of $96.4 \mathrm{~km} / \mathrm{h}$ and an average speed of $77.8 \mathrm{~km} / \mathrm{h}$. It consists of a single phase of $16.4 \mathrm{~km}$ over 12.7 minutes. The speed-time trace is shown in Figure 4.3.

The HWFET cycle does not include engine crank. The cycle was repeated twice consecutively, with emissions and vehicle parameters recorded only during the second run-through. This ensured that the engine and emission control technologies were at operating temperature during sampling. 


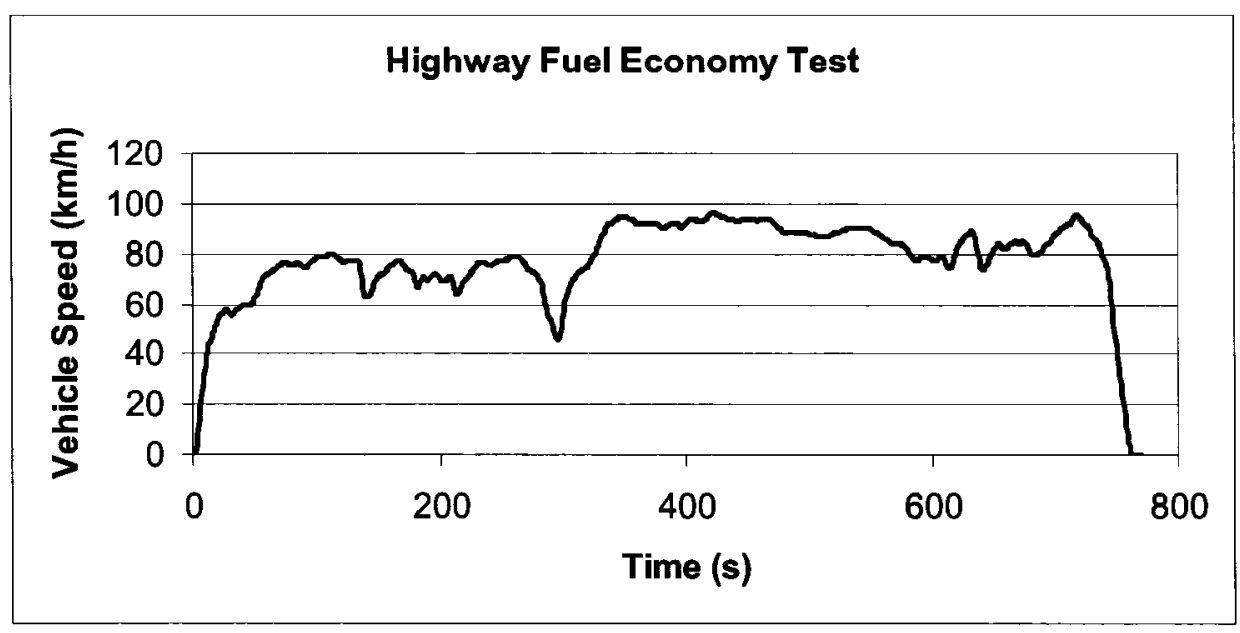

Figure 4.3.3 - Highway Fuel Economy Test (HWFET)

\subsubsection{New York City Cycle (NYCC)}

The New York City Cycle was developed by the U.S. EPA to simulate congested urban driving during chassis dynamometer testing of light duty vehicles (Environmental Protection Agency, 1997). It is a low speed cycle and includes frequent stops and long idle periods. The single phase driving schedule covers $1.89 \mathrm{~km}$ in 10 minutes with a maximum speed of $44.6 \mathrm{~km} / \mathrm{h}$ and an average speed of $11.4 \mathrm{~km} / \mathrm{h}$.

In this study, the NYCC tests were run as two consecutive repeats of the NYCC speedtime trace shown in Figure 4.2.4. Emission data were collected over the entire 20 minutes of testing. This allowed for more accurate measurement of PM filter data, which would have been very low if collected for only 10 minutes. The double test also permitted observation of transient emission and battery behaviour during a longer period of driving. 


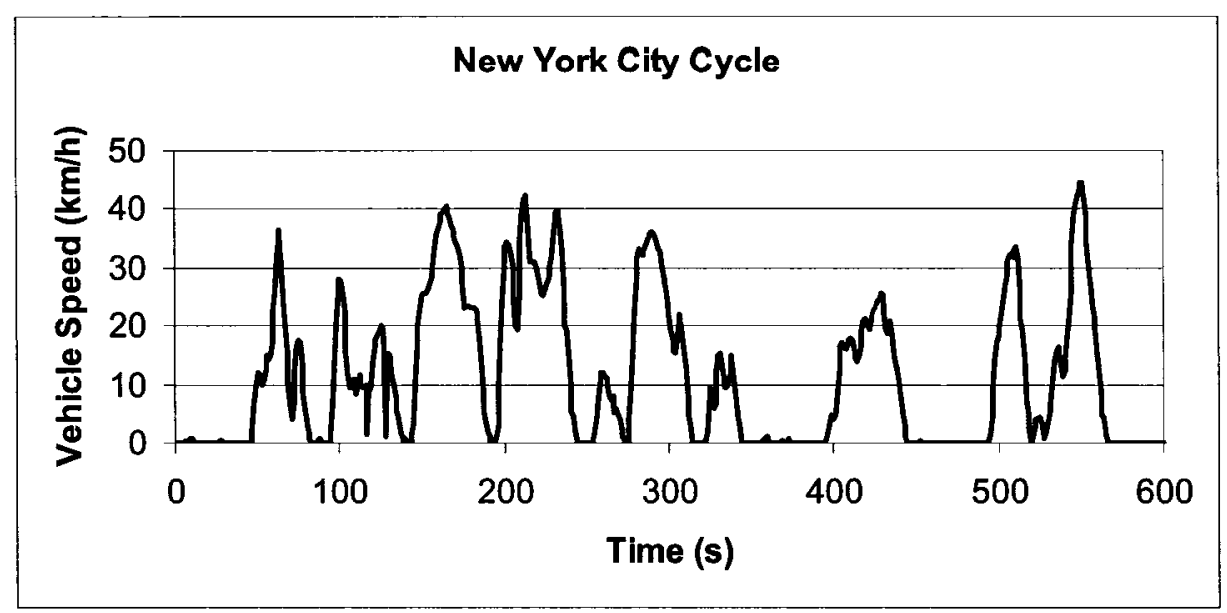

Figure 4.3.4 - New York City Cycle (NYCC)

\subsubsection{US06 Supplemental Federal Test Procedure (US06-SFTP)}

Because it is recognized that the FTP cycle, currently used to determine city fuel economy and compliance with criteria emissions standards, is not representative of realworld driving, the US06 cycle was developed by the U.S. EPA. This cycle was designed to supplement the Federal Test Procedure, providing information about vehicle emissions and fuel economy under aggressive driving conditions.

The US06 driving schedule, shown in Figure 4.3.5, represents a $12.8 \mathrm{~km}$ route travelled over 10 minutes. It has a maximum speed of $129.2 \mathrm{~km} / \mathrm{h}$ and an average speed of $77.9 \mathrm{~km} / \mathrm{h}$. Its characteristics include high speeds, hard accelerations and decelerations, as well as rapid speed fluctuations. As with the NYCC tests, the US06 tests were run as double cycles, with particulate matter filters collected for the entire double cycle. Again, this allowed examination of transient behaviour over a longer test period, and improved the accuracy achieved in weighing the PM filters. 


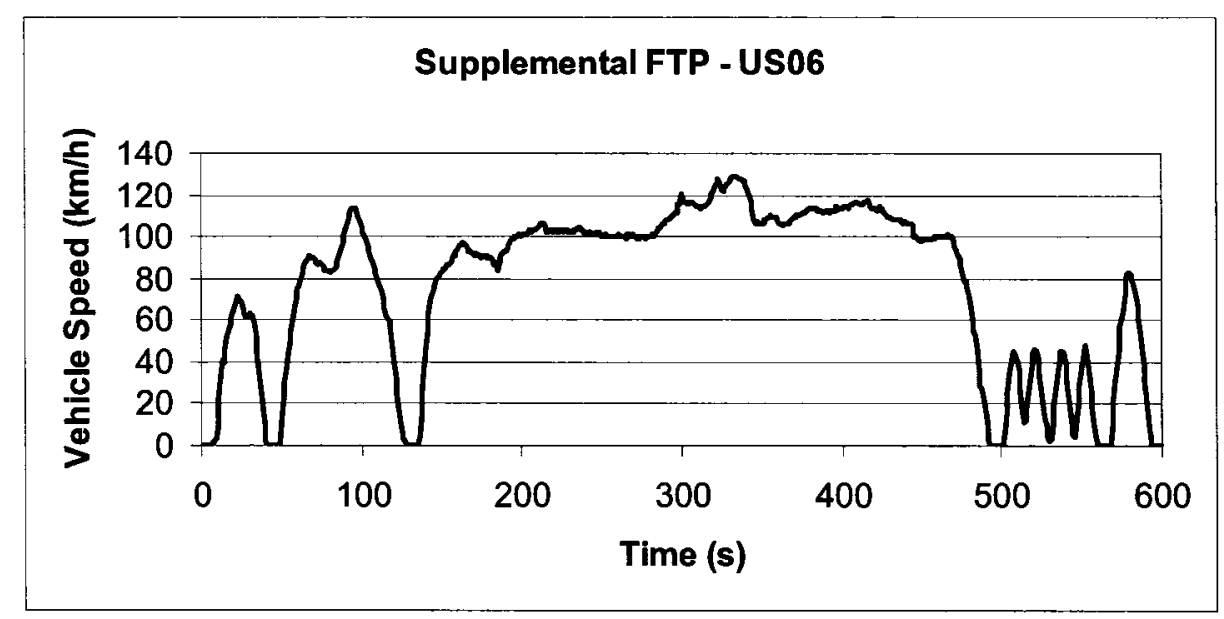

Figure 4.3.5 - US06 Supplemental FTP

\subsubsection{Steady-State Tests (SS40, SS80)}

In addition to the transient tests described above, vehicles were tested under steady-state conditions at $40 \mathrm{~km} / \mathrm{h}$ and $80 \mathrm{~km} / \mathrm{h}$. "Steady-state" refers to constant speed driving (i.e. the dynamometer speed is steady, but other test conditions are not necessarily held constant). The steady-state tests lasted for 30 minutes each, with emission samples collected only during the last 20 minutes. This ensured that the engine and emission control technologies were at operating temperature during sampling. These steady-state tests were useful for comparison with transient cycles having similar average speeds: LA92 $(39.6 \mathrm{~km} / \mathrm{h})$, HWFET $(77.8 \mathrm{~km} / \mathrm{h})$, and US06 $(77.9 \mathrm{~km} / \mathrm{h})$. A steady-state test at $10 \mathrm{~km} / \mathrm{h}$ was also attempted and would have been useful for comparison with the NYCC. The driver found, however, that it was difficult to maintain such a steady low speed. The driver was able to use cruise control to maintain the higher speeds.

\subsection{Sampling Methodology}

The dilution tunnel and sampling lines are shown in Figures 4.4.1 and 4.4.2. In Figure 4.4.1, the vehicle (5) is shown on the chassis dynamometer roller (3) with the constant 
speed cooling fan (4) in front. The exhaust was collected and diluted with HEPA filtered laboratory air (1) following conventional constant volume sampling (CVS) emissions testing protocols. Secondary dilution was performed using an ejector diluter (7) in order to bring particle concentrations down to within range of the electrical low pressure impactor (8) and condensation particle counter (9). The diluted exhaust was continuously sampled for $\mathrm{CO}_{2}, \mathrm{CO}, \mathrm{NO}_{\mathrm{x}}$, and $\mathrm{THC}$ by the gas analyzers (10), and collected in bags (14) for integrated analysis. The sample train (11) was used to collect bags of diluted exhaust for $\mathrm{NMHC}, \mathrm{NMOG}, \mathrm{CH}_{4}$, and $\mathrm{N}_{2} \mathrm{O}$ analysis. The dilution air and diluted exhaust were filtered at (2) and (12) to determine PM mass concentrations. Before filtering, the diluted exhaust passed through a cyclone which allowed only particles with diameter $<2.5 \mathrm{um}$ to accumulate on the filter. The hybrid battery state of charge or charging current was measured using an on-board diagnostic system or amp probe (13). Individual instruments and sampling methodologies are detailed in the following sections. 


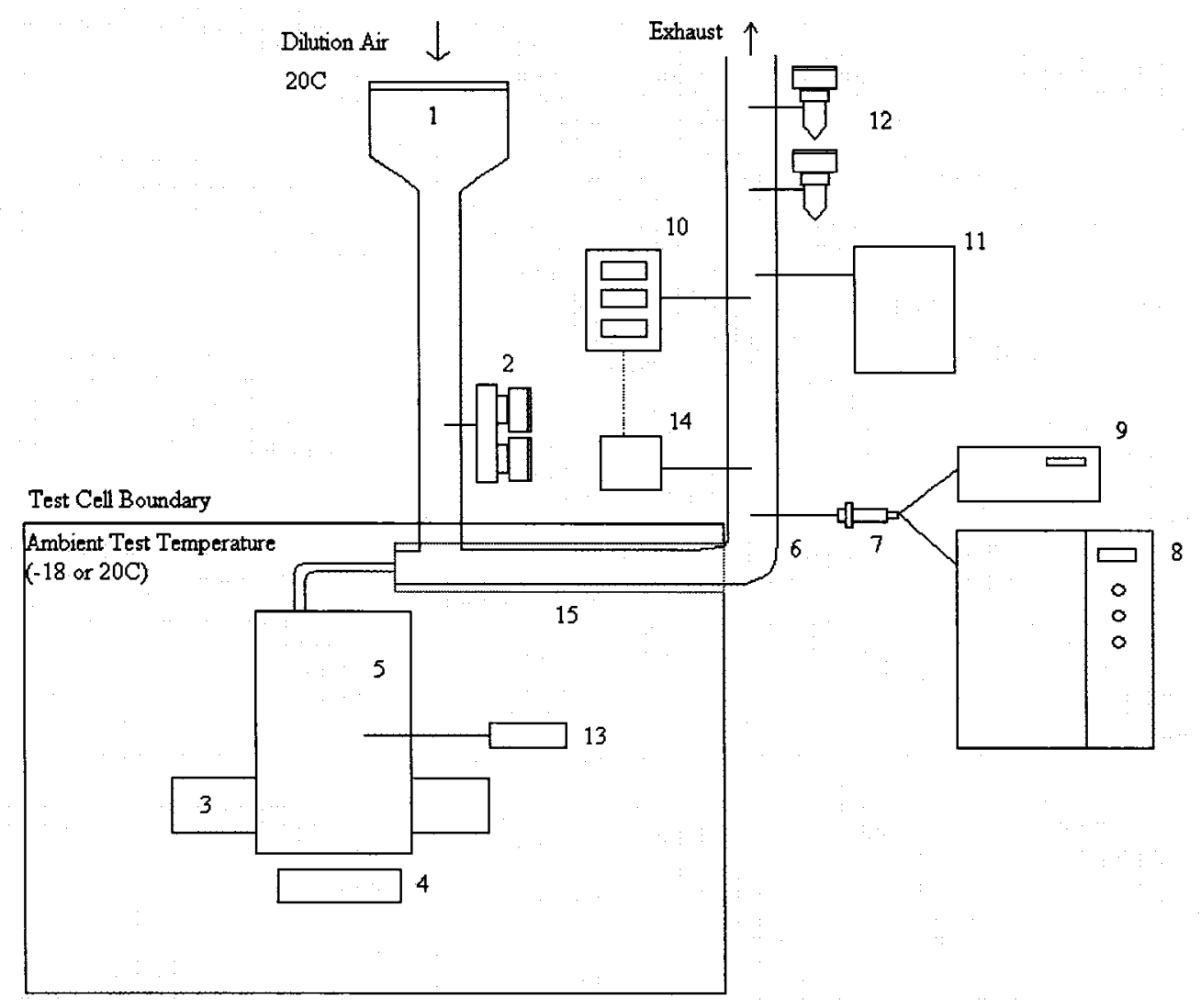

Figure 4.4.1 - Exhaust Sampling Schematic 1: HEPA filter bank for dilution air, 2: Dilution air filter packs, one containing a TMF and QFF, one containing only a QFF, 3: Dynamometer roller, 4: Fixed speed cooling fan, 5: Test vehicle, 6: CVS dilution tunnel, 7: Ejector Diluter, 8: ELPI, 9: CPC, 10: Gas analyzer bench, 11: Sample cart for collecting emissions for $\mathrm{NMHC}, \mathrm{GHG}$, and carbonyl analysis 12: Sample filter packs and cyclones, one containing a TMF and QFF, one containing a QFF only, 13: Hybrid battery monitoring: amp probe for charging current or OBD for SOC, 14: Test cell bags for integrated emission factors of $\mathrm{CO} 2, \mathrm{CO}, \mathrm{NO}_{\mathrm{x}}, \mathrm{THC}, 15$ : Heated blanket to avoid condensation on tunnel walls 


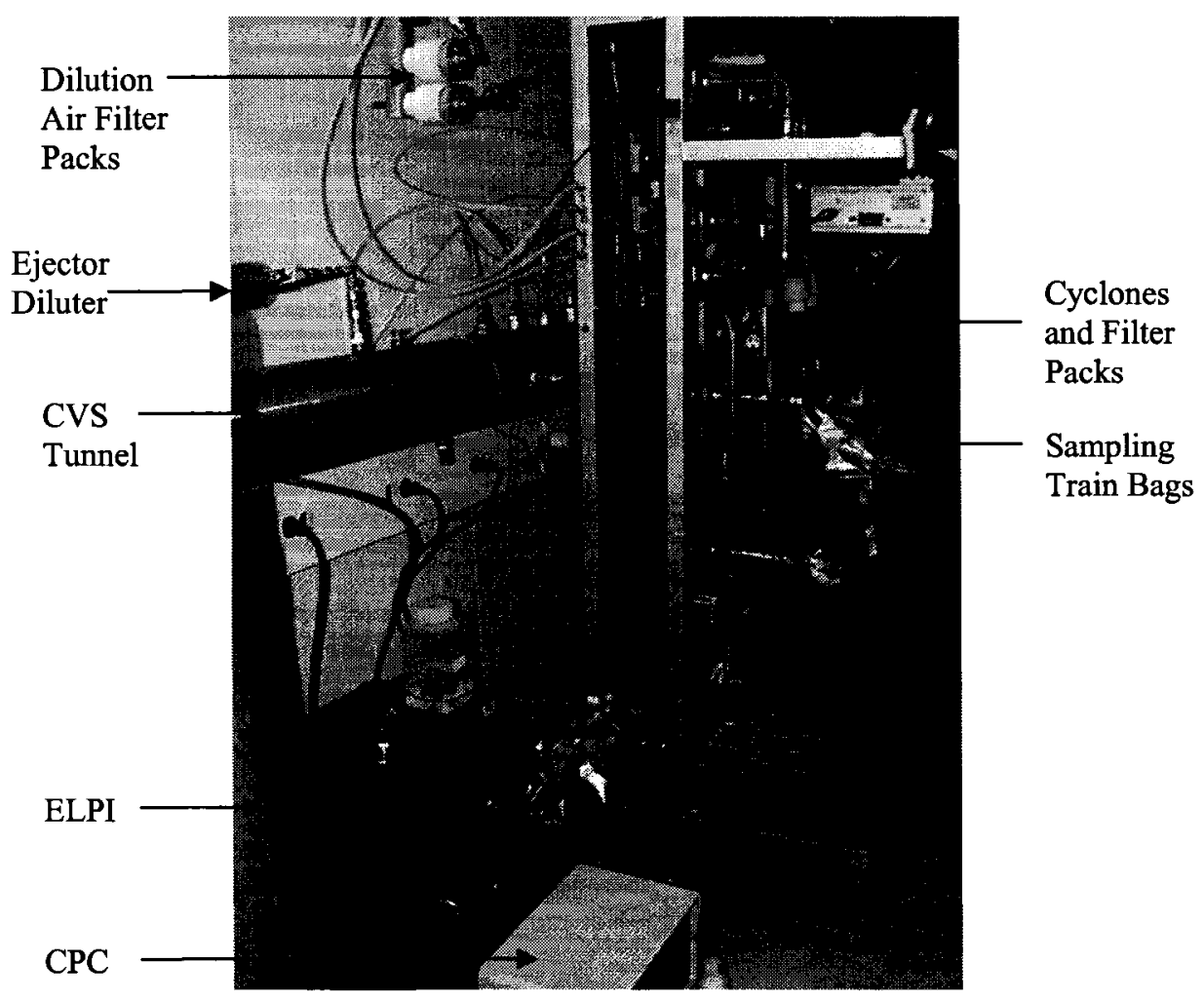

Figure 4.4.2 - Sampling System

\subsubsection{Dilution Tunnel and Ejector Diluter}

The raw exhaust stream was mixed with HEPA filtered $20^{\circ} \mathrm{C}$ dilution air within 2 feet of where it exited the tailpipe. The diluted sample then travelled through the dilution tunnel, along which samples were extracted, and was finally exhausted from the test facility. The dilution tunnel was pre-warmed with $20^{\circ} \mathrm{C}$ air and diluted with $20^{\circ} \mathrm{C}$ air regardless of the test cell temperature $\left(20^{\circ} \mathrm{C}\right.$ or $\left.-18^{\circ} \mathrm{C}\right)$. Dilution air was drawn through the tunnel for at least 5 minutes before each test in order to help purge the system. A constant volume sampler (CVS) system was used, meaning that the amount of dilution air changed as exhaust volume changed in order to maintain a constant volumetric flow rate through the dilution tunnel. This flow rate was approximately $156 \mathrm{~L} / \mathrm{s}$. The system used is typical of 
what is used for regulatory testing of vehicles with engine displacements in the current test-vehicle range. After this primary dilution, diluted exhaust temperatures were less than $40^{\circ} \mathrm{C}$.

In order to avoid exceeding the upper concentration limits of the CPC and ELPI, a Dekati Diluter with a dilution ratio of 7.1 was used to further dilute the sample seen by these instruments. The Dekati Diluter (Figure 4.4.3) is based on an ejection type dilution. In this type of dilution, dry pressurized air or nitrogen is directed to the diluter through an ejector cavity. The sample line is connected to the ejector cavity by an ejector nozzle. The high flow rate of dilution air or nitrogen in the cavity causes a pressure drop at the ejector nozzle resulting in sample flow into the diluter. The nitrogen mixes with and dilutes the sample in the ejector cavity and diffusion cavity. After this secondary dilution, temperatures were approximately $20-25^{\circ} \mathrm{C}$.

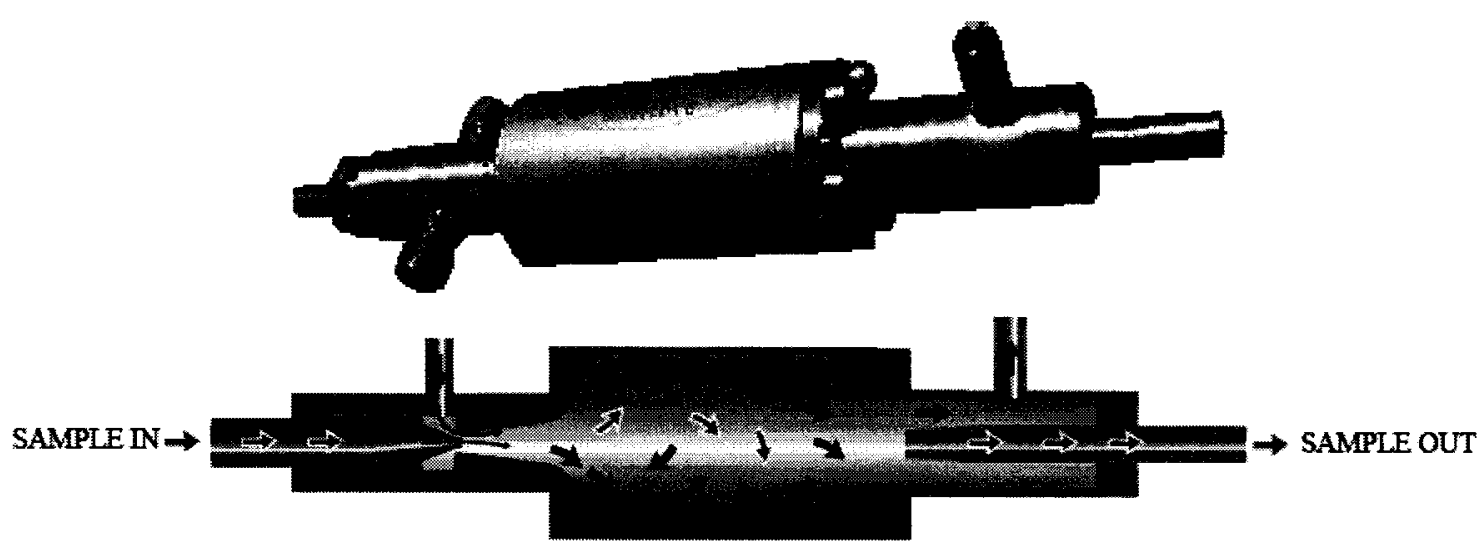

Figure 4.4.3 - Ejector diluter (Dekati Ltd., 1999) 


\subsubsection{Electrical Low Pressure Impactor (ELPI)}

The Electrical Low Pressure Impactor (ELPI) was originally designed at the Tampere University of Technology in Finland for measurement of real-time particle size distributions (Keskinen, 1992). It is commercially available from Dekati Ltd. The instrument is shown in Figure 4.4.4.

During ELPI operation, sample first passes through a unipolar positive polarity charger where particles are electronically charged by ions produced in a corona discharge. The charged particles are then separated by size in a low pressure impactor. This inertial impactor classifies particles based on their aerodynamic diameters; the largest particles stick to the first stages while the smallest follow streamlines to the lower stages. The ELPI includes 12 impaction stages which are electrically insulated and each connected to an electrometer current amplifier. The current produced as particles impact the appropriate stage is recorded by the respective electrometer channel. This current is proportional to the particle concentration in the particular size range, and particle size dependent relations describing the properties of the charger and impactor stages are used to convert current to aerodynamic size distribution. This allows the ELPI to report particle number concentrations for each stage with a time resolution of approximately 1 second (Dekati Ltd., 2005). 


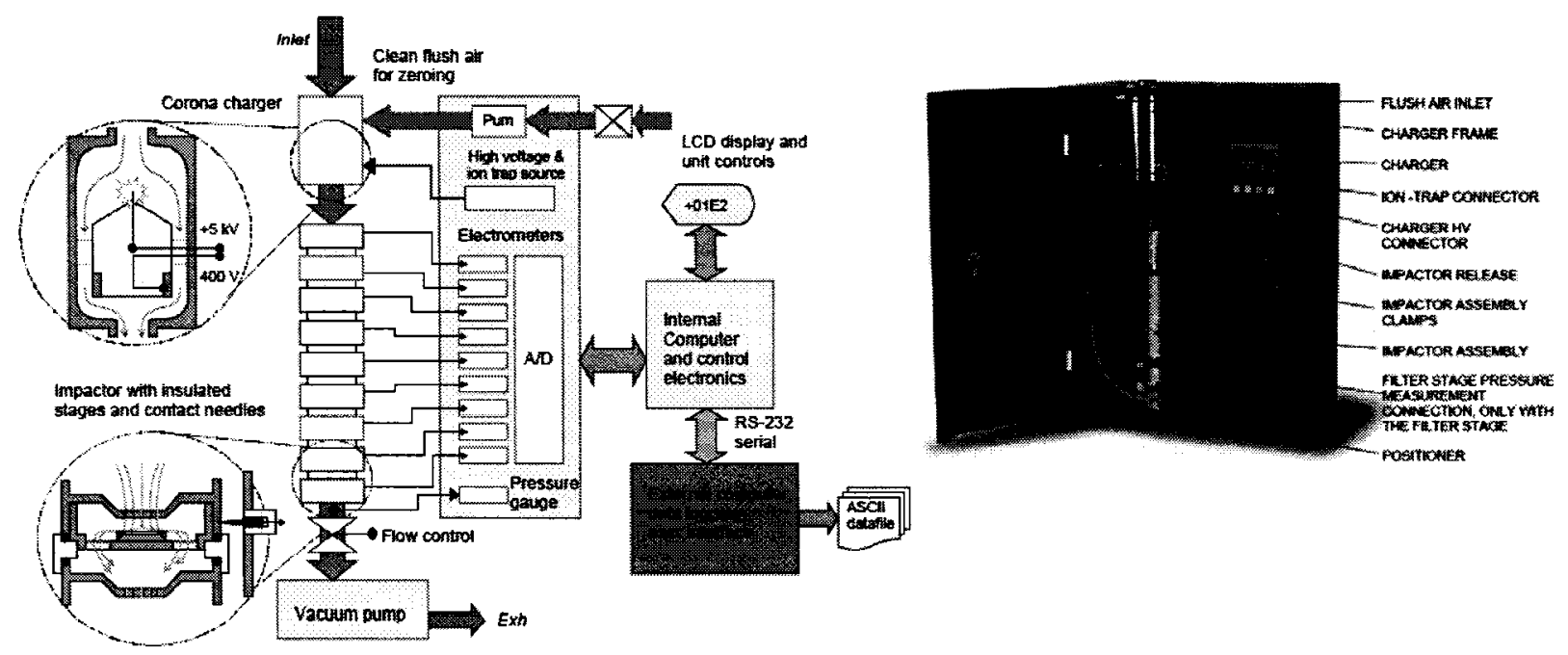

Figure 4.4.4 - Diagram of the Electrical Low Pressure Impactor (Dekati Ltd., 2005)

The Dekati ELPI used in this study is able to measure the concentration of particles with aerodynamic diameters in the range of $0.03-10 \mu \mathrm{m}$. The impactor includes 12 stages, which accumulate particles with average aerodynamic diameters of $0.0399,0.0733$, $0.121,0.2015,0.31,0.492,0.7839,1.2443,1.9554,3.08,5.0826$, and $8.1219 \mu \mathrm{m}$. The data output from the ELPI is the number concentration of particles counted per second in each size range. Each size range has a size-dependent bin width, dlogDp (log base 10). Although other particle sizing instruments exist which can measure particles in smaller size ranges, the ELPI was chosen because of its ability to measure second-by-second particle concentrations in all size bins at the same time.

A flow rate of $10 \mathrm{~L} / \mathrm{min}$ was selected and the appropriate charger and impactor data was entered from the data sheets provided in the ELPI Manual. ELPI can be used in four measurement ranges: $10000 \mathrm{fA}, 40000 \mathrm{fA}, 100000 \mathrm{fA}$ and $400000 \mathrm{fA}$. The $40000 \mathrm{fA}$ range was selected for this study. The $10000 \mathrm{fA}$ range would have had the lowest noise levels, but it would also have resulted in a longer response time. 
The sample was additionally diluted by the ejector diluter prior to reaching the ELPI inlet. The sample travelled approximately 1 meter through $3 / 8$ " electro-conductive silicon tubing from the ejector diluter to the ELPI. Electro-conductive silicon was used to prevent loss of particles due to electrostatic deposition. The sample line was free of sharp bends. During testing, ELPI sampling was started simultaneously with the cycle and was stopped at the end of the cycle. The ELPI technician and the driver communicated by radio to synchronize the sampling with the driving cycle.

The ELPI charger and impactor were cleaned every two weeks or as necessary throughout testing. Cleaning was required more frequently during testing of the high emitting vehicles.

\subsubsection{Condensation Particle Counter (CPC)}

A condensation particle counter uses the principle that supersaturated vapour will condense onto small particles, allowing them to be optically detected. The TSI Model 3022A Condensation Particle Counter (CPC) was used in this study to monitor real-time total particle concentrations. This instrument is shown in Figures 4.4.5 and 4.4.6. The sample first passes through a heated saturator where butanol evaporates and saturates the flow. The aerosol sample then enters a cooled condensing tube where butanol vapour condenses onto the airborne particles. These large particles pass through a detector where individual pulses produced by the particles are detected for concentrations less than $10^{4}$ particles $/ \mathrm{cm}^{3}$. At higher concentrations, scattered light is detected in the sensor zone and the intensity is compared to calibration levels (TSI Incorporated, 2002). 


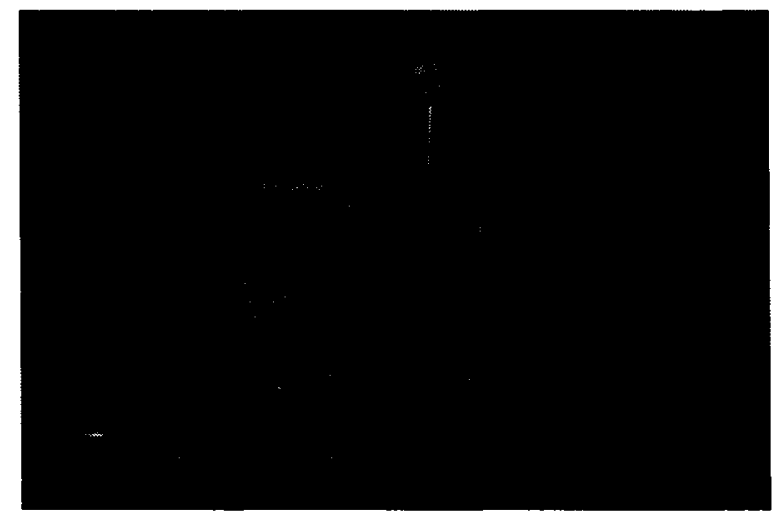

\section{Figure 4.4.5 - Condensation Particle Counter}

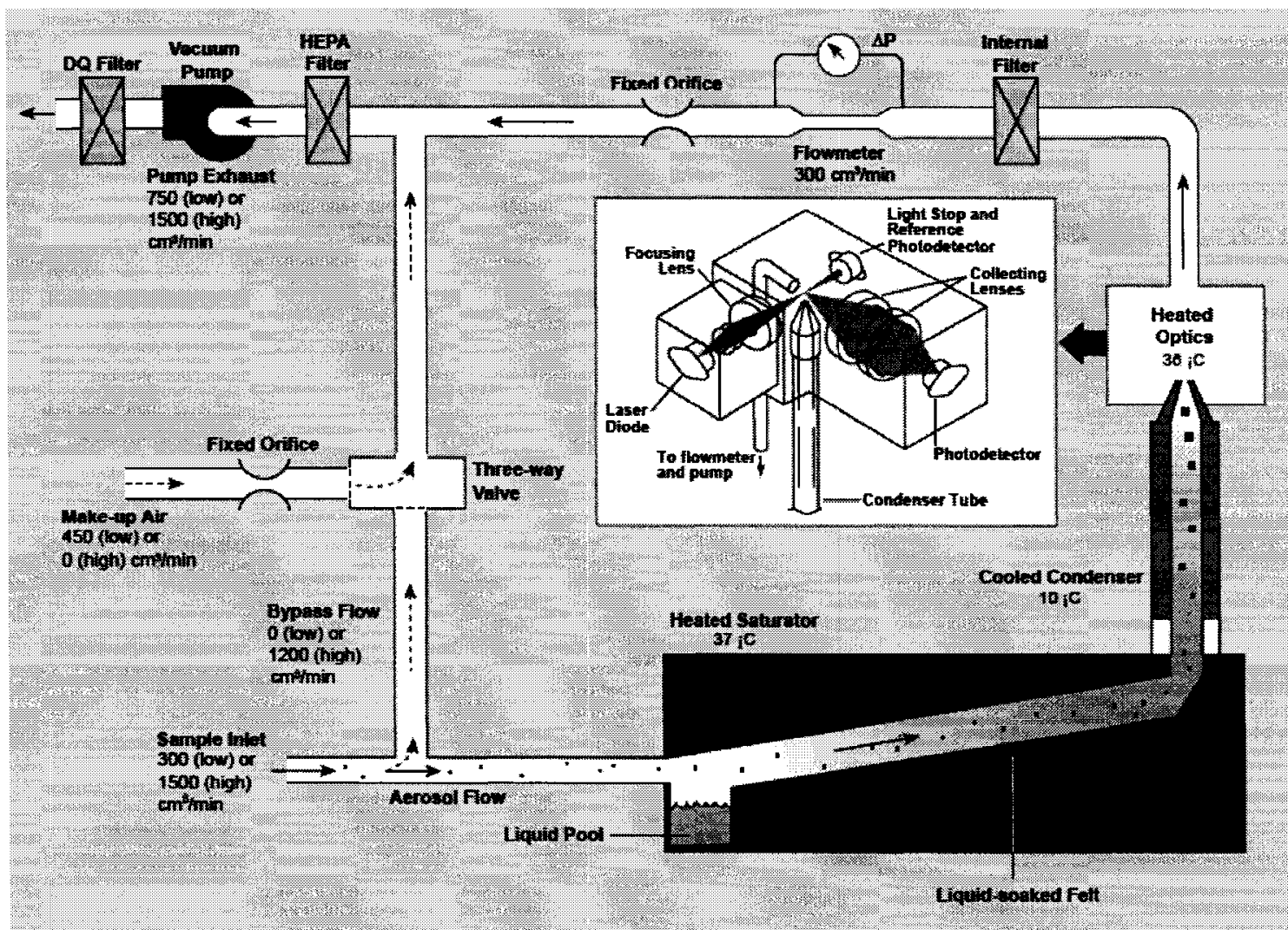

Figure 4.4.6 - Flow diagram for condensation particle counter (TSI Incorporated, 2002)

The 3022A CPC model has the ability to count particles with a minimum size of $7 \mathrm{~nm}$ with $50 \%$ efficiency and a maximum size $>3 \mu \mathrm{m}$. It has an upper concentration limit of $10^{7}$ particles $/ \mathrm{cm}^{3}$ (TSI Incorporated, 2002). Measurements often differ between CPC and 
ELPI in this study because the CPC lower size cut off is $7 \mathrm{~nm}$ while that of ELPI is $30 \mathrm{~nm}$. They may also differ because of differences in the upper cut-off size (10 $\mu \mathrm{m}$ for ELPI and $3 \mu \mathrm{m}$ for CPC). As with the ELPI, the aerosol sample entering the CPC was diluted using the ejector diluter. The CPC sample line was also 3/8" electro-conductive silicon tubing with a length of approximately $1 \mathrm{~m}$ between ejector outlet and CPC inlet. The high flow rate option was selected resulting in a sample flow rate of $1.5 \mathrm{~L} / \mathrm{min}$. The TSI software was used to begin collecting CPC data at the start of each driving cycle and stop collection at the end of each cycle.

\subsubsection{Cyclones and Filters}

The mass of fine $(<2.5 \mu \mathrm{m}$ aerodynamic diameter $)$ particulate matter was sampled using the configuration shown in Figure 4.4.7. Samples were collected via probes which allowed isokinetic isoaxial sampling. One set of dilute exhaust particulate matter samples was collected for each test. Dilution air samples were collected once per vehicle per day.

$2.5 \mu \mathrm{m}$ cut-point $\left(\mathrm{D}_{50}=2.5 \mu \mathrm{m}\right)$ URG cyclones (Figure 4.4.8 and 4.3.9) separated fine and coarse particles in the dilute exhaust samples. The cyclones are Teflon coated to minimize the loss of reactive gases (e.g. $\mathrm{HNO}_{3}$ and $\mathrm{NH}_{3}$ ) to internal surfaces. Two cyclones were employed for collection, each directing fine particles to a two stage $47 \mathrm{~mm}$ filter pack (Figure 4.4.8). One filter pack contained a Teflon membrane filter on the first stage (TMFf) for determining mass emission rates. The Teflon filter does not adsorb semivolatile organic carbon. The second stage contained a backup quartz fibre filter (QFFb) for determining the amount of semivolatile organic carbon adsorbed from the gas stream. The other filter pack had only a quartz fibre filter (QFFf) to collect a sample for 
organic and elemental carbon analysis. The organic carbon mass determined from the QFFf can be corrected for adsorbed semivolatile organic carbon using the QFFb amount.

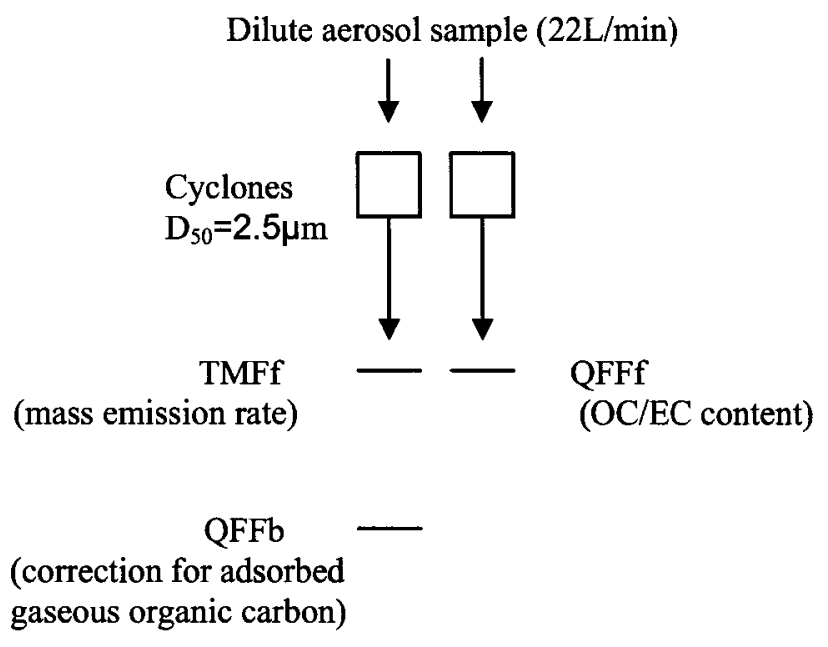

\section{Figure 4.4.7 - Diagram of $\mathbf{P M}_{2.5}$ mass collection}

The dilution air was sampled similarly, but because all particles that escape HEPA filtration were expected to be smaller than $2.5 \mu \mathrm{m}$ in aerodynamic diameter, cyclones were not used. A manifold was used which allowed both $47 \mathrm{~mm}$ filter packs to be connected simultaneously to a single dilution air sample port.

The initial and final masses of the $47 \mathrm{~mm}$ Teflon filters were determined gravimetrically using a Mettler Toledo model MT5 balance with a mass resolution capability of $1 \mu \mathrm{g}$. The balance is situated on a stone table (to minimize vibrations) in a room with a temperature range of $23 \pm 3^{\circ} \mathrm{C}$ and a relative humidity range of $40 \pm 5 \%$. Filters were humidity equilibrated for a minimum of 8 hours prior to mass determinations. Constant mass to within $2 \mu \mathrm{g}$ was obtained for each determination. 
Each set of quartz filters (front filter containing primary PM and back filter containing adsorbed carbon) was submitted to the NRCan Mining and Mineral Technology Laboratory for organic and elemental carbon analysis. The NIOSH Method 5040 “Thermal/Optical Transmittance (TOT)" was used. Using this method, a $1.5 \mathrm{~cm}^{2}$ punch is taken from each filter sample. This punch is heated sequentially to temperatures of 300 , 600 , and $900^{\circ} \mathrm{C}$ in a pure helium atmosphere causing volatile carbon to be evolved. The sample is then cooled to $600^{\circ} \mathrm{C}$ and reheated in an atmosphere of $2 \%$ oxygen in helium to 600,750 , and $940^{\circ} \mathrm{C}$. Carbon evolved is first converted to carbon dioxide by catalytic oxidation then converted to methane by catalytic reduction. A flame ionization detector is used to quantify the methane. The transmittance of laser light through the sample is monitored throughout the process. Transmittance decreases as the organic material is pyrolized in the helium atmosphere. Transmittance increases as light absorbing pyrolized carbon is combusted and removed in the oxygen containing atmosphere. Organic carbon is defined as that which evolves prior to attainment of the original transmittance value and elemental carbon is defined as that which evolves at transmittance values after the original value is attained. 


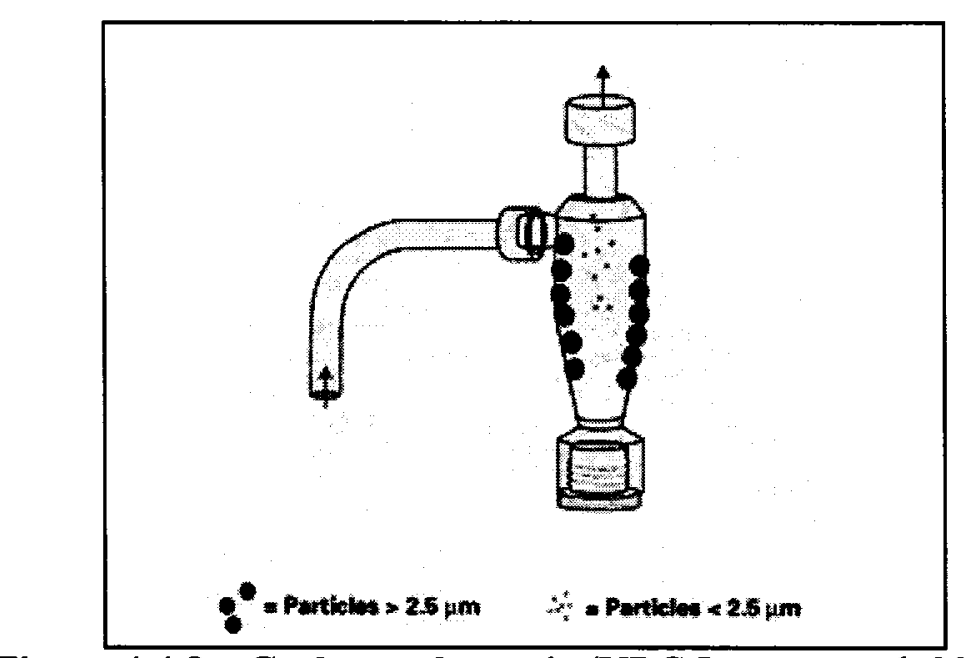

Figure 4.4.8 - Cyclone schematic (URG Incorporated, 2006)

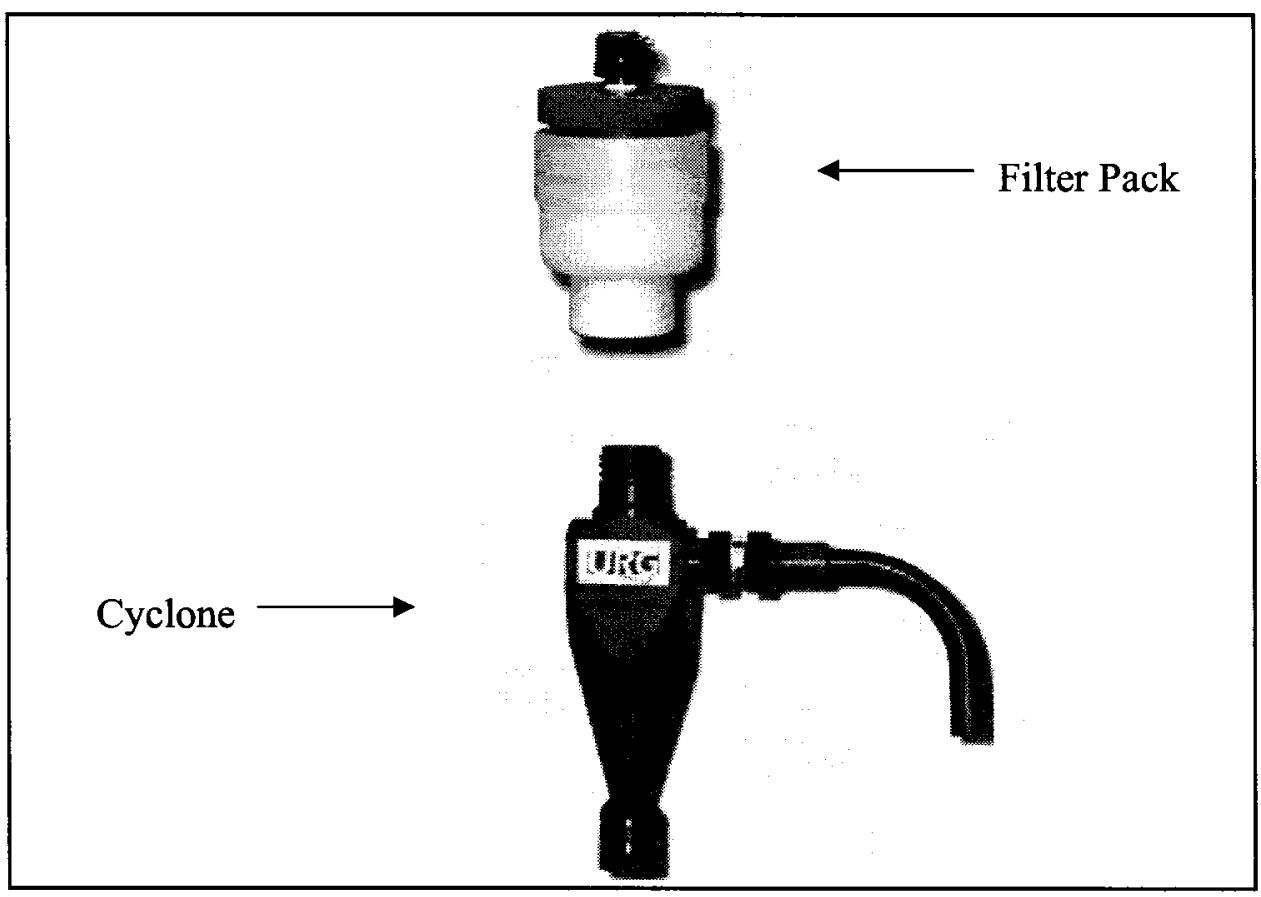

Figure 4.4.9 - URG cyclone and filter pack (URG Incorporated, 2006)

\subsubsection{Gas Analysis}

A representative sample of dilute exhaust is collected through a sample probe and either directed to Tedlar ${ }^{\mathrm{TM}}$ bags for integrated analysis at the end of the test or phase, or 
directed straight to the analyzing bench for second by second modal analysis. The instrumentation on the analyzing bench consists of:

1. Non Dispersive Infrared (NDIR) for detection of carbon dioxide $\left(\mathrm{CO}_{2}\right)$

2. Non Dispersive Infrared (NDIR) for detection of carbon monoxide (CO)

3. Chemiluminescent Analyser for detection of oxides of nitrogen (NO/NOx)

4. Heated Flame Ionisation Detector (HFID) for detection of total hydrocarbons (THC)

The driver initiated sample collection as he started the test. The gaseous results will not be discussed in detail in this study, but were used to calculate the dilution factor and fuel consumption, quantities which were needed for determining particulate matter emission rates and the total fuel energy.

A second sample probe directed a dilute exhaust sample to the sample train (11) for collection in Tedlar $^{\mathrm{TM}}$ bags. These samples were later analyzed for non-methane hydrocarbons (NMHC) and greenhouse gases (GHGs). Tedlar $^{\mathrm{TM}}$ is a thin film made of polyvinyl fluoride. It has a high tensile and tear strength, thermal stability, and is chemically inert. The use of this material reduces sample loss due to chemical reactions and the adhesion of compounds to the inside of the bag. In addition to bags, the sample train held carbonyl cartridges which were analyzed for carbonyl compounds. Again, the gaseous results are not included in this PM study, but will be discussed in future work. 


\subsubsection{State of Charge}

The state of charge (SOC) of the Civic and Insight hybrid batteries was continuously recorded during testing using a Snap-On ${ }^{\mathrm{TM}}$ diagnostics scanner. Sampling interval varied from 3-4 seconds during testing. This system could not be used for the Prius or Escape because software was not available for these vehicles at the time of testing.

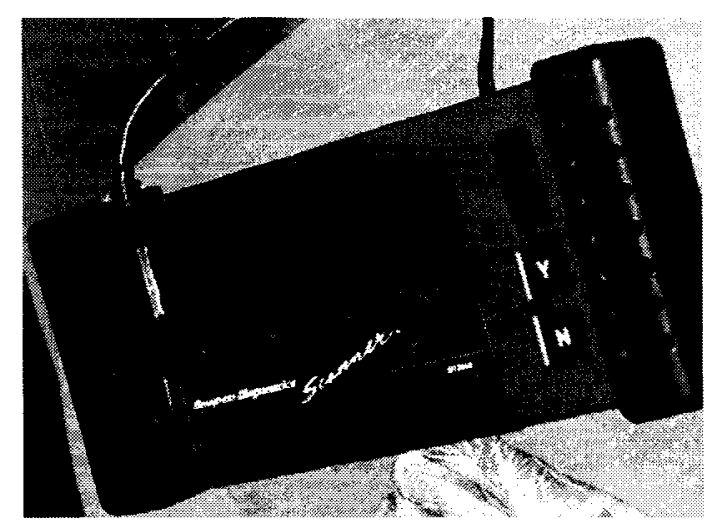

Figure 4.4.10 - Snap-on Diagnostics Scanner

\subsubsection{Charging Current}

Hybrid battery charging current (CC) was continuously recorded during tests on the Toyota Prius and Ford Escape using a digital multimeter, clamp-on ammeter and VILogger software. The sampling interval was 0.1 seconds. This method was chosen because software was not available for collection of SOC using the Snap-On ${ }^{\mathrm{TM}}$ diagnostics scanner for these newer model vehicles $(2004,2005)$. The ammeter could not be used on the Honda vehicles because the hybrid batteries were not accessible. 


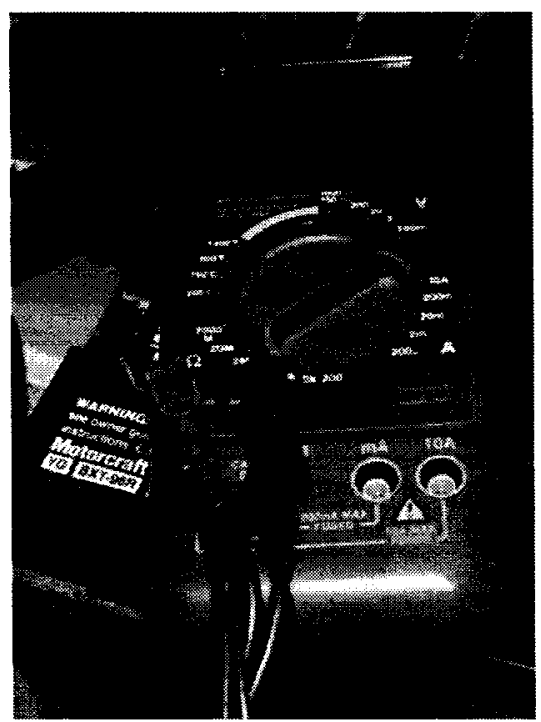

Figure 4.4.11 - Multimeter

\subsection{Data Analysis}

This chapter covers the calculations required to obtain the quantities reported in the results section from the measured data, as well as the uncertainty associated with each quantity. The terms representing measured quantities relevant to this analysis are defined in Table 5.0.1. 
Table 5.0.1 - Definition of Terms

\begin{tabular}{|c|c|}
\hline Term & Description \\
\hline $\mathrm{C}_{\mathrm{n} i}\left(\mathrm{~cm}^{-3}\right)$ & $\begin{array}{l}\text { The particle number concentration measured at the ith second during testing. } \\
\text { Each second of the test, one value was recorded by the CPC and twelve } \\
\text { values, one for each of the twelve size bins, were recorded by the ELPI }\left(C_{n 1 i-}\right. \\
\left.C_{n 12 i}\right)\end{array}$ \\
\hline $\mathrm{C}_{\mathrm{na}}\left(\mathrm{cm}^{-3}\right)$ & $\begin{array}{l}\text { The average particle number concentration measured when only dilution air } \\
\text { was flowing through the tunnel. Each day an average value was recorded for } \\
\text { the CPC }\left(C_{n a}\right) \text { and for each size bin of the ELPI }\left(C_{n a 1}-C_{n a 12}\right) \text {. }\end{array}$ \\
\hline $\begin{array}{l}\mathrm{m}_{\mathrm{TMFF}} \\
(\mu \mathrm{g})\end{array}$ & $\begin{array}{l}\text { The particulate matter mass }(<2.5 \mu \mathrm{m} \text { diameter) on the dilute exhaust Teflon } \\
\text { filter, collected for each test (described in Section } 4.4 .4)\end{array}$ \\
\hline $\begin{array}{l}\mathrm{m}_{\text {TMFfa }} \\
(\mu \mathrm{g})\end{array}$ & $\begin{array}{l}\text { The particulate matter mass }(<2.5 \mu \mathrm{m} \text { diameter) on the dilution air Teflon } \\
\text { filter, collected once per vehicle per day (described in Section } 4.4 .4)\end{array}$ \\
\hline $\begin{array}{l}\mathrm{m}_{\text {QFFF. }} \\
\mathrm{m}_{\mathrm{QFFb}} \\
\left(\mu \mathrm{g} / \mathrm{cm}^{2}\right)\end{array}$ & $\begin{array}{l}\text { The OC and EC carbon mass per unit of filter area on the front and back } \\
\text { dilution tunnel quartz fibre filters (QFF), collected for each test (described in } \\
\text { Section 4.4.4) }\end{array}$ \\
\hline $\begin{array}{l}\mathrm{m}_{\text {QFFfa, }} \\
\mathrm{m}_{\mathrm{QFFba}} \\
\left(\mu \mathrm{g} / \mathrm{cm}^{2}\right)\end{array}$ & $\begin{array}{l}\text { The OC and EC carbon mass per unit of filter area on the front and back } \\
\text { dilution air quartz fibre filters (QFF), collected once per vehicle per day } \\
\text { (described in Section 4.4.4) }\end{array}$ \\
\hline $\begin{array}{l}\mathrm{Q}_{t i} \\
\left(\mathrm{ft}^{3} / \mathrm{min}\right)\end{array}$ & $\begin{array}{l}\text { The measured dilution tunnel flow rate. In the constant volume sampler } \\
\text { (CVS) system, this was approximately constant. It was, however, recorded } \\
\text { each second. }\end{array}$ \\
\hline$V_{s}$ & $\begin{array}{l}\text { The total volume of dilute exhaust that passed through the dilution tunnel } \\
\text { during a given test }\end{array}$ \\
\hline $\begin{array}{l}\mathrm{CO}_{2} \% \\
\text { THCppm, } \\
\text { COppm }\end{array}$ & $\begin{array}{l}\text { The dilute exhaust was sampled each second for these components giving } \\
\text { second by second data, and collected in Tedlar }{ }^{\mathrm{TM}} \text { bags for a final integrated } \\
\text { analysis by the gas analyzers. }\end{array}$ \\
\hline
\end{tabular}

\subsection{Dilution Factor}

As discussed in Chapter 4, a constant volume sampler (CVS) system was used for primary dilution of the vehicle exhaust. This means that the amount of dilution air 
changed as the exhaust volume produced by the vehicle changed in order to maintain a constant volumetric flow rate through the dilution tunnel.

The dilution factor (DF) is generally defined as the volume of diluted exhaust per volume of raw exhaust but is also equivalent to the mols of diluted exhaust per mol of raw exhaust. It can be determined by a carbon balance around the mixing point of the raw exhaust and dilution air, assuming negligible contribution from the dilution air to the total carbon concentration:

$\left(C_{\text {raw }}, \frac{\text { molC }}{\text { mol raw exhaust }}\right)(1$ mol raw exhaust $)=\left(C_{\text {dilute }}, \frac{\text { molC }}{\text { mol dilute exhaust }}\right)(D F$, mol dilute exhaust $)$ $C_{\text {raw }}$, the mol ratio of carbon atoms in raw exhaust, assuming stoichiometric air/fuel ratio, can be calculated for a fuel composition of $\mathrm{C}_{x} \mathrm{H}_{y} \mathrm{O}_{z}$ by:

$$
C_{\text {raw }}=\frac{x}{x+\frac{y}{2}+3.76\left(x+\frac{y}{4}-\frac{z}{2}\right)}
$$

Where the terms in the denominator are the mols of $\mathrm{CO}_{2}, \mathrm{H}_{2} \mathrm{O}$ and $\mathrm{N}_{2}$ respectively.

For the Tier 2 fuel used during testing at $20^{\circ} \mathrm{C}$ the fuel composition was reported as:

$x=1$

$y=1.968$ 
$\mathrm{z}=0.016$

For winter grade fuel used during testing at $-18^{\circ} \mathrm{C}$,

$\mathrm{x}=1$

$y=1.956$

$z=0$

$C_{\text {dilute }}$, the mol fraction of carbon in the dilute exhaust is the sum of measured concentrations of $\mathrm{C}$ in the form of $\mathrm{CO}_{2}, \mathrm{CO}$ and $\mathrm{HC}$ :

$C_{\text {dilute }}=\frac{C O_{2} \%+0.000(\text { THCppm }+ \text { COppm })}{100}$

Thus, the U.S. Code of Federal Regulations (40 CFR Part86 144-94) which governs the measurement and reporting of emissions from motor vehicles expresses the dilution factor from the carbon balance as:

$$
\begin{aligned}
& D F=\frac{C_{\text {raw }}}{C_{\text {dilute }}} \\
& o r, \\
& D F=\frac{\frac{x}{x+\frac{y}{2}+3.76\left(x+\frac{y}{4}-\frac{z}{2}\right)}}{\frac{C O_{2} \%+0.0001(T H C p p m+C O p p m)}{100}}
\end{aligned}
$$


It was calculated on a second by second basis using the modal gaseous concentrations, and an integrated value was calculated based on the integrated gaseous concentrations.

\section{Uncertainty}

The uncertainty associated with the dilution factor depends on the uncertainty related to the gas analyzer readings. These are specified by the manufacturer as $1 \%$ of full scale for $\mathrm{CO}$ and $0.5 \%$ for $\mathrm{CO}_{2}$ and THC. This becomes an uncertainty of approximately $\pm 2-3 \%$ in the calculated dilution factor. Dilution factors reached values as low as 10 during high exhaust volume conditions. During periods of engine-off, the dilution factor should approach infinity as the exhaust contribution to carbon concentrations approaches zero. At these times, however, the assumption that the dilution air contribution to carbon concentration is negligible becomes invalid, and a maximum DF of approximately 300 was calculated.

\subsection{Modal Emission Rates from ELPI and CPC Data}

In addition to the primary dilution occurring in the dilution tunnel, the exhaust was subjected to a secondary dilution before entering the CPC and ELPI instruments. This dilution was achieved by the Dekati ejector diluter (Section 4.4.1), which had a constant dilution ratio of 7.1:1. High purity nitrogen was used as the diluent in the ejector diluter thus avoiding the introduction of any particles during this secondary dilution. 
Although the HEPA filters used on the dilution air are capable of reducing dilution air particle concentrations, it is expected that some small particles may escape filtration or otherwise leak into the system. For this reason, all measured concentrations $\left(\mathrm{C}_{\mathrm{n} i}\right)$ were corrected for the average particle concentration in the dilution air $\left(\mathrm{C}_{\mathrm{na}}\right)$ to obtain the diluted exhaust number concentration $\left(\mathrm{C}_{\mathrm{ne} i}\right)$ for each second. The contribution of the dilution air to total particle concentration depends not only on $\mathrm{C}_{\mathrm{na}}$ but also on the amount of dilution and therefore the dilution factor $\left(\mathrm{DF}_{i}\right)$. After accounting for the ejector diluter dilution ratio and the dilution air particle concentration the particle concentration in the dilute exhaust due to the exhaust is:

$C_{n e i}=7.1\left(C_{n i}-C_{n a}\left(1-\frac{1}{D F_{i}}\right)\right)$

To obtain a modal emission rate $\left(\mathrm{MER}_{\mathrm{i}}\right)\left(\mathrm{s}^{-1}\right)$, the above concentration was multiplied by the dilute exhaust flow rate $\left(\mathrm{Q}_{\mathrm{ti}}\right)$.

$\operatorname{MER}_{\mathrm{i}}\left(\mathrm{s}^{-1}\right)=\mathrm{C}_{\mathrm{nei}}\left(\mathrm{cm}^{-3}\right) \cdot \mathrm{Q}_{t \mathrm{i}}\left(\mathrm{ft}^{3}\right) \cdot 471.95\left(\mathrm{~cm}^{3} / \mathrm{ft}^{3} \cdot \mathrm{min} / \mathrm{sec}\right)$

It should be noted again that the $C_{n a}$ value used for this correction is an average measured once during each day and hence does not correspond directly to the second-by-second measurements for $C_{n i}$. The dilution air concentration measured by the CPC was generally between 0 and 500 particles $/ \mathrm{cm}^{3}$ while that measured by the ELPI was between 0 and 100 particles $/ \mathrm{cm}^{3}$ in the individual size bins. 


\section{Uncertainty}

The accuracy and precision of the CPC and ELPI depend on many factors including the particle size and composition. Specifications for each instrument, under the flow rate conditions used in this study, are summarized in Tables 5.2.1 and 5.2.2.

Because the particle concentration in the dilution air $\left(\mathrm{C}_{n a}\right)$ is only measured once per day, variation in $\mathrm{C}_{n a}$ throughout the day could lead to errors in the calculated modal emission rate. For steady-state tests, when emissions are low, the $C_{n a}$ value was found to have a strong effect on the calculated exhaust PM emissions. During driving cycles which included transients (acceleration/deceleration) the $\mathrm{C}_{n a}$ value had a negligible overall effect. In order to minimize the effect of $\mathrm{C}_{n a}$ variation during the course of testing on exhaust emission rate calculations, $\mathrm{C}_{n a}$ was set to zero for steady-state tests. This means that results reported for steady-state tests are a worst-case scenario.

Table 5.2.1 - Condensation Particle Counter Specifications

\begin{tabular}{|c|c|}
\hline $\begin{array}{l}\text { Minimum particle size } \\
(50 \% \text { efficiency, } \mu \mathrm{m})\end{array}$ & 0.007 \\
\hline $\begin{array}{l}\text { Maximum detectable particle } \\
(\mu \mathrm{m})\end{array}$ & $>3$ \\
\hline $\begin{array}{l}\text { Aerosol flow rate - high flow mode } \\
\left(\mathrm{cm}^{3} / \mathrm{min}\right)\end{array}$ & $1500 \pm 150$ \\
\hline $\begin{array}{c}\text { Upper concentration limit } \\
\left(\text { particles } / \mathrm{cm}^{3}\right)\end{array}$ & $10^{7}$ \\
\hline $\begin{array}{l}\text { Lower concentration sensitivity } \\
\left.\text { (particles } / \mathrm{cm}^{3}\right)\end{array}$ & 0 \\
\hline $\begin{array}{c}\text { False background counts } \\
\left.\text { (particles } / \mathrm{cm}^{3}\right)\end{array}$ & $<0.01$ \\
\hline $\begin{array}{c}\text { Response time } \\
\text { (sec for } 95 \% \text { response) }\end{array}$ & $<13$ \\
\hline Concentration Accuracy & $\begin{array}{l} \pm 10 \% \text { for up to } 10^{5} \text { particles } / \mathrm{cm}^{3} \\
\pm 20 \% \text { from } 10^{5} \text { to } 10^{7} \text { particles } / \mathrm{cm}^{3}\end{array}$ \\
\hline
\end{tabular}


Table 5.2.2 - Nominal Impactor Specifications for 10lpm ELPI

\begin{tabular}{|l|c|c|c|c|c|c|}
\hline Stage & $\begin{array}{c}\text { D50\% } \\
{[\mu \mathrm{m}]}\end{array}$ & $\begin{array}{c}\text { Di } \\
{[\mu \mathrm{m}]}\end{array}$ & $\begin{array}{c}\text { Number min } \\
{\left[1 / \mathrm{cm}^{3}\right]}\end{array}$ & $\begin{array}{c}\text { Number max } \\
{\left[1 / \mathrm{cm}^{3}\right]}\end{array}$ & $\begin{array}{c}\text { Mass min } \\
{\left[\mu \mathrm{g} / \mathbf{m}^{3}\right]}\end{array}$ & $\begin{array}{c}\text { Mass max } \\
{\left[\mathbf{m g}^{3} \mathbf{m}^{3}\right]}\end{array}$ \\
\hline 13 & 9.970 & & & & & \\
\hline 12 & 6.800 & 8.4 & 0.10 & $2.7 \mathrm{E}+04$ & 31 & 8269 \\
\hline 11 & 4.400 & 5.3 & 0.17 & $4.5 \mathrm{E}+04$ & 13 & 3496 \\
\hline 10 & 2.500 & 3.2 & 0.30 & $7.9 \mathrm{E}+04$ & 5 & 1362 \\
\hline $\mathbf{9}$ & 1.600 & 2.0 & 0.51 & $1.4 \mathrm{E}+05$ & 2 & 566 \\
\hline $\mathbf{8}$ & 1.000 & 1.3 & 0.82 & $2.2 \mathrm{E}+05$ & 1 & 253 \\
\hline $\mathbf{7}$ & 0.650 & 0.810 & 1.6 & $4.1 \mathrm{E}+05$ & 0.43 & 115 \\
\hline $\mathbf{6}$ & 0.400 & 0.510 & 3 & $7.8 \mathrm{E}+05$ & 0.20 & 54 \\
\hline $\mathbf{5}$ & 0.260 & 0.330 & 5 & $1.4 \mathrm{E}+06$ & 0.10 & 27 \\
\hline $\mathbf{4}$ & 0.170 & 0.210 & 10 & $2.7 \mathrm{E}+06$ & 0.05 & 12.9 \\
\hline $\mathbf{3}$ & 0.108 & 0.140 & 18 & $4.7 \mathrm{E}+06$ & 0.03 & 6.7 \\
\hline $\mathbf{2}$ & 0.060 & 0.081 & 41 & $1.1 \mathrm{E}+07$ & 0.01 & 3.0 \\
\hline 1 & 0.030 & 0.042 & 142 & $3.8 \mathrm{E}+07$ & 0.01 & 1.5 \\
\hline
\end{tabular}

\subsection{Integrated Emission Rate from CPC and ELPI}

An integrated emission rate normalized to the distance travelled was calculated for each test. This was done by taking the sum of the second by second modal emission rates (Section 5.2) for the entire test ( $i=1$ to end of test) and dividing by the distance travelled during the test (d). This was done for the CPC data to obtain an integrated total number emission rate for each test, and for the twelve size bins of ELPI data to obtain an integrated size distribution for each test.

$$
\sum_{i=1}^{E n d} \frac{M E R_{i}\left(s^{-1}\right)}{d(k m)}
$$


The mass of fuel consumed $\left(\mathrm{m}_{\text {fuel }}\right)$ could be substituted for the distance travelled $(d)$ in order to normalize the emission rate with respect fuel consumed instead of distance travelled. This was calculated as:

$m_{f u e l}=\rho_{f u e l} \cdot F C \cdot d$

Where,

$\rho_{\text {fuel }}=$ the density of the fuel $(\mathrm{kg} / \mathrm{L})$

$\mathrm{FC}=$ the fuel consumption $(\mathrm{L} / \mathrm{km})$ calculated based on fuel properties and carbon emissions ( $\mathrm{THC}, \mathrm{CO}, \mathrm{CO}_{2}$ ) - calculated in Section 5.6

$\mathrm{d}=$ the distance travelled $(\mathrm{km})$ during the phase or cycle.

\section{Uncertainty}

For the drive cycle tests, an average and a standard deviation for repeated tests were calculated. For steady-state tests, an average and a standard deviation were calculated across the duration of the second by second measured values for each test.

\subsection{PM $_{2.5}$ Mass Emission Rate}

The mass of $\mathrm{PM}_{2.5}$ collected on the front Teflon Membrane Filters (TMFf) for the dilute exhaust $\left(\mathrm{m}_{\mathrm{TMF} f}\right)$ and dilution air $\left(\mathrm{m}_{\mathrm{TMF} f a}\right)$ were converted to concentrations $(\mathrm{mg} / \mathrm{L})$ in the dilute exhaust and in the dilution air using the following equations:

$$
C_{m e}=\frac{m_{T M F f}}{1000 Q_{f} t}
$$


Where,

$\mathrm{C}_{\mathrm{me}}=\mathrm{PM}_{2.5}$ mass concentration in the dilute exhaust (mg/L)

$\mathrm{m}_{\mathrm{TMF} f}(\mu \mathrm{g})=$ net mass collected on dilution tunnel Teflon filter

$\mathrm{Q}_{\mathrm{f}}(\mathrm{L} / \mathrm{min})=$ dilute exhaust flow rate to filters $(22 \mathrm{~L} / \mathrm{min})$

$\mathrm{t}(\mathrm{min})=$ sampling time (test time for dilute exhaust sample)

1000: conversion factor from $\mu \mathrm{g}$ to $\mathrm{mg}$

$$
C_{m a}=\frac{m_{T M F f a}}{1000 Q_{f a} t_{a}}
$$

Where,

$$
\begin{aligned}
& \mathrm{C}_{\mathrm{ma}}=\mathrm{PM}_{2.5} \text { mass concentration in dilution air }(\mathrm{mg} / \mathrm{L}) \\
& \mathrm{m}_{\mathrm{TMF} f a}(\mu \mathrm{g})=\text { net mass collected on dilution air Teflon filter } \\
& \mathrm{Q}_{\mathrm{fa}}(\mathrm{L} / \mathrm{min})=\text { dilution air flow rate to filters }(22 \mathrm{~L} / \mathrm{min}) \\
& \mathrm{t}_{\mathrm{a}}(\mathrm{min})=\text { sampling time (total daily test time for the dilution air sample) } \\
& 1000 \text { : conversion factor from } \mu \mathrm{g} \text { to } \mathrm{mg}
\end{aligned}
$$

Like the ELPI and CPC readings, the mass concentrations measured in the tunnel had to be corrected for dilution air particle concentration $\left(\mathrm{C}_{\mathrm{ma}}\right)$, using the dilution factor (DF). To obtain the emission rate $(\mathrm{mg} / \mathrm{km})$ the corrected concentration was multiplied by the total volume of dilute exhaust that was sampled, and divided by the distance travelled during the test. 
$\mathrm{PM}_{2.5}$ mass emission rate, $\mathrm{mg} / \mathrm{km}=\frac{\left(C_{m e}-C_{m_{a}}\left(1-\frac{1}{D F}\right)\right) \cdot 28.316 \cdot V_{s}}{d}$

Where,

$$
\begin{aligned}
& C_{m e}=\mathrm{PM}_{2.5} \text { mass concentration in the dilute exhaust }(\mathrm{mg} / \mathrm{L}) \\
& C_{m a}=\mathrm{PM}_{2.5} \text { mass concentration in dilution air }(\mathrm{mg} / \mathrm{L}) \\
& \mathrm{DF}=\text { integrated dilution factor, calculated in Section } 5.1 \\
& \mathrm{~V}_{s}\left(\mathrm{ft}^{3}\right)=\text { total volume sampled during the cycle } \\
& 28.316 \text { : conversion factor from } \mathrm{ft}^{3} \text { to } \mathrm{L} \\
& \mathrm{d}(\mathrm{km})=\text { distance travelled }
\end{aligned}
$$

Again, the mass of fuel consumed, calculated in Section 5.3, could be substituted for the distance travelled in order to normalize the emission rate with respect to fuel consumption.

\section{Uncertainty}

For the drive cycle tests, an average and standard deviation were calculated for repeated tests. The Mettler Toledo model MT5 balance has a resolution of $1 \mu \mathrm{g}$ but it is expected that static and humidity influences on the PM increase the uncertainty. Each filter is measured a minimum of three times before and after sampling because of the relative variability. The uncertainty calculated on the net mass averages approximately $2 \mu \mathrm{g}$. Emission rate detection limits for each drive cycle are given in Table 5.4.1. 
Table 5.4.1 - PM 2.5 Emission Rate Detection Limits (mg/km)

\begin{tabular}{|c|c|}
\hline LA4 CS/HS & 0.07 \\
LA92 CS/HS & 0.05 \\
NYCC & 0.23 \\
US06 & 0.03 \\
HWFET & 0.05 \\
SS40 & 0.06 \\
SS80 & 0.03 \\
\hline
\end{tabular}

\subsection{OC-EC Mass Emission Rate}

As detailed in Section 4.4.4 the elemental and organic carbon content of particulate matter collected on quartz fibre filters (QFF) is determined by the Thermal Optical Transmittance (TOT) method. Quartz fibre filters are required for the procedure (as opposed to the Teflon membrane filters for total mass determination) since elevated temperatures are involved. On the other hand, quartz fibre filters can introduce positive sampling artefacts by adsorbing hydrocarbons from the sampled gas or from the ambient air during handling and transportation that would otherwise not be associated with the particulate matter. A second "back-up" quartz filter is therefore used in series with a Teflon filter in the front position in an attempt to correct for this artefact. The front quartz filter contains both $\mathrm{PM}_{2.5}$ and adsorbed gaseous organic carbon. The back quartz filter is placed behind the Teflon filter and therefore contains only adsorbed gaseous organic carbon and can be used to correct for any gaseous organic carbon that may be on the front filter. Blank filters were also collected and analyzed to account for any changes in mass during transportation and storage. Duplicates were measured in several instances, and in such cases the masses were averaged prior to the following calculations. 
The organic carbon (OC) and elemental carbon (EC) densities $\left(\mu \mathrm{g} / \mathrm{cm}^{2}\right)$ were measured on front $\left(\mathrm{m}_{\mathrm{QFFf}}\right)$ and back $\left(\mathrm{m}_{\mathrm{QFFb}}\right)$ quartz fibre filters for both the dilution tunnel and the dilution air and were corrected for readings from blank filters.

The mass concentrations of organic and elemental carbon in the dilute exhaust were calculated:

$$
C_{m e}=\frac{\left(m_{Q F F}-m_{\text {blank }}\right) \times A_{\text {Filter }}}{Q_{f} t}
$$

Where,

$$
\begin{aligned}
& \mathrm{C}_{\mathrm{me}}(\mu \mathrm{g} / \mathrm{L})=\text { mass concentration of either organic or elemental carbon in the } \\
& \text { CVS tunnel (calculated for both front and back QFF) } \\
& m_{Q F F}\left(\mu \mathrm{g} / \mathrm{cm}^{2}\right)=\text { the amount of either OC or EC on the front or back QFF } \\
& m_{\text {blank }}\left(\mu \mathrm{g} / \mathrm{cm}^{2}\right)=\text { the measured blank filter amount of OC or EC } \\
& A_{\text {Filter }}=\text { the exposed filter area }\left(13.33 \mathrm{~cm}^{2}\right) \\
& \mathrm{Q}_{\mathrm{f}}=\text { the flow rate to filters }\left(22 \mathrm{~L} / \mathrm{min}^{2}\right) \\
& \mathrm{t} \mathrm{(min)}=\text { the sampling time (test time for dilute exhaust sample) } \\
& C_{m a}=\frac{\left(m_{Q F F a}-m_{\text {blank }}\right) \times A_{\text {Filter }}}{Q_{f} t_{a}}
\end{aligned}
$$


$\mathrm{C}_{\mathrm{ma}}(\mu \mathrm{g} / \mathrm{L})=$ mass concentration of either organic or elemental carbon in the dilution air (calculated for both front and back QFF)

$m_{Q F F a}\left(\mu \mathrm{g} / \mathrm{cm}^{2}\right)=$ the amount of either OC or EC on the dilution air QFF

$m_{\text {blank }}\left(\mu \mathrm{g} / \mathrm{cm}^{2}\right)=$ the measured blank filter amount of OC or EC

$A_{\text {Filter }}=$ the exposed filter area $\left(13.33 \mathrm{~cm}^{2}\right)$

$\mathrm{Q}_{\mathrm{f}} \quad=$ the flow rate to filters $(22 \mathrm{~L} / \mathrm{min})$

$t_{a}(\min )=$ the sampling time (total test time for the vehicle on the given day)

\section{Artefact Correction for $O C$}

The positive sampling bias introduced by gaseous organic carbon adsorbed to the quartz fibre filter was corrected for by subtracting the OC mass concentration on the back filter from the $\mathrm{OC}$ mass concentration on the front filter as follows. :

$$
C_{m O C}=\left(C_{m O C f}-C_{m O C b}\right)
$$

Where,

$$
\begin{aligned}
C_{m O C} & =\text { Mass concentration of organic carbon } \\
C_{m O C f} & =\text { Mass concentration of organic carbon based on the front filter mass } \\
& \text { (equation 5.5.1) } \\
C_{m O C b} & =\text { Mass concentration of organic carbon measured based on the back filter } \\
& \text { mass (equation 5.5.1) }
\end{aligned}
$$


Equation 5.5.3 applies to both CVS tunnel filters and dilution air filters.

Finally, the dilute exhaust concentrations were corrected for dilution air concentrations using equation 5.4.3 giving the mass emission rates of $\mathrm{PM}_{2.5} \mathrm{OC}$ and $\mathrm{EC}$.

\section{Uncertainty}

For the drive cycle tests, an average and standard deviation were calculated for repeated tests. The analysis report contained uncertainties for each sample from which emission rate uncertainties were calculated. Emission rate detection limits are given in Table 5.5.1.

Table 5.5.1 - OC-EC Emission Rate Detection Limits (mg/km)

\begin{tabular}{|c|l|}
\hline LA4 CS/HS & 0.02 \\
LA92 CS/HS & 0.01 \\
NYCC & 0.06 \\
US06 & 0.01 \\
HWFET & 0.01 \\
SS40 & 0.02 \\
SS80 & 0.01 \\
\hline
\end{tabular}

\subsection{Fuel Consumption}

It was necessary to calculate fuel consumption in order to determine the net energy change (NEC) variance (Section 5.7). It could also be used to normalize particle emission rates to fuel consumption, and to observe the relationship between fuel consumption and particle emissions.

Like the dilution factor calculation presented earlier, the fuel consumption during the test can also be determined from a carbon balance: 
$g C$ in exhaust per mile $=\mathrm{CWF} \cdot g \mathrm{HC}+0.429 \cdot g \mathrm{CO}+0.273 \cdot g \mathrm{CO}_{2}$ (assuming unburned $\mathrm{HC}$ has the same $\mathrm{C}$ weight fraction as fuel)

$g C$ in fuel per mile $=\frac{C W F \cdot S G \cdot 3785 \mathrm{~g} / \mathrm{gal}}{\mathrm{mpg}}$

Thus :

$m p g=\frac{C W F \cdot S G \cdot 3785 \mathrm{~g} / \mathrm{gal}}{C W F \cdot g H C+0.429 \cdot g C O+0.273 \cdot g C O_{2}}$

Where:

$$
\begin{aligned}
& \mathrm{CWF}=\text { carbon weight fraction of fuel } \\
& \mathrm{SG}=\text { specific gravity of fuel } \\
& \mathrm{gHC}, \mathrm{gCO}, \mathrm{gCO}_{2}=\text { gram } / \text { mile emission rates of } \mathrm{HC}, \mathrm{CO} \text {, and } \mathrm{CO}_{2} \\
& \mathrm{mpg}=\text { miles driven per gallon of fuel consumed }
\end{aligned}
$$

The fuel consumption measured in gallons per mile is not a true measure of the energy efficiency of a vehicle since the energy content per gallon of fuel can show some variation with the fuel composition. To take this effect into account, fuel consumption is reported after correcting for the heating value and specific gravity of the fuel. Thus the regulatory equation used for fuel consumption can be expressed (40 CFR600.113-93): 


$$
F C=\frac{235.22}{\frac{C \% \cdot S G \cdot 5174 \times 10^{4}}{\left(C \% \cdot g H C+0.429 \cdot g C O+0.273 \cdot g C \mathrm{O}_{2}\right) \cdot(0.6 \cdot S G \cdot N H V+5471)}}
$$

Where,

$\mathrm{FC}=$ fuel consumption, $\mathrm{L} / 100 \mathrm{~km}$

$\mathrm{NHV}=$ net heating value of fuel (BTU/lb)

235.22 = conversion factor between mpg and $\mathrm{L} / 100 \mathrm{~km}$

$5174 \times 10^{4}, 0.6$, and 5471 are constants that describe the relationship between fuel economy in mpg and net heating value.

\subsection{Net Energy Change Variance}

Hybrid electric vehicles can draw energy from the battery or store energy in the battery depending on the driving conditions. If the energy stored in the battery is not the same at the beginning and end of test, the measured amount of fuel used in the internal combustion engine during the test is not a true reflection of the performance of the vehicle. It is therefore necessary to monitor the energy storage in the battery and make corrections for changes when appropriate.

The net energy change (NEC) is a measure of how much energy was gained or lost by the hybrid battery during a test. NEC variance, defined by SAE (Society of Automotive Engineers, 2002) is expressed relative to the total cycle energy. 
The NEC was calculated based on state of charge (SOC) data for the Civic and Insight, and charging current $(\mathrm{CC})$ data for the Prius and Escape. Given SOC data, the NEC of the hybrid battery is:

$N E C_{\text {battery }}(k W h)=\frac{\left(S O C_{f}-S O C_{i}\right) \cdot C \cdot V_{n}}{10^{5}}$

Where,

$\mathrm{NEC}_{\text {battery }}=$ the net energy change of the battery during the phase or cycle

$\mathrm{SOC}_{\mathrm{i}}$ and $\mathrm{SOC}_{\mathrm{f}}(\%)=$ the initial and final state of charge for the cycle or phase as measured by the OBD system

$\mathrm{C}=$ the hybrid battery capacity $(\mathrm{Ah})$

$\mathrm{V}_{\mathrm{n}}=$ the battery nominal DC voltage $(\mathrm{V})$

$10^{5}$ : changes units to $\mathrm{kW}$ and accounts for the original percentage units of SOC

The total cycle energy (TCE) is the energy required for the vehicle to complete the given cycle. For HEVs, the total fuel energy (TFE) may vary from test run to test run depending on battery activity. It can be calculated as the total fuel energy used minus the battery energy gained.

$$
T C E=T F E-N E C_{\text {battery }}
$$

The mass of fuel consumed was calculated in equation (5.3.2). The total fuel energy (TFE) was calculated as: 
$T F E=\frac{N H V \cdot m_{\text {fuel }}}{3412}$

Where,

$$
\begin{aligned}
& \mathrm{NHV}=\text { the net heating value of fuel (BTU/kg) } \\
& \mathrm{m}_{\text {fuel }}=\text { mass of fuel used }(\mathrm{kg}) \\
& \text { 3412: converts from BTU to } \mathrm{kWh} \text {. }
\end{aligned}
$$

The net energy change variance is the percentage of total cycle energy represented by the net energy change of the battery:

$N E C_{\text {Variance }}=\frac{N E C_{\text {battery }}}{T C E} \cdot 100 \%$

For the Prius and Escape, the net energy change variance was calculated from the charging current data. The calculation was the same as above, but equation 5.7.1 was replaced with:

$$
N E C_{\text {battery }}(k W h)=\frac{I_{\text {ave }} \cdot t \cdot V_{n}}{1000}
$$

Where, 


$$
\begin{aligned}
& I_{\text {ave }}=\text { the average current measured during the test or phase (A) } \\
& \mathrm{t}=\text { the test or phase time (hours) } \\
& \mathrm{V}_{\mathrm{n}}=\text { nominal battery voltage }(\mathrm{V})
\end{aligned}
$$

\subsection{Results and Discussion}

This chapter begins with an exploration of transient PM emission characteristics. The goal is to examine, on a second-by-second basis, what happens to PM emissions during different operating modes: steady-state (constant speed) operation, start-up (hot-start and cold-start), acceleration, deceleration, idle, and engine-off. The effect of cold $\left(-18^{\circ} \mathrm{C}\right)$ ambient test-cell temperatures on PM emissions during these operating modes will also be discussed. The focus is primarily on second-by-second number emissions and size distributions (number/sec). Although only several individual tests were selected as representative examples to show the transient nature of particle emissions, data and graphs of each of the $300+$ tests are available in electronic format. Each test (date, vehicle, driving cycle) is listed, along with its associated files, in Appendix 1.

The second major section of this chapter deals with integrated PM emission rates. Integrated emission rates are used in emission inventories, source apportionment studies, health effects studies, and atmospheric models. The difficulties associated with accounting for changes in battery state-of-charge when determining integrated emission rates will be discussed. The impacts of steady-state operation, driving cycle, cold-start, and cold ambient temperature on number and mass emission rates as well as numberweighted size distributions will be examined. Integrated emission rates are typically 
distance based (number $/ \mathrm{km}, \mathrm{mg} / \mathrm{km}$ ), time based (number $/ \mathrm{sec}, \mathrm{mg} / \mathrm{sec}$ ), or fuel based (number/kgfuel, mg/kgfuel). This study focuses primarily on distance based emission rates.

\subsection{The Transient Nature of Particulate Matter Emissions}

As discussed in Chapter 2, operating mode has an impact on PM emissions from conventional gasoline engine vehicles. It is expected that PM emissions will be relatively low during steady-state (constant speed) operation and idle, and will show peaks at engine start-up and during periods of acceleration (Kasper et al., 2005; Kayes, Hochgreb, Maricq, Podsiadlik, \& Chase, 2000; Maricq, Podsiadlik, \& Chase, 1999). In addition, PM emissions are typically higher during the first few minutes of cold-start compared to hotstart (Kayes \& Hochgreb, 1999a; Ludykar, Westerholm, \& Almen, 1999) and at cold ambient temperature (Ludykar et al., 1999; Mathis, Mohr, \& Forss, 2005). Deviations from these expected patterns were observed in this study when the hybrid motor was assisting the engine or powering the vehicle, and when other emission reduction technologies were functioning.

\subsubsection{Steady-State Operation}

Steady-state operation was carried out at dynamometer speeds of 40 and $80 \mathrm{~km} / \mathrm{h}$, at 20 and $-18^{\circ} \mathrm{C}$. Second-by-second particle emission rates (particles/s) measured by the CPC are shown in Figures 6.1.1 to 6.1.5. Steady-state $80 \mathrm{~km} / \mathrm{h}$ emission data for the Escape at $20^{\circ} \mathrm{C}$ were not obtained. 
It was found that the HEV electric motor and battery played little to no role in assisting or powering the vehicle while cruising at 40 and $80 \mathrm{~km} / \mathrm{h}$. Battery charging was often observed during the first few minutes of testing after which the state of charge for the Civic and Insight remained at a steady level, and the Prius and Escape showed very little charging/discharging activity. Despite approximately steady dynamometer speeds and battery state of charge, emissions were not steady during these tests; instead they showed small random fluctuations. These probably occurred because the engine controller was dynamically adjusting parameters such as spark timing and air/fuel ratio as observed during steady-state tests in previous SI engine studies (Kayes et al., 2000).

In addition to emission rate fluctuation patterns, a gradual decrease in particle number emissions was often observed over the duration of steady-state tests. For instance, the Prius showed a $40 \%$ decrease in emission rate over the $20 \mathrm{~min} 80 \mathrm{~km} / \mathrm{h}$ steady-state test at $20^{\circ} \mathrm{C}$. One possible explanation is that particles stored in the vehicle exhaust system and/or the dilution and sampling system during previous transient tests were being gradually released. Another possibility is that decreased friction resulting from the tires and dynamometer bearings gradually heating up lowered the amount of energy demanded of the engine. This would be consistent with the very small gradual decrease in $\mathrm{CO}_{2}$ emissions (and hence fuel consumption) that were often observed during steady-state tests.

The particle emission rates in the steady-state tests were of the order $10^{6}-10^{11} \mathrm{particles} / \mathrm{sec}$ with the Insight having the lowest emission rates of the four hybrid vehicles. Recall that 
dilution air particle concentrations were set to zero for steady-state emission rate calculations in order to minimize errors introduced by variation of this parameter as explained in Chapter 5. Hence, these emission rates represent a worst-case scenario. It should be noted that under the flow conditions of this study, $10^{8}$ particles/sec corresponds to a CPC reading of approximately 100 particles $/ \mathrm{cm}^{3}-$ in the vicinity of estimated dilution air concentrations. Thus, at steady-state $40 \mathrm{~km} / \mathrm{h}$ conditions, most of the vehicles showed particle number emission rates that were comparable to dilution air concentrations.

The higher speed $(80 \mathrm{~km} / \mathrm{h}$ vs $40 \mathrm{~km} / \mathrm{h})$ generally resulted in noticeably higher particle number emission rates with the exception of the Insight. The Insight showed only a modest increase in emissions at the higher speed at $20^{\circ} \mathrm{C}$. The emission rates of the Insight running at steady-state speeds at $-18^{\circ} \mathrm{C}$ were some of the lowest observed throughout the entire project. Second-by-second particle concentrations on these tests were under 10particles $/ \mathrm{cm}^{3}$. One explanation for this could be that dilution air particle concentrations were particularly low on these testing days (June 1 and 2), while on the $20^{\circ} \mathrm{C}$ Insight testing days the dilution air was making a significant contribution to the low emission rates.

The four hybrid vehicles demonstrated distinct patterns of emission rate as a function of time over the 20 minutes of the steady-state tests. The Prius and Escape emission rates showed virtually no fluctuations with time while the Insight showed some oscillation and the Civic showed much higher oscillations. The oscillations observed for the Civic had 
similar frequencies at the higher and lower speeds but the amplitudes were noticeably higher at the higher speed.

No effect of cold ambient temperature was observed for the hybrid vehicles (with the exception of the Insight which was discussed above). At $80 \mathrm{~km} / \mathrm{h}$ the Smart (non-hybrid) showed much higher emissions at $-18^{\circ} \mathrm{C}$ compared to $20^{\circ} \mathrm{C}$. Also, the effect of speed on the emission rate was stronger for the Smart.

All in all, emissions for these vehicles at steady-state speeds of $40 \mathrm{~km} / \mathrm{h}$ were very low; so low in fact that dilution air particle concentration became significant, and it was possible to observe the gradual release of particle deposits left in the engine and dilution system during previous tests. Because dilution air particle concentration was not measured while testing (only one CPC was available and this measured dilute exhaust concentrations), these concentrations could not be properly accounted for. With the exception of the Insight, emissions were much higher at higher $(80 \mathrm{~km} / \mathrm{h})$ speeds. The Smart showed a stronger effect of speed on emission rate, and also showed higher emissions at low ambient temperature $\left(-18^{\circ} \mathrm{C}\right)$ compared to warm ambient temperature $\left(20^{\circ} \mathrm{C}\right)$ whereas the hybrids did not.

Results from the ELPI showed random fluctuations in all size ranges, and a gradual decrease over the length of the test. Particle emission rates in each size range were often less than 100 particles $/ \mathrm{cm}^{3}$. Because of the large uncertainty associated with such small measurements, steady-state test results from the ELPI will not be discussed further. 


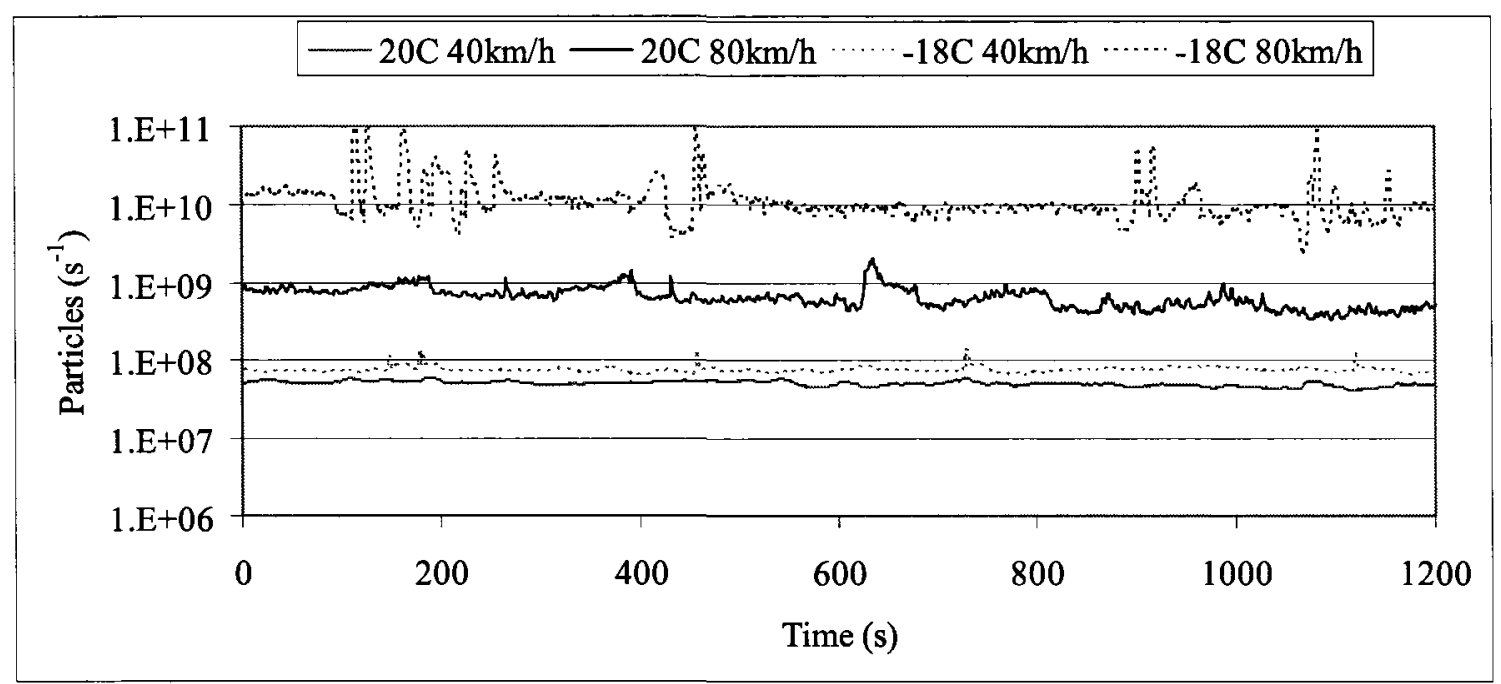

Figure 6.1.1 - Variation of particle emission rates for steady-state operation of the Smart

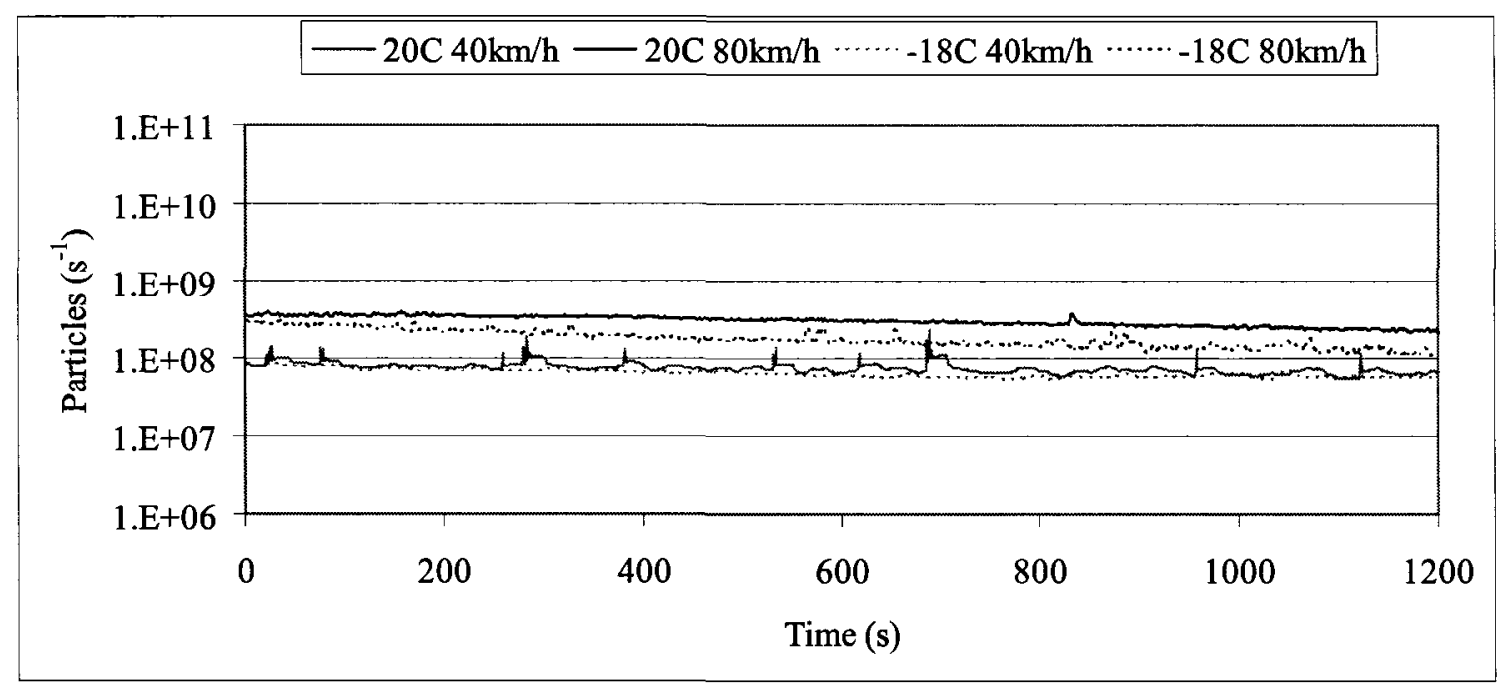

Figure 6.1.2 - Variation of particle emission rates for steady-state operation of the Prius 


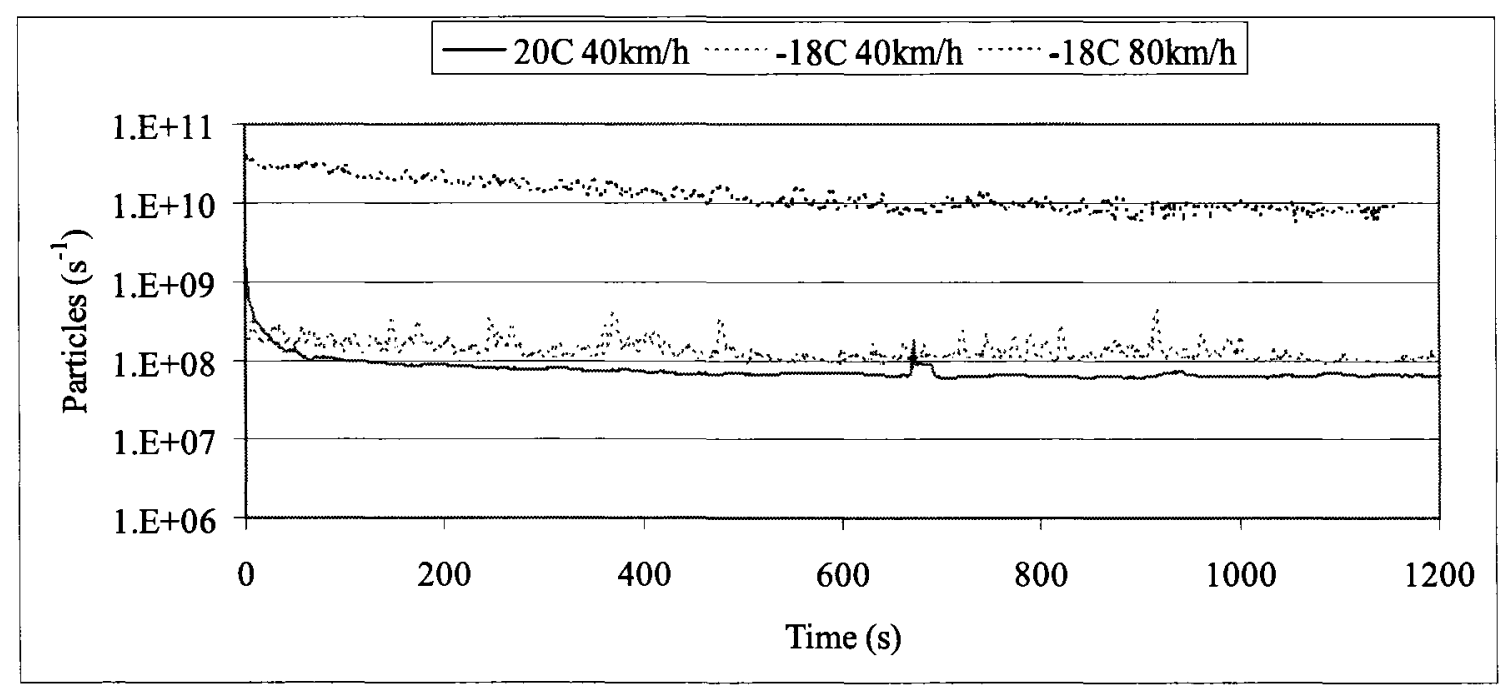

Figure 6.1.3 - Variation of particle emission rates for steady-state operation of the Escape

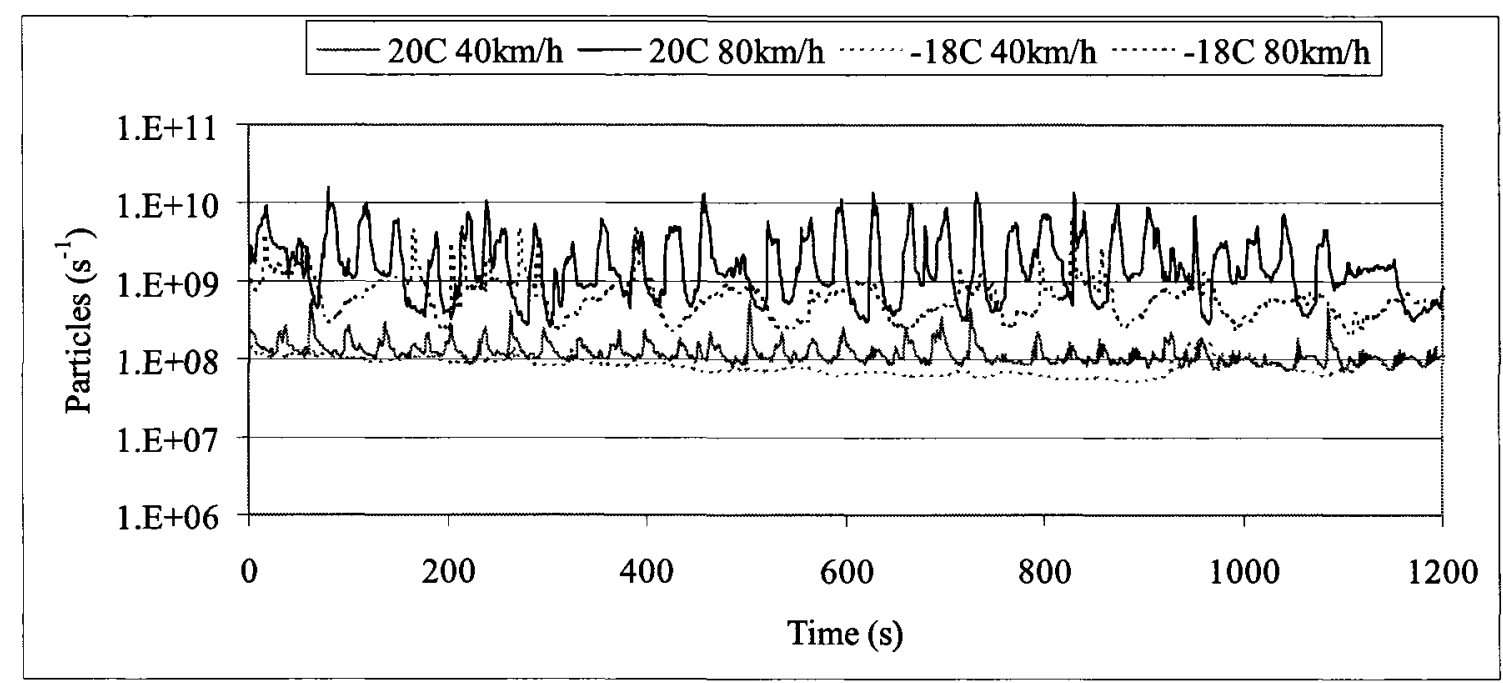

Figure 6.1.4 - Variation of particle emission rates for steady-state operation of the Civic 


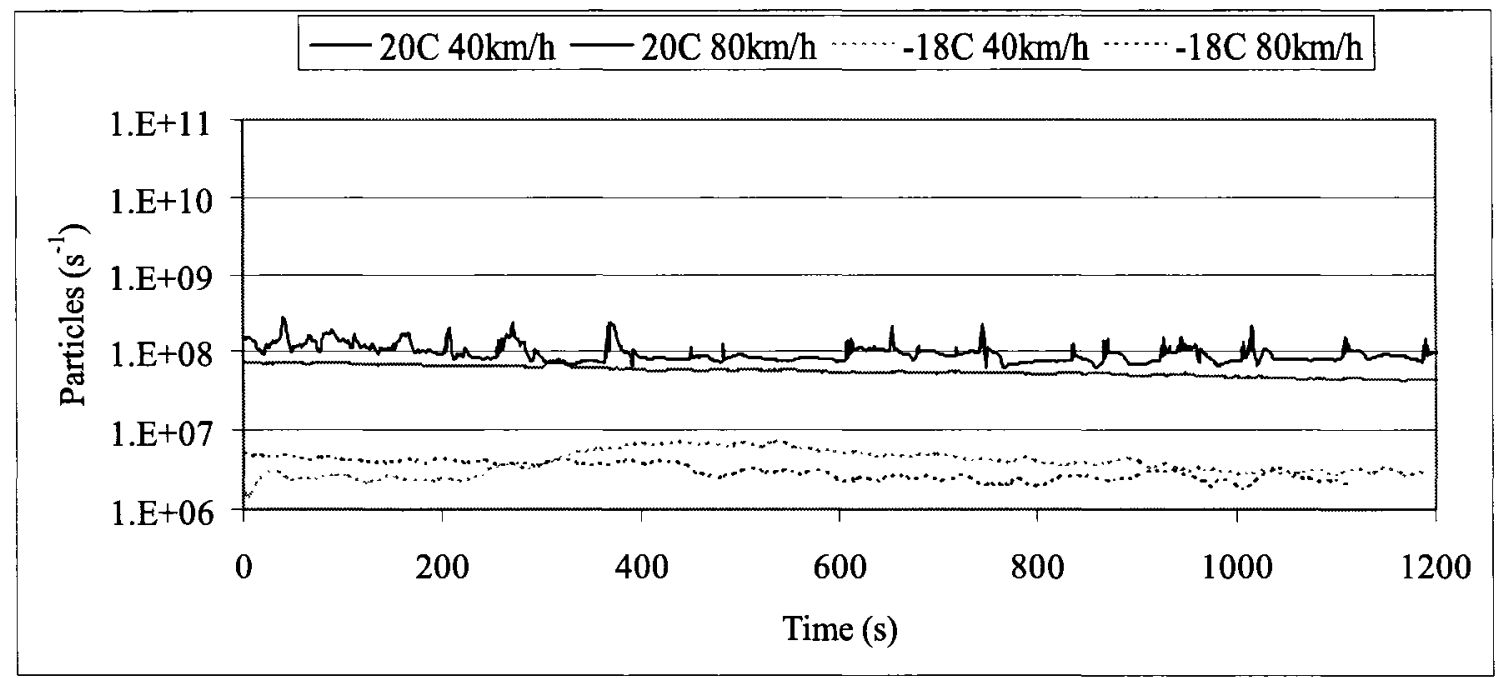

Figure 6.1.5 - Variation of particle emission rates for steady-state operation of the Insight

\subsubsection{Acceleration, Deceleration, Idle, Engine-Off}

Figures $6.1 .6,6.1 .7$, and 6.1 .8 provide examples of transient emissions over the NYCC*2 for each type of system studied: a small conventional gasoline engine vehicle, the Hybrid Synergy Drive (HSD), and the Integrated Motor Assist (IMA). Transient emissions characteristics including particle number measured by the $\mathrm{CPC}, \mathrm{CO}_{2}$ mass measured by the gas analyzer, and dynamometer speed are shown. For the HEVs, either state-ofcharge (SOC) or charging current is shown. The NYCC*2 was chosen to demonstrate emission characteristics because it includes many periods of acceleration, deceleration, and idle. Keep in mind that the speed-time trace for the first 600 s is the same as for the last $600 \mathrm{~s}$ of this $1200 \mathrm{~s}$ test. While only three vehicles (representing different drive-train technologies) are discussed here, information on the other two vehicles can be found in Appendix 2. 
In general, peak particle number emissions occurred during short periods of heavy acceleration and coincided with peak $\mathrm{CO}_{2}$ emissions. During periods of idle, for instance between 454 and 494s, PM number emissions dropped to a low level for all five vehicles. As can be seen in the figures, the Smart (Figure 6.1.6) maintained a steady level of $\mathrm{CO}_{2}$ emissions during periods of idle, while the HEVs (Figures 6.1.7 and 6.1.8) often had low to zero $\mathrm{CO}_{2}$ emissions indicating that the engine was off.

An interesting observation during idle periods was the gradually decreasing PM emissions. Whereas a rapid adjustment of emissions to the lower rate of fuel combustion might have been expected whenever the IC engine returned to idle or was turned off, the declines in emission rates were usually gradual, as opposed to the sharp increases that occurred at acceleration or start-up events. These gradual declines were likely due to the gradual purging of particles and/or HC vapours stored in the vehicle exhaust system and/or sampling system during periods of increased PM emissions.

During periods of acceleration, all vehicles typically showed peaks in particle number emissions of variable magnitude and up to five orders of magnitude higher than emissions at steady-state operation of a similar average speed $(40 \mathrm{~km} / \mathrm{h})$. The HEVs, however, did not follow this pattern when the electric motor assisted or powered the vehicle. For instance, in Figure 6.1.7 showing the Escape on the $\mathrm{NYCC}^{*} 2$, we can tell that the engine is off when $\mathrm{CO}_{2}$ emissions drop to zero, and that the battery is providing power to the electric motor when the charging current is negative. At $t=0$, a peak in $P M$ emissions is observed as combustion begins. Start-up emissions will be further discussed 
in the following section. After start-up, the engine idled for the first 40 seconds. During the first acceleration, the engine powered the vehicle and the excess energy was used to charge the batteries (positive charging current). When the charging current is negative, the electric motor is providing power to the wheels from the battery. Between $325 \mathrm{~s}$ and $500 \mathrm{~s}$, the engine was off $\left(\mathrm{CO}_{2}\right.$ emissions were zero $)$ and the batteries were providing all of the energy required to move the vehicle. Between 950 s and 1100 s, the same place in the driving cycle as the region discussed above, the engine was required for power and was restarted at $1000 \mathrm{~s}$. This could be due to the batteries reaching a minimum state of charge. The Toyota Prius, like the Ford Escape, employs the HSD and showed similar transient emission patterns. The Honda Civic and Insight, which employ the IMA, showed engine-off conditions only during periods of idle, when the vehicle speed was zero (Figure 6.1.8).

During deceleration events, the charging current in Figure 6.1.7 often turns positive due to regenerative braking. As with idle and steady-state driving, deceleration resulted in low PM emissions for all vehicles.

Emission patterns at cold $\left(-18^{\circ} \mathrm{C}\right)$ ambient temperature are shown in Figures 6.1.9, 6.1.10, and 6.1.11. These were in most ways similar to those at $20^{\circ} \mathrm{C}$, with peaks during accelerations and at IC engine start-up. One clear difference was that the hybrid IC engines were shut off less frequently during the cold temperature testing as evidenced by the higher $\mathrm{CO}_{2}$ emission rates during periods of idle. 
The magnitudes of particle emission peaks were noticeably higher for the Smart at $-18^{\circ} \mathrm{C}$ compared to at $20^{\circ} \mathrm{C}$, but $\mathrm{PM}$ emissions from the hybrids appeared to be somewhat lower for the examples discussed here. Overall differences in average emission rates for each vehicle and driving cycle will be discussed in section 6.2. 


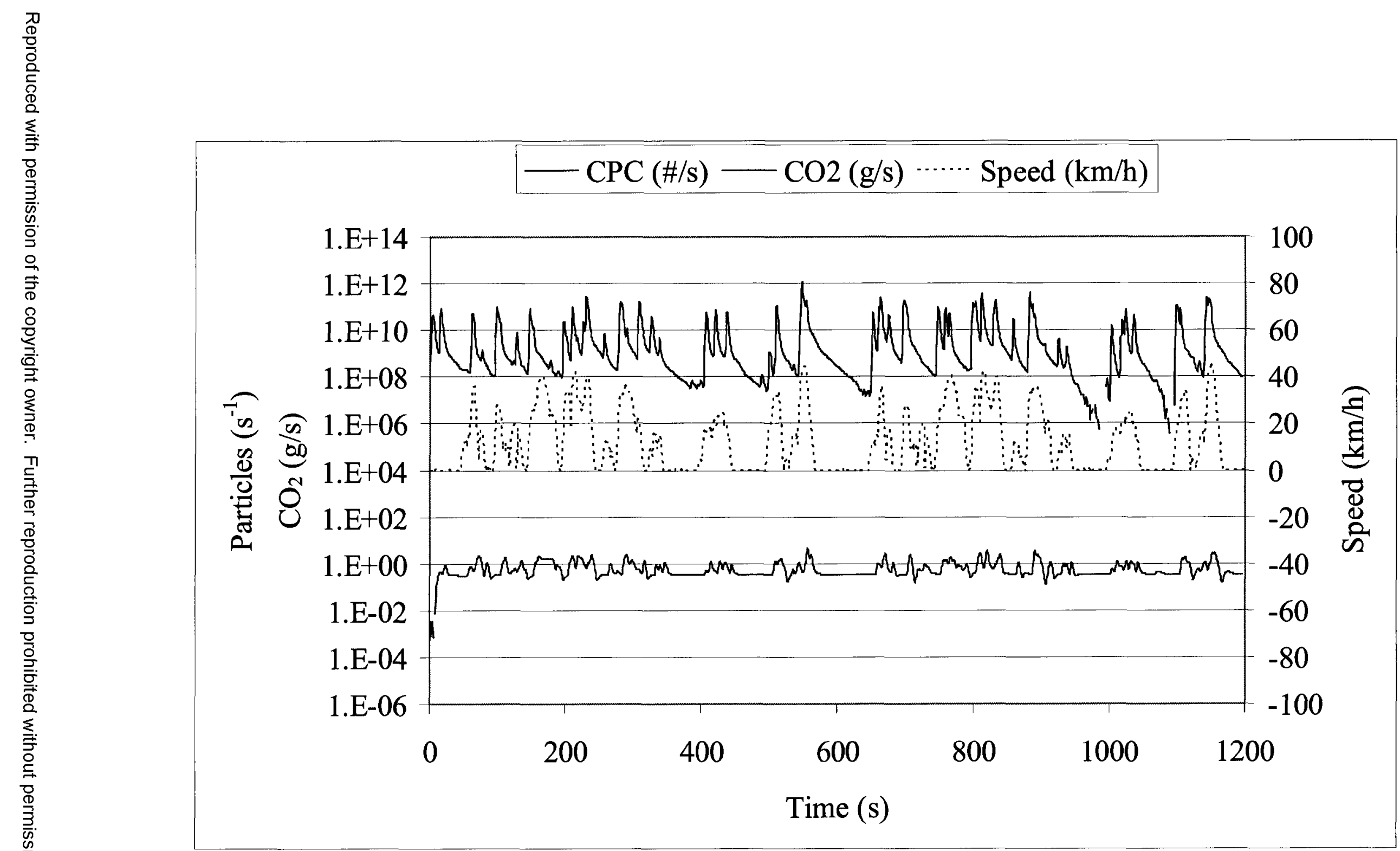

Figure 6.1.6 - Example transient emissions from a small conventional gasoline vehicle: Smart on the NYCC*2 at $20^{\circ} \mathrm{C}$ 


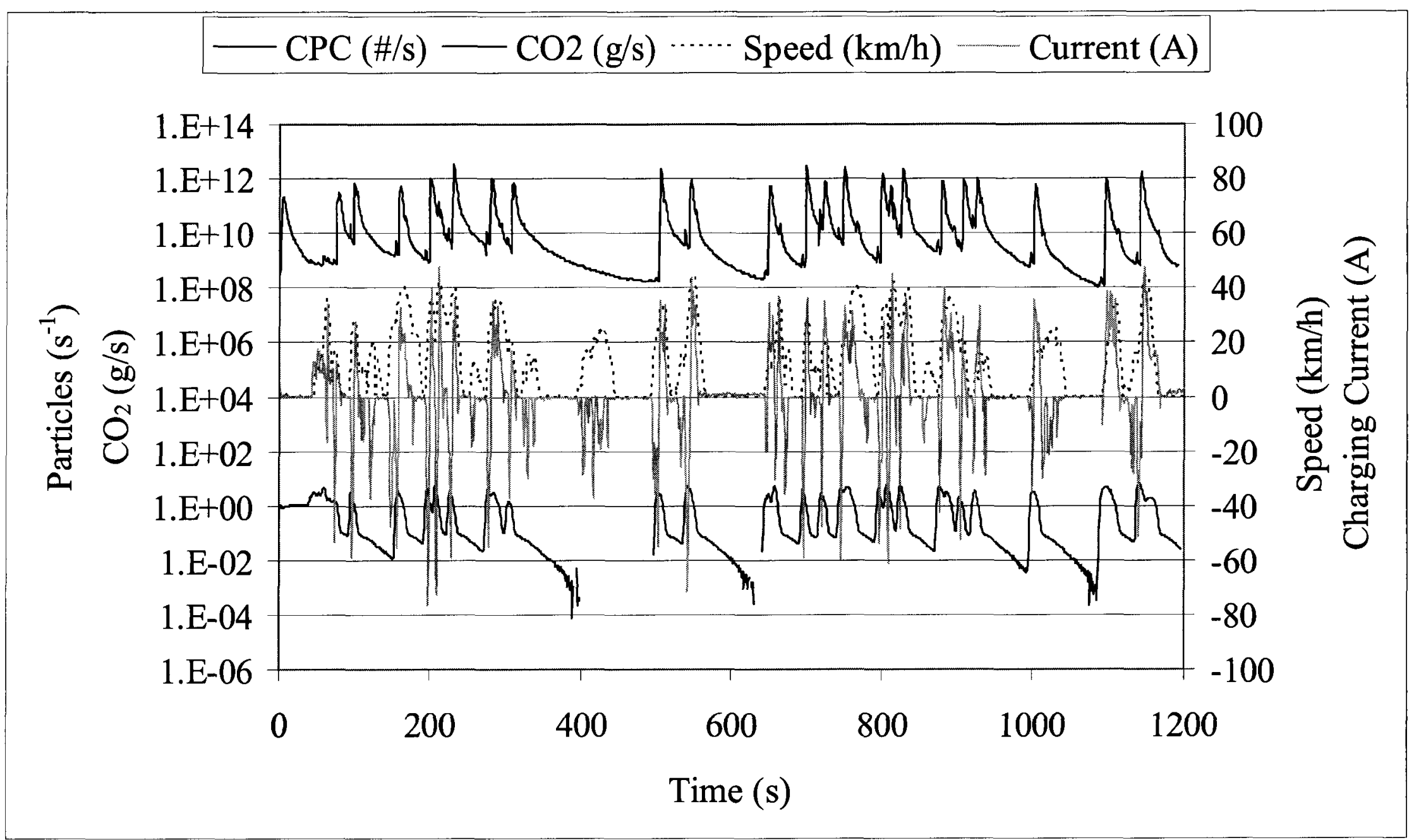

Figure 6.1.7 - Example transient emissions from a vehicle featuring the Hybrid Synergy Drive system: Ford Escape Hybrid on the $\mathrm{NYCC} * 2$ at $20^{\circ} \mathrm{C}$ 


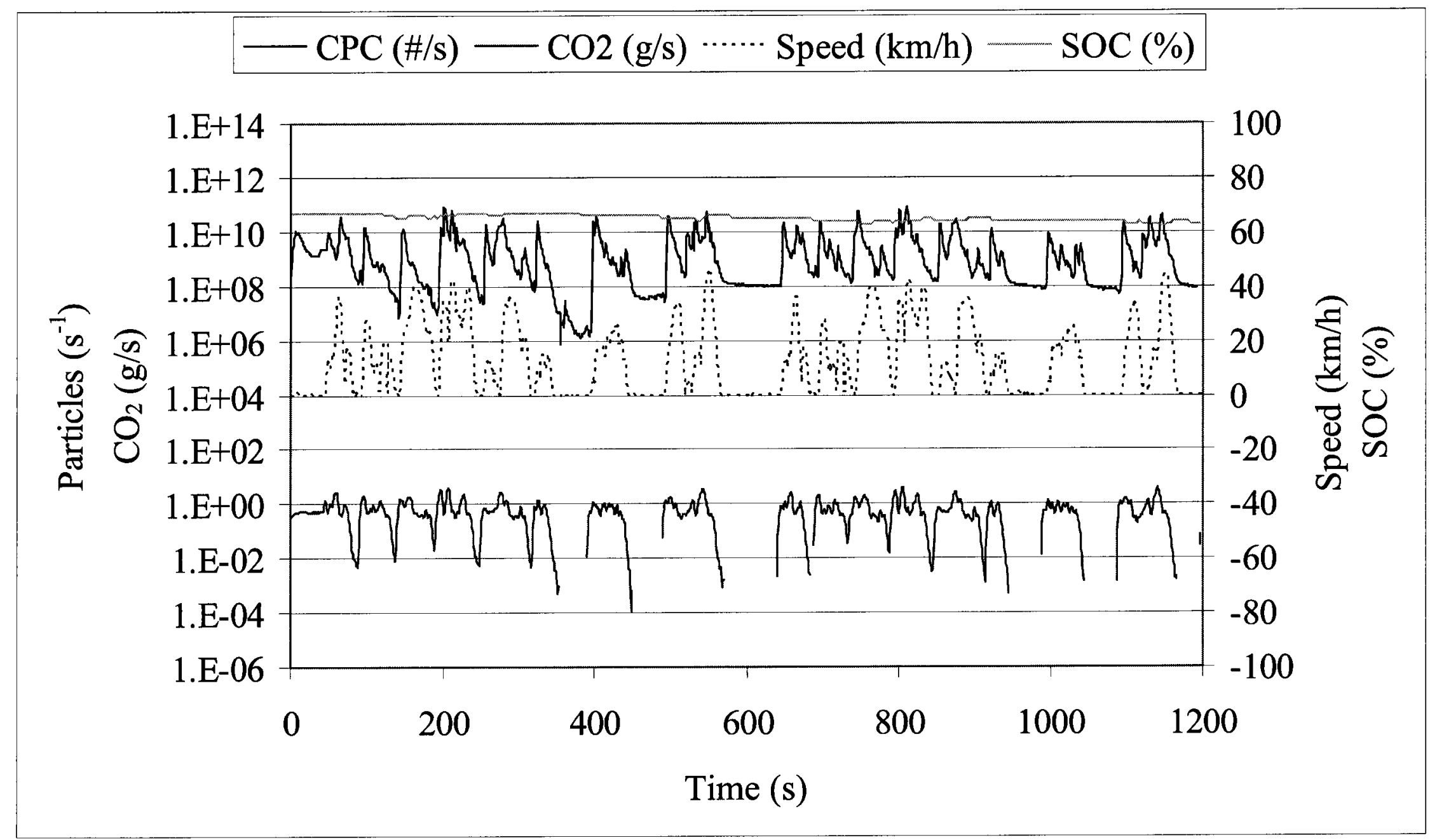

Figure 6.1.8 - Example transient emissions from a vehicle featuring the Integrated Motor Assist system: Civic on the NYCC*2 at $20^{\circ} \mathrm{C}$ 


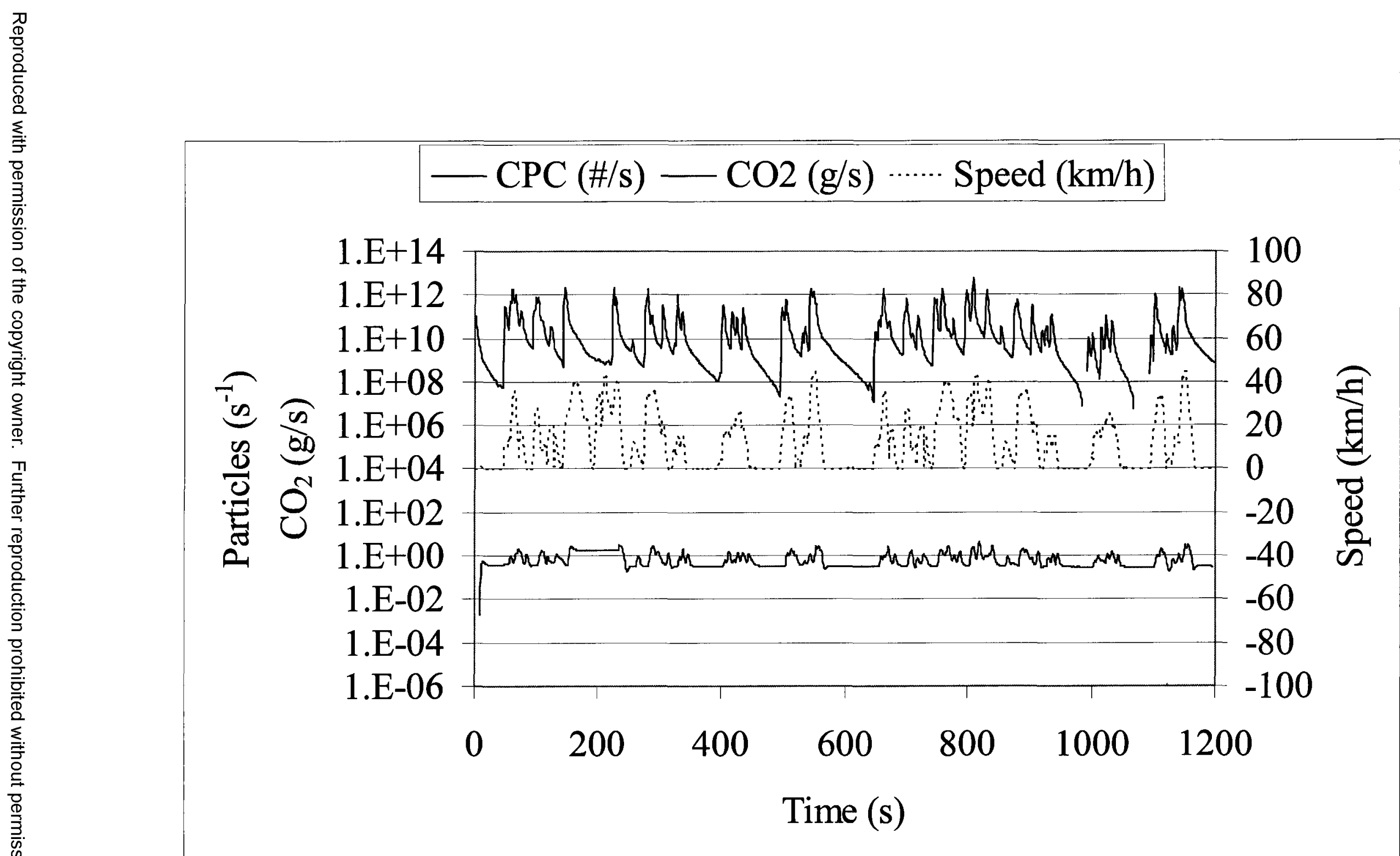

Figure 6.1.9 - Example transient emissions from a small conventional gasoline vehicle: Smart on the $\mathrm{NYCC}^{*} 2$ at $-18^{\circ} \mathrm{C}$ 


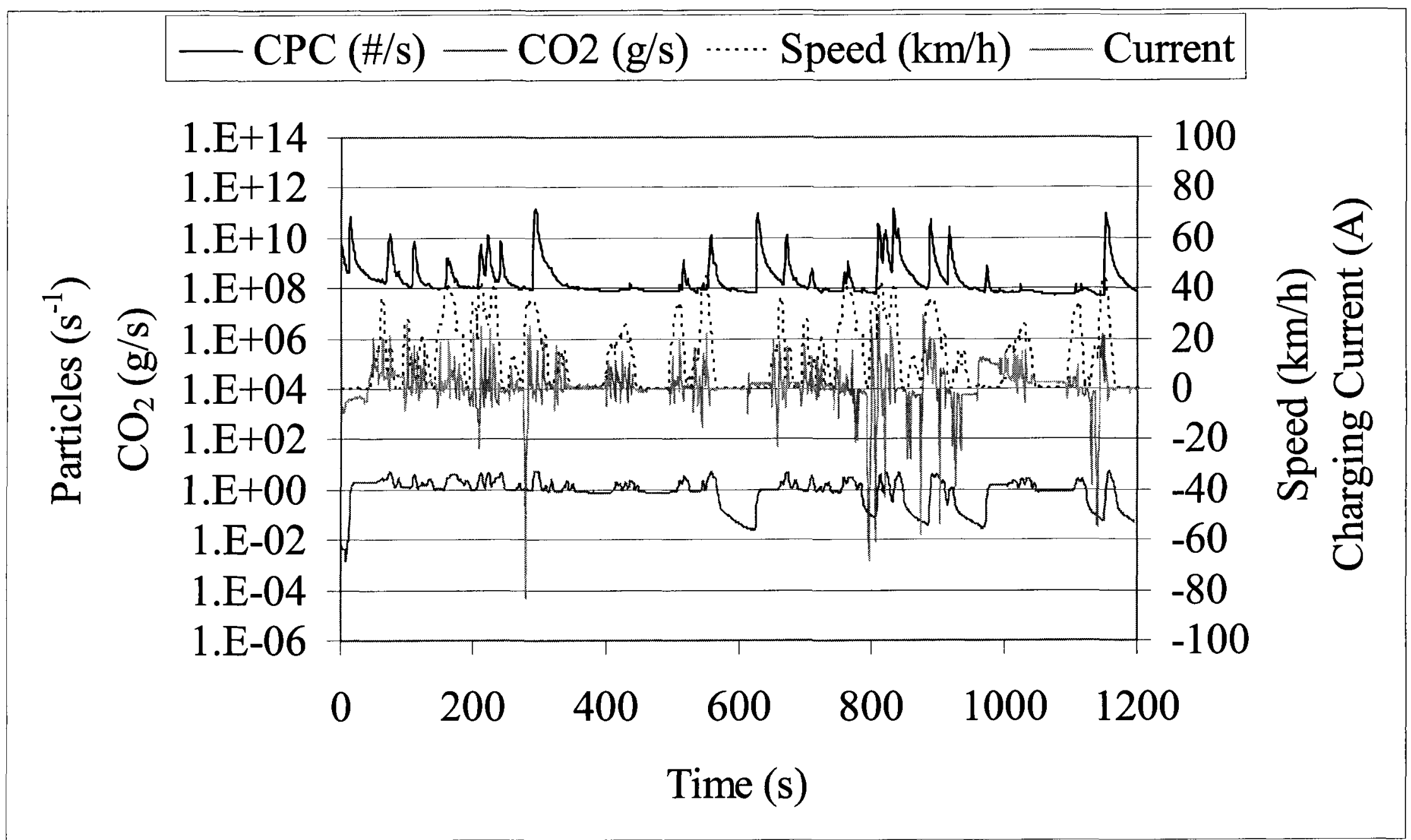

Figure 6.1.10 - Example transient emissions from a vehicle featuring the Hybrid Synergy Drive system: Ford Escape Hybrid on the NYCC* 2 at $-18^{\circ} \mathrm{C}$ 


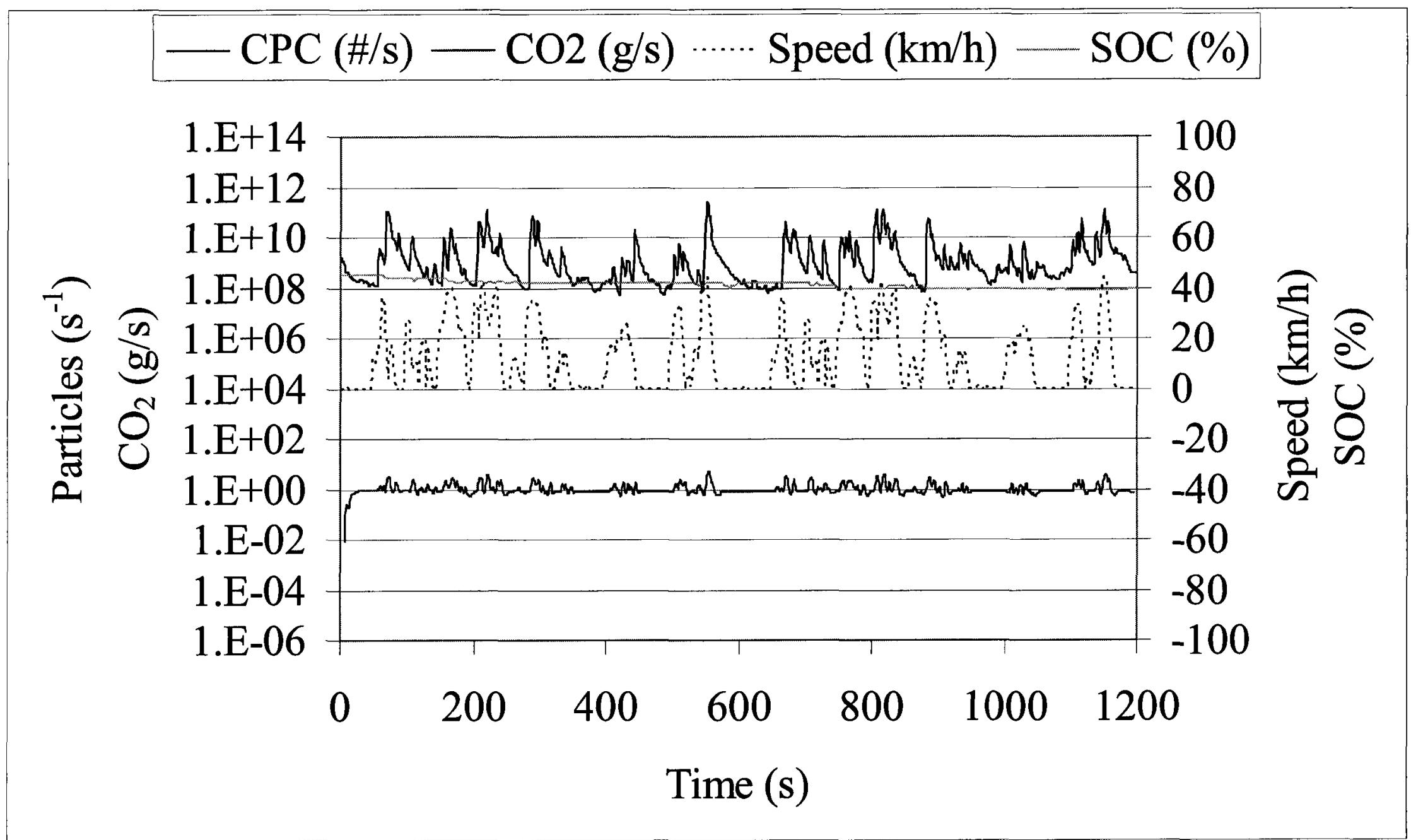

Figure 6.1.11 - Example transient emissions from a vehicle featuring the Integrated Motor Assist system: Civic on the NYCC $* 2$ at $-18^{\circ} \mathrm{C}$ 


\section{Size Distributions}

Size distributions were measured on a second-by-second basis using the electrical low pressure impactor (ELPI). The ELPI used in this study is able to measure the concentration of particles with aerodynamic diameters in the range of $0.03-10 \mu \mathrm{m}$. The impactor includes 12 stages, which accumulate particles with average aerodynamic diameters of $0.0399,0.0733,0.121,0.2015,0.31,0.492,0.7839,1.2443,1.9554,3.08$, 5.0826 , and $8.1219 \mu \mathrm{m}$. Unfortunately it was found that the vehicles of this study often emitted a high proportion of particles that were smaller than $0.03 \mu \mathrm{m}$ and so this study cannot be used to determine distribution parameters such as mean particle size or size variation. One can, however, observe the proportions of particles in the available size bins and determine when the mean particle diameter is relatively smaller or larger.

Figures 6.1.12 and 6.1.13 show second-by-second number-weighted size distributions measured by ELPI for the Prius on the NYCC* 2 at $20^{\circ} \mathrm{C}$ and $-18^{\circ} \mathrm{C}$. Dynamometer speed is not shown, but it is the same as in Figures 6.1.6-6.1.11. Only the four smallest size bins $(0.0399,0.733,0.121$, and $0.2015 \mu \mathrm{m})$ are shown because emissions in the larger size bins were much lower than in these four. Like the CPC results, the ELPI results show peaks in particle emissions during periods of acceleration. Concentrations measured in each size bin were very low during steady-state (constant speed) and idle conditions and thus, only size distributions during accelerations were meaningful.

Several trends are observable during accelerations in Figures 6.1 .12 and 6.1.13. At $20^{\circ} \mathrm{C}$, the smallest size range (shown in solid black) accounted for the largest proportion of 
particles emitted. At $-18^{\circ} \mathrm{C}$, the second smallest size range (solid light grey) contained a higher proportion of particles than at $20^{\circ} \mathrm{C}$ indicating that the mean particle size was larger at the colder temperature. This effect was often observed but was not consistent for all vehicles and cycles. Information on the other four vehicles can be found in Appendix 2, and overall integrated average size distributions for each vehicle and cycle are discussed in section 6.2 . 


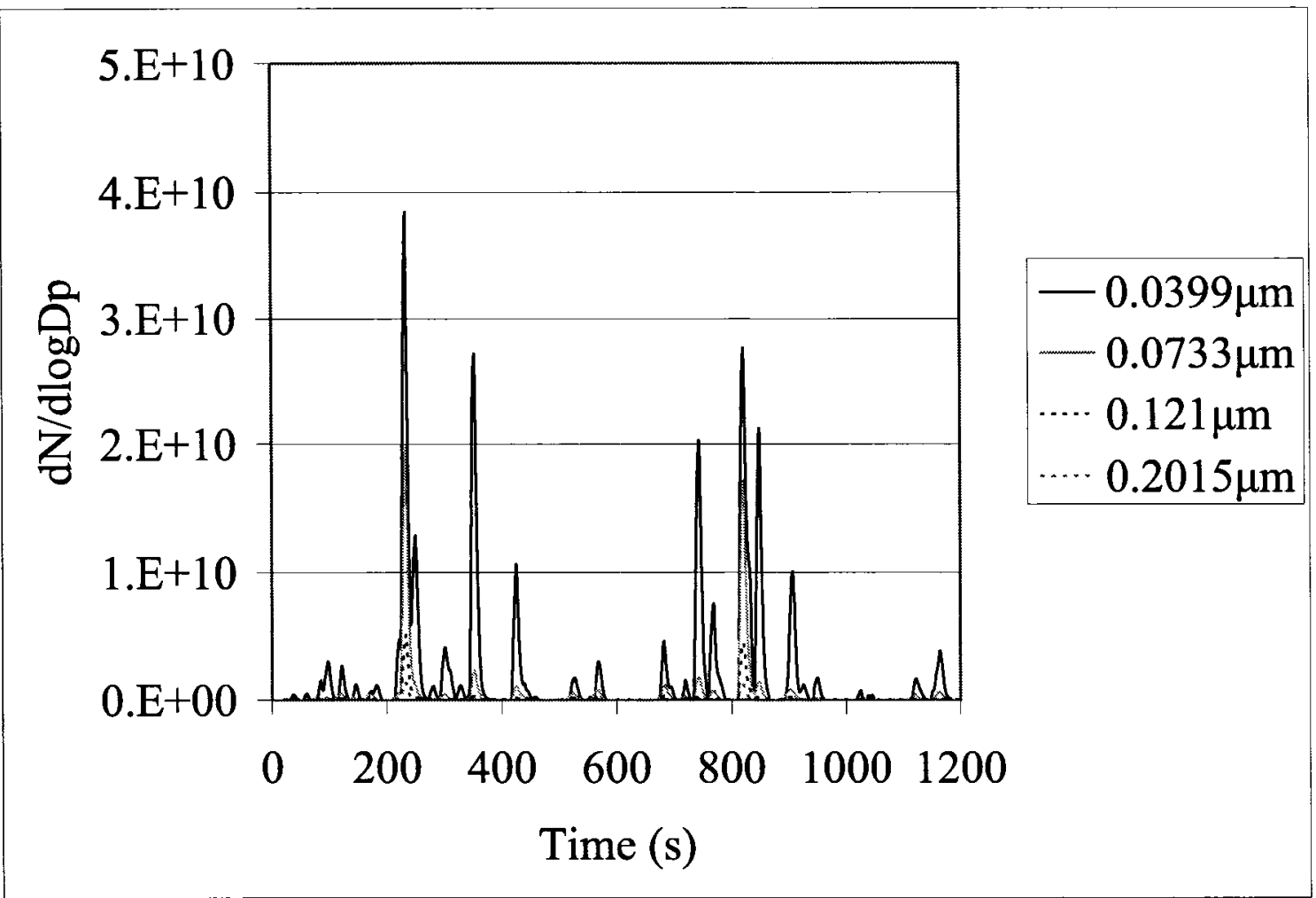

Figure 6.1.12 - Example transient number-weighted size distribution for the Prius on the NYCC* 2 at $20^{\circ} \mathrm{C}$

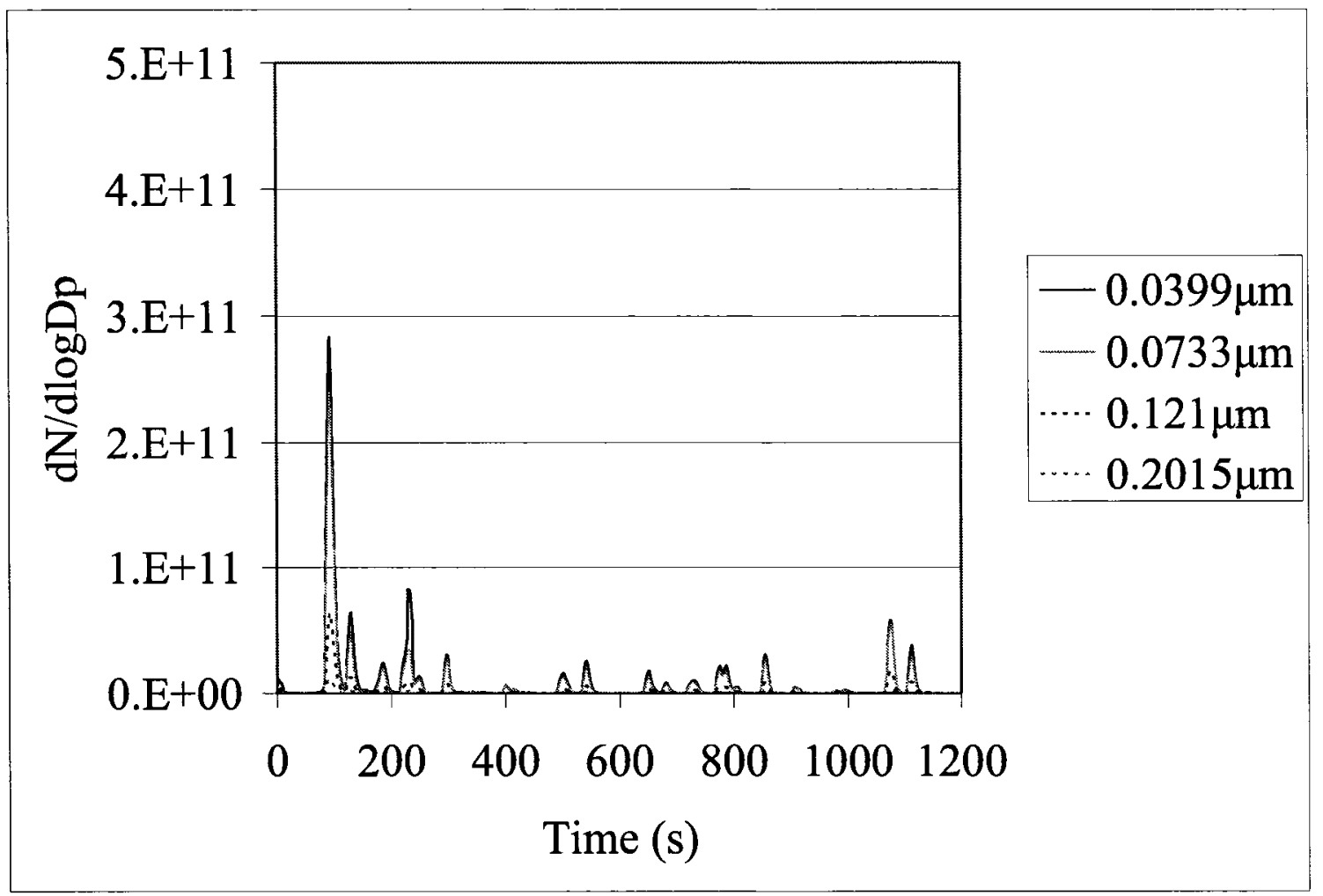

Figure 6.1.13 - Example transient number-weighted size distribution for the Prius on the $\mathrm{NYCC} * 2$ at $-18^{\circ} \mathrm{C}$ 


\subsubsection{Start-Up}

A peak in particle number emissions can be seen on start-up in Figure 6.1.9. This peak has been observed in previous studies and is attributed to several engine effects that occur at the start of combustion: higher engine speeds, variation from stoichiometric air/fuel ratio, and cooler intake port and valve temperatures (Kayes et al., 2000).

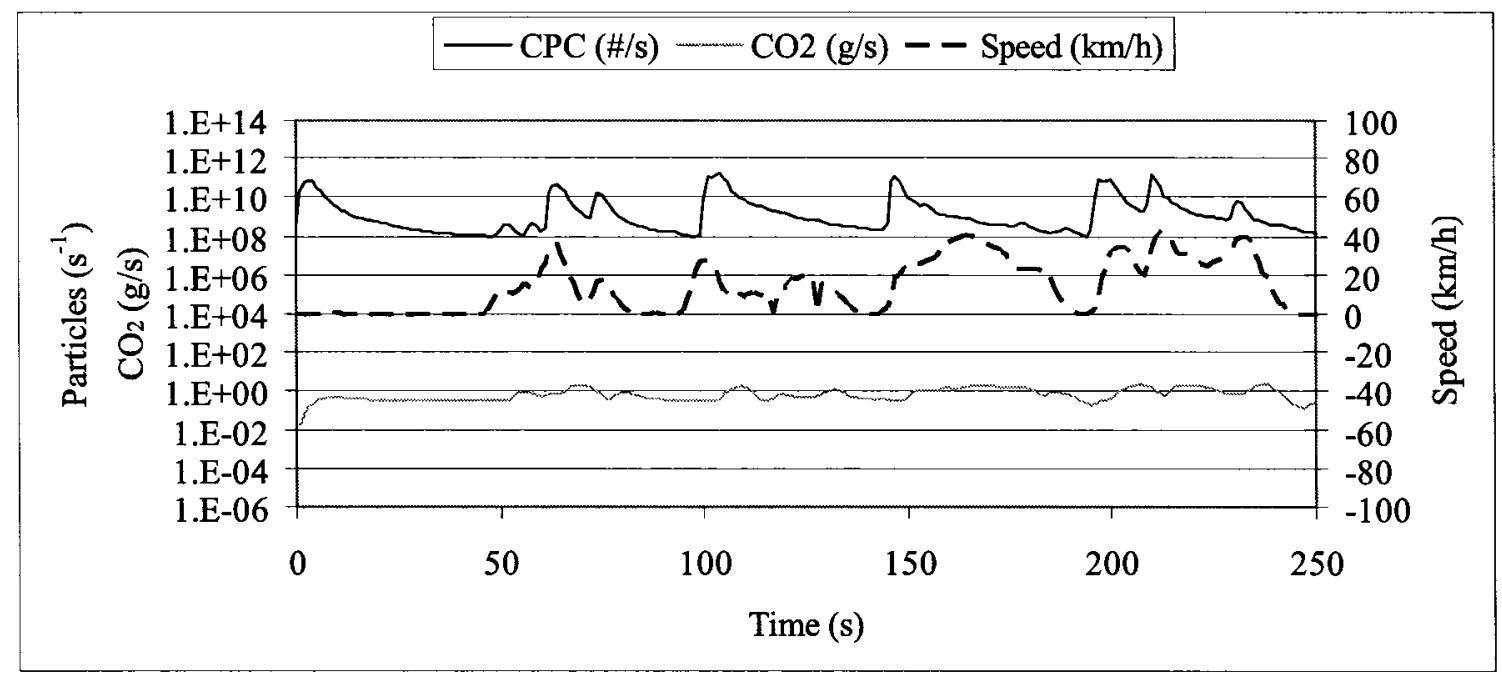

Figure 6.1.14 - Example of start-up emissions: Smart during the first 250s of the NYCC at $20^{\circ} \mathrm{C}$

Unlike the Smart, the hybrid vehicle IC engines did not necessarily start at the beginning of tests. In the example shown in Figure 6.1.10, the low $\mathrm{CO}_{2}$ emissions (less than $0.01 \mathrm{~g} / \mathrm{s}$ ) before the acceleration at 20 seconds are evidence that the Prius engine did not start until this point. When the engine starts and begins accelerating at the 20 second mark, a peak in PM emissions is observed. At 125 seconds, the engine shuts down once again but then restarts at 140 seconds, in advance of the next acceleration, producing a peak in PM emissions. It is unclear why the engine starts in advance of the acceleration, but it could be due to the electric heater automatically turning on, or the battery reaching a minimum state-of-charge. 
A unique characteristic of HEVs is the ability to use the electric motor to bring the engine up to a high rpm before ignition. This should lead to a lower load experienced by the engine to overcome inertia on start-up, and thus relatively lower PM emissions. Cooler intake port and valve temperatures after a period of engine-off may, however, lead to peaks in PM emissions observed during engine start-up. In addition, the changing load as the engine starts and has to respond to the throttle in the middle of the driving cycle could also lead to a peak in PM emissions on IC engine start-up. A possible explanation for the low and decreasing PM emissions at the start of the test (up to 15 seconds) is that residual PM in the dilution system from the last test was being slowly released.

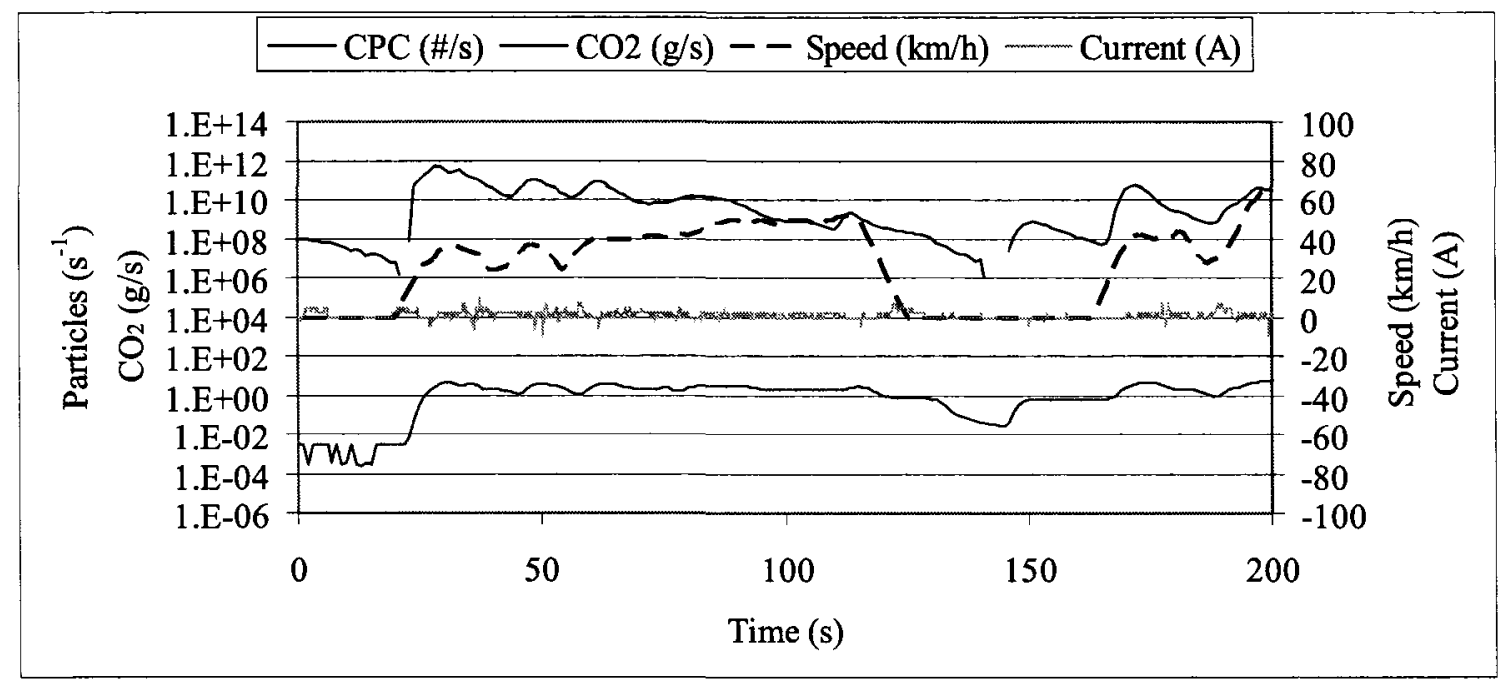

Figure 6.1.15 - Example of HEV start-up emissions: Prius on the LA4HS at $-18^{\circ} \mathrm{C}$

The emission factor model MOBILE6.2 treats emissions during the start-up of conventional internal combustion engine vehicles separately from the emissions per distance driven during typical trips since it is generally recognized that the start-up period contributes disproportionately to emissions per distance traveled. The model makes provision for specifying the number of starts per day by vehicle class so that the 
emissions modeled per start-up event can be accurately combined with the emissions per distance traveled and the average distance traveled per day for that vehicle class. The distance traveled per day by vehicle is typically estimated from vehicle fleet statistics or transportation demand model results in a particular region. The fact that the IC engines on HEVs can have multiple starts during the course of a trip and that these starts can be different in their characteristics from the ones modeled for IC engines on conventional vehicles presents challenges for the modeling of emissions from HEVs. This factor will gain significance in relation to the fraction of the vehicle fleet represented by HEVs.

\subsubsection{Cold-Start}

While the previous section discussed the single peak in particle emissions that occurs at the start of combustion regardless of engine temperature (hot-start or cold-start), the subject of this section is the first few minutes after a cool engine starts (cold-start). Two driving cycles were used to examine the impact of cold-start on PM emissions: the LA4 and LA92. The LA4 represents a non-demanding style of urban driving with an average speed of $30 \mathrm{~km} / \mathrm{h}$ while the LA92 is a more aggressive cycle with more transients and an average speed of $40 \mathrm{~km} / \mathrm{h}$.

It is generally expected that the first few minutes of a cold-start will produce high PM number emissions when compared to a hot-start on the same driving cycle. This is due to several cold-start effects: cool intake port and valve temperatures, high engine speeds, and locally fuel-rich areas caused by high fuel/air ratios. Figure 6.1.16 demonstrates that, as expected, the cold-start (CS) LA4 emissions of the Smart are significantly higher than the hot-start (HS) LA4 emissions for the first 500 seconds of the test. The difference 
diminished over time, with the largest differences between cold- and hot- start emissions occurring during the first 300 seconds. Particle number emissions are at least an order of magnitude higher during the first 300 seconds of cold-start. Similar trends were observed between hot- and cold- start LA92 driving cycle emissions.

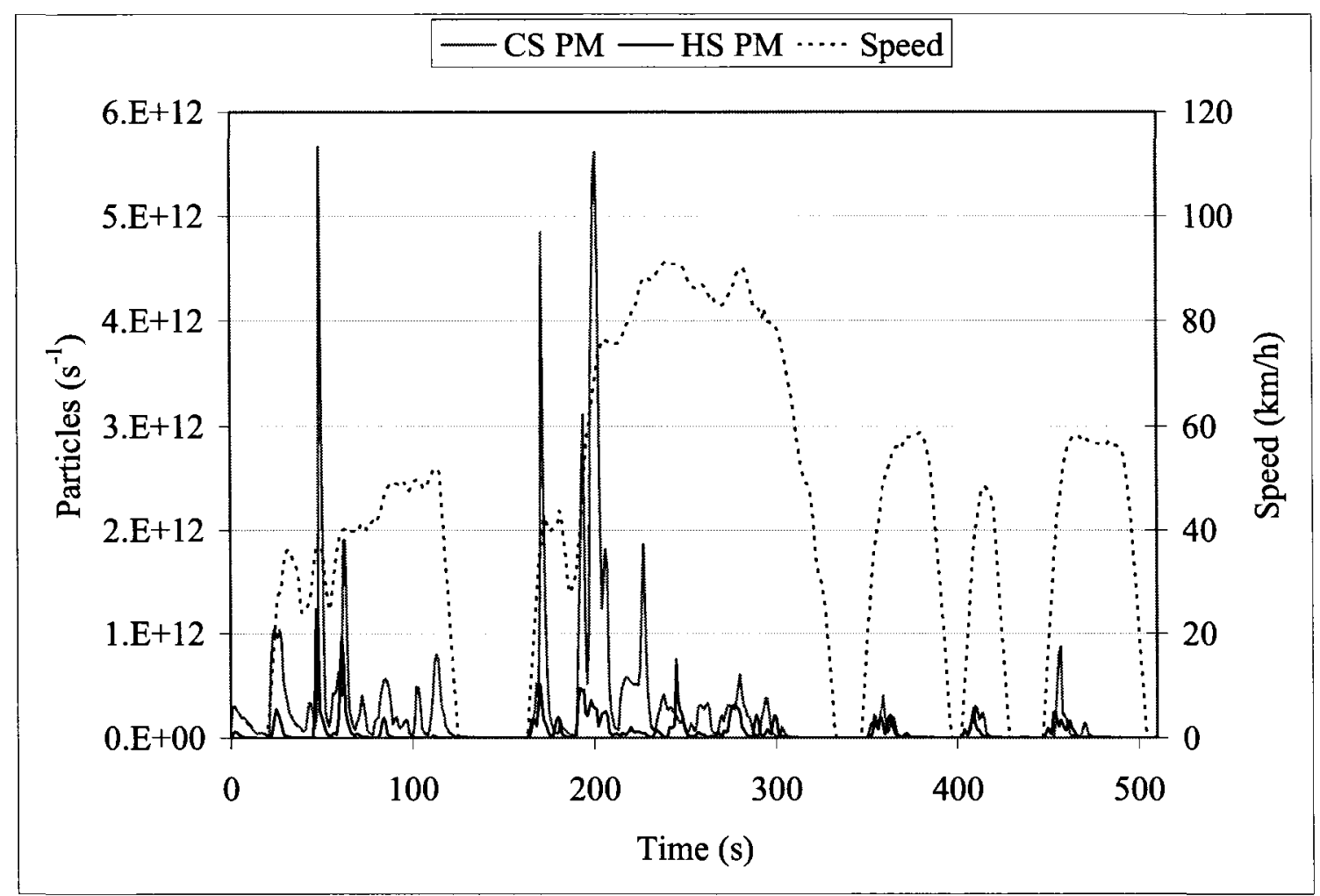

Figure 6.1.16 - Particle number emissions (CPC) for the Smart on the first 500s of the cold- and hot-start LA4 at $20^{\circ} \mathrm{C}$

The Civic and Insight also showed higher PM emissions during cold-start compared to hot-start. Example PM emissions and SOC data are given in Figure 6.1.17. PM number emissions from both the Civic and Insight were in general much lower than from the Smart (notice that the scale for the axis showing PM emissions is $1 / 10^{\text {th }}$ that of Figure 6.1.16), but the difference in cold- and hot-start emissions was still observable over the first 300 seconds. Cold- and hot-start LA92 emissions showed similar trends. 


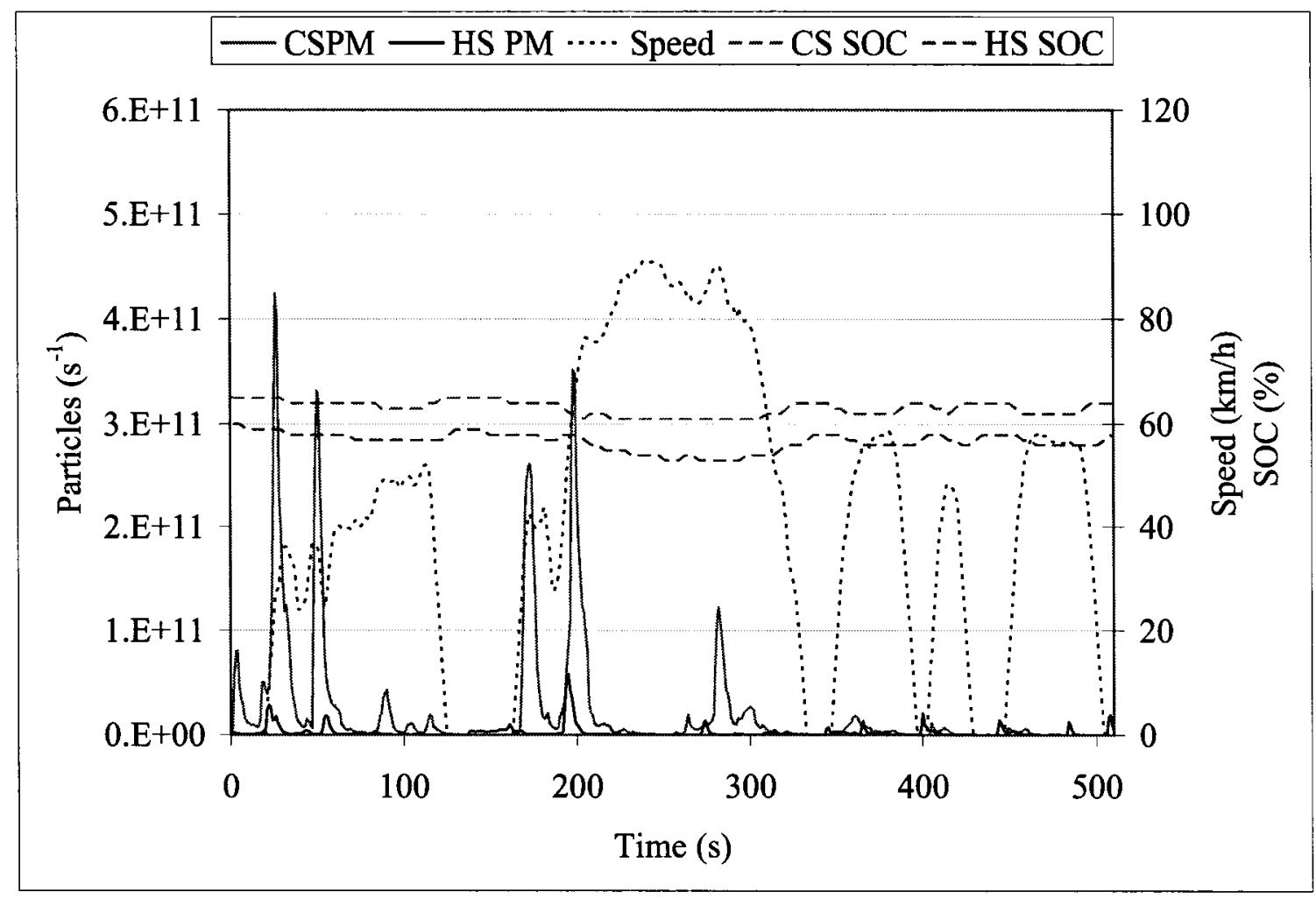

Figure 6.1.17 - Particle number emissions (CPC) for the Civic on the first 500s of the cold- and hot-start LA4 at $20^{\circ} \mathrm{C}$

In contrast to the effect of cold-starts on the emissions from the Smart, Civic, and Insight, both the Prius and Escape showed little to no difference in cold- and hot-start particle emissions on the majority of tests at $20^{\circ} \mathrm{C}$. Emissions for the Escape on the LA4 at $20^{\circ} \mathrm{C}$ can be seen in Figure 6.1.18, with very little difference between cold- and hot-start tests. It should also be noted that the scale of the PM emissions axis for Figure 6.1 .18 is $1 / 10^{\text {th }}$ of the scale of Figure 6.1.16 (Smart). It is likely that the Escape and Prius employ one or several technologies meant to reduce cold-start emissions. The Prius, for instance, uses a vacuum flask to store hot engine coolant after operation. This hot coolant is circulated on start-up to heat the engine. While information on all of the emission reducing strategies employed by these vehicles is not readily available, it is clear that Ford and Toyota have achieved large reductions in cold-start particle emissions. 


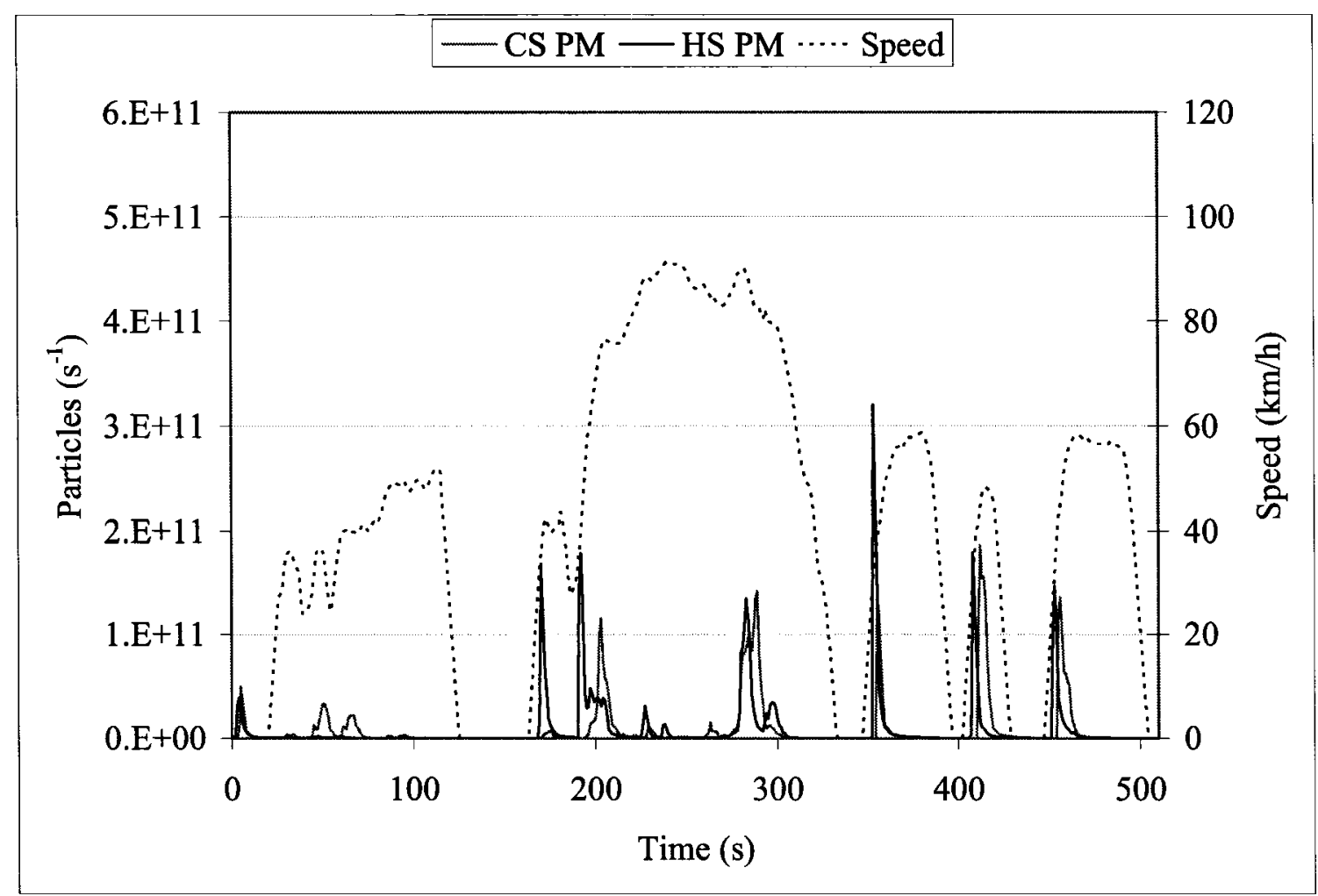

Figure 6.1.18 - Particle number emissions (CPC) for the Escape on the first 500s of the cold- and hot-start LA4 at $20^{\circ} \mathrm{C}$

The results discussed above were for tests at $20^{\circ} \mathrm{C}$. During tests at $-18^{\circ} \mathrm{C}$, all vehicles showed observable differences between cold- and hot-start particle number emissions. For example, emissions for the Ford Escape, which showed little to no difference between cold- and hot-start at $20^{\circ} \mathrm{C}$, are clearly affected by cold-start at $-18^{\circ} \mathrm{C}$ in Figure 6.1.19. For this test, peaks in number emissions were similar in magnitude to those of the Smart at $20^{\circ} \mathrm{C}$, but instead of showing sharp spikes, the emissions stayed high over longer periods of time. 


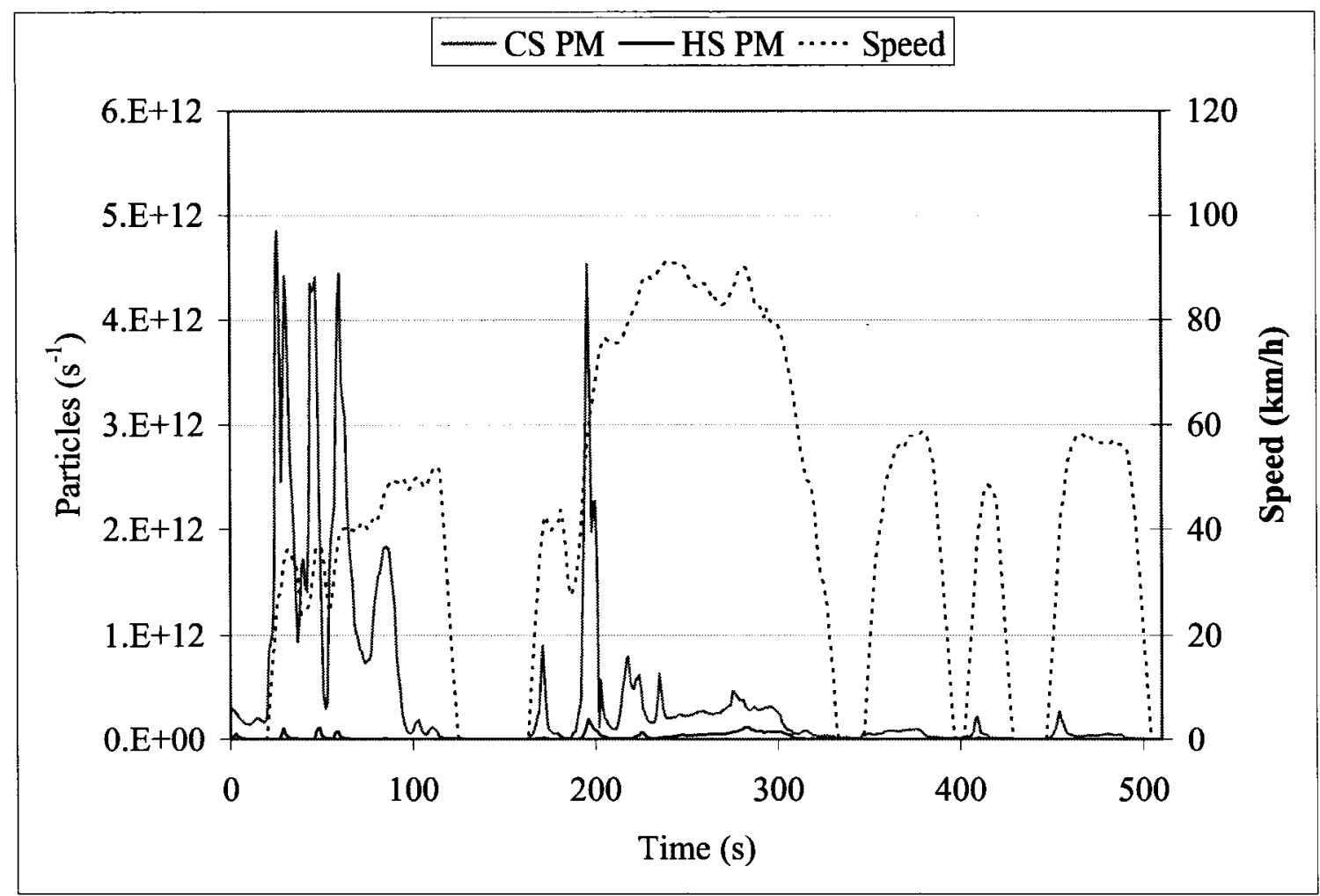

Figure 6.1.19 - Particle number emissions (CPC) for the Escape on the first 500s of the cold- and hot-start LA4 at $-18^{\circ} \mathrm{C}$

In addition to affecting overall particle number emission rates, cold-start was found to have an effect on particle size distribution at $-18^{\circ} \mathrm{C}$. Figure 6.1 .20 shows data for the Smart as a representative example. During hot-start at $20^{\circ} \mathrm{C}(\mathrm{a})$, the smallest particle size bin covered by ELPI $(40 \mathrm{~nm})$ had the highest proportion of particle number emissions. Cold-start at $-18^{\circ} \mathrm{C}$ (b) had two noticeable effects: emissions increased generally by an order of magnitude, and emissions in the larger size bins (73 and $121 \mathrm{~nm}$ ) increased disproportionately, now representing the highest emissions. 


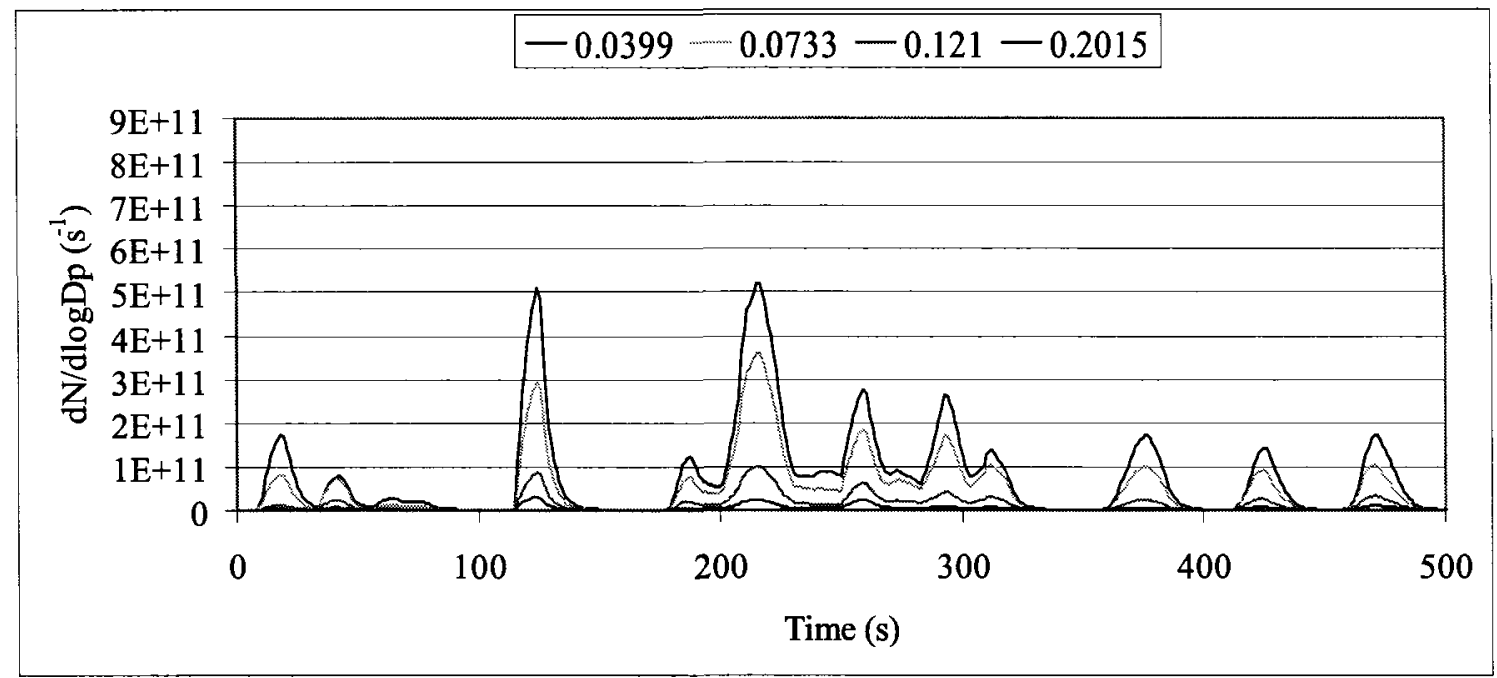

(a) Hot-start at $20^{\circ} \mathrm{C}$

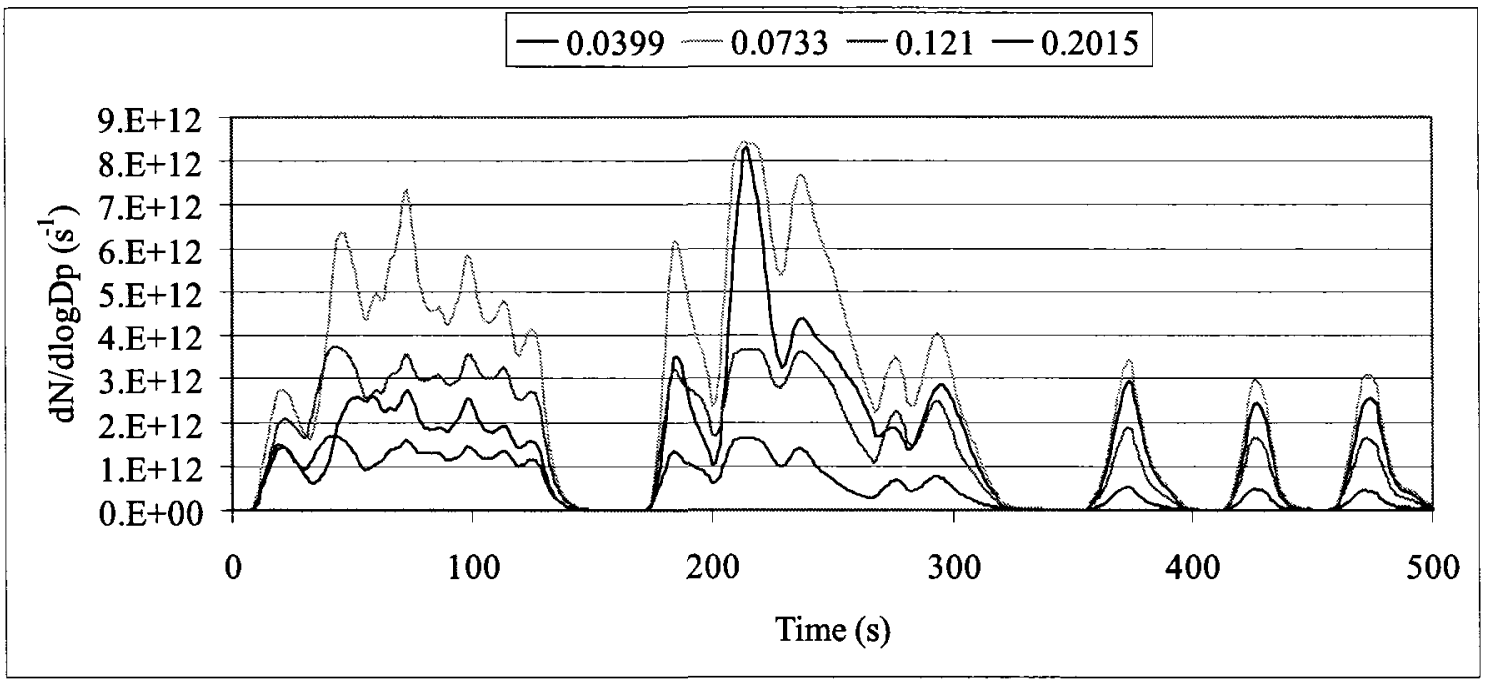

(b) Cold-start at $-18^{\circ} \mathrm{C}$

Figure 6.1.20 - Second-by-second particle number by size (ELPI) measured for the Smart on the LA4 at $20^{\circ} \mathrm{C}$ hot-start and $-18^{\circ} \mathrm{C}$ cold-start

\subsection{Integrated Emission Rates}

In the previous section, second-by-second results were presented and discussed. It was found that the hybrid vehicles showed emission patterns that were at times similar to those of conventional vehicles, with peaks in PM emissions during accelerations. Hybrid vehicle PM emissions differed from those of conventional vehicles when the electric 
motor assisted or powered the vehicle. Like conventional vehicles, the Civic and Insight (hybrids) showed higher PM emissions during the first 300-500 seconds of cold-start, but these emissions were, overall, at least an order of magnitude lower than those of the conventional gasoline engine Smart. In contrast, the Prius and Escape did not always show higher emissions during cold-start. At cold ambient temperature $\left(-18^{\circ} \mathrm{C}\right)$, all of the vehicles showed higher emissions during cold-start compared to hot-start, and size distributions during cold-start at $-18^{\circ} \mathrm{C}$ showed a higher proportion of large particles compared to other tests.

In this section, PM emissions will be examined in terms of integrated emission rates. These emission rates are used in emission inventories, source apportionment studies, health effects studies, and atmospheric modelling studies. While the previous section reported only on PM number emissions, integrated emission rates were calculated for both PM mass (from filter data), and PM number (CPC and ELPI).

Integrated emission rates are typically distance based (number $/ \mathrm{km}, \mathrm{mg} / \mathrm{km}$ ), time based (number/sec, mg/sec), or fuel based (number/kgfuel, $\mathrm{mg} / \mathrm{kgfuel}$ ). This study focuses on distance based emission rates. Integrated size distributions were determined by calculating average emission rates for each size-bin of the electrical low pressure impactor (ELPI).

\subsubsection{Net Energy Change Variance and Emission Rate}

The major difference between emission rate testing of conventional vehicles and hybrid electric vehicles is that with HEVs any change in battery state-of-charge that occurs over 
the test needs to be taken into account. In Chapter 3, HEV testing procedures published by the California Air Resources Board (CARB) and the Society of Automotive Engineers (SAE) were discussed. The CARB procedure requires that tests used to determine emission rates have absolute NEC variances (NECvar) (called state-of-charge net tolerance in the CARB procedure) of less than $1 \%$. Unfortunately, this would have meant discarding a high percentage of test data and many more tests would have to be performed in order to complete this project. The number of tests for each vehicle in this study with absolute NECvar $>1 \%$ are given in Table 6.2.1. Based on CARB requirements, $64 \%$ of tests on the Escape would have to be discarded and repeated, $34 \%$ for the Prius, $30 \%$ for the Civic, and $10 \%$ for the Insight.

Table 6.2.1 -Tests with absolute NEC greater than $1 \%$

\begin{tabular}{|c|c|c|c|}
\hline $\begin{array}{c}\text { Vehicle and Test } \\
\text { Temperature }\end{array}$ & $\begin{array}{c}\text { Number of Tests } \\
\text { with Absolute } \\
\text { NECvar }>\mathbf{1 \%}\end{array}$ & $\begin{array}{c}\text { Total Number of } \\
\text { Tests with NEC } \\
\text { Data }\end{array}$ & $\begin{array}{c}\text { Percentage of } \\
\text { Tests with } \\
\text { absolute NECvar } \\
>1 \%\end{array}$ \\
\hline Insight & 4 & 40 & $\mathbf{1 0}$ \\
$20^{\circ} \mathrm{C}$ & 2 & 22 & 9 \\
$-18^{\circ} \mathrm{C}$ & 2 & 18 & 11 \\
\hline Civic & 15 & 50 & 30 \\
$20^{\circ} \mathrm{C}$ & 12 & 25 & 48 \\
$-18^{\circ} \mathrm{C}$ & 3 & 25 & 12 \\
\hline Prius & 16 & 47 & 34 \\
$20^{\circ} \mathrm{C}$ & 12 & 20 & 60 \\
$-18^{\circ} \mathrm{C}$ & 4 & 27 & 16 \\
\hline Escape & 41 & 64 & 64 \\
$20^{\circ} \mathrm{C}$ & 34 & 39 & 87 \\
$-18^{\circ} \mathrm{C}$ & 7 & 25 & 28 \\
\hline
\end{tabular}

Alternatively, the SAE recommended practice allows tests with absolute NECvar $<5 \%$ to be included in emission rate and fuel economy calculations, with a correction for tests with absolute NECvar $>1 \%$. Almost all of the tests performed for this study had absolute NECvar $<5 \%$. The SAE correction method involves finding the linear relationship between NECvar and emission rate, and then reporting the emission rate that would 
theoretically yield an NECvar of $0 \%$. An example of a correction procedure is given in Figure 6.2.1. This example is for the Escape on the LA4 at $-18^{\circ} \mathrm{C}$. Four repeats of this test were performed and mass and number emission rates were obtained from filter and CPC data respectively. CPC data was not available for one of tests, so only three number emission rates are reported. According to this correction, the emission rates at $0 \%$ NECvar are $22 \mathrm{mg} / \mathrm{km}$ and $2 \times 10^{13}$ particles $/ \mathrm{km}$. The $\mathrm{R}^{2}$ values for this linearization are, however, very low $(0.28$ and 0.08$)$. Also, the trend shows decreasing emission rates with increased battery charging (recall that positive NEC means an overall increase in battery state-of-charge). Intuitively, this is not what we would expect. A multitude of similar problems were encountered when attempting corrections for other tests: low $\mathrm{R}^{2}$ values, vertical trend lines, and corrected emission rates that were negative or otherwise did not make sense. Emission rate variation from test to test appeared to be greater than changes in emission rate due to net energy change variation. Thus, emission rates were not corrected using this method, and are reported as measured for the remainder of this thesis. NECvar for each individual test can be found in Appendix 1.

While the correction method, if it worked, would be useful for rating hybrids on a "level playing field" with conventional vehicles, it may not be appropriate for determining true emission rates of hybrids under various driving conditions. For instance, vehicles may consistently have high or low net energy change variances over certain driving cycles or under certain conditions that promote battery charging or discharging. It is interesting to note that for the Civic, Prius, and Escape, the number of tests with absolute NECvar exceeding $1 \%$ was much higher for testing at $20^{\circ} \mathrm{C}$ compared to at $-18^{\circ} \mathrm{C}$. This could be 
due to decreased use of the electrical system at low temperatures, and/or could be because NECvar is calculated relative to total cycle energy which depends on total fuel energy; fuel consumption is usually higher at cold ambient temperatures.

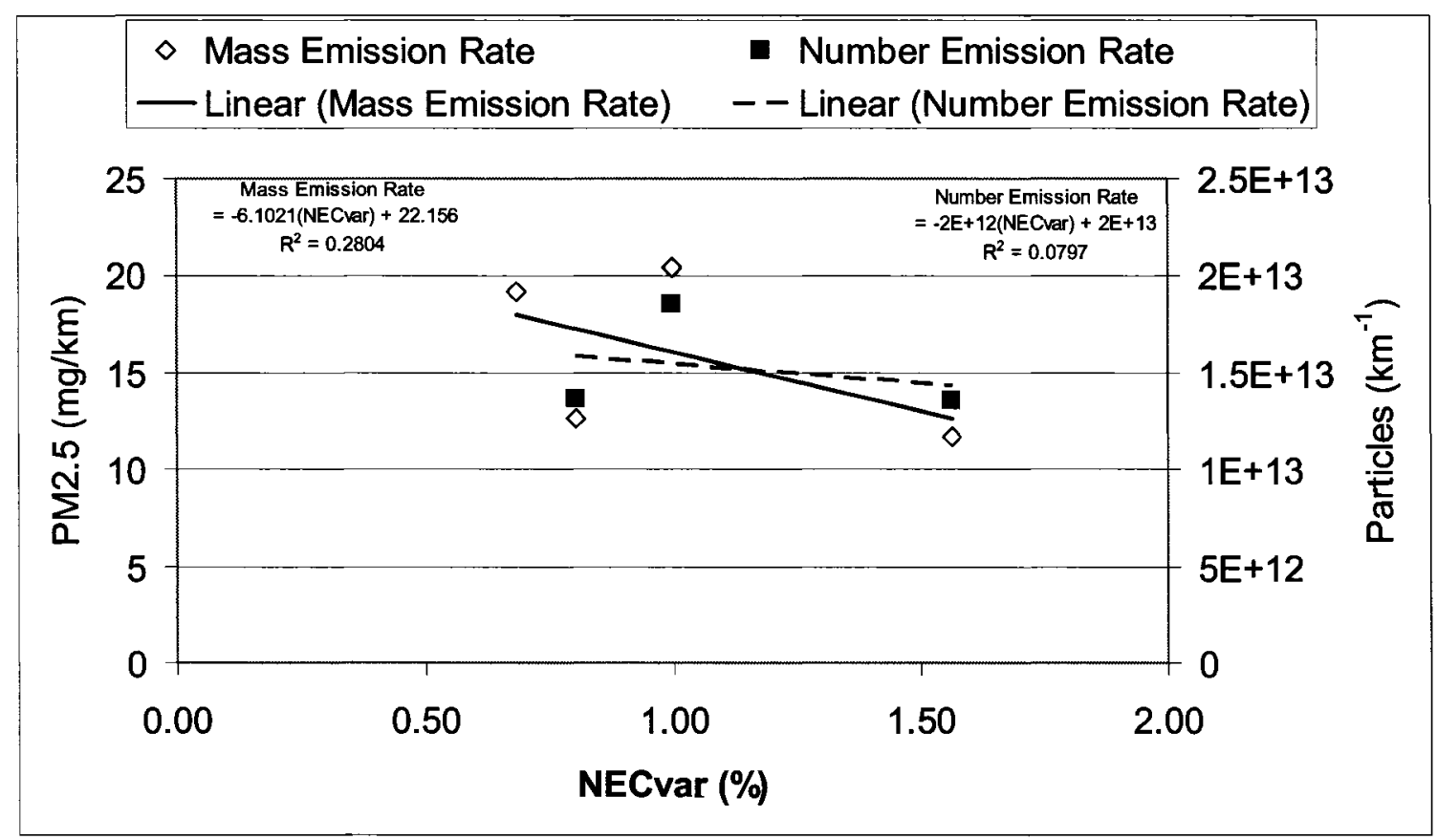

Figure 6.2.1 - Example state-of-charge correction: the Escape on the LA4 at $-18^{\circ} \mathrm{C}$

\subsubsection{Steady-State Emission Rates}

Integrated steady-state number emission rates calculated from CPC data are shown in Figures 6.2.2 and 6.2.3. One standard deviation across the second-by second emission rate data is shown. A high standard deviation, such as for the Civic on the $80 \mathrm{~km} / \mathrm{h} 20^{\circ} \mathrm{C}$ test, indicates a high level of emission rate fluctuation during steady-state driving. Steady-state $80 \mathrm{~km} / \mathrm{h}$ emission data for the Escape at $20^{\circ} \mathrm{C}$ were not obtained.

Unlike the steady-state time series data shown in section 6.1 .1 , these emission rates are normalized to distance travelled. Moving at $80 \mathrm{~km} / \mathrm{h}$, the vehicle travels a longer distance 
in the same amount of time, and this is taken into account in distance based emission rates. With the exception of the Insight, high speed driving at $80 \mathrm{~km} / \mathrm{h}$ resulted in higher number-based emission rates compared to driving at $40 \mathrm{~km} / \mathrm{h}$. The difference was especially apparent for the Smart and for the Escape. Ambient temperature had no noticeable effect on the emission rates except in the case of the Insight, but Insight results at $-18^{\circ} \mathrm{C}$ likely had high levels of uncertainty as discussed in section 6.1.1. The Smart had a higher and more variable emission rate at $-18^{\circ} \mathrm{C}$ compared to at $20^{\circ} \mathrm{C}$.

Total $\mathrm{PM}_{2.5}$ mass emission rates are given in Figures 6.2.4 and 6.2.5. Steady-state mass emission rates were often below detection limits for these vehicles, appearing as $0 \mathrm{mg} / \mathrm{km}$ in the charts. Unlike number emission rates, higher mass emission rates were not necessarily observed for the higher speed compared to the lower speed. Also in contrast to number emission rates, cold ambient temperature appeared to cause an increased mass emission rate for all vehicles but the Smart. The majority of organic and elemental carbon mass emission rates were below detection limits and are not shown here. Table and graph summaries of total $\mathrm{PM}_{2.5}$, organic carbon, and elemental carbon mass emission rates can be found in Appendix 4. 


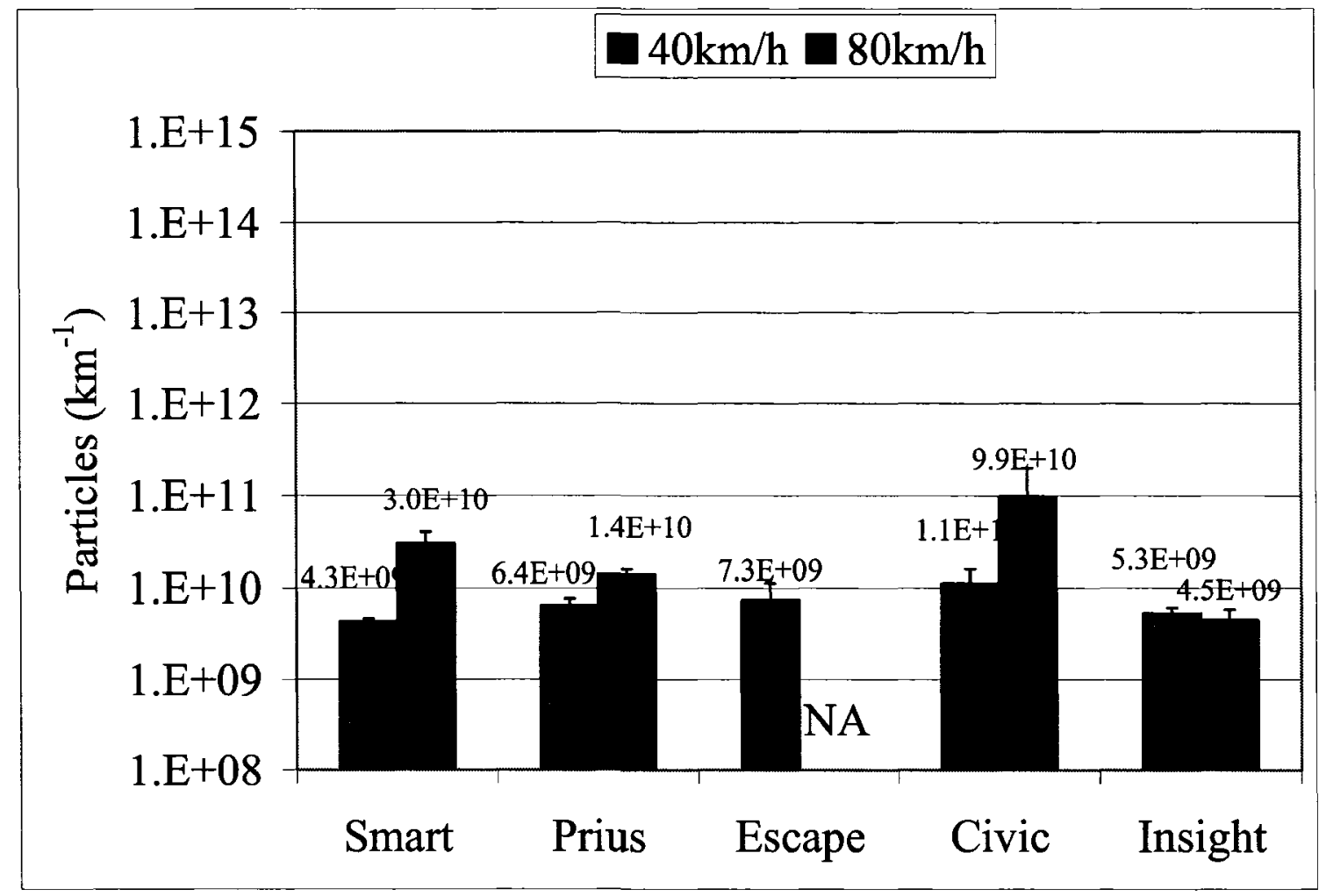

Figure 6.2.2 - Integrated steady-state emission rates \pm 1 standard deviation at $20^{\circ} \mathrm{C}$

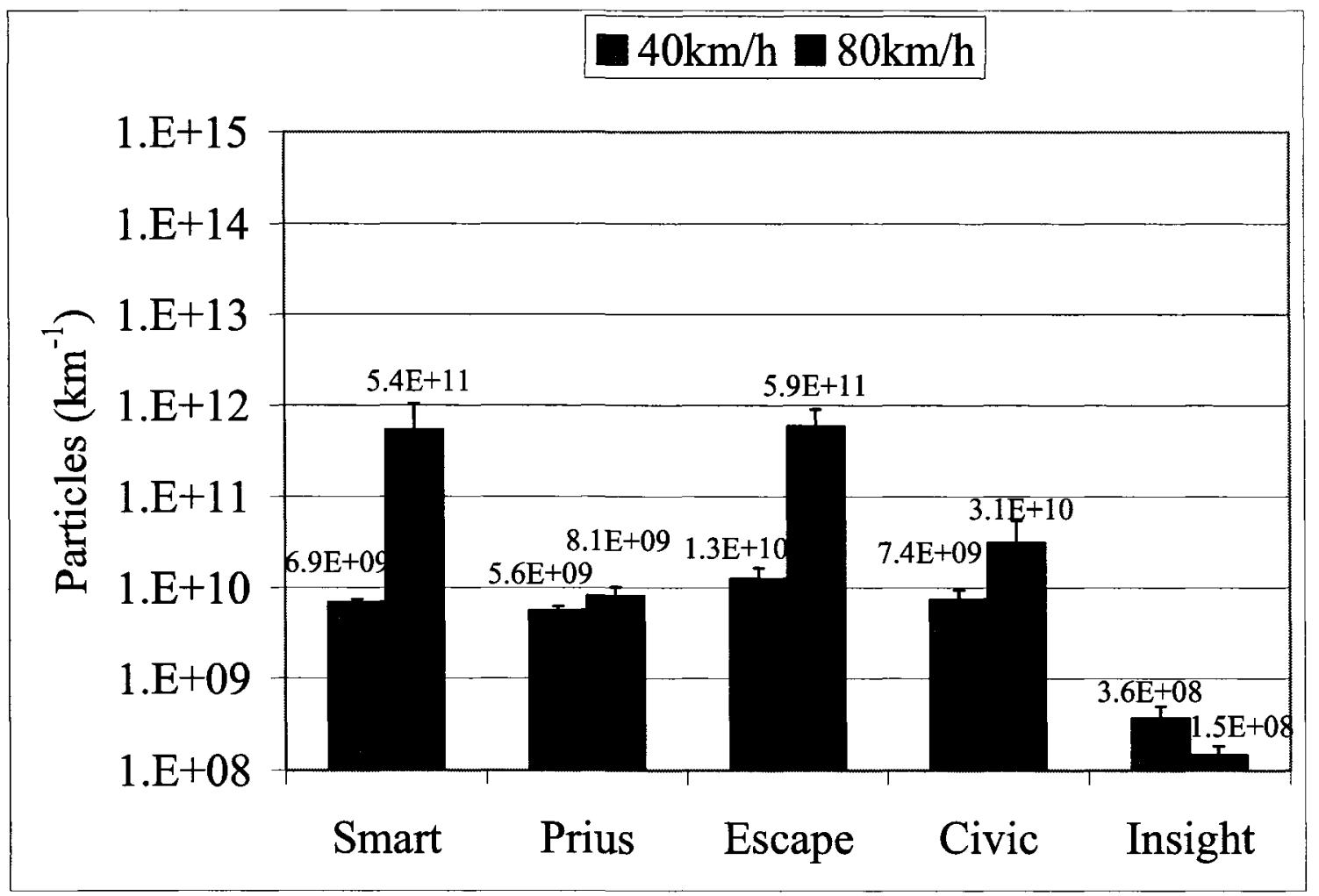

Figure 6.2.3 - Integrated steady-state emission rates \pm 1 standard deviation at $-18^{\circ} \mathrm{C}$ 


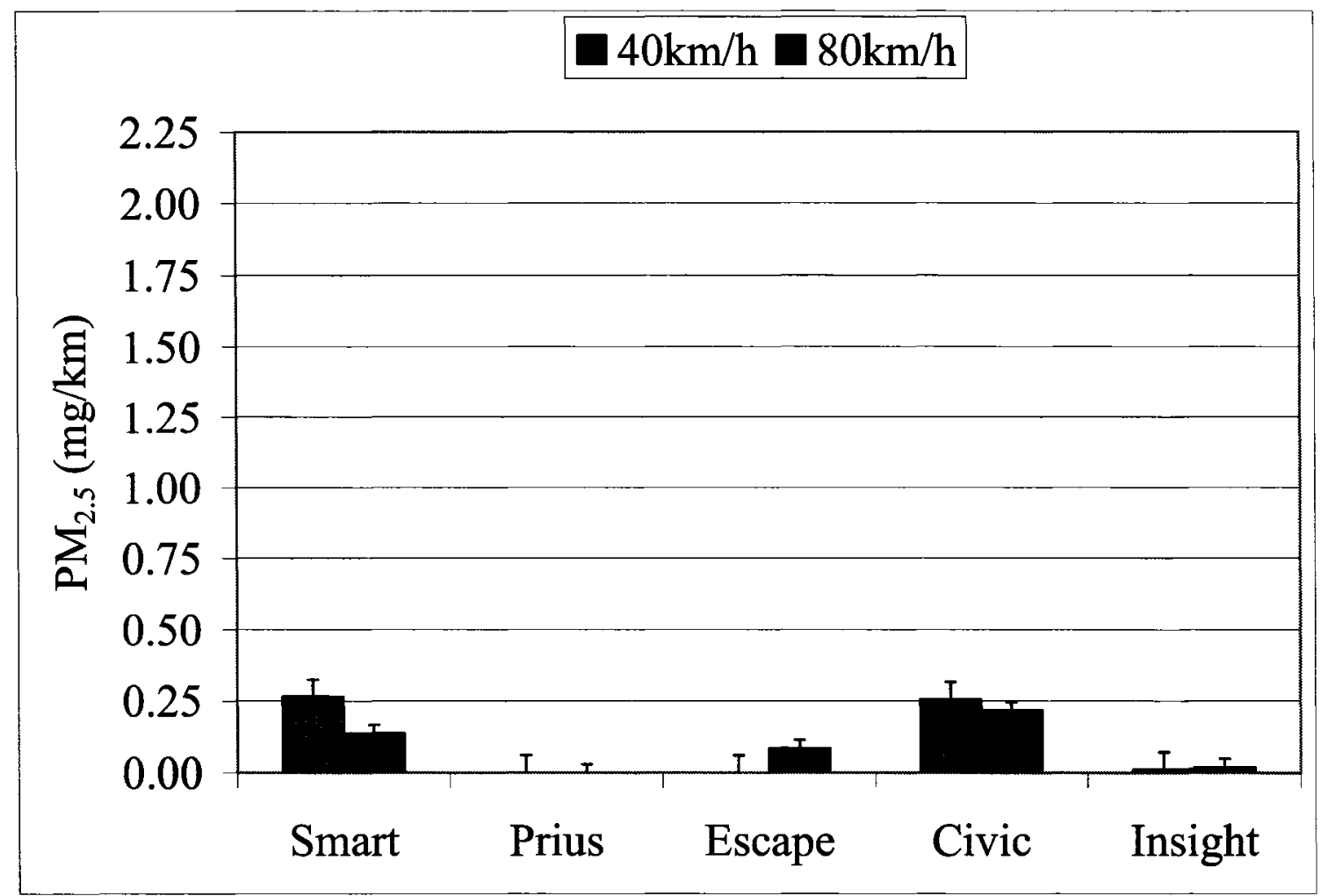

Figure 6.2.4 - Integrated steady-state emission rates \pm uncertainty at $20^{\circ} \mathrm{C}$

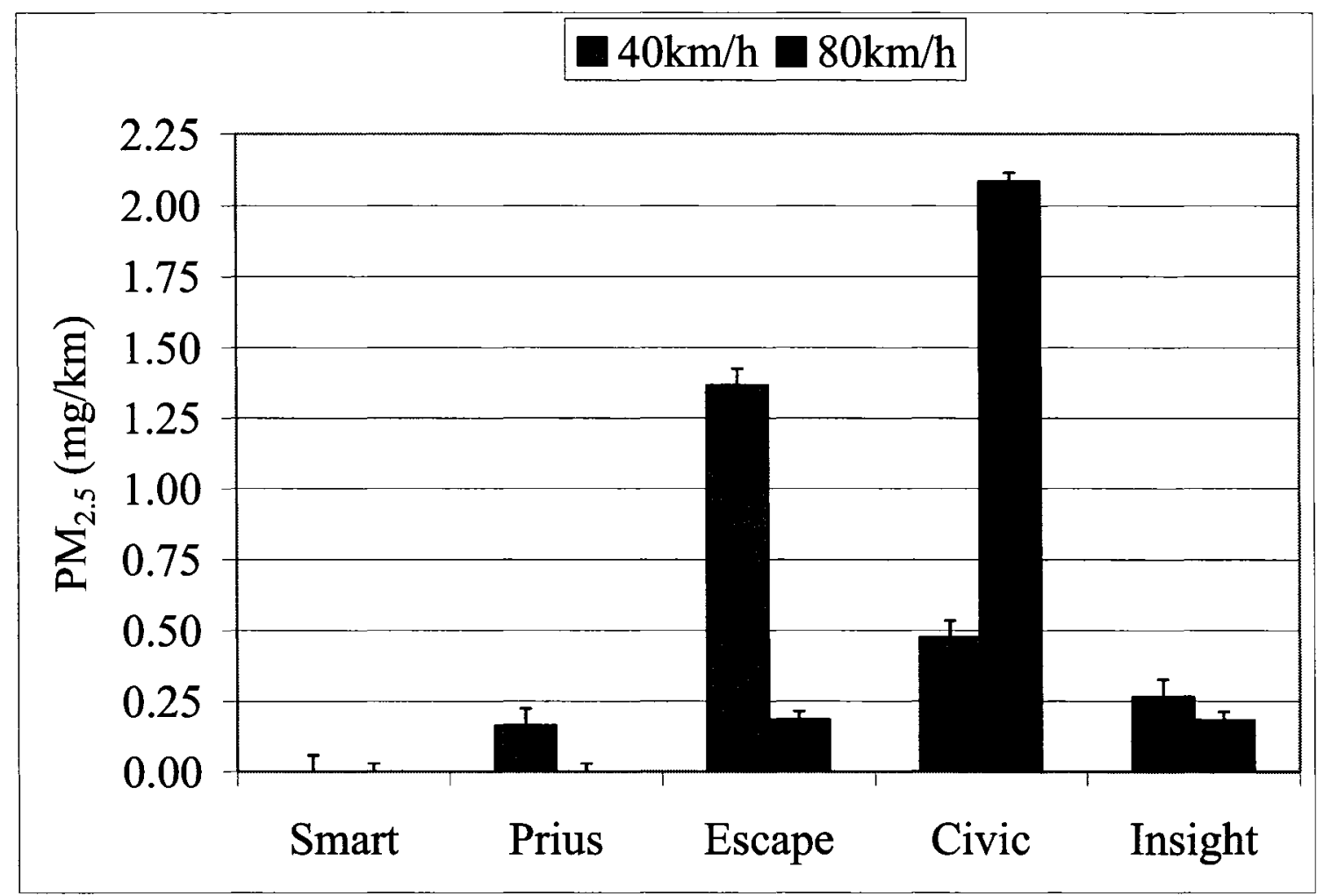

Figure 6.2.5 - Integrated steady-state emission rates \pm uncertainty at $-18^{\circ} \mathrm{C}$ 


\subsubsection{Impact of Driving Cycle on Emission Rate}

Average integrated PM number emission rates from CPC data are shown in Figures 6.2.6 and 6.2.7 for four driving cycles: the LA4HS, NYCC, US06, and HWFET. These cycles represent a non-demanding style of urban driving (LA4HS), highly congested urban driving (NYCC), aggressive high speed driving with hard accelerations and decelerations (US06), and free-flow highway driving (HWFET). Average integrated $\mathrm{PM}_{2.5}$ mass emission rates from filter data are shown for the same four cycles in Figures 6.2.8 and 6.2.9. Results of the LA92 cycle, which is similar to the LA4 but with more transients and higher speeds, will be discussed in the following section along with cold-start data (LA4CS/LA4HS and LA92CS/LA92HS).

Emission rates reported here are distance-based. It is important to note that cycle to cycle relative emission rates could change depending on the type of emission rate (distancebased, fuel-based, time-based etc.). The NYCC covers only $3.8 \mathrm{~km}$ in a 20 minute test time, and distance based emission rates for this cycle can therefore be high relative to other types of emission rates.

\section{Number Emission Rates}

In general, number emission rates of the transient cycles discussed here were at least an order of magnitude higher than those of the steady-state cycles. Emission rates from the US06 cycle and HWFET cycle, which have average speeds of approximately $80 \mathrm{~km} / \mathrm{h}$, are compared to the steady-state $80 \mathrm{~km} / \mathrm{h}$ (SS80) emission rates in Table 6.2.2. Because the 
cycles have similar average speeds, this comparison highlights the effect of transient operation. The HWFET, which is a fairly steady speed test but includes several hard accelerations and small speed variations throughout, had emission rates that were a minimum of 2 and a maximum of 400 times higher than the SS80 emission rates. The effect of transients was even more obvious when the US06 was compared to the SS80 emission rates were a minimum of 20 and a maximum of 8400 times higher for the US06. The effect was stronger for the hybrids than for the conventional IC engine Smart. It should be noted that number emission rates of the hybrid vehicles on the US06 exceeded the upper concentration limit of the CPC on several occasions and thus, the US06 emission rates reported here are actually lower than the true emission rates.

Between driving cycles, number emission rates at $20^{\circ} \mathrm{C}$ were generally highest for the US06, then NYCC, then LA4HS, and finally the HWFET. Exceptions to this were the Civic, which had very low emissions on the LA4HS and had nearly equal emission rates on the NYCC and HWFET, as well as the Escape which had similar emission rates for the LA4HS and HWFET. The Smart showed only slight differences between emission rates on the LA4HS, NYCC, and US06 but the HWFET emission rate was significantly lower than the others. Compared to the conventional gasoline engine Smart, the hybrids had lower number emission rates on the LA4HS, NYCC, and HWFET. In particular, the Civic and Insight had very low emissions over the LA4HS cycle. On the US06 driving cycle, however, the number emission rates of the hybrids were especially high. They exceeded emission rates of the Smart on the same cycle by at least an order of magnitude. 
At $-18^{\circ} \mathrm{C}$, compared to at $20^{\circ} \mathrm{C}$, the conventional IC engine Smart had higher number emission rates for all driving cycles. The effect was minimized for the HWFET, US06 and steady-state tests, presumably because the engine warmed up faster for these tests due to high speeds and/or a pre-cycle drive (the HWFET, SS40, and SS80 follow a precycle warm-up drive). The hybrid vehicles, on the other hand, did not necessarily have higher number emission rates at cold ambient temperature. Most notably, the hybrid vehicle US06 emission rates were much lower at $-18^{\circ} \mathrm{C}$ compared to at $20^{\circ} \mathrm{C}$. 


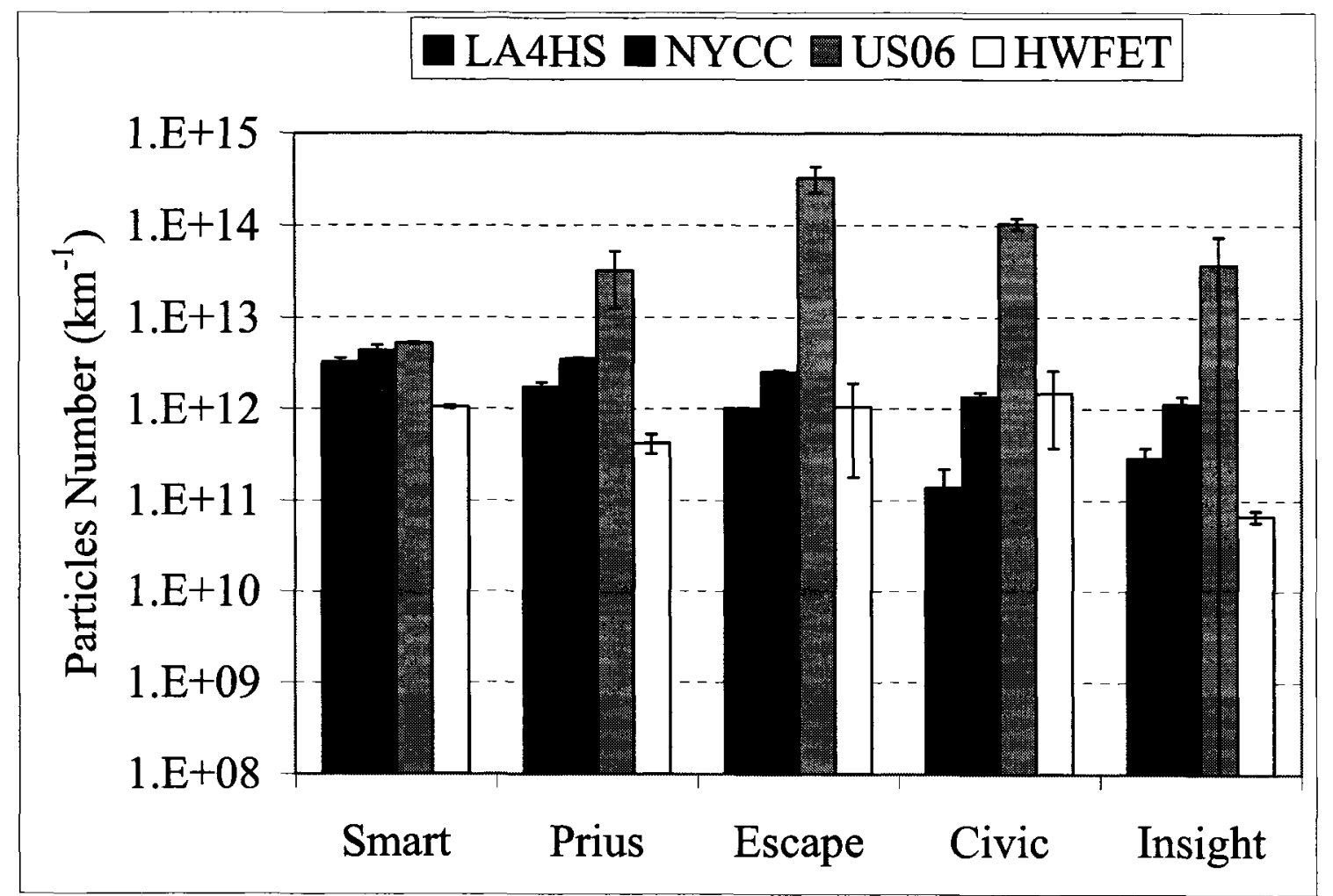

Figure 6.2.6 - Average PM number emission rates \pm 1 standard deviation at $20^{\circ} \mathrm{C}$ : impact of driving cycle

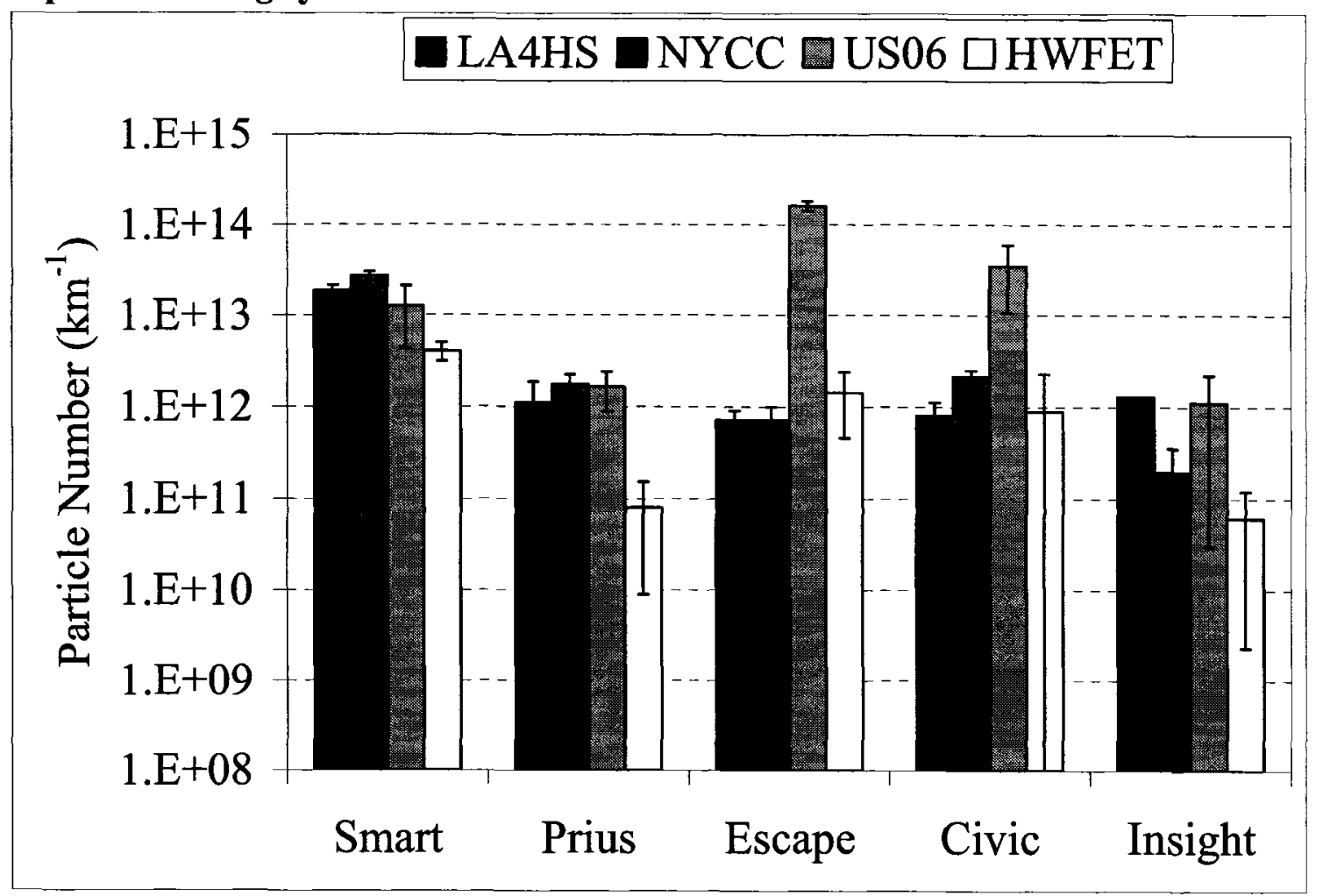

Figure 6.2.7 - Average PM number emission rates \pm 1 standard deviation at $-18^{\circ} \mathrm{C}$ : impact of driving cycle 
Table 6.2.2 - Ratio of US06 and HWFET number emission rates $\left(\mathrm{km}^{-1}\right)$ to $80 \mathrm{~km} / \mathrm{h}$ steady-state emission rate

\begin{tabular}{|c|c|c|c|}
\hline Temperature & Vehicle & US06/SS80 & HWFET/SS80 \\
\hline & Smart & 170 & 35 \\
& Prius & 2400 & 31 \\
$\mathbf{2 0}^{\circ} \mathbf{C}$ & Escape & NA & NA \\
& Civic & 1100 & 15 \\
& Insight & 8400 & 15 \\
\hline \multirow{3}{*}{$\mathbf{- 1 8}^{\circ} \mathbf{C}$} & Smart & 24 & 7.6 \\
& Prius & 200 & 9.9 \\
& Escape & 280 & 2.4 \\
& Civic & 1100 & 29 \\
& Insight & 7700 & 430 \\
\hline
\end{tabular}

\section{Mass Emission Rates}

Average integrated $\mathrm{PM}_{2.5}$ mass emission rates ( \pm 1 standard deviation) are shown in Figures 6.2.8 and 6.2.9. These emission rates are in general quite low, and have fairly high standard deviations.

At $20^{\circ} \mathrm{C}$, emission rates on all four cycles were, for the most part, not notably different. One obvious exception is the emission rate of the Escape Hybrid on the US06 cycle. This emission rate was at least five times higher than for the other vehicles on the same cycle. This result agrees with the exceptionally high number emission rate that was observed for the Escape on the US06 (Figure 6.2.6). This result could be explained by the larger engine size and greater mass of this vehicle compared to the others. It is worthwhile to note that this vehicle also had the highest measured fuel consumption of the vehicles on all test cycles. The US06 was, however, the only test cycle over which the Escape had much higher PM emission rates than the other vehicles. 
Mass emission rates from the Smart, like its number emission rates, were increased at cold ambient temperature. The Insight also showed increased mass emission rates at cold ambient temperature except on the HWFET at $-18^{\circ} \mathrm{C}$ when the mass emission rate was below the detection limit. No notable effect of ambient temperature was observed for the other vehicles.

The California LEV II PM emission standards for ultra low-emissions vehicles (ULEV) and super ultra low-emissions vehicles (SULEV) for $\mathrm{PM}_{2.5}$ mass emission rate based on the composite FTP at $20^{\circ} \mathrm{C}$ is $6.2 \mathrm{mg} / \mathrm{km}$. As described in Chapter 4 , the composite FTP emission rate is calculated by adding cold- and hot-start LA4 emission rates weighted by 0.43 and 0.57 respectively. These are summarized in Table 6.2 .3 for the current study. Clearly, the vehicles studied have emission rates well below this standard. The standard applies to testing at $20^{\circ} \mathrm{C}$, but it is interesting to see that at $-18^{\circ} \mathrm{C}$ the emission rates are much higher. This is primarily due to the high cold-start emission rates that were observed at low ambient temperature. 


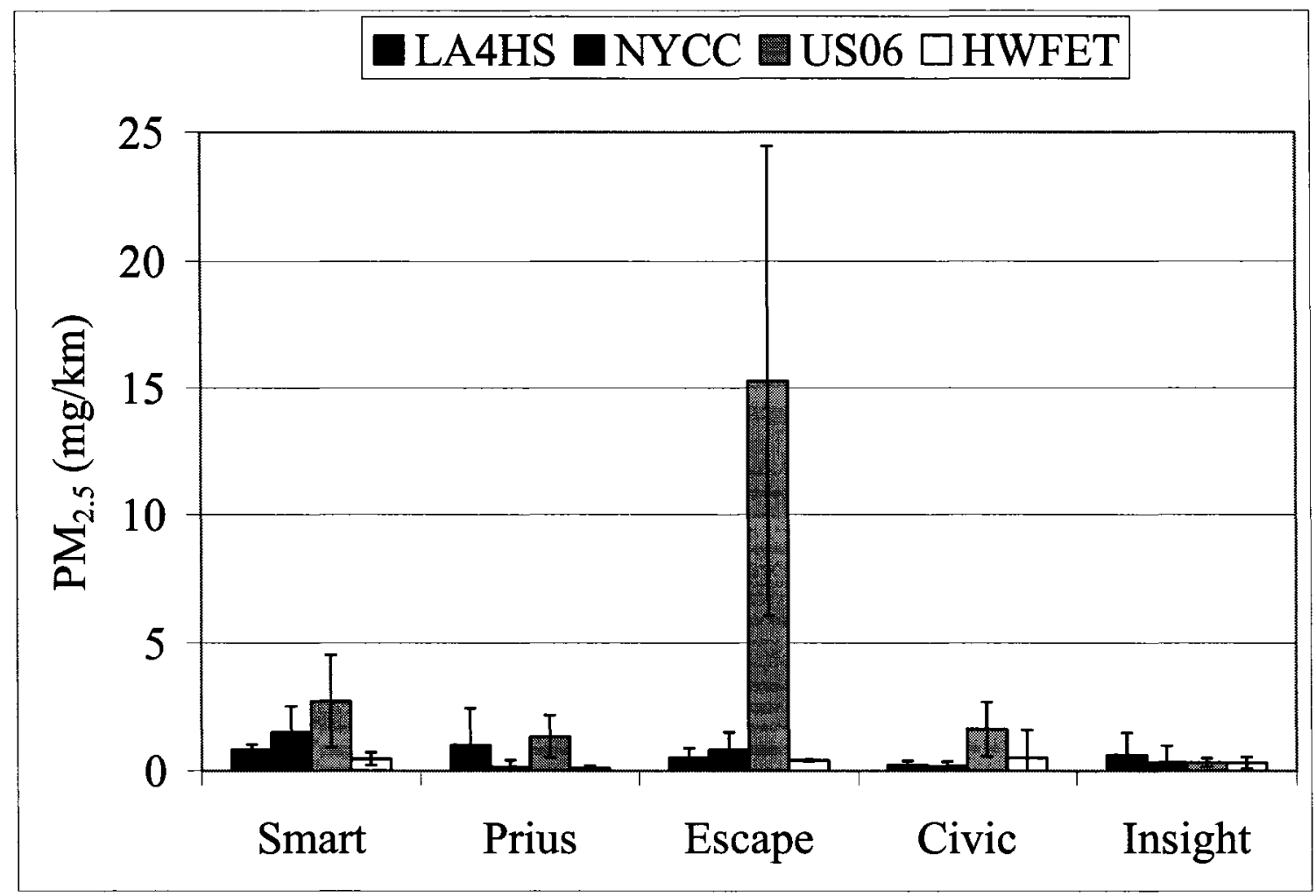

Figure 6.2.8 - Average total $P_{2.5}$ mass emission rates \pm 1 standard deviation at $20^{\circ} \mathrm{C}$ : impact of driving cycle

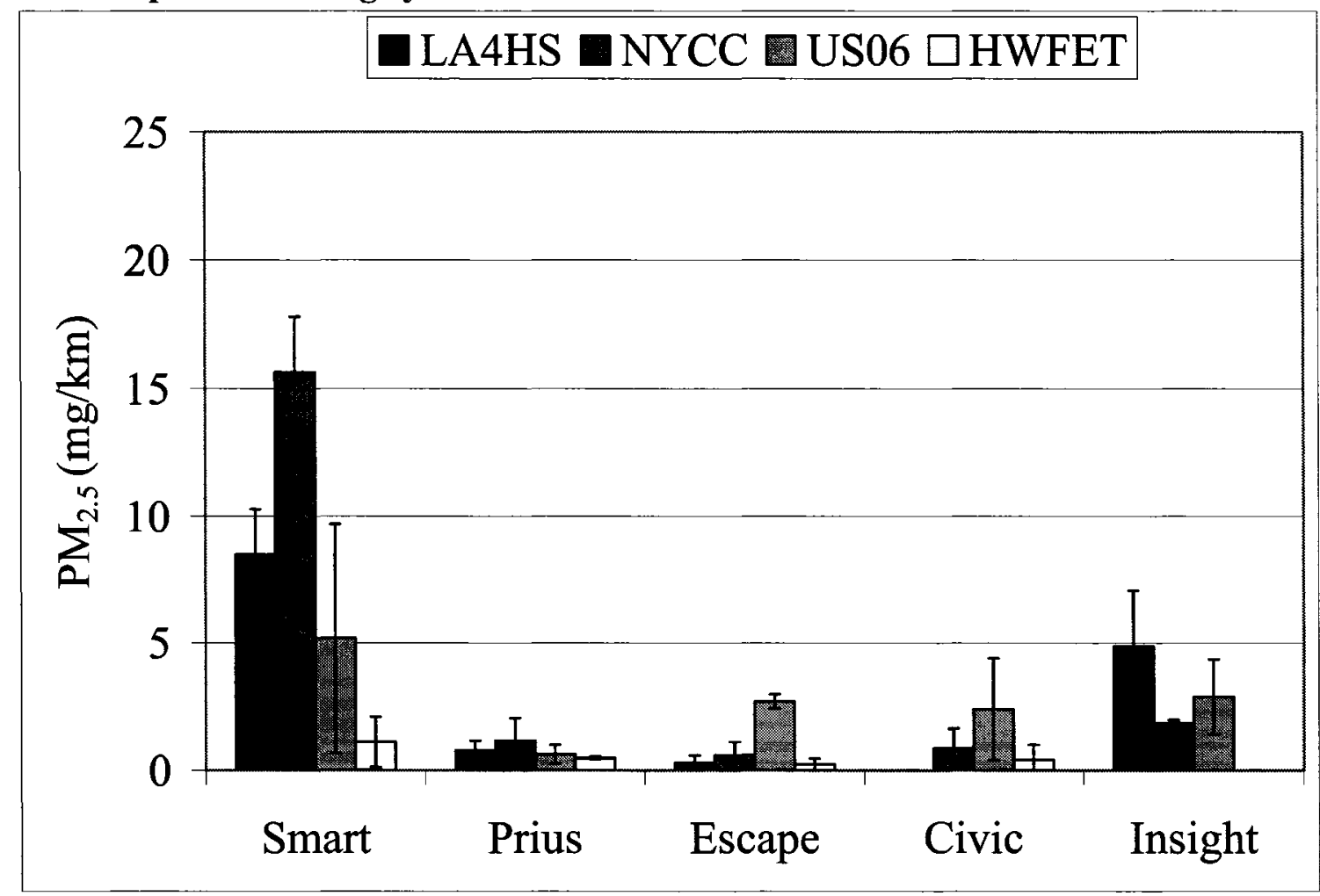

Figure 6.2.9 - Average total $P M_{2.5}$ mass emission rates \pm 1 standard deviation at $18^{\circ} \mathrm{C}$ : impact of driving cycle 
Table 6.2.3 - FTP composite emission rates

\begin{tabular}{|c|c|c|c|}
\hline \multirow{3}{*}{ Temperature } & \multirow{2}{*}{ Vehicle } & \multicolumn{2}{|c|}{ FTPcomp Emission Rate } \\
\cline { 3 - 4 } & & $\begin{array}{c}\text { Average } \\
\text { (mg/km) }\end{array}$ & $\begin{array}{c}\text { Stdev } \\
\text { (mg/km) }\end{array}$ \\
\hline \multirow{3}{*}{$\mathbf{2 0}^{\circ} \mathbf{C}$} & Smart & 4.50 & 0.46 \\
& Prius & 0.99 & 1.27 \\
& Escape & 0.75 & 0.33 \\
& Civic & 2.34 & 2.43 \\
& Insight & 0.62 & 0.88 \\
\hline \multirow{3}{*}{$\mathbf{1 8}^{\circ} \mathbf{C}$} & Smart & 73.26 & 4.73 \\
& Prius & 8.49 & 6.02 \\
& Escape & 7.18 & 1.67 \\
& Civic & 12.15 & 0.39 \\
& Insight & 10.28 & 3.51 \\
\hline
\end{tabular}

*The California LEV II ULEV and SULEV light duty vehicle standard is $6.2 \mathrm{mg} / \mathrm{km}$

\section{Organic and Elemental Carbon Emission Rates}

As detailed in Chapter 4, the $\mathrm{PM}_{2.5}$ mass collected on quartz filters was analyzed for elemental carbon (EC) and organic carbon (OC) content by the Thermal Optical Transmittance (TOT) method. The organic and elemental carbon emission rates that correspond to the data presented for $\mathrm{PM}_{2.5}$ in the previous section are shown in Figures 6.2.10 $\left(20^{\circ} \mathrm{C}\right)$ and 6.2.11 $\left(-18^{\circ} \mathrm{C}\right)$. Again, results for the LA4HS, NYCC, US06, and HWFET driving cycles are shown. Organic carbon emissions are a result of over-fuelling (ie. unburned hydrocarbons) while elemental carbon emissions are usually caused by hard accelerations. Compared to gasoline engine emissions, diesel engine carbon emissions generally contain a higher proportion of EC.

In general, results from this analysis agreed with those of the total $\mathrm{PM}_{2.5}$ analysis with total carbon emission rates (organic + elemental) measured by the TOT method being close to the total $\mathrm{PM}_{2.5}$ emission rates. In cases where $\mathrm{PM}_{2.5}$ mass exceeds total carbon mass, the extra mass can be attributed to metals, sulphates, and the hydrogen which 
accompanies the organic carbon fraction. It is interesting to note that the variability in elemental and organic carbon emission rates (shown by the standard deviation bars in Figures 6.2.10 and 6.2.11) was much lower than that of total $\mathrm{PM}_{2.5}$ emission rates (shown in Figures 6.2.8 and 6.2.9). This could indicate that sulphate or metal particles were causing the high variability in $\mathrm{PM}_{2.5}$ mass emission rate.

The vehicles had distinct $\mathrm{OC} / \mathrm{EC}$ compositions. At $20^{\circ} \mathrm{C}$, total carbon emissions of the Smart were composed of between 80 and $90 \%$ elemental carbon. The Escape emissions also showed high elemental carbon content but only on the LA4HS, NYCC, and HWFET. On the US06 the organic carbon content was much higher. In contrast, elemental carbon made up less than $40 \%$ of carbon emissions for the Prius, Civic, and Insight. For these vehicles, elemental carbon made up an especially low proportion of total carbon on the NYCC. This could be because the hybrid system was used to smooth transients during this cycle.

At low ambient temperature (Figure 6.2.11), both $\mathrm{EC}$ and $\mathrm{OC}$ emission rates were increased for the Smart. The percentage of EC present in the total carbon decreased for the LA4HS and US06 but increased for the NYCC and HWFET. EC composition remained in the $80-90 \%$ range. The Prius, Civic, and Insight all showed higher EC emission rates at $-18^{\circ} \mathrm{C}$ compared to at $20^{\circ} \mathrm{C}$, but the $\mathrm{OC}$ emission rates were not necessarily higher. EC compositions for these vehicles were much higher at cold ambient temperature: $70-90 \%$ for the Prius, $70-80 \%$ for the Civic, and $80-100 \%$ for the Insight. For the Escape, EC emission rates actually decreased at $-18^{\circ} \mathrm{C}$ and $\mathrm{EC}$ composition decreased for the LA4HS and NYCC but increased for the US06 and HWFET. At $-18^{\circ} \mathrm{C}$, 
the EC composition of carbon emissions from the Escape ranged between 60 and $90 \%$, much like the other vehicles.

Tables and graphs presenting further analysis of mass emission rates of total $\mathrm{PM}_{2.5}$, organic carbon, and elemental carbon can be found in Appendix 4. 

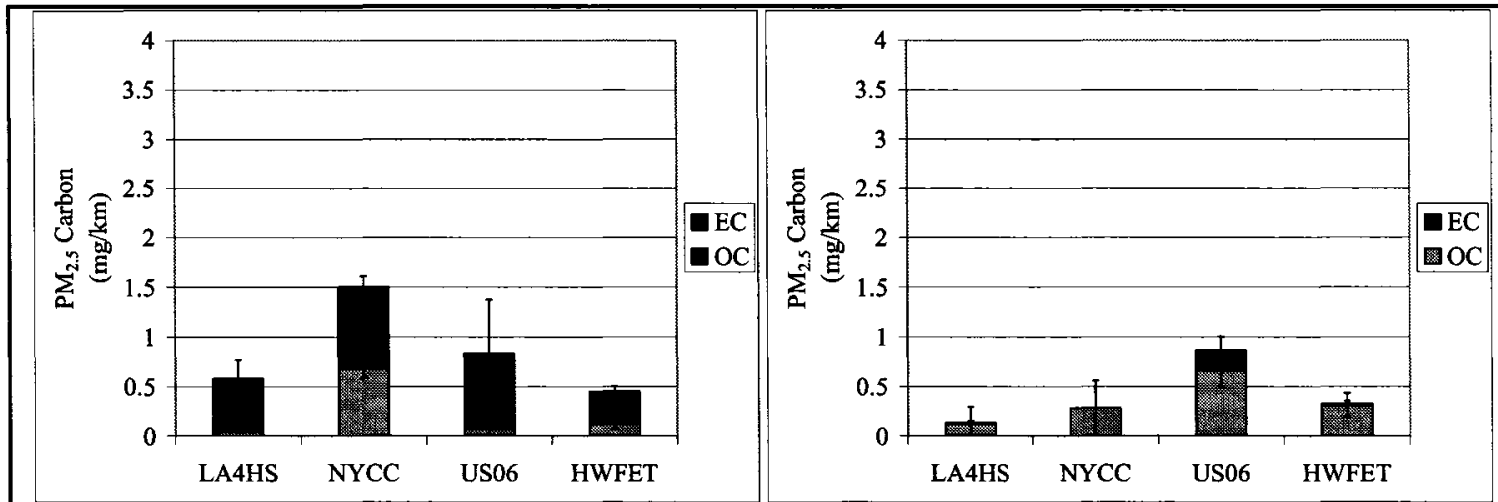

(a) Smart

(b) Prius
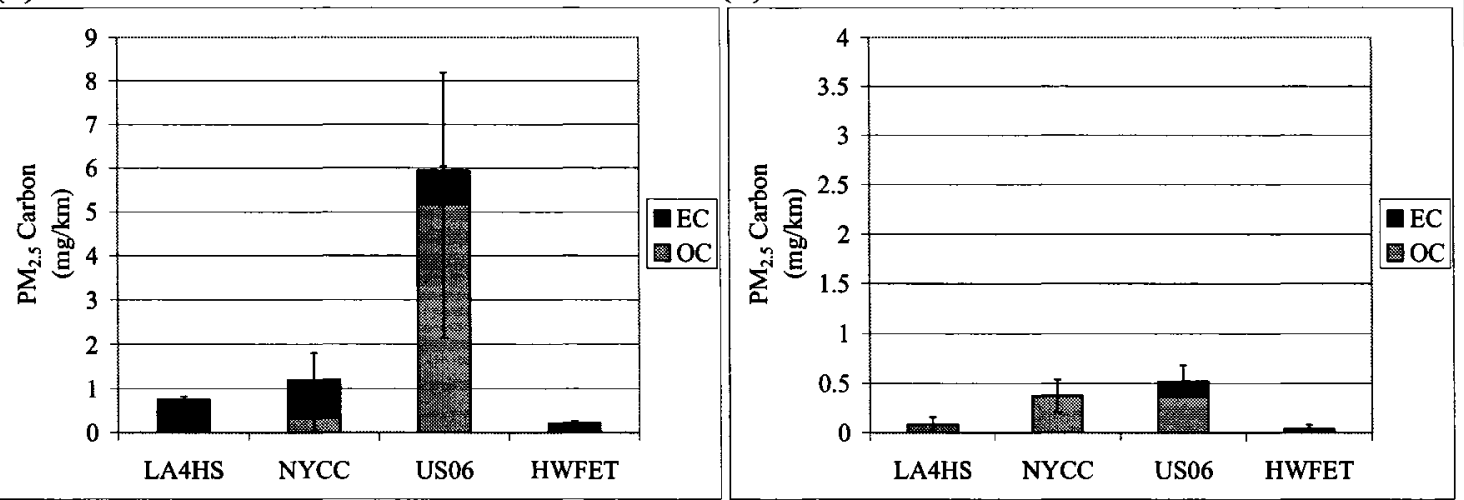

(c) Escape $(*$ note scale difference)

(d) Civic

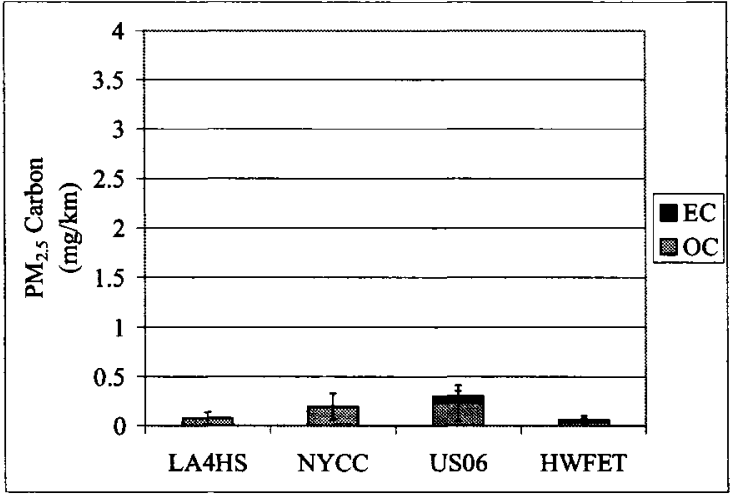

(e) Insight

Figure 6.2.10 - Average organic and elemental carbon emission rates \pm 1 standard deviation at $20^{\circ} \mathrm{C}$ : impact of driving cycle 

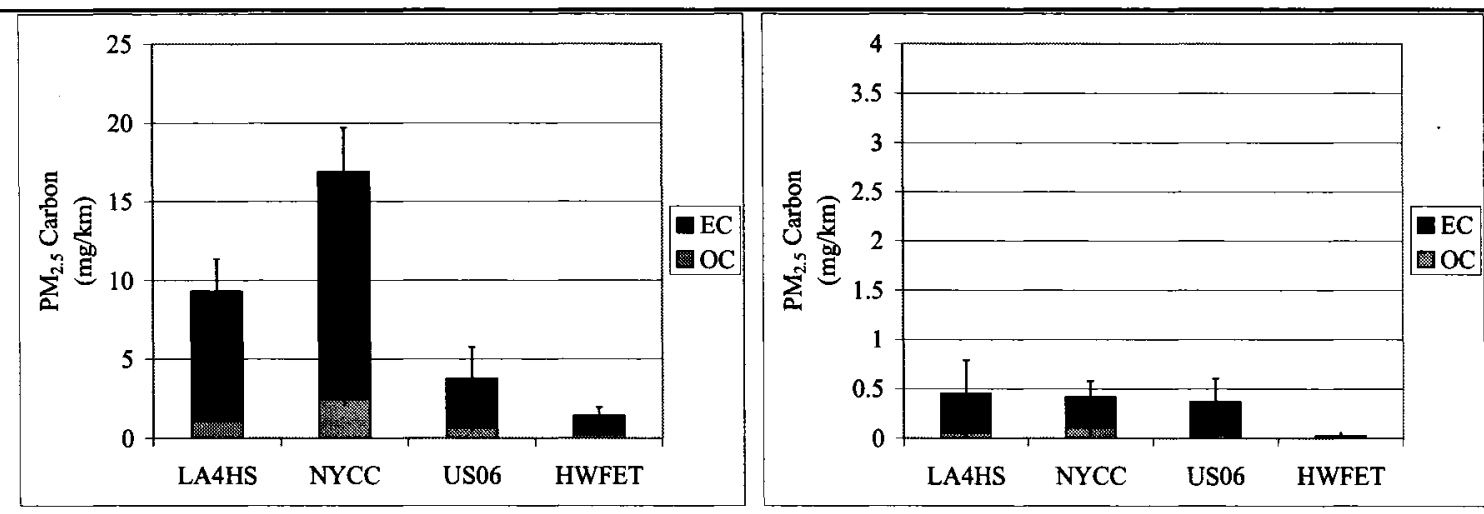

(a) Smart (*note scale difference)

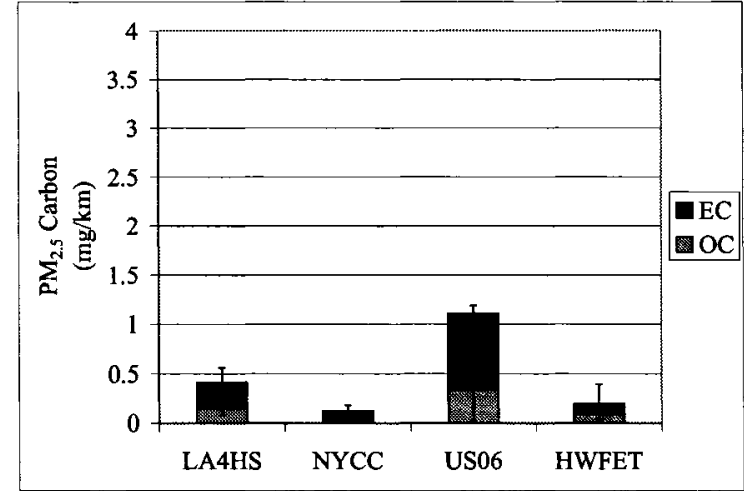

(b) Prius

(c) Escape

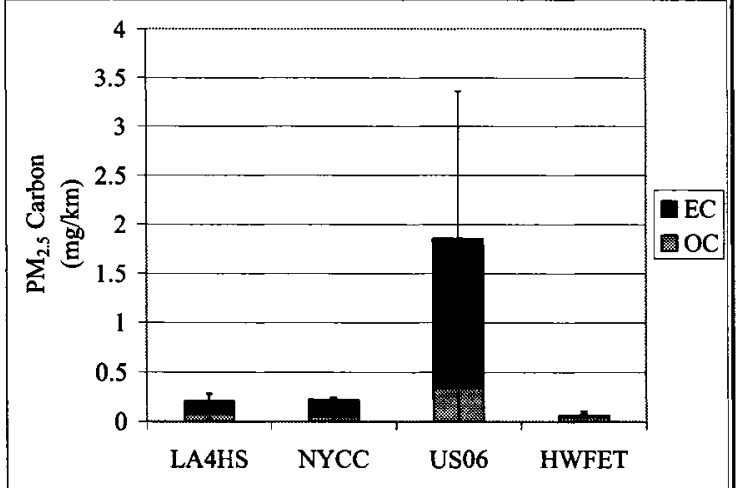

(d) Civic

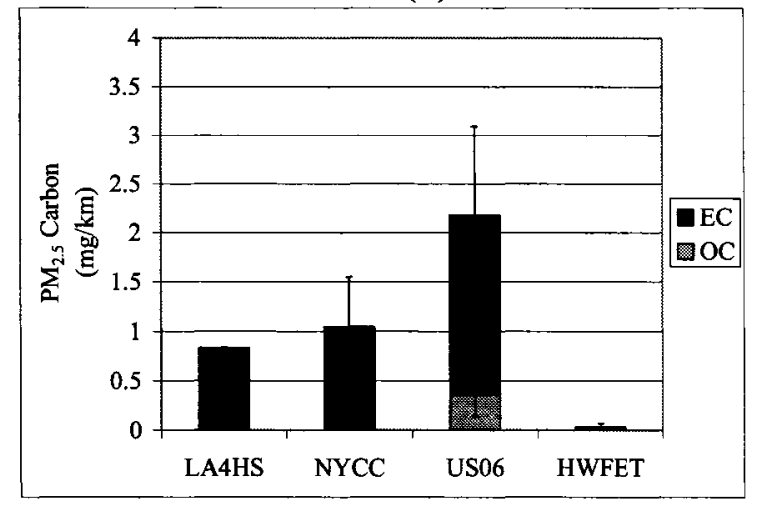

(e) Insight

Figure 6.2.11 - Average organic and elemental carbon emission rates \pm 1 standard deviation at $-18^{\circ} \mathrm{C}$ : impact of driving cycle

\subsubsection{Impact of Driving Cycle on Size Distribution}

From a comparison of CPC and ELPI total emission rates (Appendix 3), it is clear that the vehicles in this study emit particles that are below the ELPI cut-off diameter of $30 \mathrm{~nm}$ : CPC emission rates are often slightly higher than those of ELPI, and in some cases much 
higher. The CPC cut-off size is $7 \mathrm{~nm}$. This section includes a summary of normalized particle size distributions for each vehicle on the same driving cycles as discussed in the previous section: the LA4HS, NYCC, US06, and HWFET. Because many particles are below the lower ELPI cut-off size, the results of this study cannot be used to find mean particle sizes or other distribution parameters. One can, however, observe the relative proportions of particles in the available size bins and estimate where the mean may fall based on a lognormal distribution (typical exhaust PM size distribution as discussed in Chapter 2).

The average size distributions, normalized to total particle number, for each vehicle and temperature $\left(20^{\circ} \mathrm{C}\right.$ or $\left.-18^{\circ} \mathrm{C}\right)$ are shown in Figures 6.2 .12 to 6.2 .21 . In order to simplify the Figures, standard deviations are not shown here, but are available along with tabulated averages in Appendix 5. With a few exceptions, vehicle identity had a stronger impact on size distribution than did driving cycle. The Smart had quite consistent size distributions across the four driving cycles. However, the mean particle size was clearly shifted towards a larger diameter at $-18^{\circ} \mathrm{C}$ compared to at $20^{\circ} \mathrm{C}$. Results for the four hybrids varied more with driving cycle, but still appeared to depend less on driving style than on vehicle identity. The Prius and Insight had between 70 and $90 \%$ of particles in the lowest size bin for all driving cycles except the HWFET. On this cycle, both vehicles showed more particles in the larger size ranges. It should be noted that emissions for these vehicles on the HWFET were low, and standard deviations were higher than usual. For this test, accumulation mode particles from the dilution air may have affected individual test results. The Civic had 55-95\% of particles in the lowest size bin with 
smallest particles emitted on the US06 and largest particles emitted on the LA4HS. The Escape had only $35-55 \%$ of particles in the smallest size bin with the distribution shifted to larger sizes when compared to the other vehicles. An exception was the US06, where the Escape emitted a higher proportion of particles in the smallest size bin.

As with the Smart, ambient temperature had an effect on particle size distributions for the hybrids. On most cycles at low ambient temperature $\left(-18^{\circ} \mathrm{C}\right)$, the Prius, Civic, and Insight emitted a higher proportion of particles in the larger size bins compared to at $20^{\circ} \mathrm{C}$, but without data in the lower size range it is difficult to tell whether or not the mean particle size would be larger or smaller at cold temperature. One exception was the Prius on the HWFET which emitted a high proportion of particles in the smallest size bin at $-18^{\circ} \mathrm{C}$ compared to at $20^{\circ} \mathrm{C}$. Unlike the other vehicles, the Escape actually emitted a higher proportion of small particles during cold temperature driving compared to warm temperature driving.

Although the smallest sized particles emitted by these vehicles were not counted by the ELPI, one can get an idea of the number of particles emitted between the ELPI lower cutoff size $(0.03 \mu \mathrm{m})$ and the CPC lower cut-off size $(0.007 \mu \mathrm{m})$ by comparing $\mathrm{CPC}$ and ELPI total number emission rates. This was done in Appendix 3. CPC number emission rates were often higher than those of ELPI, indicating high emission rates of nanoparticles less than $0.03 \mu \mathrm{m}$ in diameter. This was most often observed for the hybrids on the US06 cycle, and to a lesser extent on the HWFET. 
Particle size distribution could be influenced by many factors including engine parameters, temperature (Mathis et al., 2005), and dilution conditions. Some studies have shown particle size to be affected by the catalytic converter (Kim et al., 2001) while others did not observe this effect (D. Kayes \& Hochgreb, 1999b; Maricq, Chase, Xu, \& Podsiadlik, 2002). Clearly, ambient temperature had an effect on size distribution in this study with a higher proportion of larger particles being emitted at cold ambient temperature. The primary dilution ratio, which depends on the exhaust volume and hence on the engine displacement, varies from vehicle to vehicle and may have had an influence in determining particle size distribution for a given vehicle, regardless of the driving cycle. Size distribution effects that can be specifically attributed to hybrid technology were not observed. 


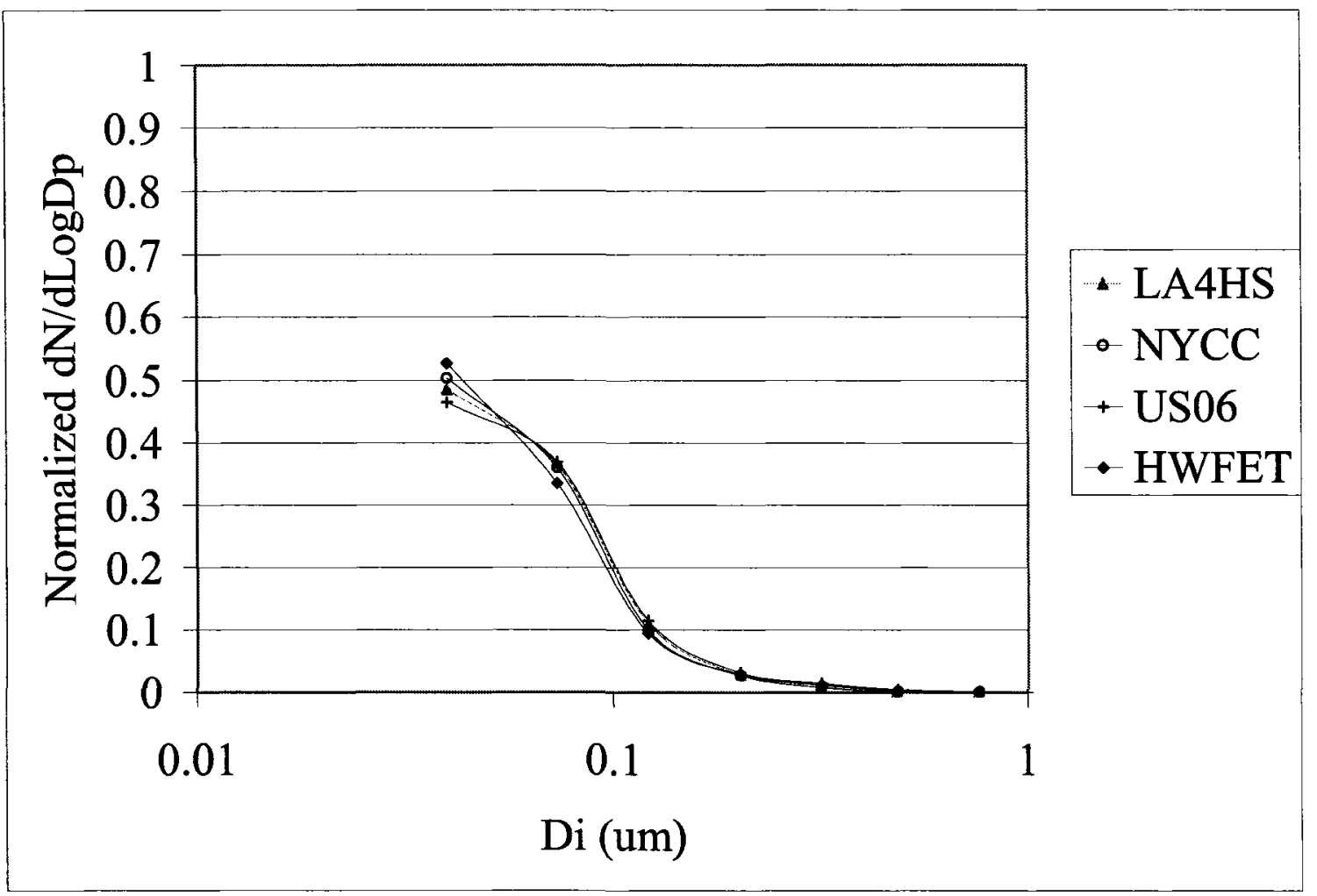

Figure 6.2.12 - Average integrated number-weighted size distribution for the Smart at $20^{\circ} \mathrm{C}$ : impact of driving cycle

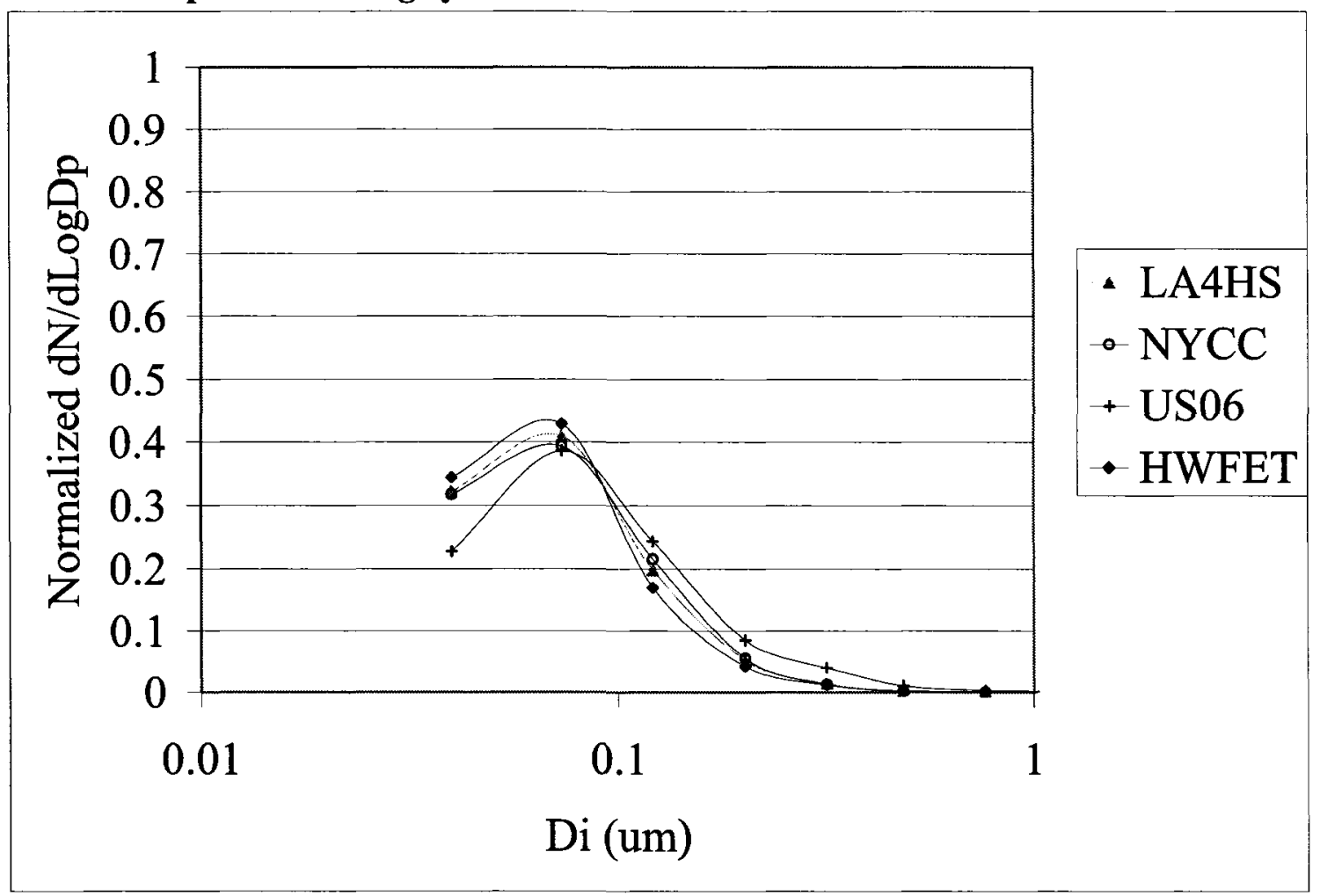

Figure 6.2.13 - Average integrated number-weighted size distribution for the Smart at $-18^{\circ} \mathrm{C}$ : impact of driving cycle 


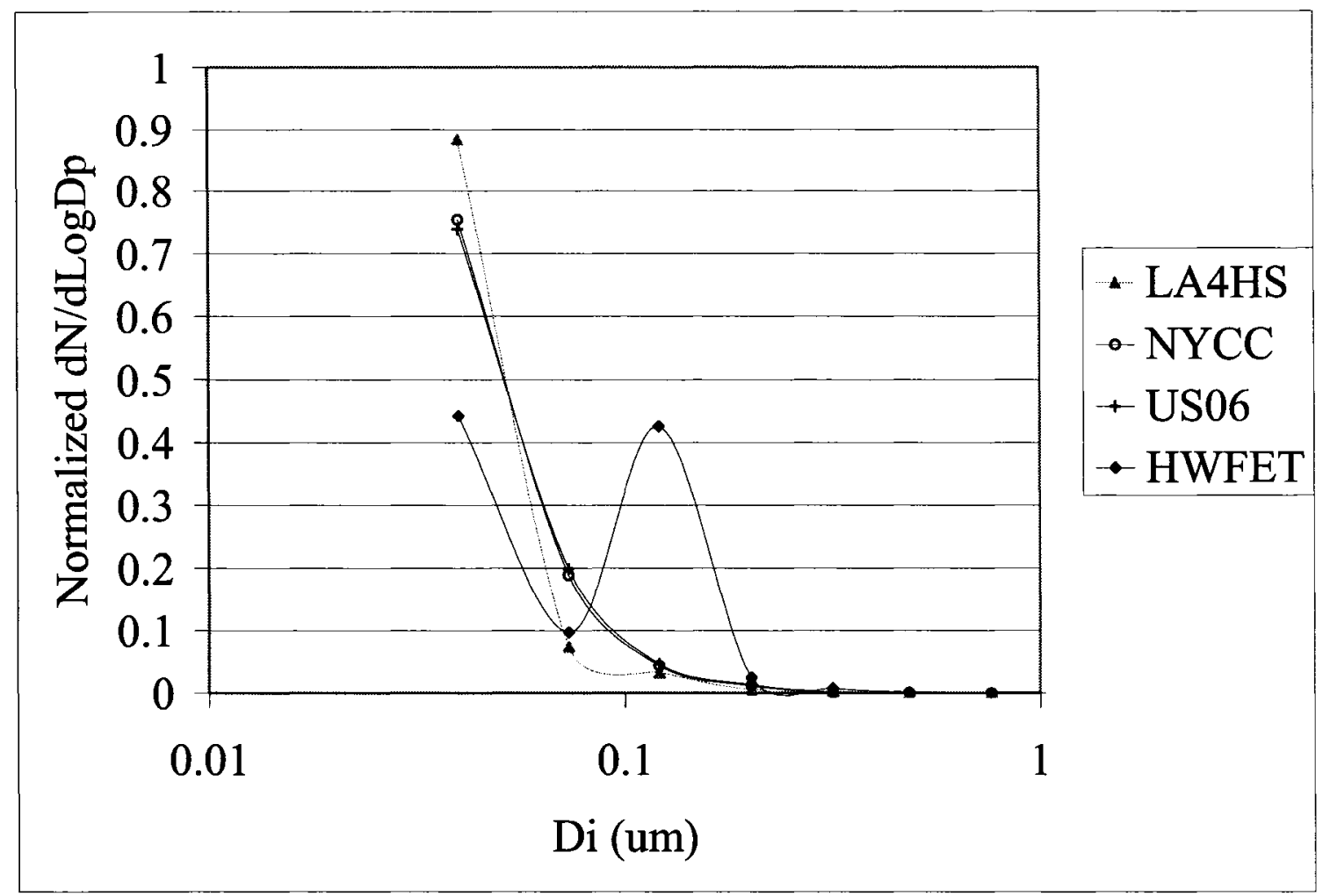

Figure 6.2.14 - Average integrated number-weighted size distribution for the Prius at $20^{\circ} \mathrm{C}$ : impact of driving cycle

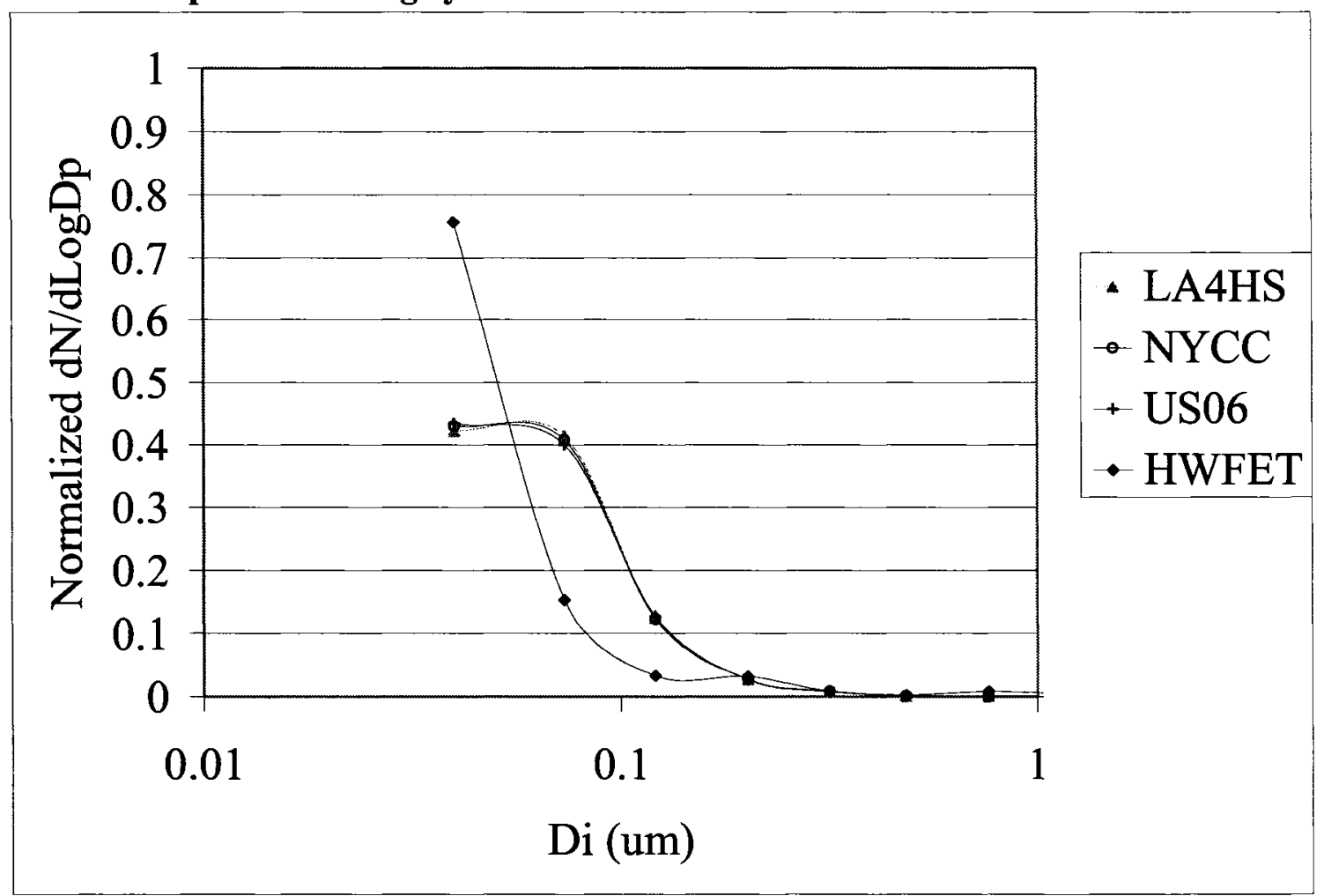

Figure 6.2.15 - Average integrated number-weighted size distribution for the Prius at $-18^{\circ} \mathrm{C}$ : impact of driving cycle 


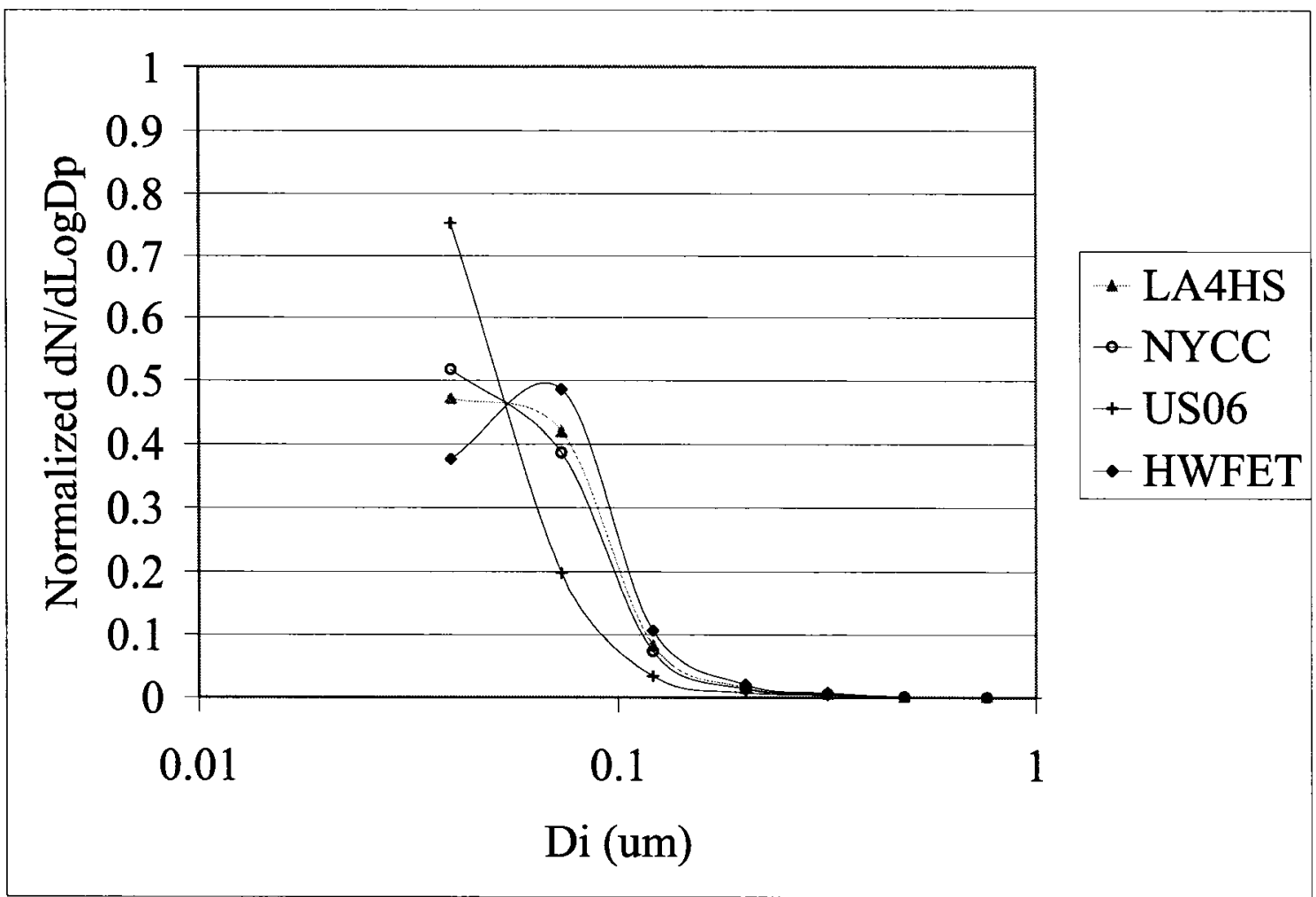

Figure 6.2.16 - Average integrated number-weighted size distribution for the Escape at $20^{\circ} \mathrm{C}$ : impact of driving cycle

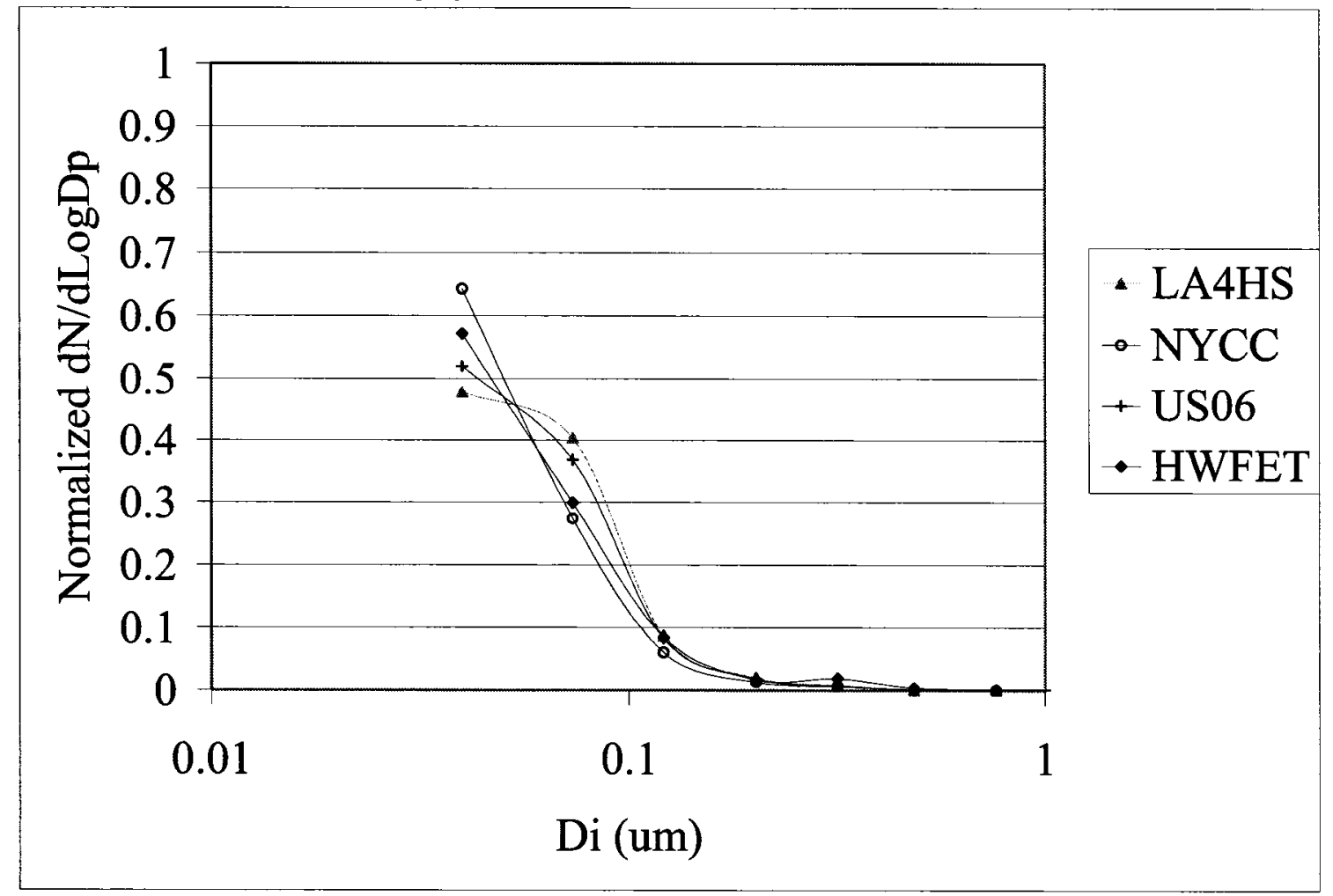

Figure 6.2.17 - Average integrated number-weighted size distribution for the Escape at $-18^{\circ} \mathrm{C}$ : impact of driving cycle 


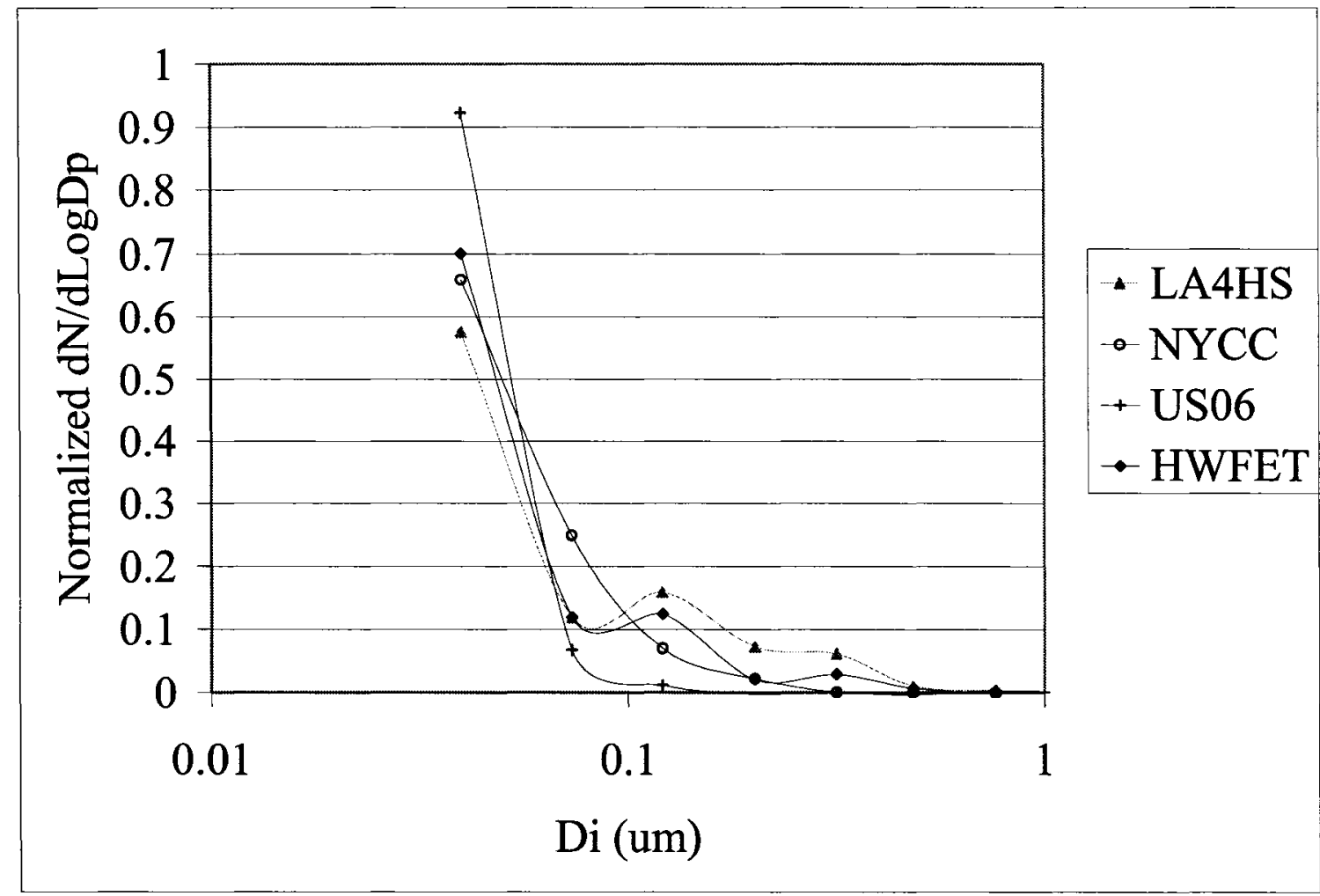

Figure 6.2.18 - Average integrated number-weighted size distribution for the Civic at $20^{\circ} \mathrm{C}$ : impact of driving cycle

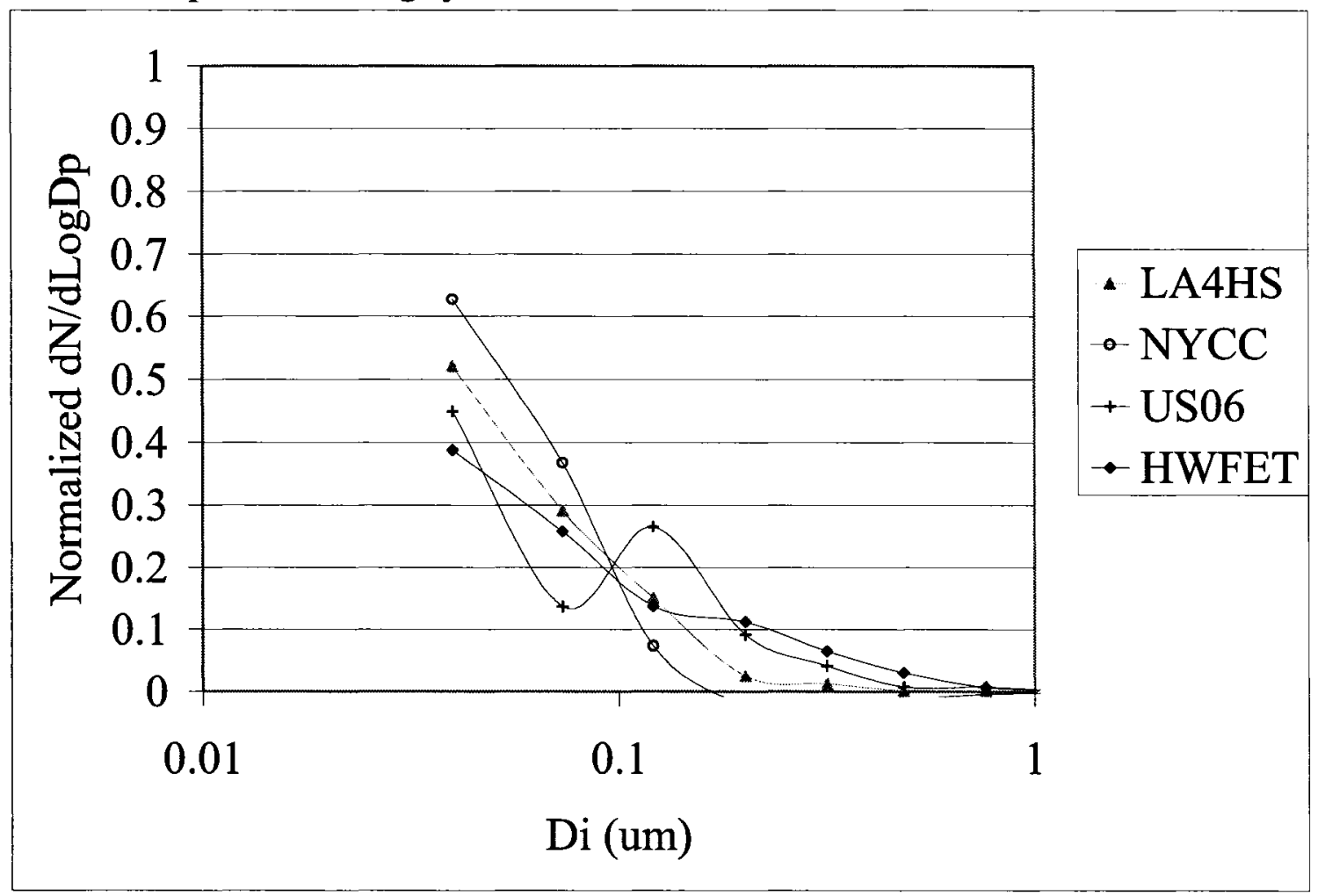

Figure 6.2.19 - Average integrated number-weighted size distribution for the Civic at $-18^{\circ} \mathrm{C}$ : impact of driving cycle 


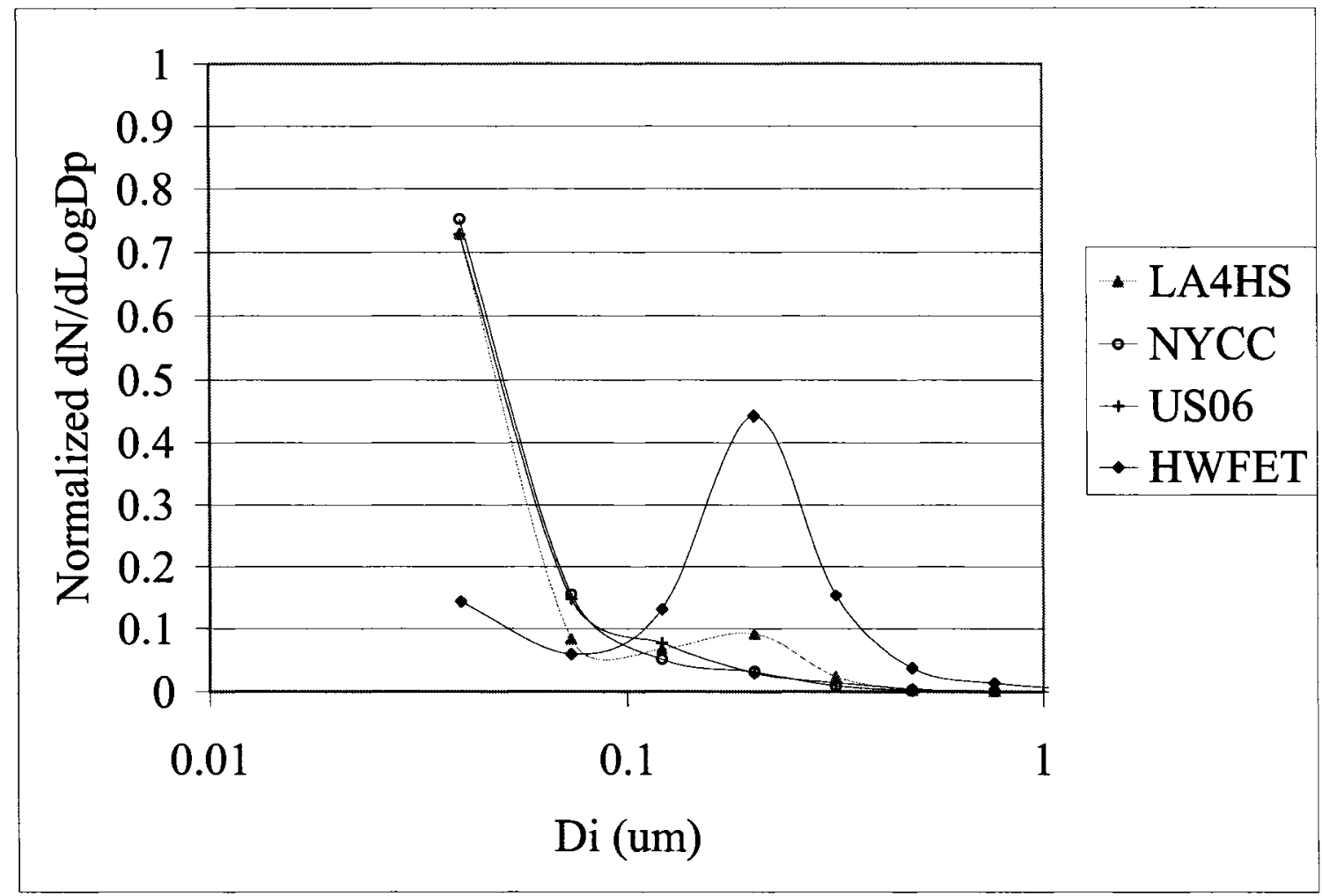

Figure 6.2.20 - Average integrated number-weighted size distribution for the Insight at 200C: impact of driving cycle

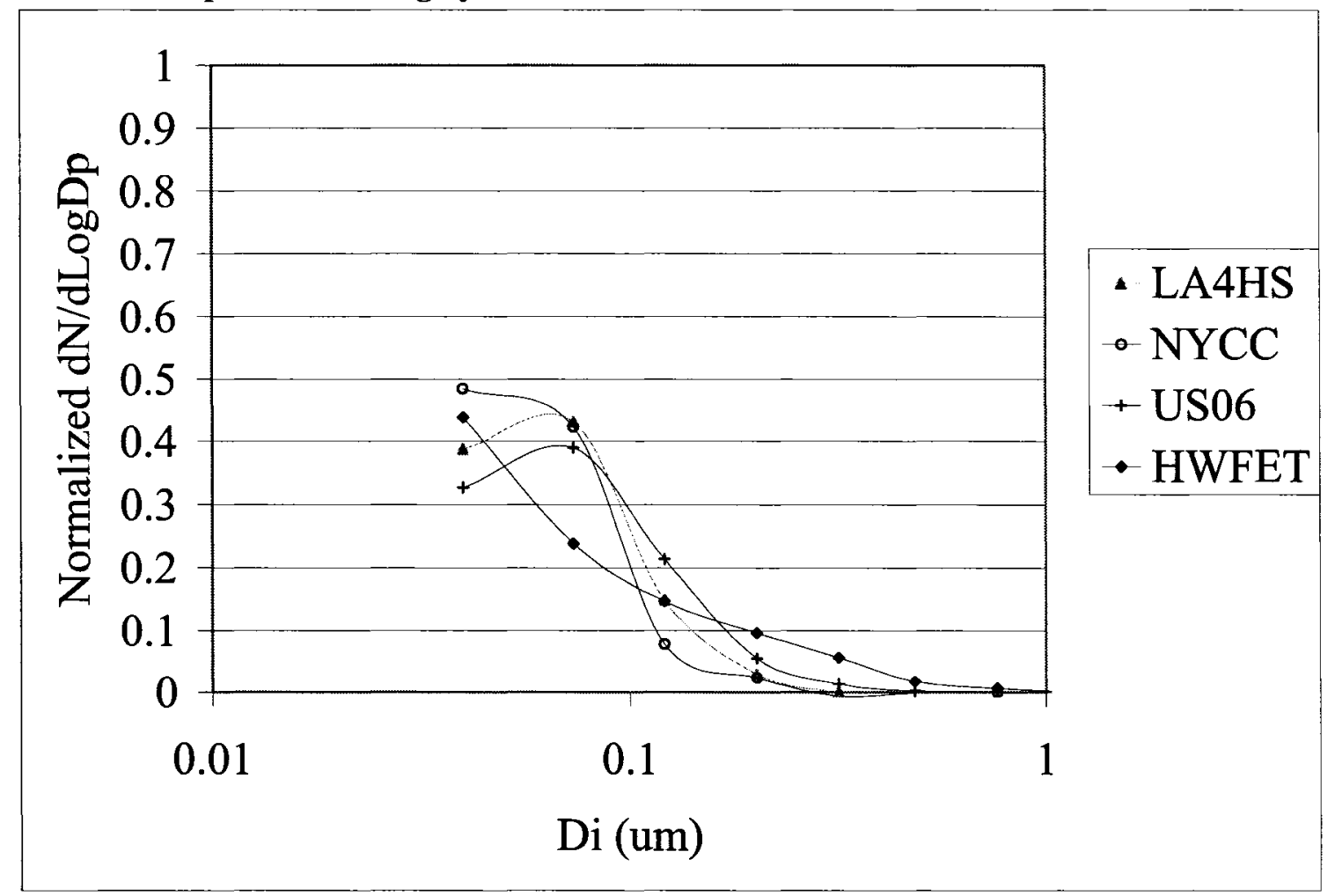

Figure 6.2.21 - Average integrated number-weighted size distribution for the Insight at $-18^{\circ} \mathrm{C}$ : impact of driving cycle 


\subsubsection{Impact of Cold-Start on Emission Rate}

Two driving cycles were used to examine the effect of cold-start on PM emissions: the LA4 and LA92. The LA4 represents a non-demanding style of urban driving with an average speed of $30 \mathrm{~km} / \mathrm{h}$ while the LA92 is a more aggressive cycle with more transients and an average speed of $40 \mathrm{~km} / \mathrm{h}$. In section 6.1.3, the transient nature of PM number emissions during cold-start versus hot-start was demonstrated. Higher emissions were typically observed for the first 300-500 seconds after a cold-start compared to a hot-start. In this section, average integrated number and mass emission rates are presented for coldand hot-start tests.

The average number emission rates obtained for the cold- and hot-start versions of the LA4 and LA92 tests are presented in Figures $6.2 .12\left(20^{\circ} \mathrm{C}\right)$ and $6.2 .13\left(-18^{\circ} \mathrm{C}\right)$. Ratios of average cold-start to average hot-start emission rates are shown in Table 6.2.4. From the figures it is clear that there was little to no difference in emission rates on the LA4 versus LA92 driving cycles when standard deviations are taken into account. Also, cold-start effects were not observable for either the Prius or the Escape at $20^{\circ} \mathrm{C}$. This agrees with the second-by-second results discussed earlier. The other vehicles showed cold-start effects for the most part, but standard deviations were high for the Insight and Smart on the LA92. At $-18^{\circ} \mathrm{C}$ all vehicles showed higher PM number emission rates for cold-start compared to hot-start.

Total $\mathrm{PM}_{2.5}$ mass emission rates had high standard deviations, as on the other driving cycles. As such, it was not possible to observe any effect of cold-start on total mass 
emission rate. At $-18^{\circ} \mathrm{C}$, cold-start did generally have an effect on mass emission rate although error bars overlapped for the Prius and Escape on the LA92 and for the Insight on the LA4. The Smart had particularly high mass emission rates during cold-start at $18^{\circ} \mathrm{C}$.

Table 6.2.4 - Ratio of cold-start to hot-start emission rates

\begin{tabular}{|c|c|c|c|c|c|}
\hline \multirow{2}{*}{ Temperature } & \multirow{2}{*}{ Vehicle } & \multicolumn{2}{|c|}{ Number } & \multicolumn{2}{c|}{ Total PM $_{\mathbf{2 . 5}}$} \\
\cline { 3 - 6 } & & LA4 & LA92 & LA4 & LA92 \\
\hline \multirow{3}{*}{$\mathbf{2 0}^{\circ} \mathbf{C}$} & Smart & 3.08 & 2.84 & 6.06 & 4.62 \\
& Prius & 1.28 & 1.03 & 0.10 & 1.10 \\
& Escape & 0.99 & 1.49 & 0.75 & 1.26 \\
& Civic & 5.68 & 5.15 & 13.22 & 1.48 \\
& Insight & 14.62 & 2.53 & 0.13 & 1.18 \\
\hline \multirow{3}{*}{$\mathbf{1 8}^{\circ} \mathbf{C}$} & Smart & 5.66 & 4.21 & 11.16 & 8.05 \\
& Prius & 10.16 & 13.97 & 14.24 & 2.13 \\
& Escape & 21.58 & 5.80 & 32.62 & 3.80 \\
& Civic & 9.67 & 9.36 & NA & 30.19 \\
& Insight & 7.48 & 29.67 & 1.73 & 2.27 \\
\hline
\end{tabular}




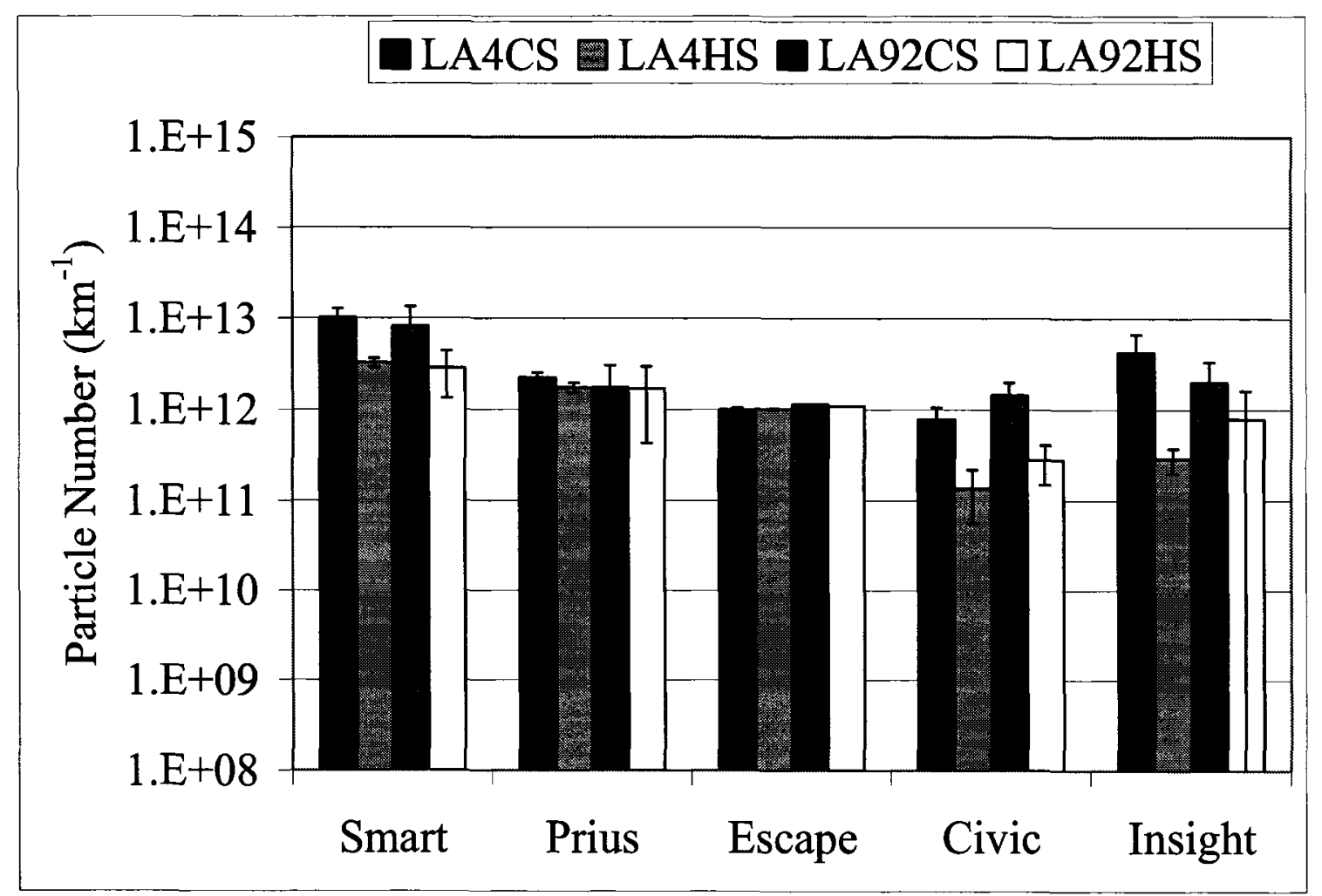

Figure 6.2.22 - Average PM number emission rates \pm 1 standard deviation at $20^{\circ} \mathrm{C}$ : impact of cold-start

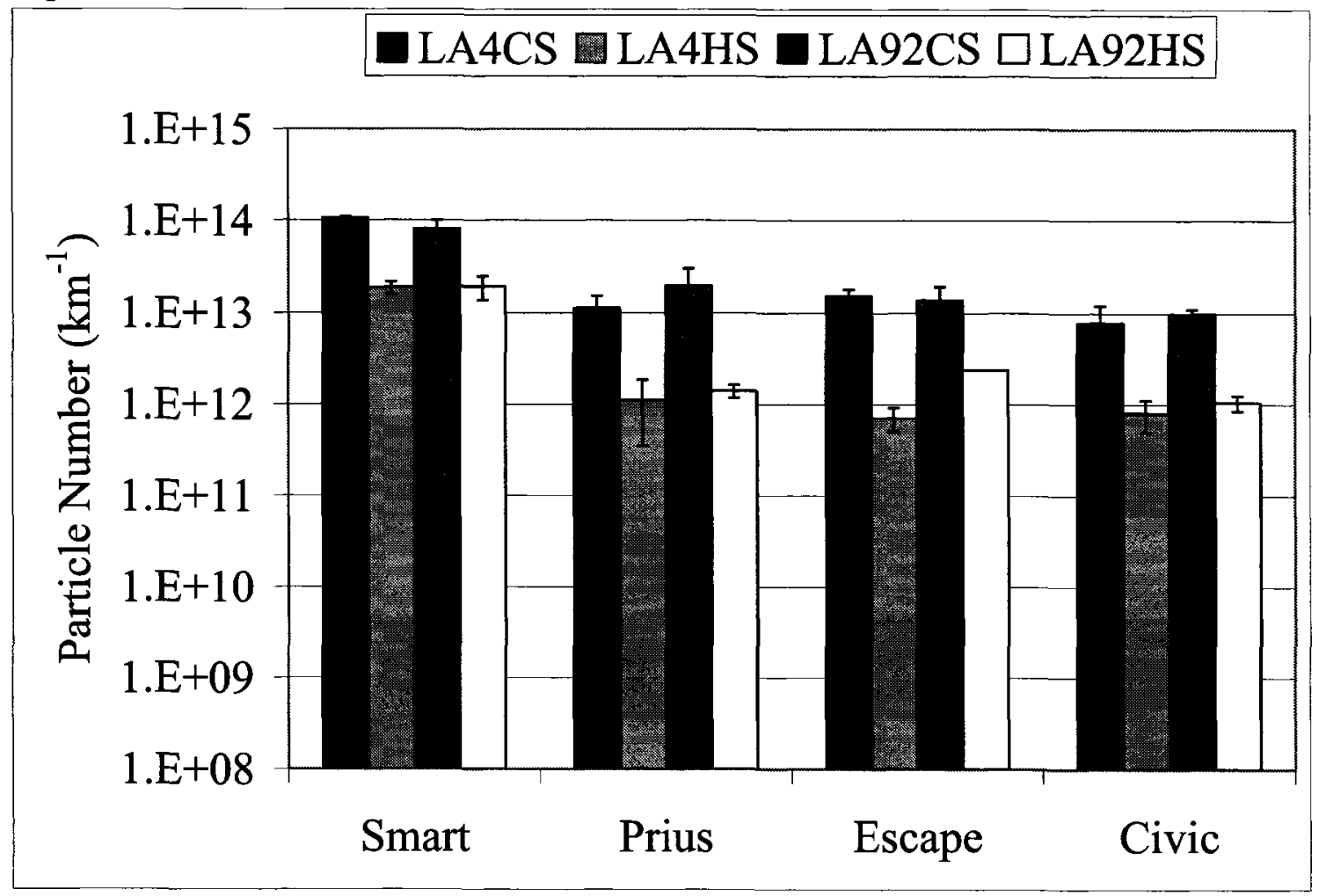

Figure 6.2.23 - Average PM number emission rates \pm 1 standard deviation at $-18^{\circ} \mathrm{C}$ : impact of cold-start 


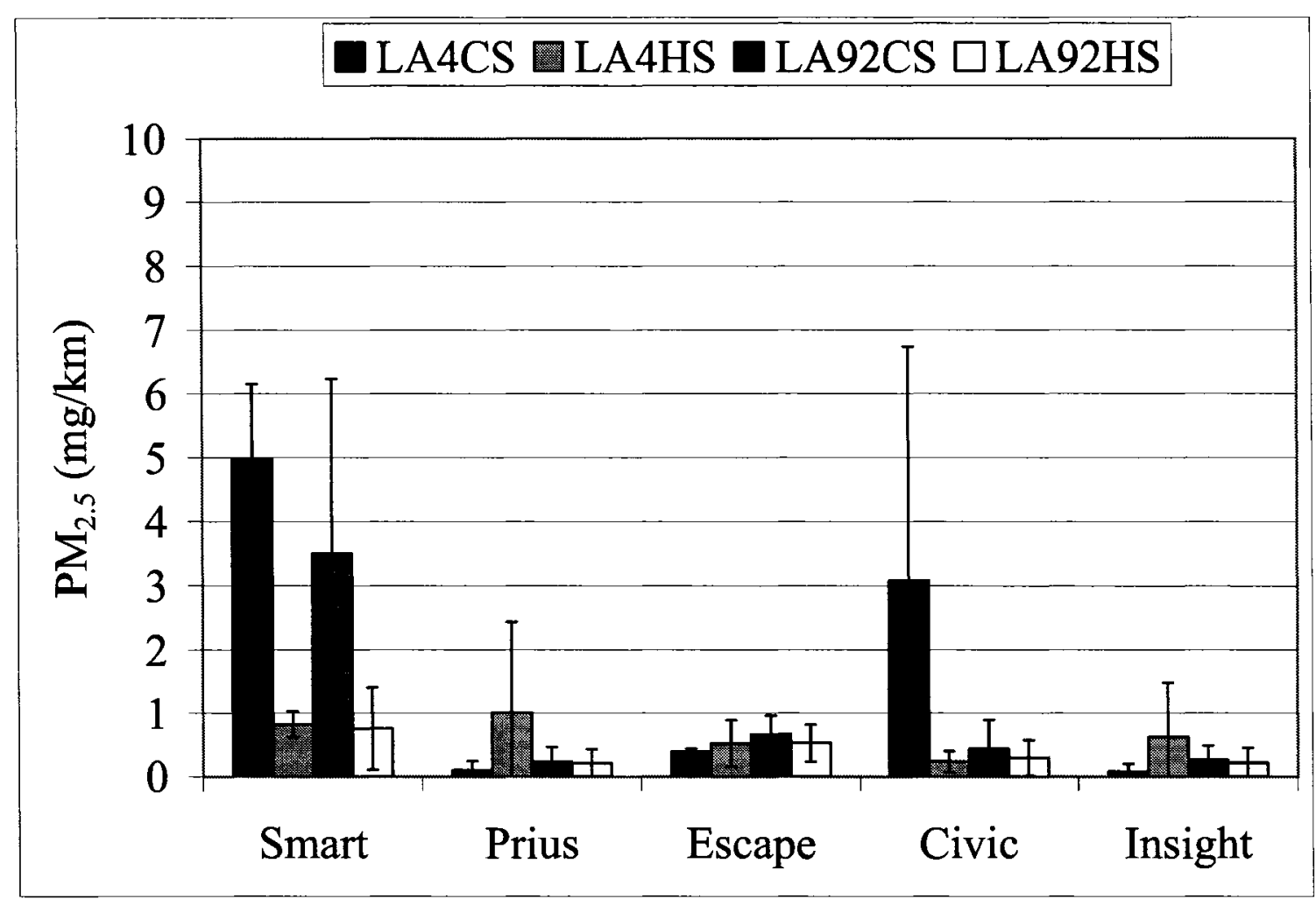

Figure 6.2.24 - Average $\mathrm{PM}_{2.5}$ mass emission rates \pm 1 standard deviation at $20^{\circ} \mathrm{C}$ : impact of cold-start

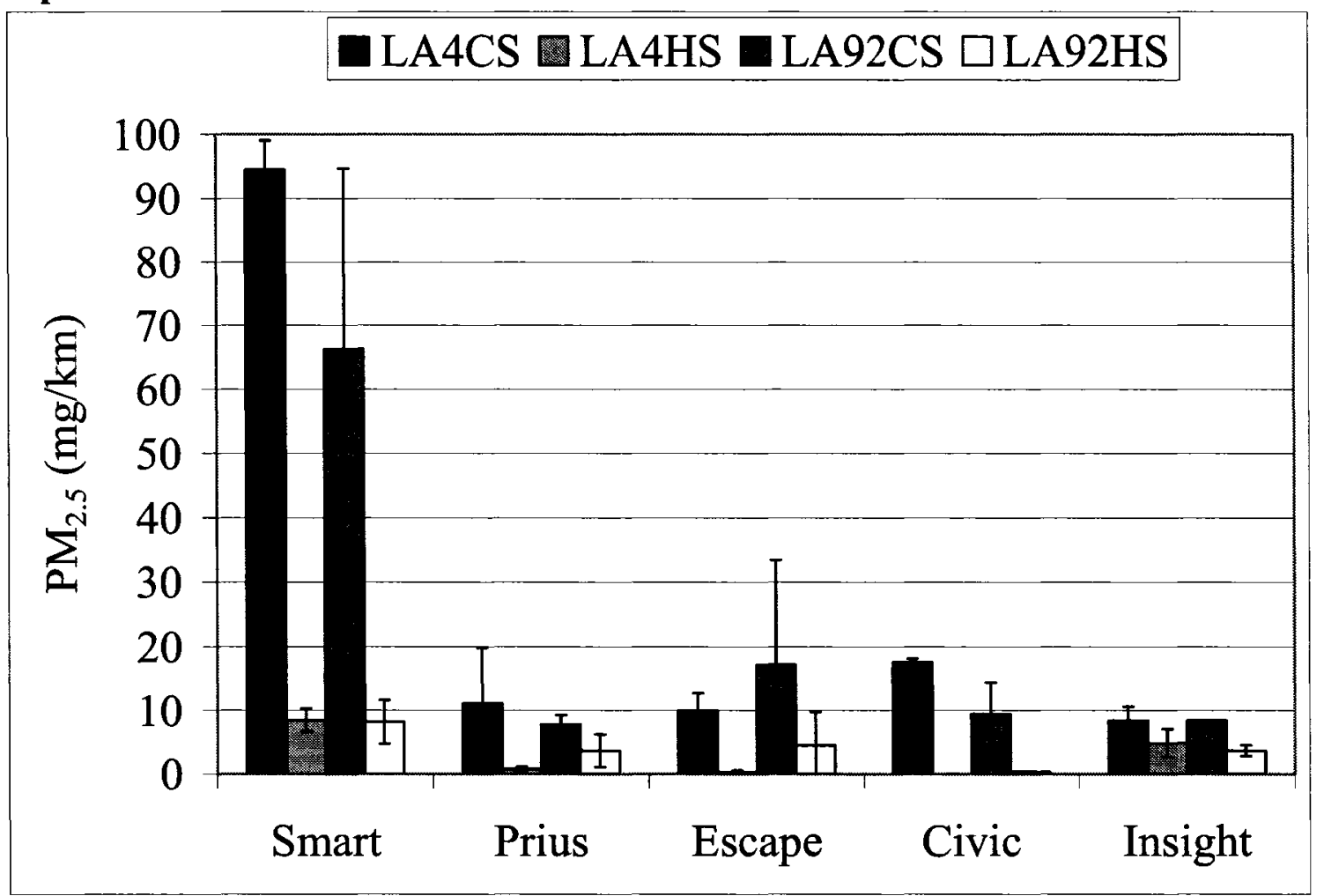

Figure 6.2.25 - Average $P M_{2.5}$ mass emission rates \pm 1 standard deviation at $-18^{\circ} \mathrm{C}$ : impact of cold-start 


\section{Organic and Elemental Carbon Emission Rates}

Average organic (OC) and elemental (EC) carbon emission rates on the LA4 and LA92 cold-start (CS) and hot-start (HS) cycles are shown in Figures 6.2.26 and 6.2.27. As with other driving cycles, standard deviations were generally smaller for the OC/EC results than for the total $\mathrm{PM}_{2.5}$ results. Total $\mathrm{PM}_{2.5}$ emission rates are plotted with $\mathrm{OC} / \mathrm{EC}$ emission rates for comparison in Appendix 4.

At $20^{\circ} \mathrm{C}$, the Smart clearly had higher total carbon emission rates on the cold-start tests compared to the hot-start tests. Both organic and elemental carbon emissions increased during cold-start. The hybrid vehicles, on the other hand, did not show obvious cold-start effects. The Escape had higher carbon emission rates on the aggressive LA92 compared to on the LA4. The Prius had a higher proportion of elemental carbon on the LA92 compared to the LA4. The Civic and Insight both had higher elemental carbon emission rates on cold-start tests compared to on hot-start tests.

At $-18^{\circ} \mathrm{C}$ (Figure 6.2.27), all vehicles had higher total carbon emission rates on cold-start compared to hot-start, with emission rates of both organic and elemental carbon increasing for cold-start. Proportionally, elemental carbon emission rates were higher during cold-start compared to hot-start for the Escape (approximately $60 \%$ for both hotstarts and $85 \%$ for both cold-starts), but lower for the Prius (approximately $90 \%$ for both hot-starts and $80 \%$ for both cold-starts). For the Smart, Civic, and Insight carbon composition remained similar from cold- to hot-start. 

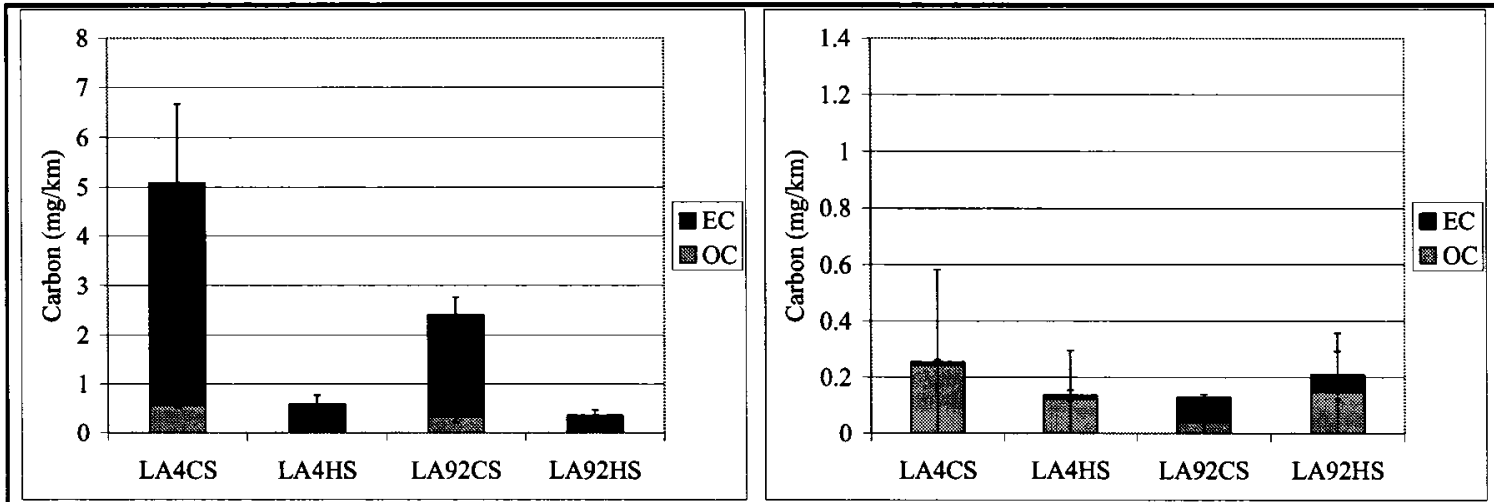

(a) Smart (*note scale difference)

(b) Prius
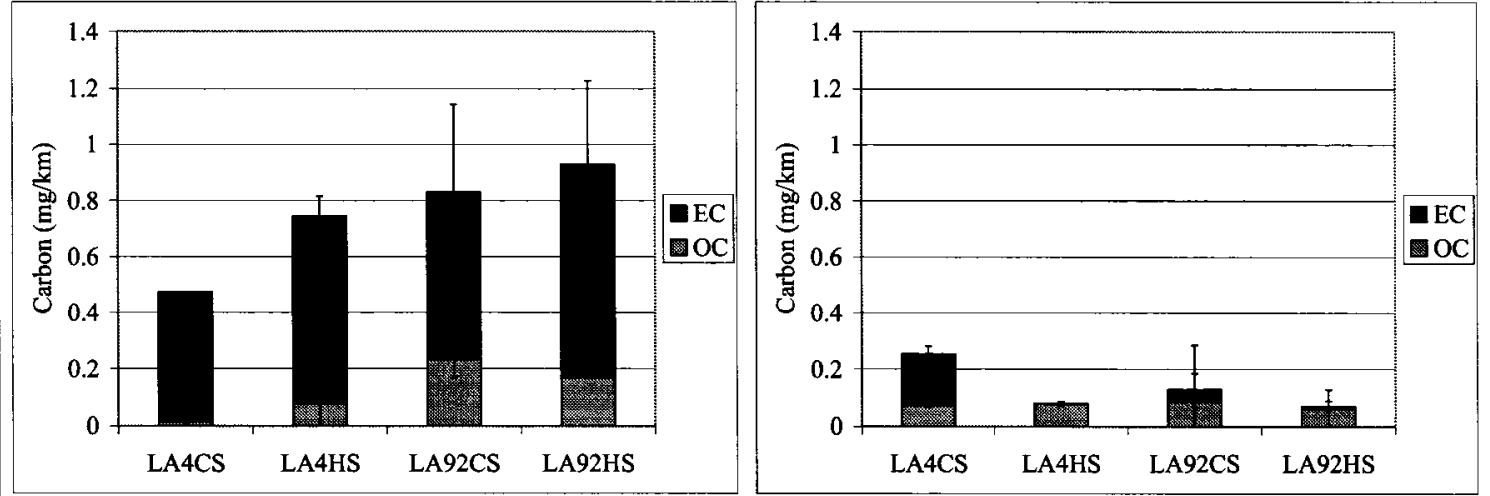

(c) Escape

(d) Civic

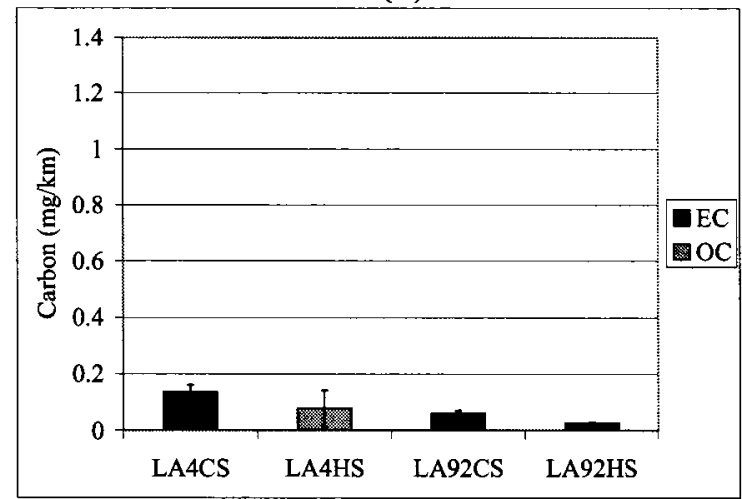

(e) Insight

Figure 6.2.26 - Average organic and elemental carbon mass emission rates \pm 1 standard deviation at $20^{\circ} \mathrm{C}$ : impact of cold-start 

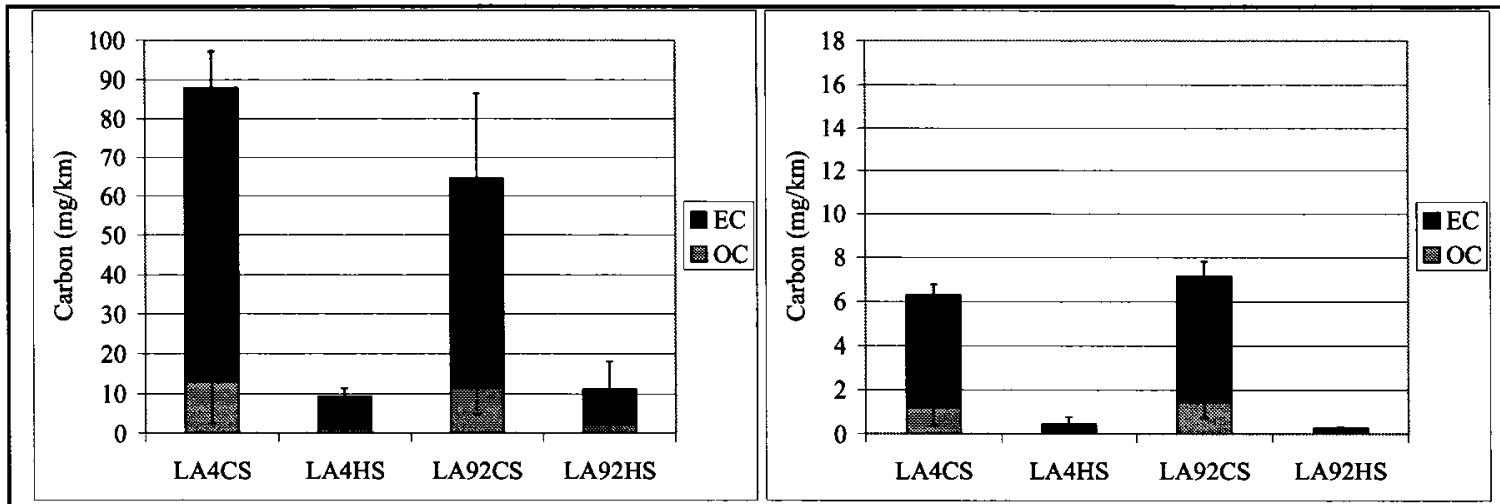

(a) Smart (*note scale difference)

(b) Prius
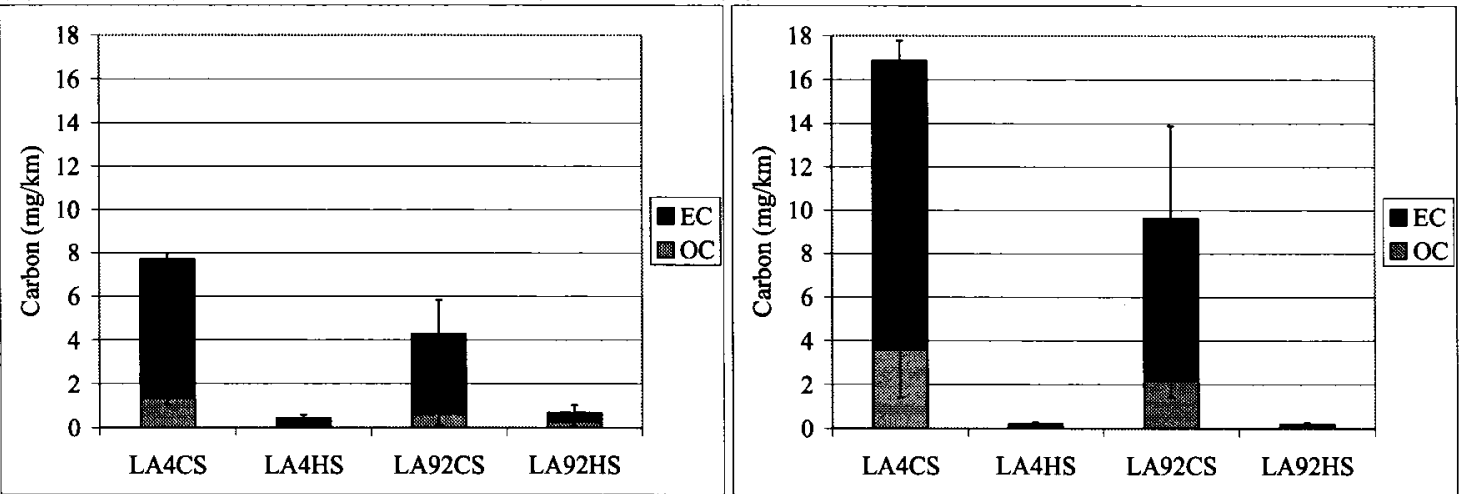

(c) Escape

(d) Civic

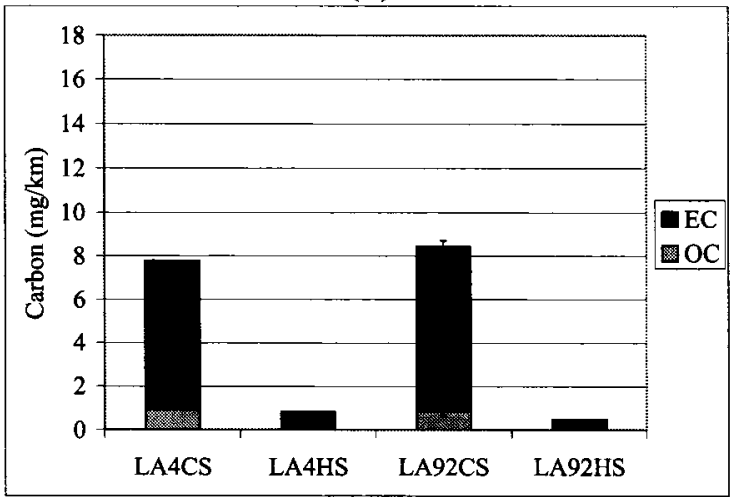

(e) Insight

Figure 6.2.27 - Average organic and elemental carbon mass emission rates \pm 1 standard deviation at $-18^{\circ} \mathrm{C}$ : impact of cold-start

\subsubsection{Impact of Cold-Start on Size Distribution}

At $20^{\circ} \mathrm{C}$, the Prius, Civic, and Insight had slightly higher proportions of particles in the larger size range during cold-start compared to hot-start. In all three cases, a clear peak emission rate is not observed in the ELPI size range and so it is impossible to tell where 
the mean particle diameter would fall. The Smart emitted a higher proportion of large particles during the LA4CS compared to the LA4HS, but distributions were similar for the LA92 cold- and hot-starts. In contrast to the other vehicles, the Escape emitted a higher proportion of small particles during cold-start compared to hot-start.

At $-18^{\circ} \mathrm{C}$, all five vehicles emitted a higher proportion of particles in the larger size ranges at cold-start compared to at hot-start with mean particle sizes appearing to be between 30 and $70 \mathrm{~nm}$. Cold temperature had an effect on both cold- and hot-start emissions, reducing the proportion of particles measured in the smallest size bin compared to at warm ambient temperature. Size distribution is strongly influenced by both cold-start and cold ambient temperature conditions. 


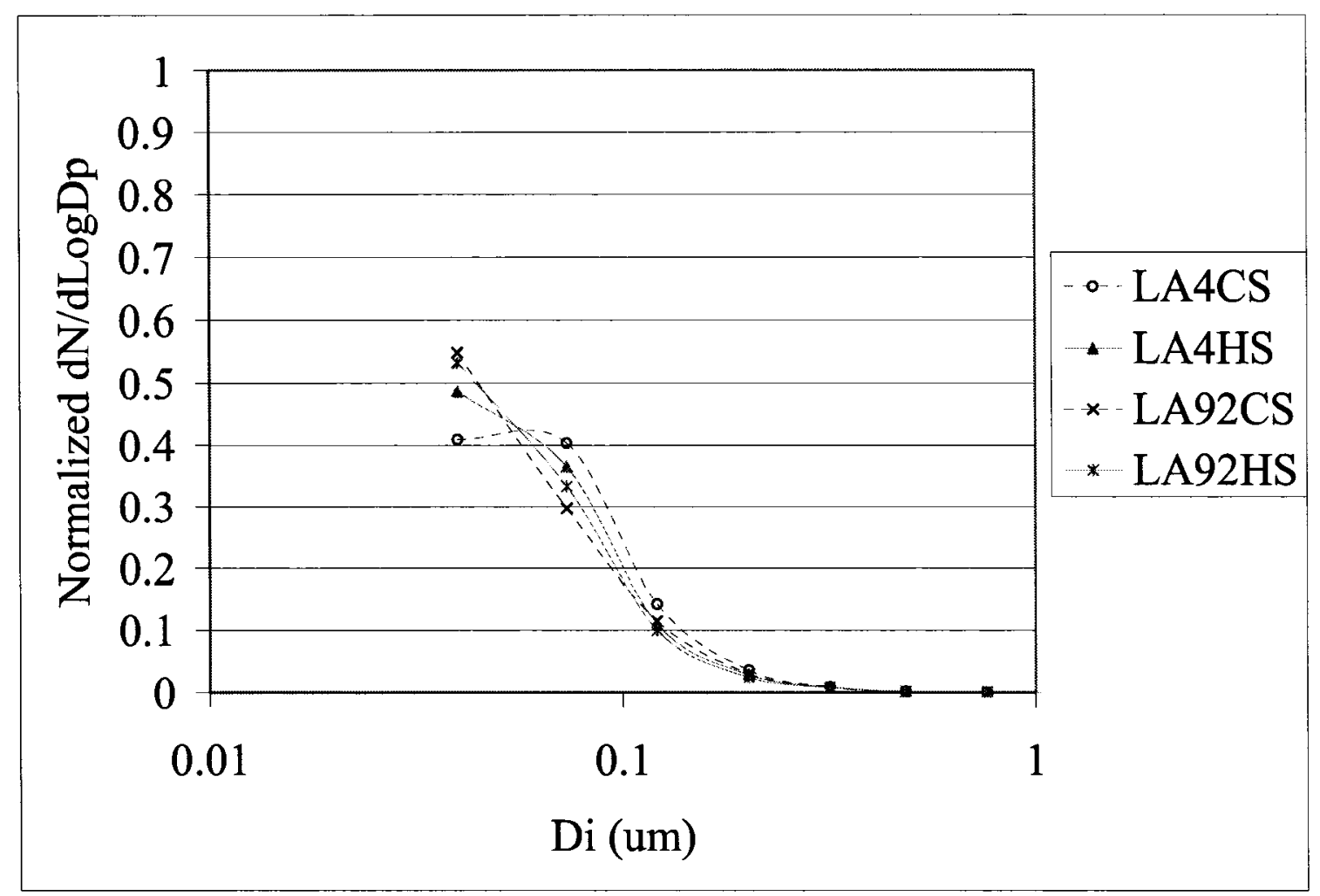

Figure 6.2.28 - Average integrated number-weighted size distribution for the Smart at $20^{\circ} \mathrm{C}$ : impact of cold-start

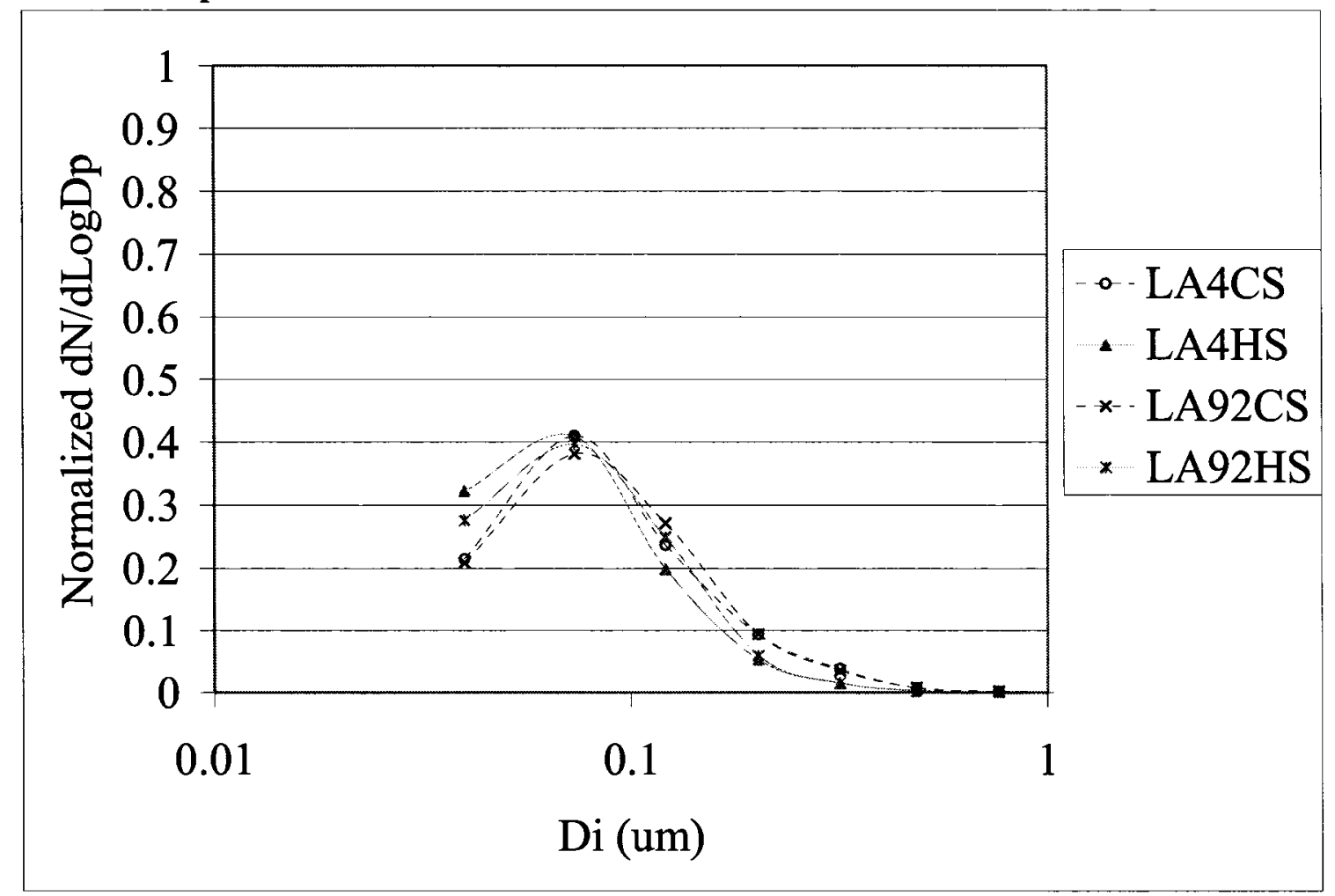

Figure 6.2.29 - Average integrated number-weighted size distribution for the Smart at $-18^{\circ} \mathrm{C}$ : impact of cold-start 


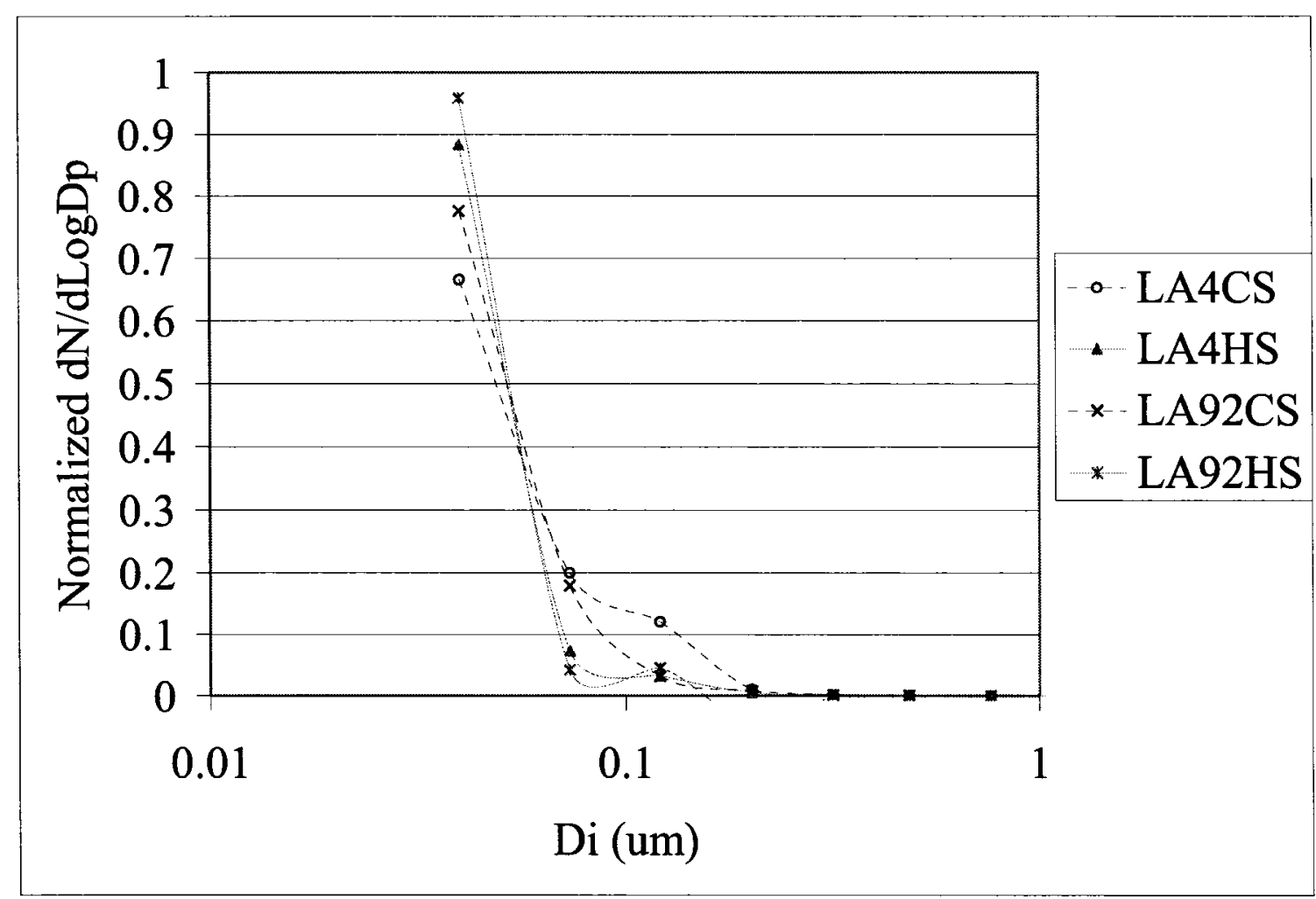

Figure 6.2.30 - Average integrated number-weighted size distribution for the Prius at $20^{\circ} \mathrm{C}$ : impact of cold-start

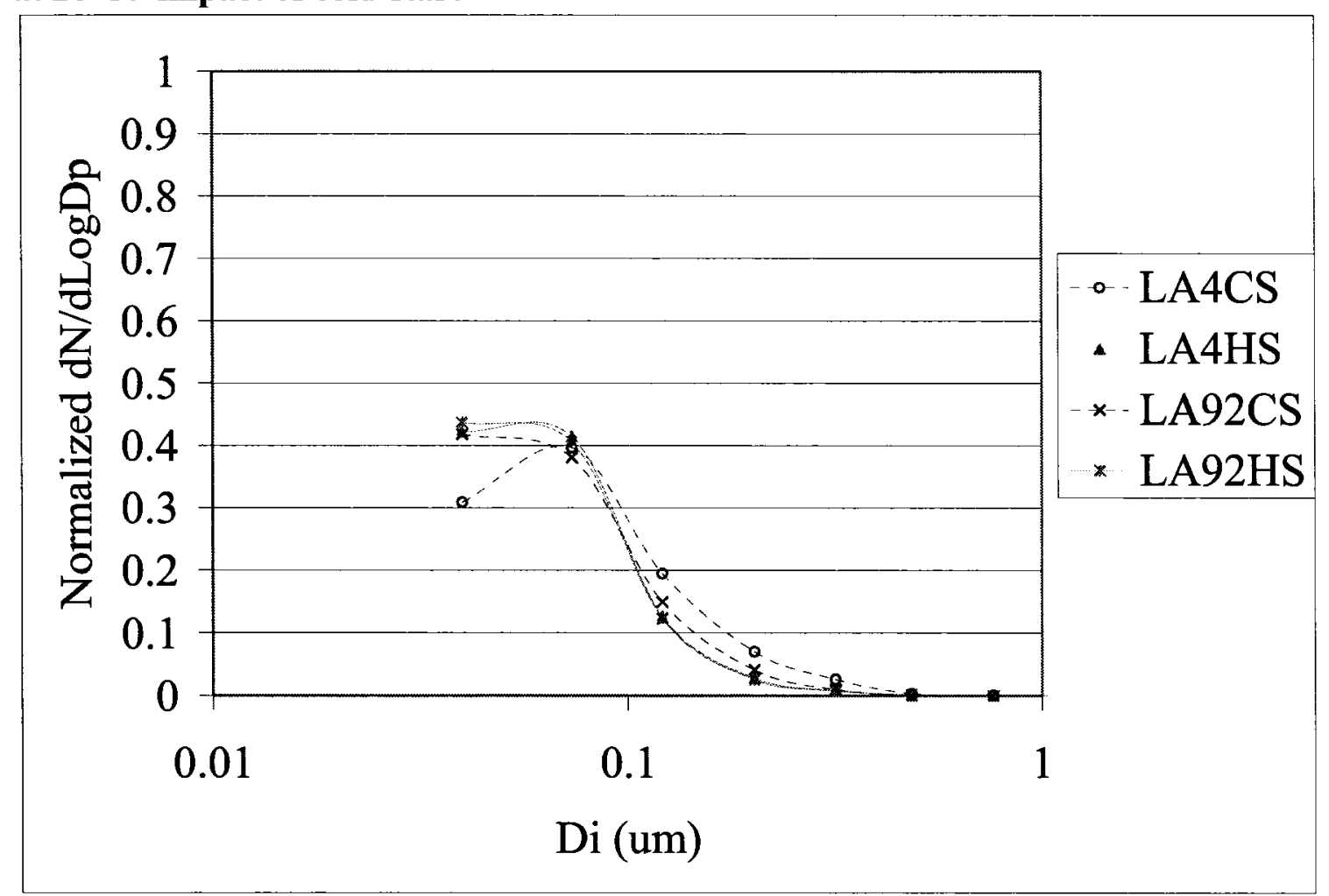

Figure 6.2.31 - Average integrated number-weighted size distribution for the Prius at $-18^{\circ} \mathrm{C}$ : impact of cold-start 


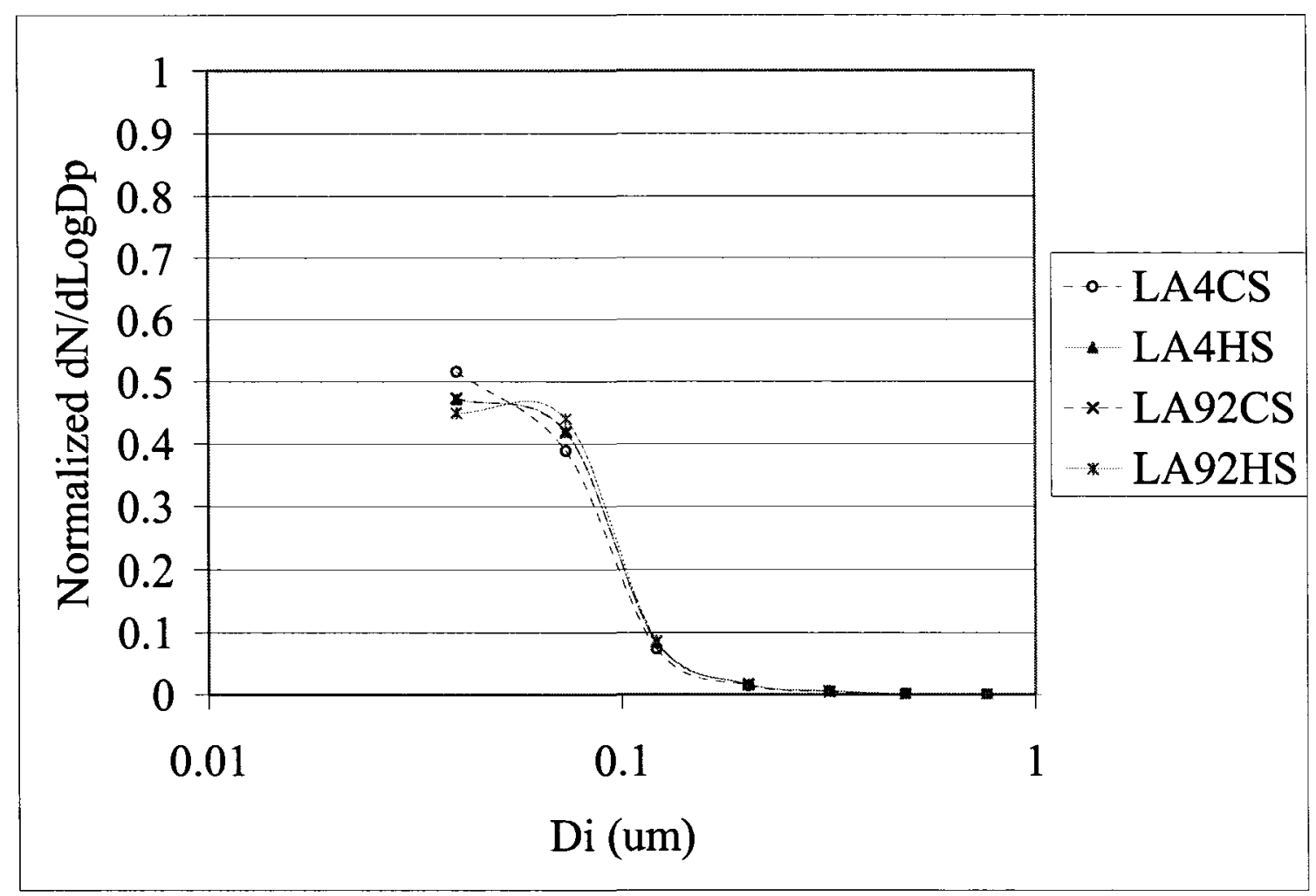

Figure 6.2.32 - Average integrated number-weighted size distribution for the Escape at $20^{\circ} \mathrm{C}$ : impact of cold-start

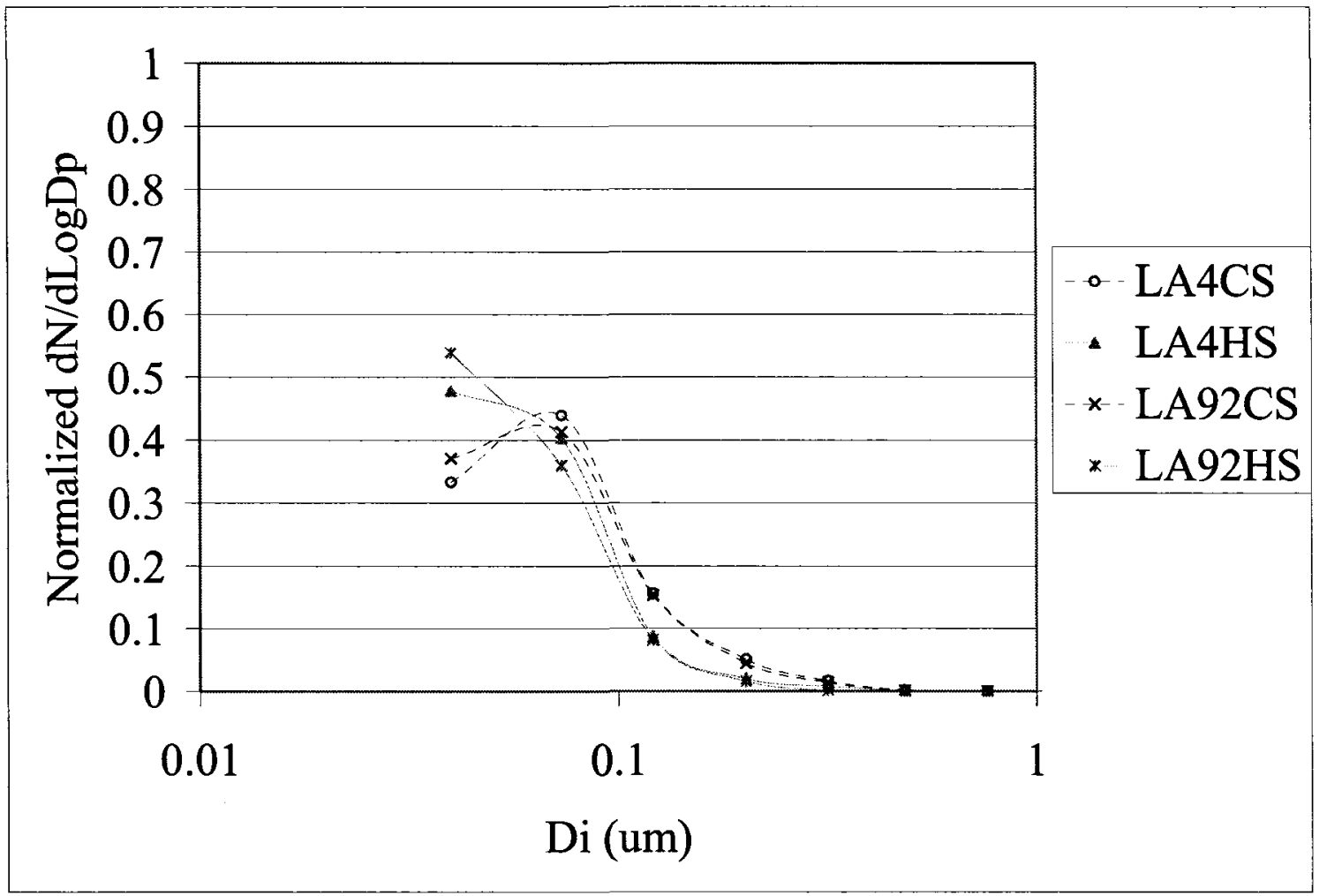

Figure 6.2.33 - Average integrated number-weighted size distribution for the Escape at $-18^{\circ} \mathrm{C}$ : impact of cold-start 


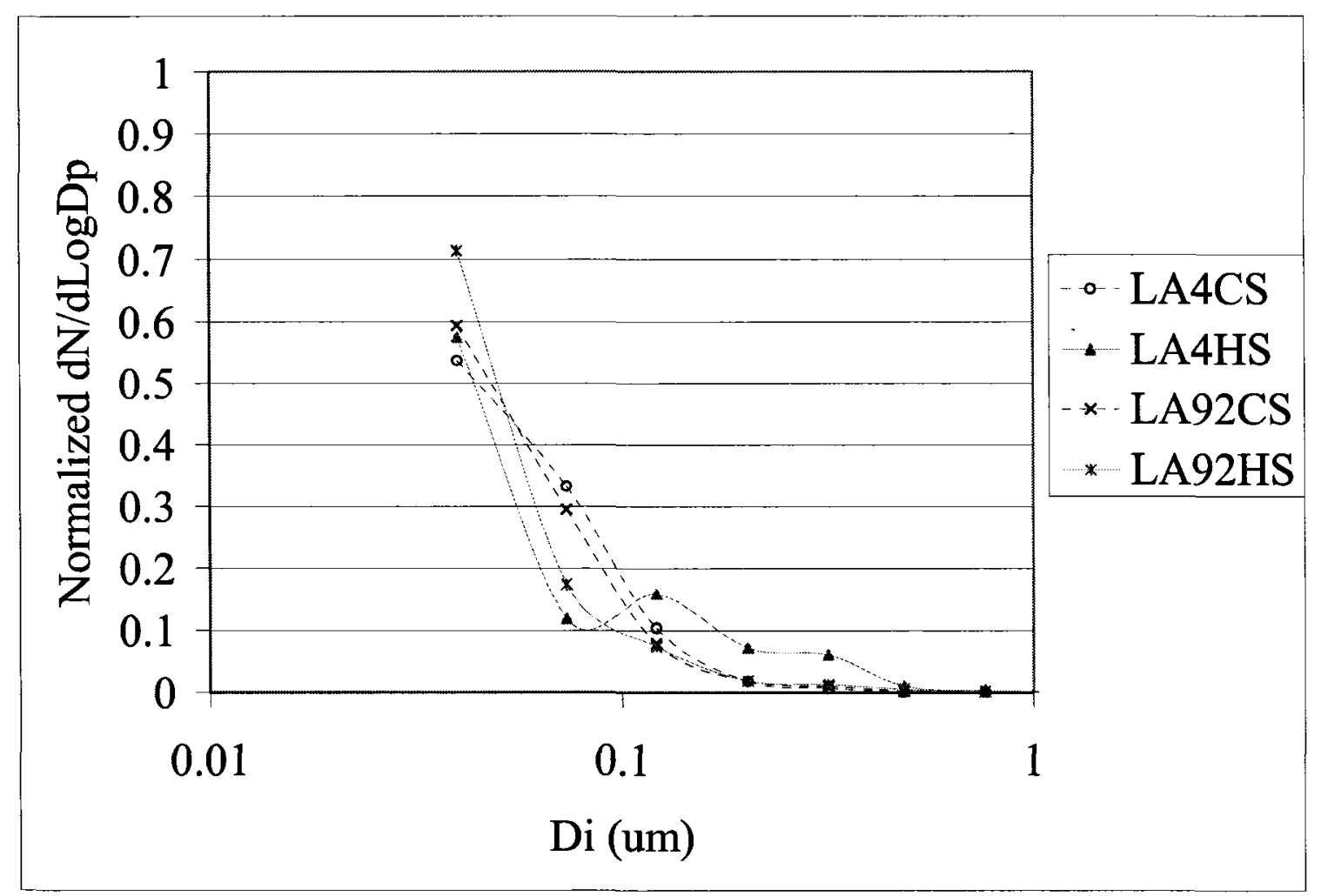

Figure 6.2.34 - Average integrated number-weighted size distribution for the Civic at $20^{\circ} \mathrm{C}$ : impact of cold-start

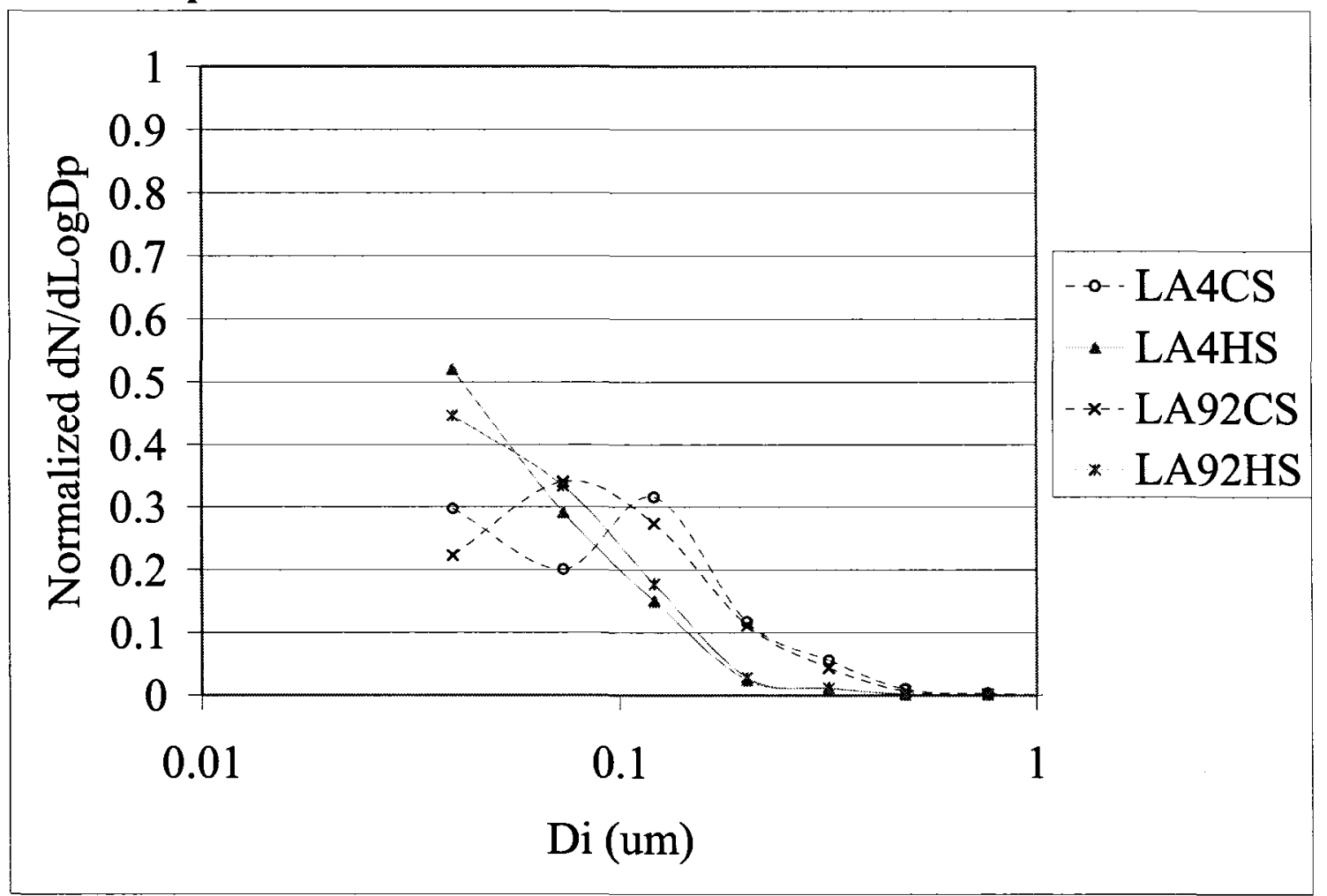

Figure 6.2.35 - Average integrated number-weighted size distribution for the Civic at $-18^{\circ} \mathrm{C}$ : impact of cold-start 


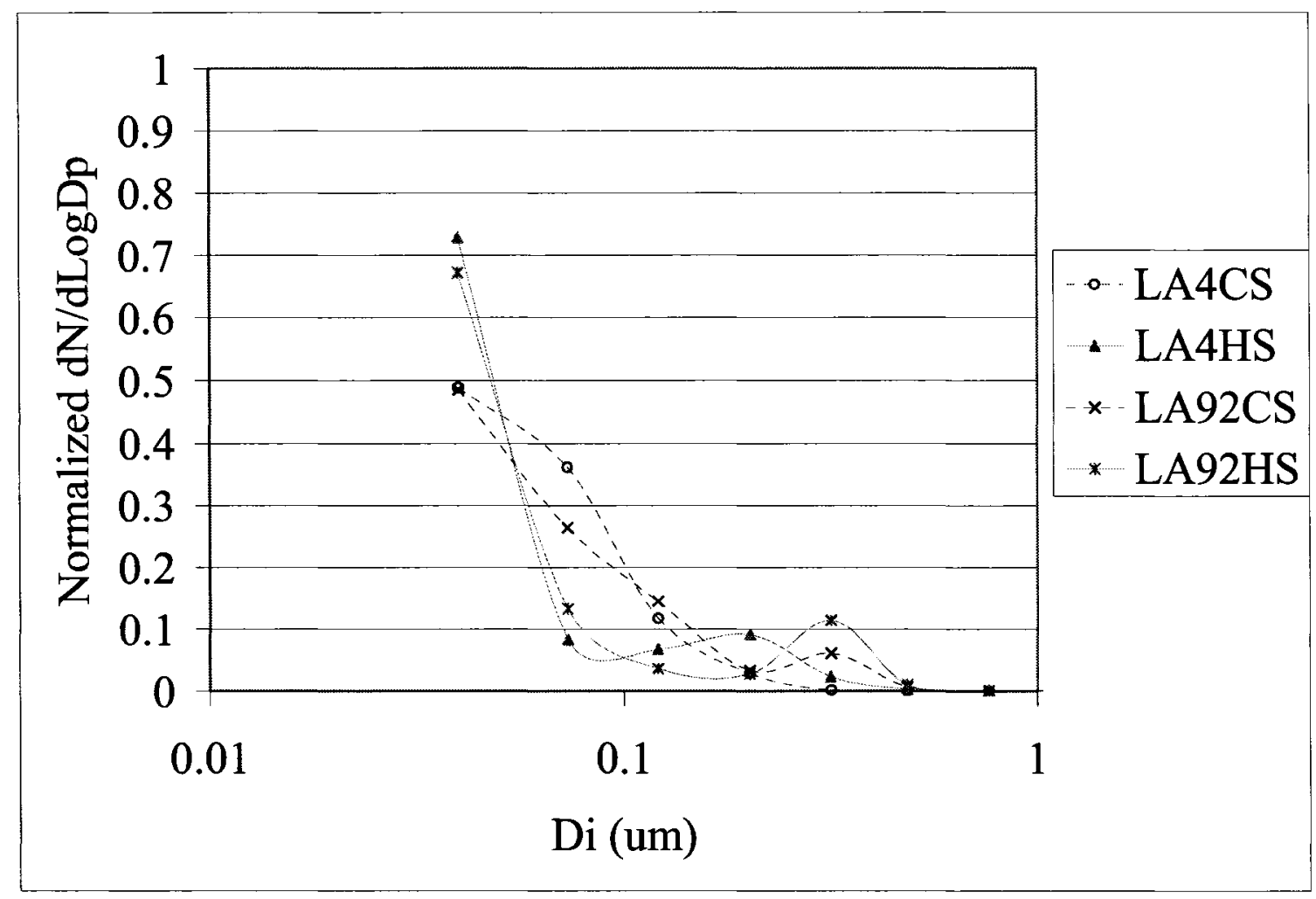

Figure 6.2.36 - Average integrated number-weighted size distribution for the Insight at $20^{\circ} \mathrm{C}$ : impact of cold-start

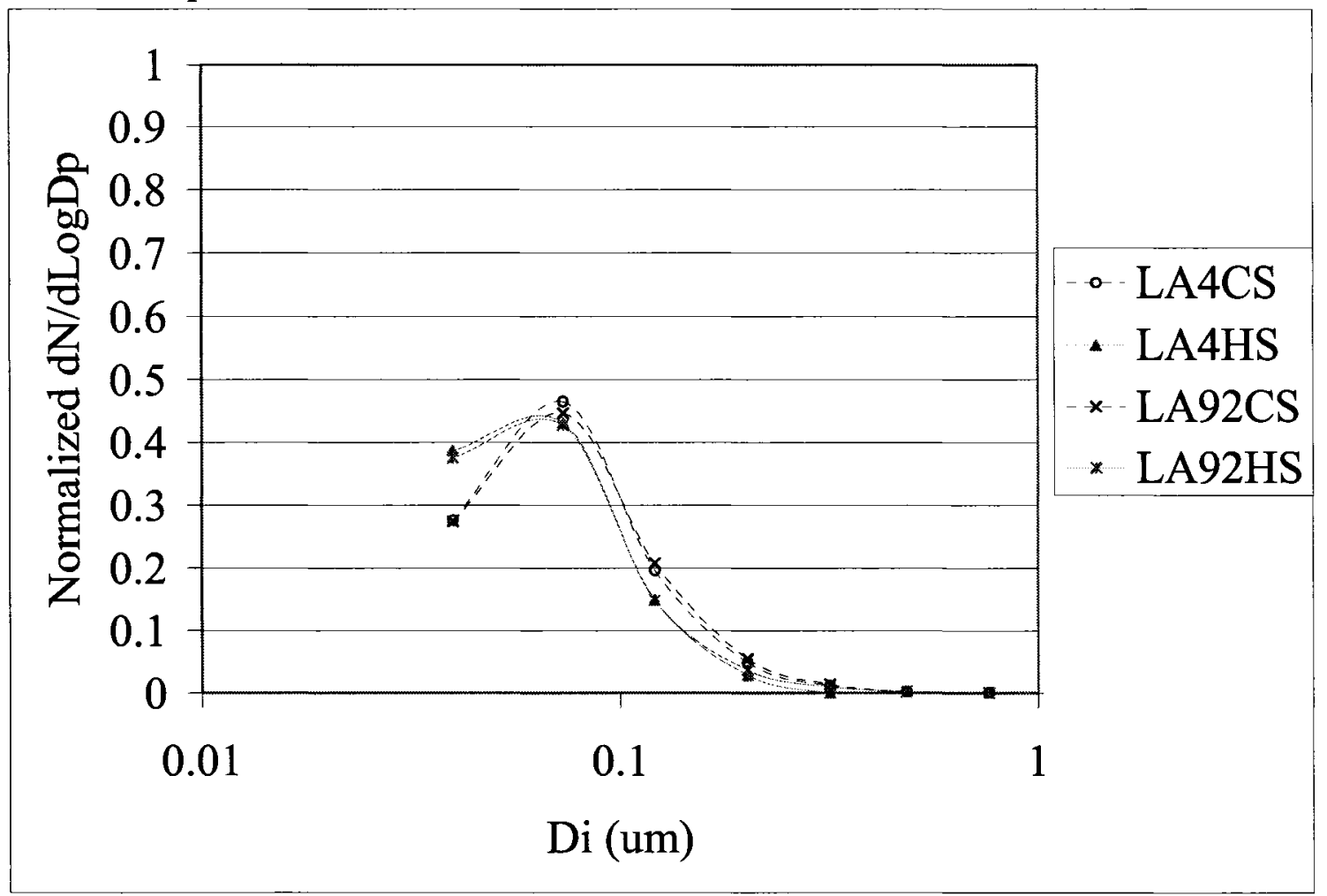

Figure 6.2.37 - Average integrated number-weighted size distribution for the Insight at $-18^{\circ} \mathrm{C}$ : impact of cold-start 


\subsection{Conclusions}

In this study, the effects of driving conditions and ambient temperature on number emission rates of $\mathrm{PM}$, number-weighted size distributions of $\mathrm{PM}$, total $\mathrm{PM}_{2.5}$ mass emission rates, and organic and elemental carbon mass emission rates of four commercially available gasoline-electric hybrid vehicles and one small conventional gasoline vehicle were examined. The hybrids were the 2000 Honda Insight, 2003 Honda Civic Hybrid, 2004 Toyota Prius, and 2005 Ford Escape Hybrid. The small conventional gasoline engine vehicle, the 2002 Smart Cabrio, was included as a comparably low emission alternative to hybrid technology. Vehicles were tested in the laboratory at the Emissions Research and Measurement Division of Environment Canada using standard chassis dynamometer testing protocols.

The hybrid vehicle emission patterns were in some ways similar to those that are typically observed for conventional vehicles (CVs). For instance, the PM number emission rate usually increased sharply during periods of acceleration, and was higher at high speeds compared to at low speeds. Both mass and number emission rates were low during steady-state (constant dynamometer speed) operation compared to transient (varying dynamometer speed) operation. At a cold ambient temperature of $-18^{\circ} \mathrm{C}$ the hybrids, like CVs, had mass and number emission rates that were higher during cold-start operation compared to hot-start operation.

Hybrid vehicle emission patterns were also, in some ways, different from those of conventional vehicles. The hybrids often showed engine-off conditions during periods of 
rest, and the Escape and Prius often showed engine-off conditions during low speed operation. The emission rates during these events dropped to zero whereas conventional vehicles would still be emitting, albeit at a low rate, at the same point in the test cycle. It was found that these patterns could vary from one repeat of a test to another and could vary for the same driving conditions repeated within the same test. It was also observed that engine-off conditions occurred less frequently at cold ambient temperature $\left(-18^{\circ} \mathrm{C}\right)$ compared to at warm ambient temperature $\left(20^{\circ} \mathrm{C}\right)$. Another major difference between hybrid vehicles and conventional vehicles was that, after periods of engine-off, the hybrids often showed IC engine start-up events mid-cycle resulting in an increased emission rate over several seconds. These differences may influence the overall emission rates of hybrid vehicles and, if hybrid vehicles become more prevalent, would be worth taking into account when developing new PM emission modeling approaches.

Some unexpected trends were observed which may or may not be the result of hybrid technology. When compared to the Smart, the hybrid vehicles were less affected by cold ambient temperature. Hybrid vehicle PM emission rates were not necessarily higher at cold ambient temperature compared to at warm ambient temperature. The hybrids also showed unusual emission patterns during cold-start operation at $20^{\circ} \mathrm{C}$. For these vehicles, when cold-start emission rates were compared to hot-start emission rates at $20^{\circ} \mathrm{C}$, only the Civic and Insight showed an increase and this was only for number emission rate. As mentioned above, during testing at the colder temperature $\left(-18^{\circ} \mathrm{C}\right)$ cold-start emission rates were clearly increased compared to hot-start emission rates for all vehicles. Another trend was that compared to the Smart, the hybrid vehicle number emission rates were 
very susceptible to the aggressive high-speed driving conditions of the US06. Number emission rates of the hybrids over this driving cycle were orders of magnitude higher than those of the Smart. In particular, the Ford Escape had the highest number emission rate of the vehicles for this cycle, and also had an especially high mass emission rate on this cycle at $20^{\circ} \mathrm{C}$. Again, these trends could be taken into account when developing new PM emission modeling approaches. Further studies with matching conventional vehicles (ie. conventional Ford Escape etc.) could show whether or not these effects are specific to hybrid technology, or are related to other vehicle characteristics.

While the organic/elemental carbon (OC/EC) mass emission rates and number-based size distributions did not show trends that could be specifically attributed to hybrid technology, they did show distinct patterns depending on the vehicle, driving cycle, and temperature. For instance, size distribution usually shifted from the nuclei mode towards the accumulation mode at cold $\left(-18^{\circ} \mathrm{C}\right)$ compared to warm $\left(20^{\circ} \mathrm{C}\right)$ ambient temperatures and during cold-start compared to hot-start operation. The OC/EC emission rates and number-based size distributions reported in this thesis could be used in source apportionment models.

Because hybrid vehicle emission testing is relatively new, testing procedures for these vehicles are still being developed and improved. One difficulty encountered when testing hybrid vehicle emission rates is the need to account for changes in battery state-of-charge over a cycle. Testing procedures published by the California Air Resources Board (CARB) require that the absolute net energy change variance (NECvar) during a cycle be 
$<1 \%$. For the tests performed in this study, this would have meant that $10 \%$ of tests on the Insight, $30 \%$ of tests on the Civic, $34 \%$ of tests on the Prius, and $64 \%$ of tests on the Escape could not be included in the results. Another testing procedure published by the Society of Automotive Engineers (SAE) suggests that emission rates be corrected to $0 \%$ NECvar by using multiple repeats of tests to find a linear relationship between NECvar and emission rate for each vehicle and driving cycle. In this study, no consistent relationship between PM emission rate and NECvar was observed with 2-4 repeats of each cycle. The use of results from a higher number of repeats may improve the correlation between PM emission rates and NECvar, or the correlation may simply not exist. The latter is possible considering that PM formation depends not only on energy use, but also on engine operating conditions and temperatures. This subject deserves further study.

Because this is the first study to examine particle number emission rates and size distributions from gasoline-electric hybrid vehicles, results could not be directly compared with those of previous studies. Several questions remain which would be interesting topics for future research projects. As previously mentioned, testing of emission rates from similar conventional vehicles (ie. the conventional Honda Civic or Ford Escape) would provide useful information on exactly which of the observed effects are due specifically to hybrid technology. It would also allow for comparison of hybrid emission rates with those of similarly sized conventional vehicles. Also, because of the high PM emission rates observed for the Ford Escape on the US06 cycle, it would be 
worthwhile to test another version of the same model in order to ensure that the first was not somehow malfunctioning.

One final recommendation is that PM mass and number concentrations in the dilution air be minimized and closely monitored during future testing of low emitting vehicles in order to avoid any error due to changes in this parameter over the test cycle or over the day. 


\section{References}

Brain, J. D., \& Valberg, P. A. (1979). Deposition of aerosol in the respiratory tract. American Review of Respiratory Disease, 120, 1325-1373.

California Environmental Protection Agency, Air Resources Board. (1999). California exhaust emissions standards and test procedures for 2005 and subsequent model zero-emissions vehicles, and 2001 and subsequent model hybrid electric vehicles, in the passenger car, light-duty truck and medium-duty vehicle classes No. Last Amended: December 19, 2003)

Canadian Council of Ministers of the Environment. (2000). Canada-wide standards for particulate matter (PM) and ozone

Canadian Federal Government. (2002). On-road vehicle and emission regulations. Canada Gazette, 136(13)

Dekati Ltd. (2005). ELPI user manual ver. 4.0.

Dekati Ltd. (1999). Dekati diluter manual.

Delfino, R. J., Sioutas, C., \& Malik, S. (2005). Potential role of ultrafine particles in associations between particle mass and cardiovascular health. Environmental health perspectives, $113(8)$

Environment Canada. (2006a). Criteria air contaminants (CAC) emission summaries., 2006, from http://www.ec.gc.ca/pdb/cac 
Environment Canada. (2006b). National inventory report, annex 8: Canada's greenhouse gas emission tables, 1990-2004., 2006, from http://www.ec.gc.ca/pdb/ghg/inventory_report/2004_report

Environmental Protection Agency. (2004). Technical guidance on the use of MOBILE6.2 for emission inventory preperation. EPA420-R-04-013

Environmental Protection Agency. (1997). Proposed rules, 40 CFR part 86. Federal Registry, 62(44753)

Graham, L. (2005). Chemical characterization of emissions from advanced technology light-duty vehicles. Atmospheric Environment, 39(13), 2385-2398.

Greywitt, M., \& Tews, J. (2005). Hybrid vehicle market share expected to peak at three percent. J.D. Power and Associates News/Information

Harris, S. J., \& Maricq, M. M. (2001). Signature size distributions for diesel and gasoline engine exhaust particulate matter. Journal of Aerosol Science, 32, 749-764.

Honda Motor Co., Ltd. (2006). Honda IMA system., 2006, from http://world.honda.com/CIVICHYBRID/Technology/NewHondaIMASystem/Power Unit/index_1.html

Husted, H. L. (2003). A comparative study of the production applications of hybrid electric powertrains. SAE Technical Paper Series, 2003-01-2307 
Kasper, A., Burtscher, H., Johnson, J. P., Kittelson, D. B., Watts, W. F., \& Baltensperger, U., et al. (2005). Particle emissions from SI-engines during steady state and transient operating conditions. SAE Technical Paper Series, 2005-01-3136

Kayes, D., Hochgreb, S., Maricq, M. M., Podsiadlik, D. H., \& Chase, R. E. (2000). Particulate matter emission during start-up and transient operation of a spark-ignition engine (2): Effect of speed, load, and real-world driving cycles. SAE Technical Paper Series, 2000-01-1083

Kayes, D., \& Hochgreb, S. (1999a). Mechanisms of particulate matter formation in sparkignition engines. 1. effect of engine operating conditions. Environmental Science \& Technology, 33(22), 3957.

Kayes, D., \& Hochgreb, S. (1999b). Mechanisms of particulate matter formation in spark-ignition engines. 2. effect of fuel, oil, and catalyst parameters. Environmental Science \& Technology, 33(22), 3968.

Kayes, D., \& Hochgreb, S. (1998). Investigation of the dilution process for measurement of particulate matter from spark-ignition engines. SAE Technical Paper Series, 982601

Kayes, D., Liu, H., \& Hochgreb, S. (1999). Particulate matter emission during start-up and transient operation of a spark-ignition engine. SAE Technical Paper Series, 1999-01-3529 
Kayes, D., \& Hochgreb, S. (1999). Mechanism of particulate matter formation in sparkignition engines. 3. model of PM formation. Environmental science \& technology, $33(22), 3978-3992$.

Keskinen, J., Pietarinen, K., \& Lehtimaki, M. (1992). Electrical low-pressure impactor. Journal of Aerosol Science, 23(4), 353-360.

Kim, W., Kim, S. H., Lee, D. W., Lee, S., Lim, C. S., \& Ryu, J. H. (2001). Size analysis of automobile soot particles using field-flow fractionation. Environmental science \& technology, 35, 1005-1012.

Kittelson, D. B., Arnold, M., \& Watts, W. S. (1999). Review of diesel particulate sampling methods final report

Kittelson, D. B. (1998). Engines and nanoparticles: A review. Journal of Aerosol Science, $29(5 / 6), 575-588$.

Kittelson, D. B., Watts, W. F., Johnson, J. P., Goodier, S., Payne, M., \& Preston, H., et al. (2005). On-road nanoparticle measurements: Filter evaluations; ambient levels. 2nd International Symposium on Nanoparticles and Health,

Kittelson, D. B., Watts, W. F., \& Johnson, J. P. (2006/8). On-road and laboratory evaluation of combustion aerosols--Part1: Summary of diesel engine results. Journal of Aerosol Science, 37(8), 913-930. 
Kittelson, D. B., Watts, W. F., Johnson, J. P., Schauer, J. J., \& Lawson, D. R. (2006/8). On-road and laboratory evaluation of combustion aerosols--part 2: Summary of spark ignition engine results. Journal of Aerosol Science, 37(8), 931-949.

Ludykar, D., Westerholm, R., \& Almen, J. (1999). Cold start emissions at+22, -7 and -20 degrees $\mathrm{C}$ ambient temperatures from a three-way catalyst (TWC) car: Regulated and unregulated exhaust components. Science of the Total Environment, 235(1-3), 65-69.

Maricq, M. M., Chase, R. E., Xu, N., \& Podsiadlik, D. H. (2002). The effects of the catalytic converter and fuel sulfur level on motor vehicle particulate matter emissions: Gasoline vehicles. Environmental science \& technology, 36(2), 276-282.

Maricq, M. M., Podsiadlik, D. H., \& Chase, R. E. (1999a). Examination of the sizeresolved and transient nature of motor vehicle particle emissions. Environmental science \& technology, 33(10), 1618-1626.

Maricq, M. M., Podsiadlik, D. H., \& Chase, R. E. (1999b). Gasoline vehicle particle size distributions: Comparison of steady state, FTP, and US06 measurements. Environmental science \& technology, 33, 2007-2015.

Mathis, U., Mohr, M., \& Forss, A. (2005). Comprehensive particle characterization of modern gasoline and diesel passenger cars at low ambient temperatures. Atmospheric Environment, 39(1), 107.

Office of Energy Efficiency, Natural Resources Canada and Statistics Canada. (2006). National energy use database., 2006, from http://oee.nrcan.gc.ca/corporate/statistics/neud/dpa/data_e/database_e.cfm 
Pope, C. A., \& Dockery, D. W. (2006). Health effects of fine particulate air pollution: Lines that connect. Journal of the Air \& Waste Management Association, 56(6), 709 742.

Pope, C. A., Dockery, D. W., \& Schwartz, J. (1995). Review of epidemiological evidence of health-effects of particulate air-pollution. Inhalation toxicology, 7(1), 1-18.

Pope, C. A., Thun, M. J., Namboodiri, M. M., Dockery, D. W., Evans, J. S., \& Speizer, F. E., et al. (1995). Particulate air-pollution as a predictor of mortality in a prospectivestudy of us adults. American Journal of Respiratory and Critical Care Medicine, 151(3), 669-674.

Rickeard, D. J., Bateman, J. R., Kwon, Y. K., McAughey, J. J., \& Dickens, C. J. (1996). Exhaust particle size distribution: Vehicle and fuel influences in light duty vehicles. SAE Technical Paper Series, 961980

Saldiva, P. H. N., Pope, C. A., Schwartz, J., Dockery, D. W., Lichtenfels, A. J., \& Salge, J. M., et al. (1995). Air-pollution and mortality in elderly people - a time-series study in sao-paulo, brazil. Archives of Environmental Health, 50(2), 159-163.

Salvi, S., \& Holgate, S. T. (1999). Mechanisms of particulate matter toxicity. Clinical and Experimental Allergy, 29(9), 1187-1194.

Scherrer, H. C., \& Kittelson, D. B. (1982). Light absorption cross sections of diesel particles. SAE Technical Paper Series, 810181 
Society of Automotive Engineers. (2002). Recommended practice for measuring fuel economy and emissions of hybrid-electric and conventional heavy-duty vehicles (Surface Vehicle Recommended Practice No. SAE - J2711)

Society of Automotive Engineers. (1995). Recommended practice for measuring the exhaust emissions, fuel economy, electrical energy consumption, and all-electric range of hybrid-electric vehicles No. SAE - J1711)

Swiss EPA and DOT. (2002). Simultaneous comparison of 20 instrument candidates for diesel particle measurement. Workshop San Diego,

Sydbom, A., Blomberg, A., Parnia, S., Stenfors, N., Sandstrom, T., \& Dahlen, S. E. (2001). Health effects of diesel exhaust emissions. European Respiratory Journal, 17(4), 733-746.

Toyota Motor Corporation. (2006). Hybrid synergy drive., 2006, from http://www.hybridsynergydrive.com/en/top.html

Transport Canada. (2005). Advanced technology vehicles program. Retrieved 01/05, 2005, from www.tc.gc.ca/atvp

TSI Incorporated. (2002). Model 3022A condensation particle counter instruction manual.

United Nations Economic Commission for Europe. (2002). World forum for harmonization of vehicle regulations (WP.29).

URG Incorporated. , 2006, from http://www.urgcorp.com/ 
Whitby, K. T., \& Cantrell, B. K. (1975). Atmospheric aerosols - characteristics and measurement. ICESA Conference Proceedings, , IEEE \#75-CH 1004-1 ICESA, paper $29-16 \mathrm{pp}$. 


\section{Appendix 1 - Test Summary}

\section{Contents}

(1) Record of every test included in the results of this thesis organized by vehicle ID, test date, and driving cycle

(2) Integrated and transient files associated with each test

(3) Net energy change variance (NECvar - \%) for each test

(4) Notes describing missing data

Transport Canada Vehicle IDs:

TC2000-001 - Honda Insight

TC2002-015 - Gasoline Smart Cabrio

TC2003-001 - Honda Civic Hybrid

TC2004-010 - Toyota Prius

TC2005-003 - Ford Escape Hybrid

*White background denotes $20^{\circ} \mathrm{C}$ testing, grey denotes $-18^{\circ} \mathrm{C}$ testing 


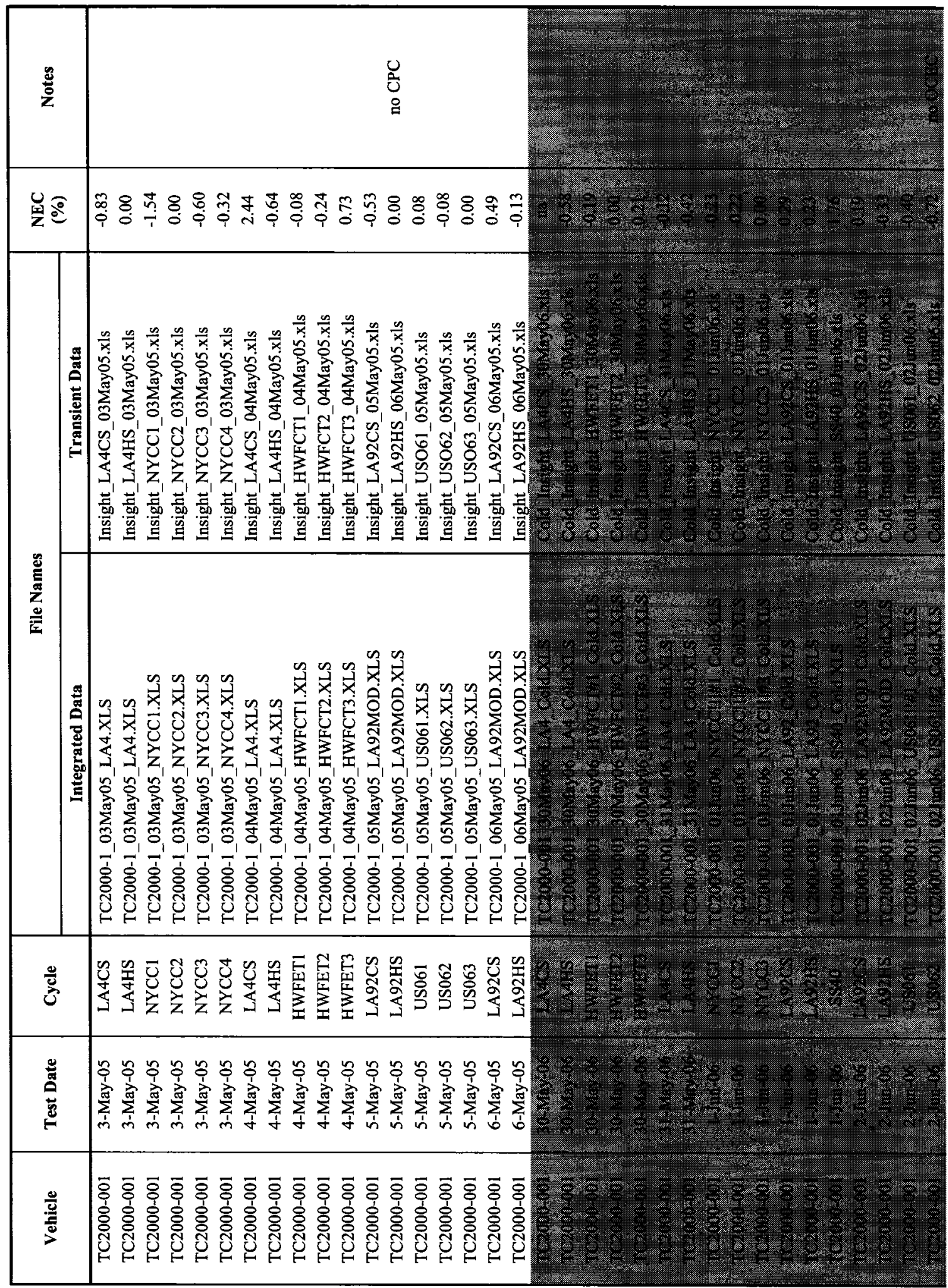




\begin{tabular}{|c|c|}
\hline 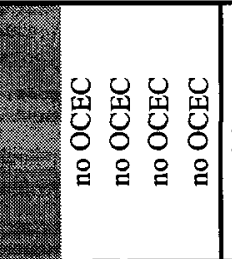 & 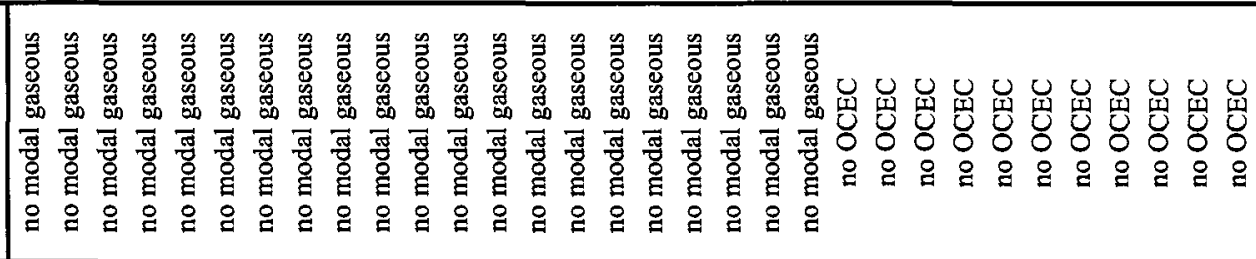 \\
\hline 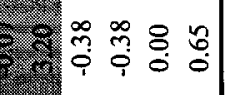 & 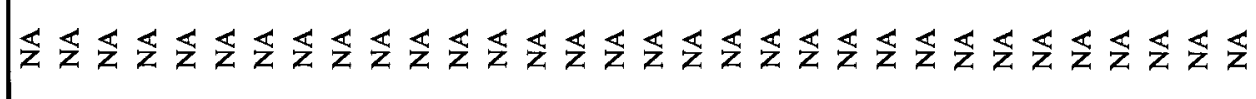 \\
\hline 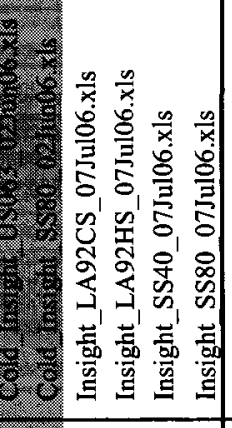 & 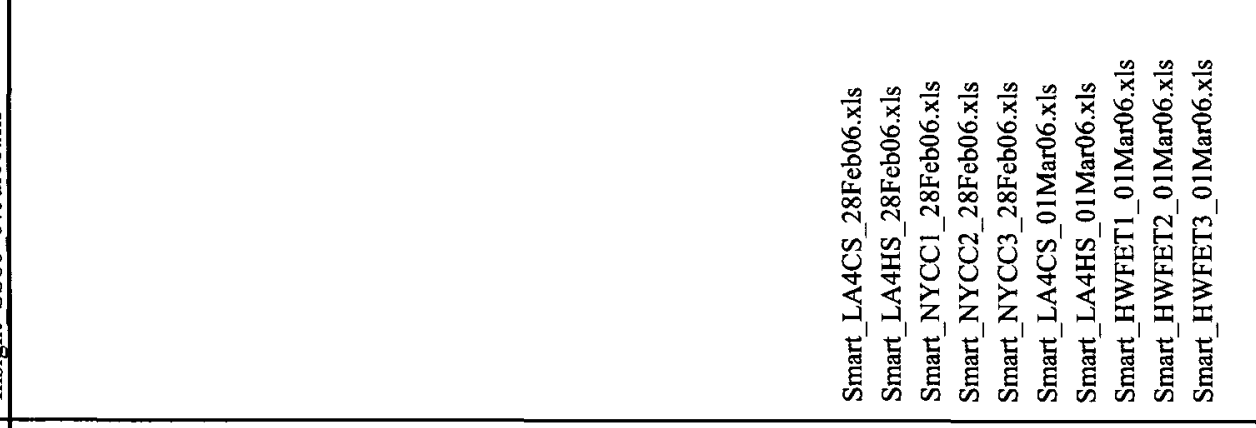 \\
\hline 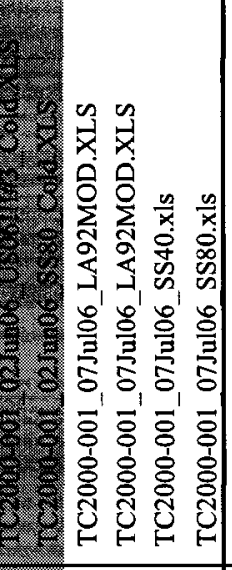 & 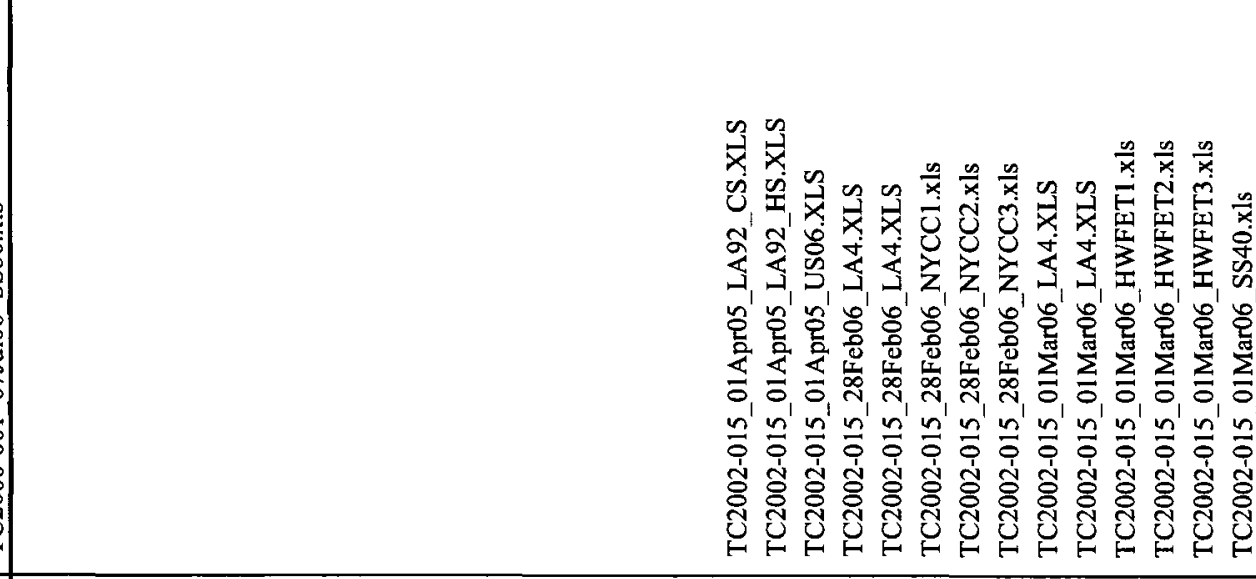 \\
\hline 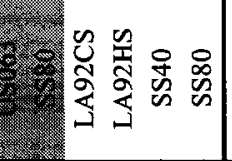 & 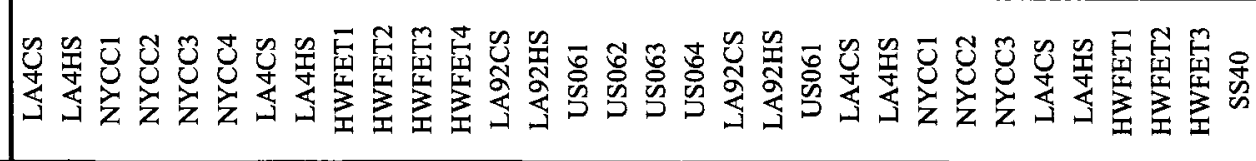 \\
\hline 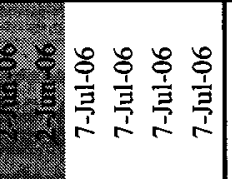 & 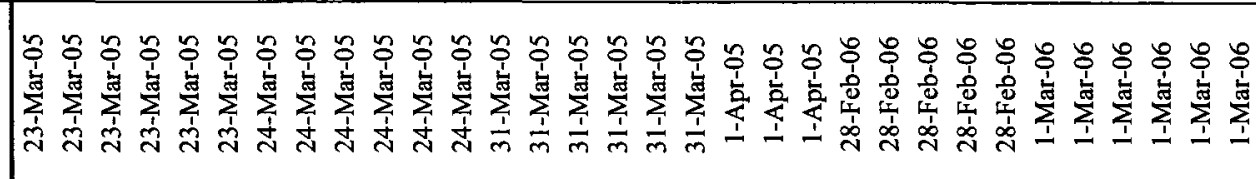 \\
\hline 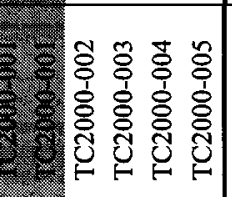 & 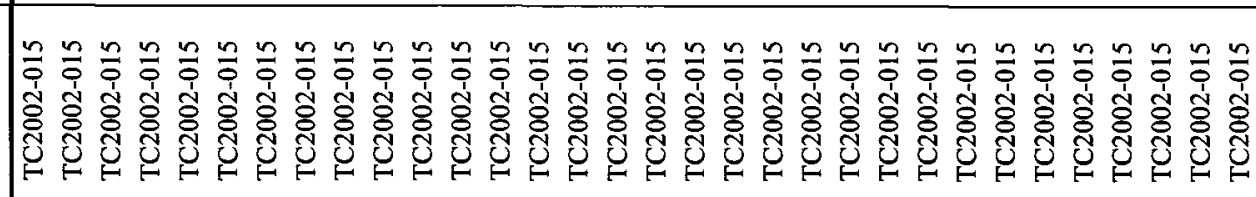 \\
\hline
\end{tabular}




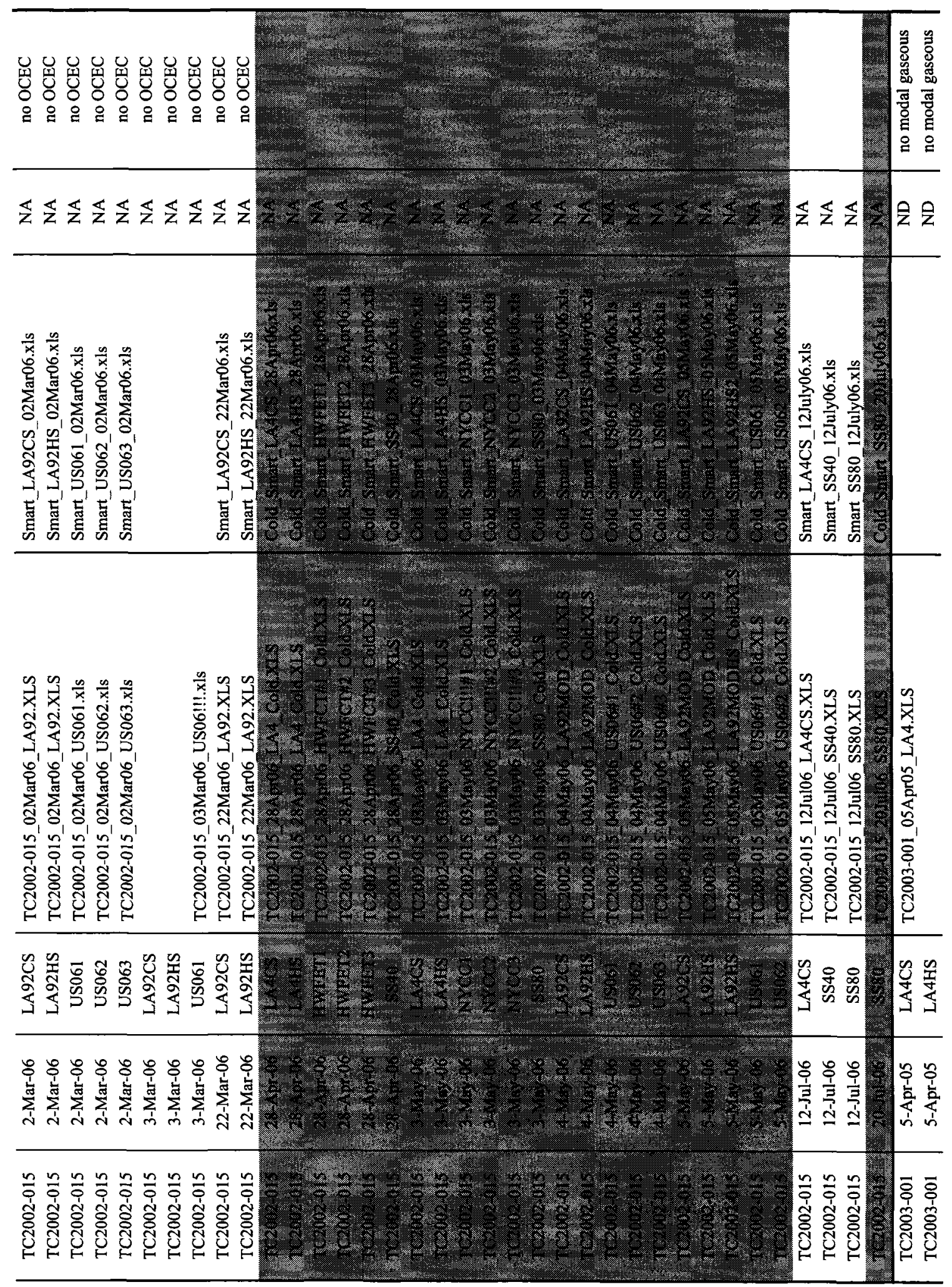




\begin{tabular}{|c|c|}
\hline 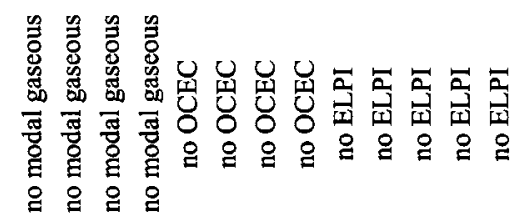 & 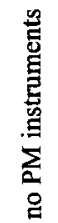 \\
\hline
\end{tabular}

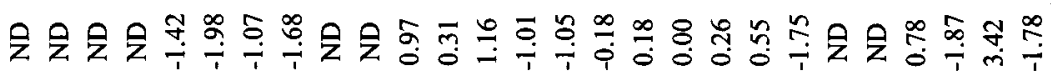

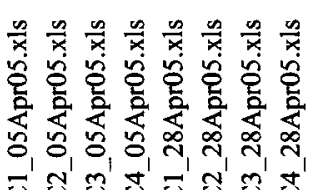

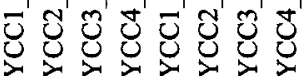

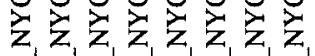

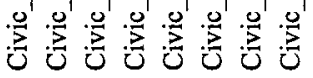
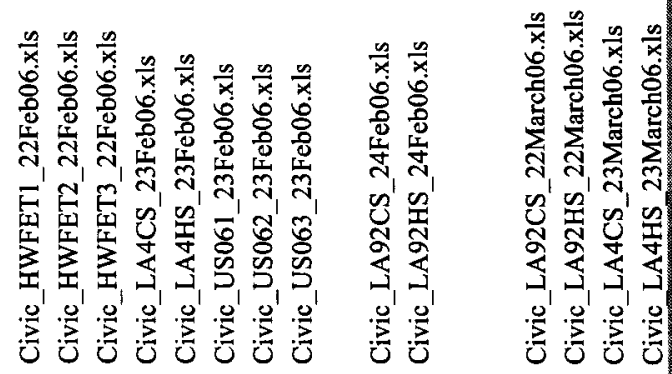

$\frac{n}{x} \frac{n}{x} \frac{n}{x} \frac{n}{x} \frac{n}{x} \frac{n}{x} \frac{n}{x} \frac{n}{x} \frac{n}{x}$

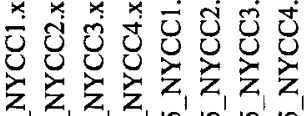

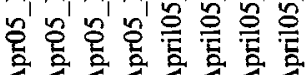

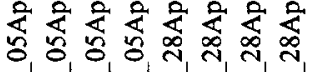

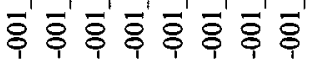

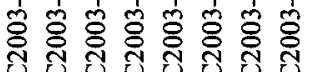

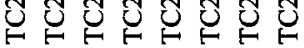
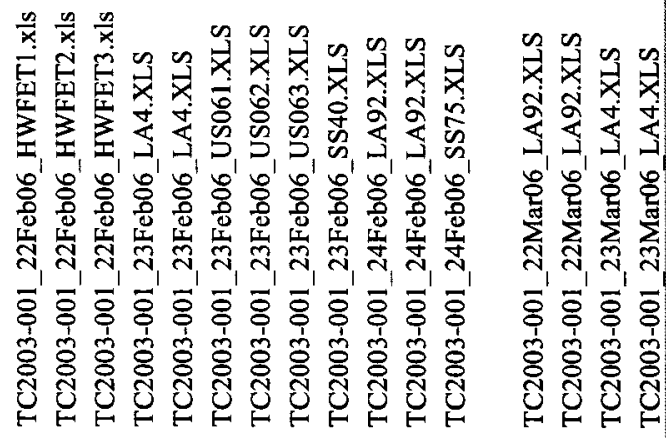

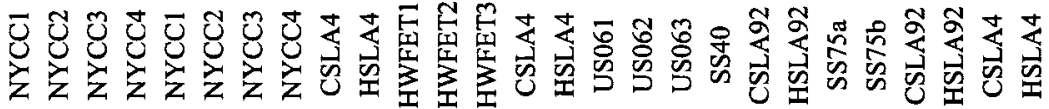

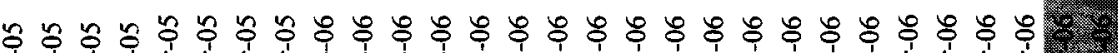

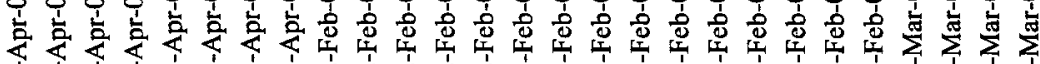

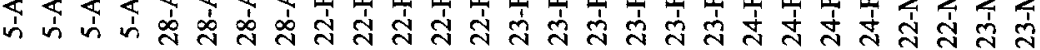

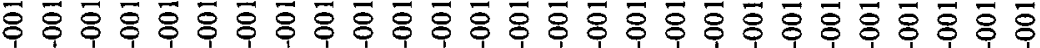

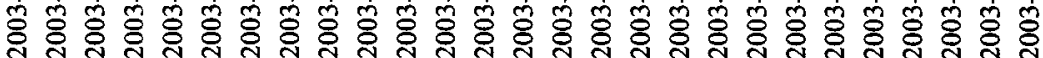

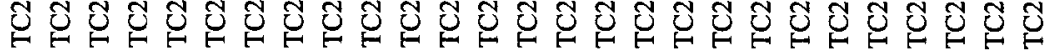




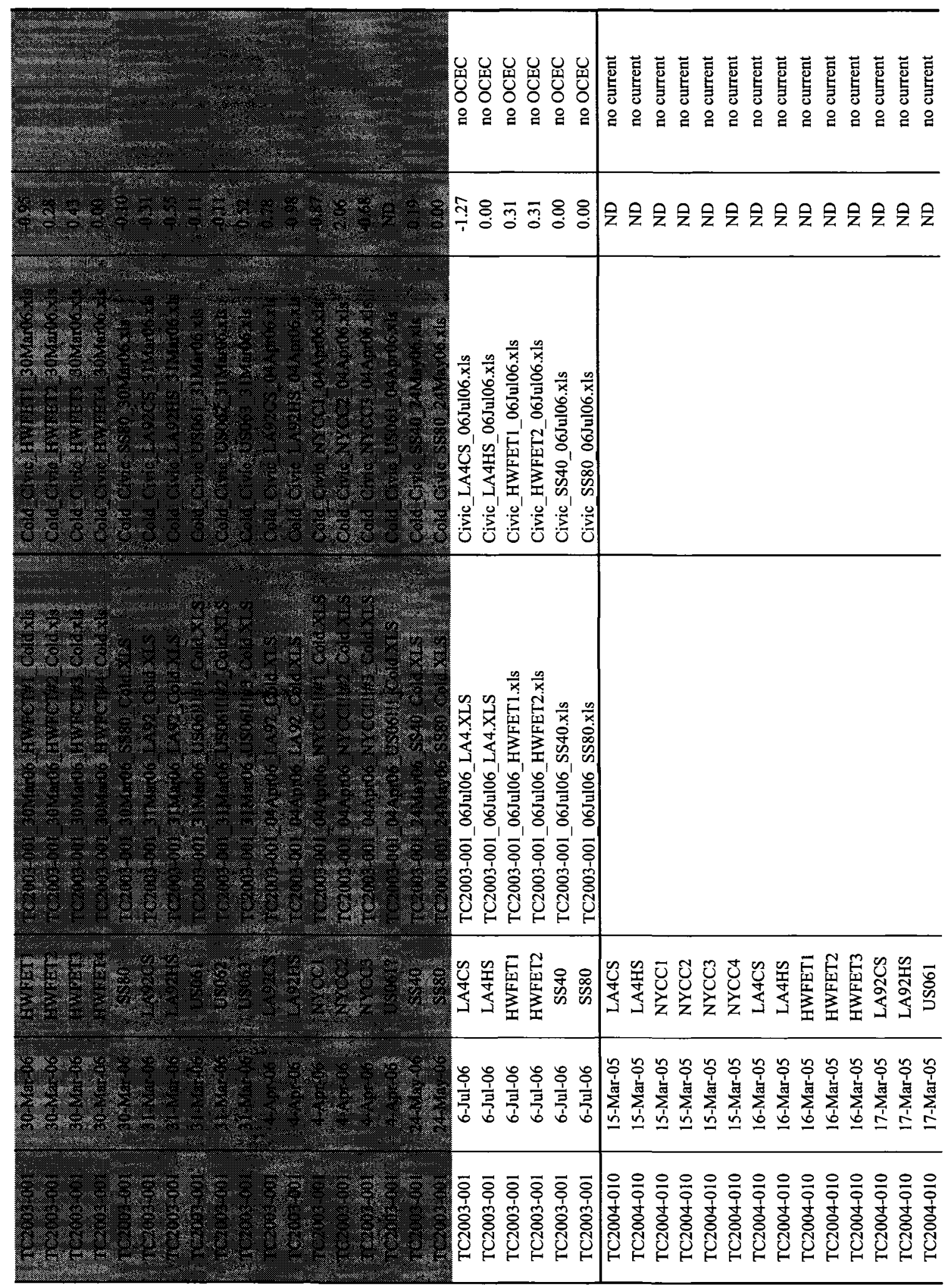




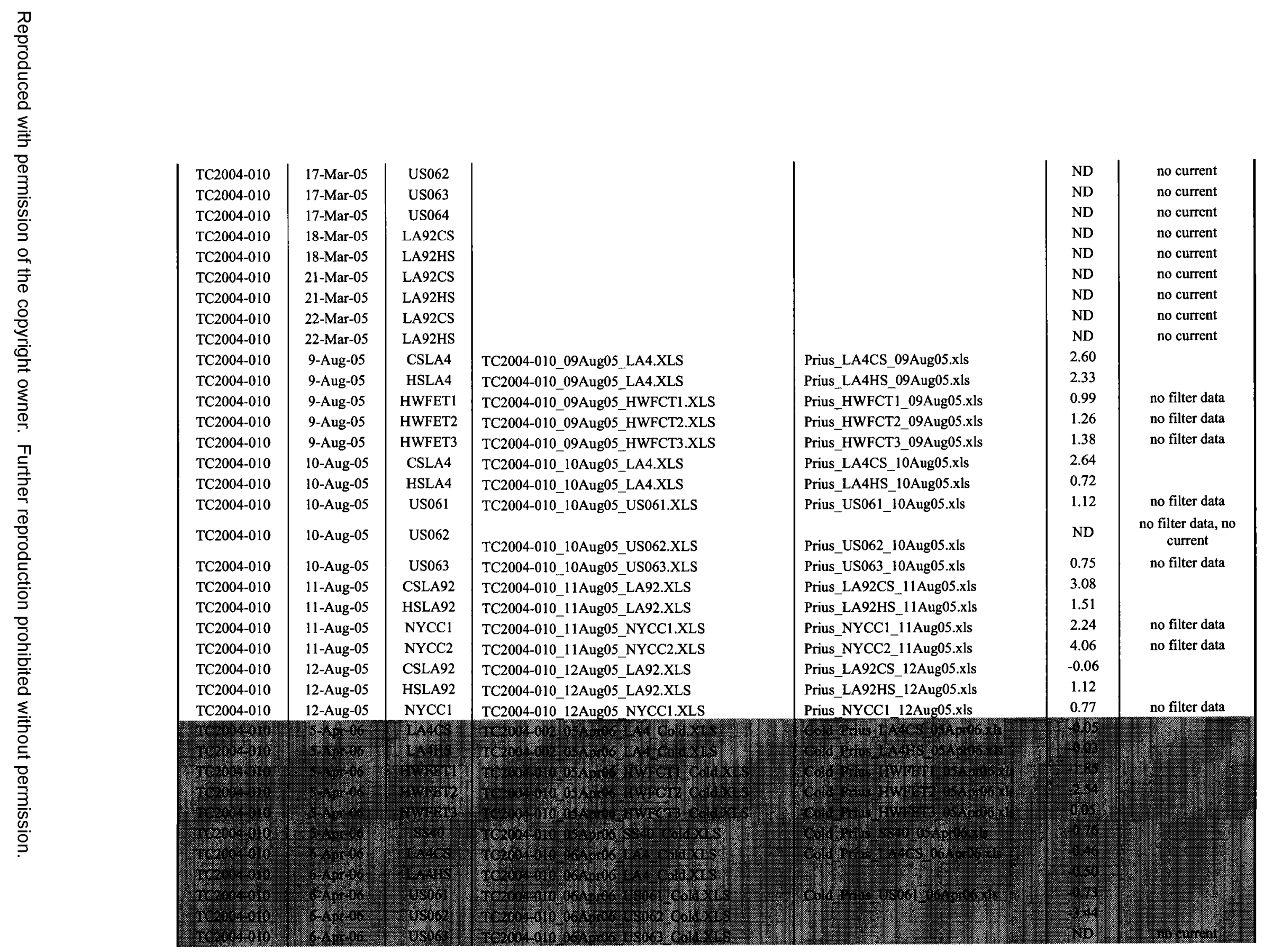




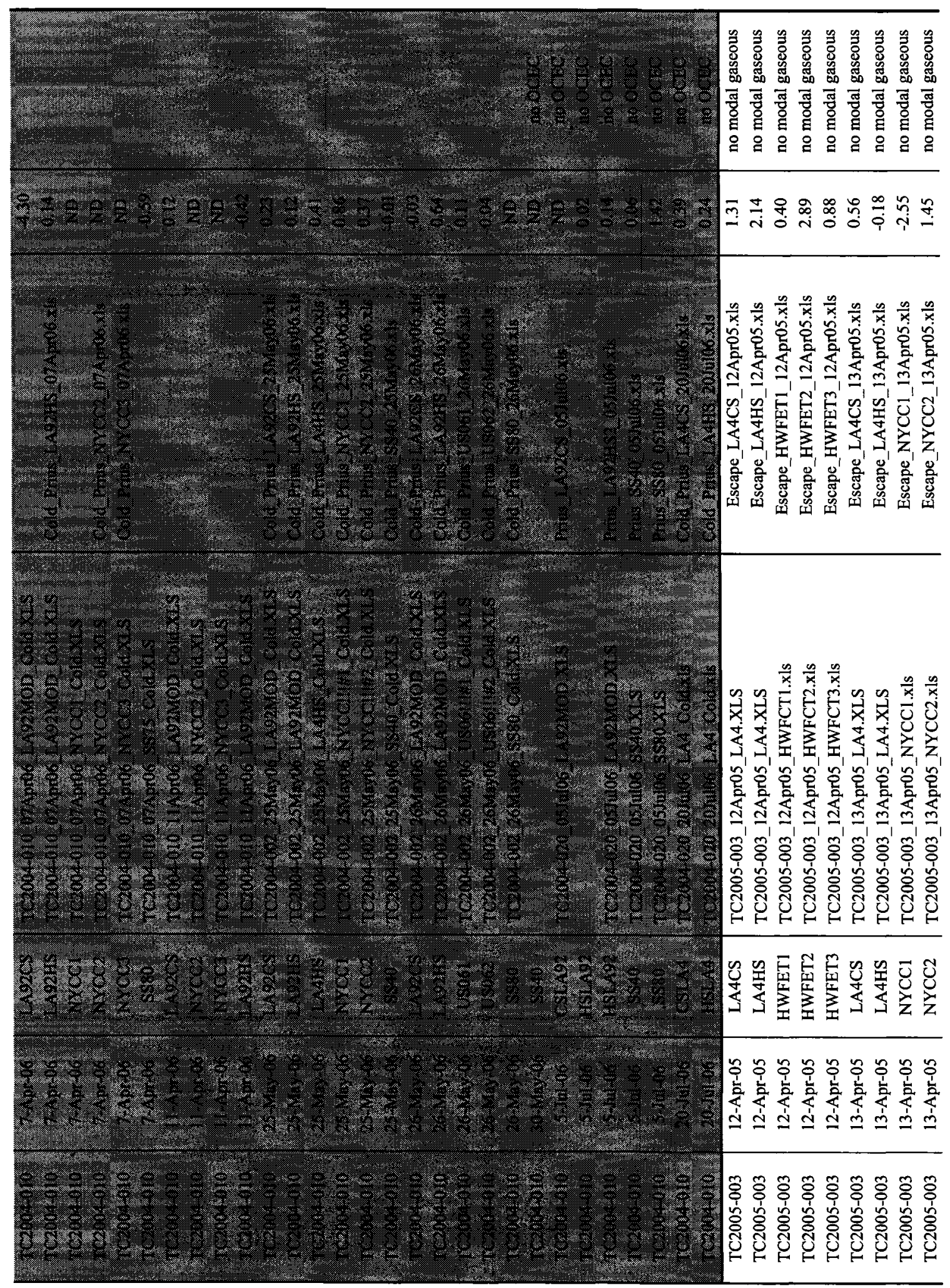




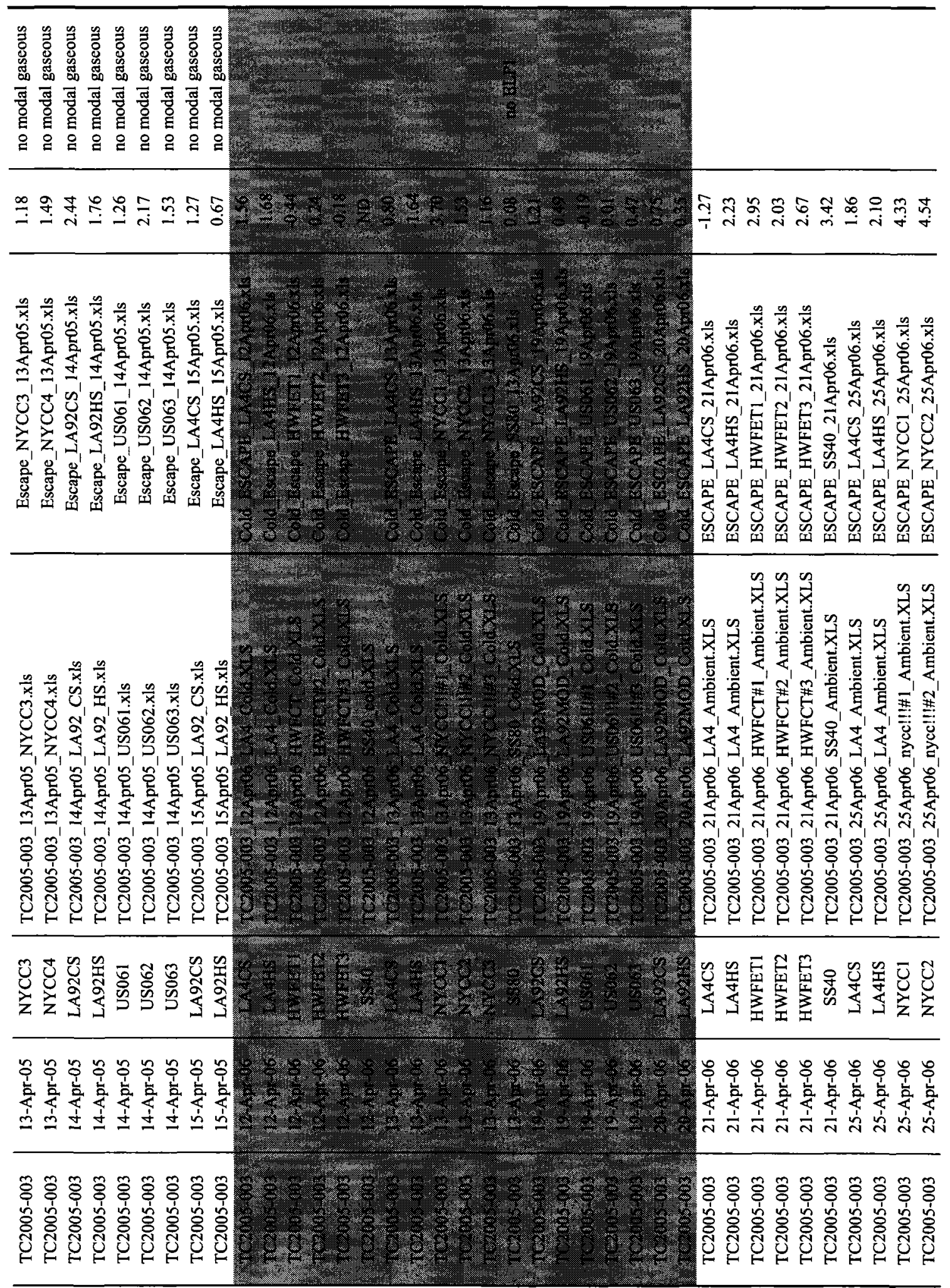




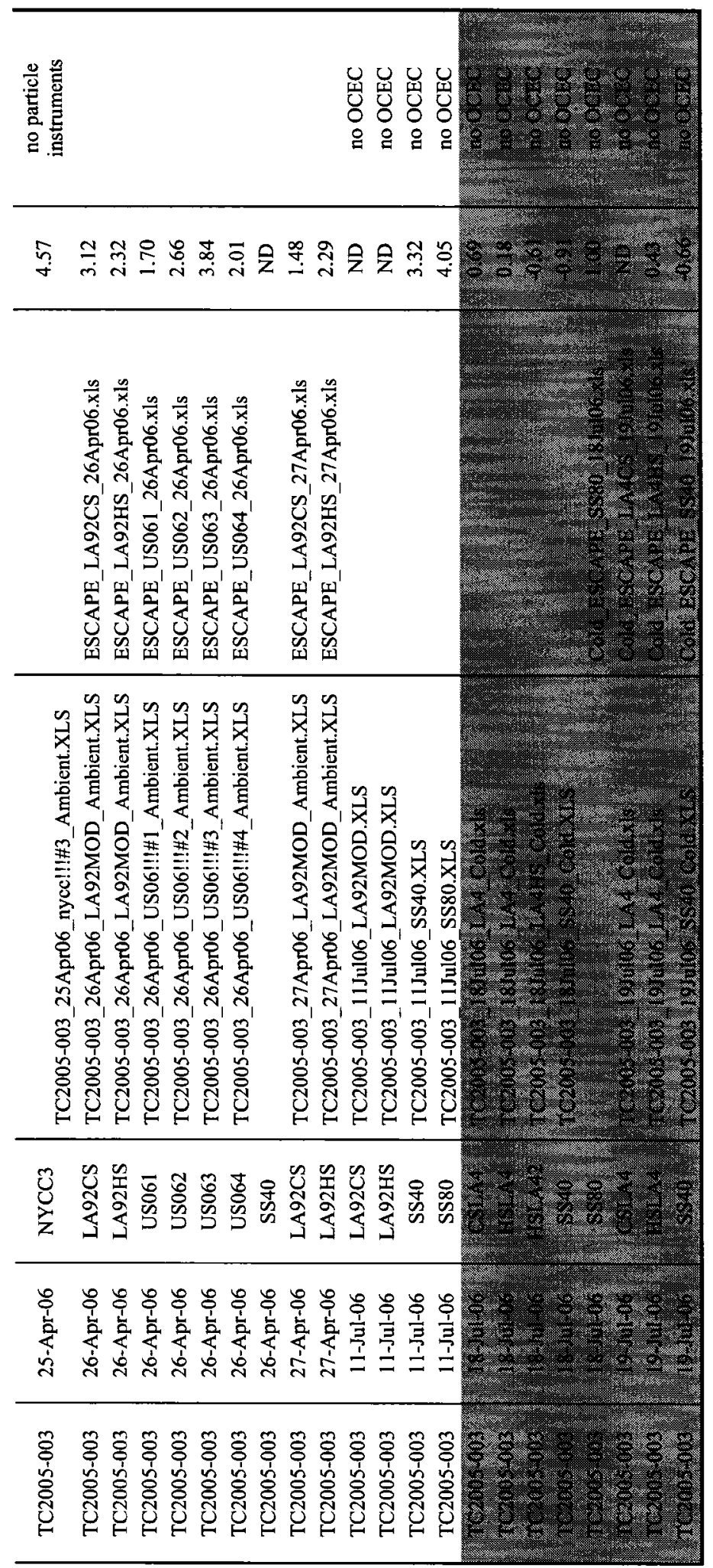




\title{
Appendix 2 - Supplementary Transient Examples
}

\author{
Contents
}

(1) Examples of transient emissions for the Insight and Prius on the NYCC*2 at $20^{\circ} \mathrm{C}$ and at $-18^{\circ} \mathrm{C}$

(2) Examples of transient number-weighted size distributions for the Smart, Escape, Civic, and Insight on the NYCC*2 at $20^{\circ} \mathrm{C}$ and $-18^{\circ}$ 


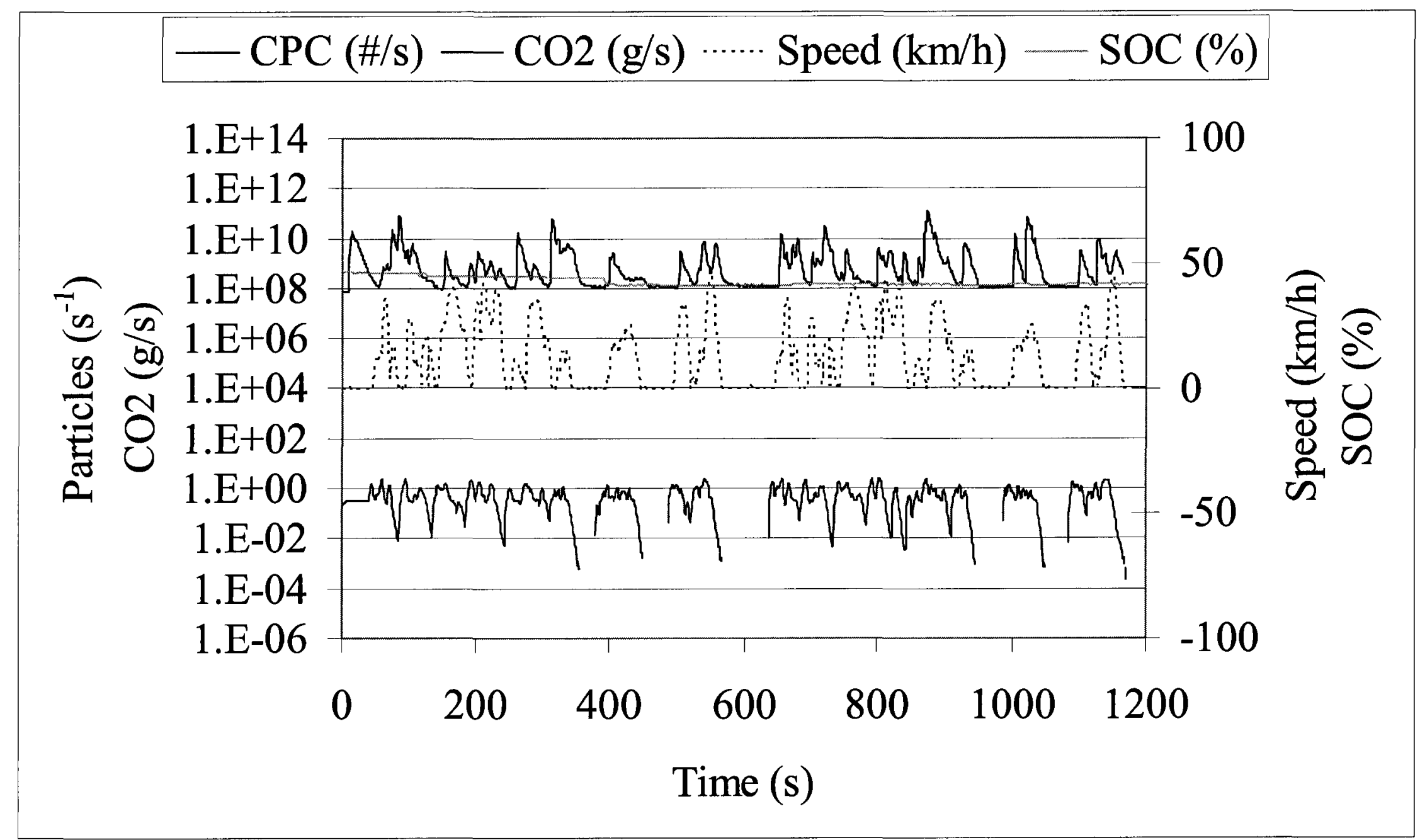

Figure A.1 - Example transient emissions from the Insight on the $\mathrm{NYCC}^{*} 2$ at $20^{\circ} \mathrm{C}$ 


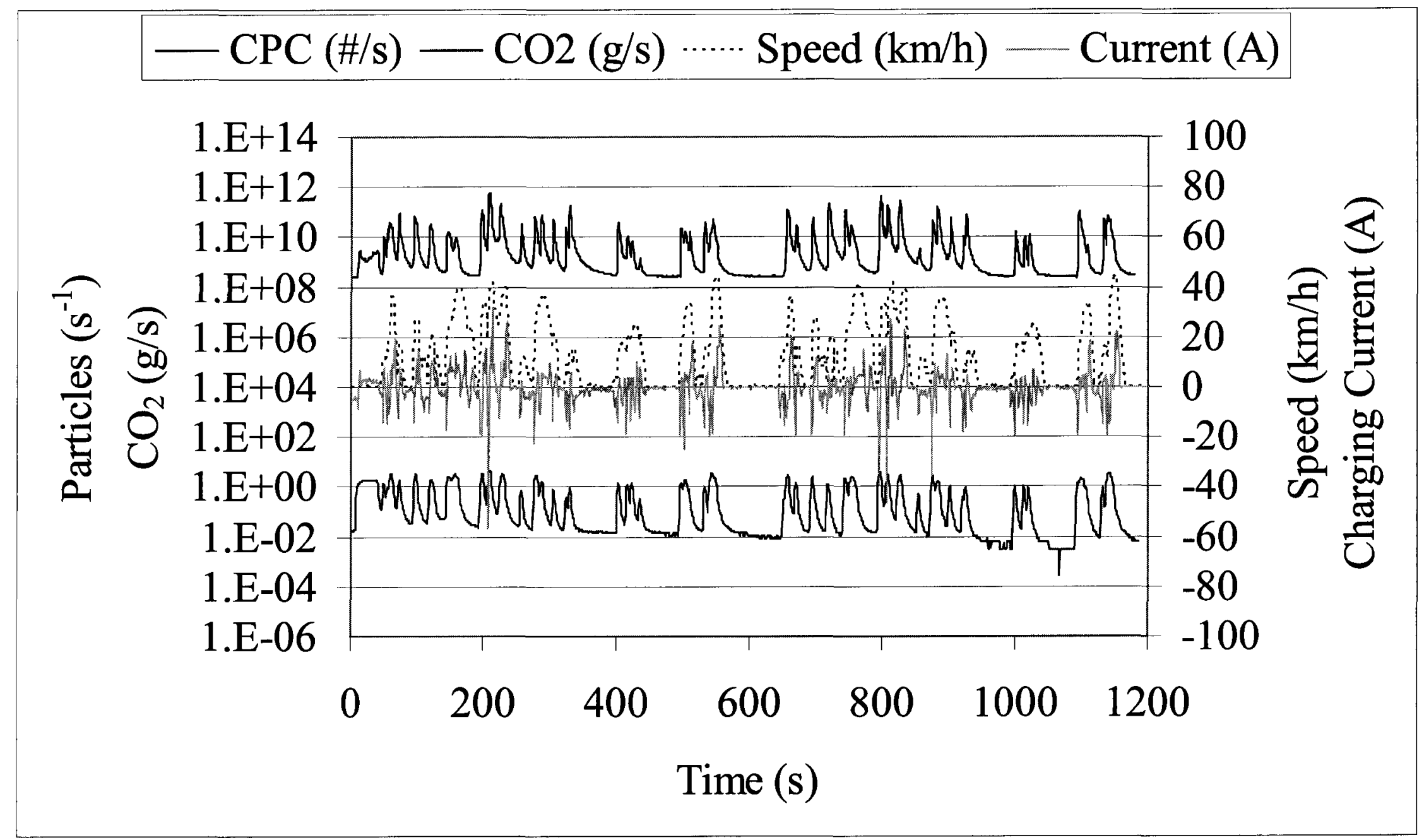

Figure A.2 - Example transient emissions from the Prius on the NYCC*2 at $20^{\circ} \mathrm{C}$ 


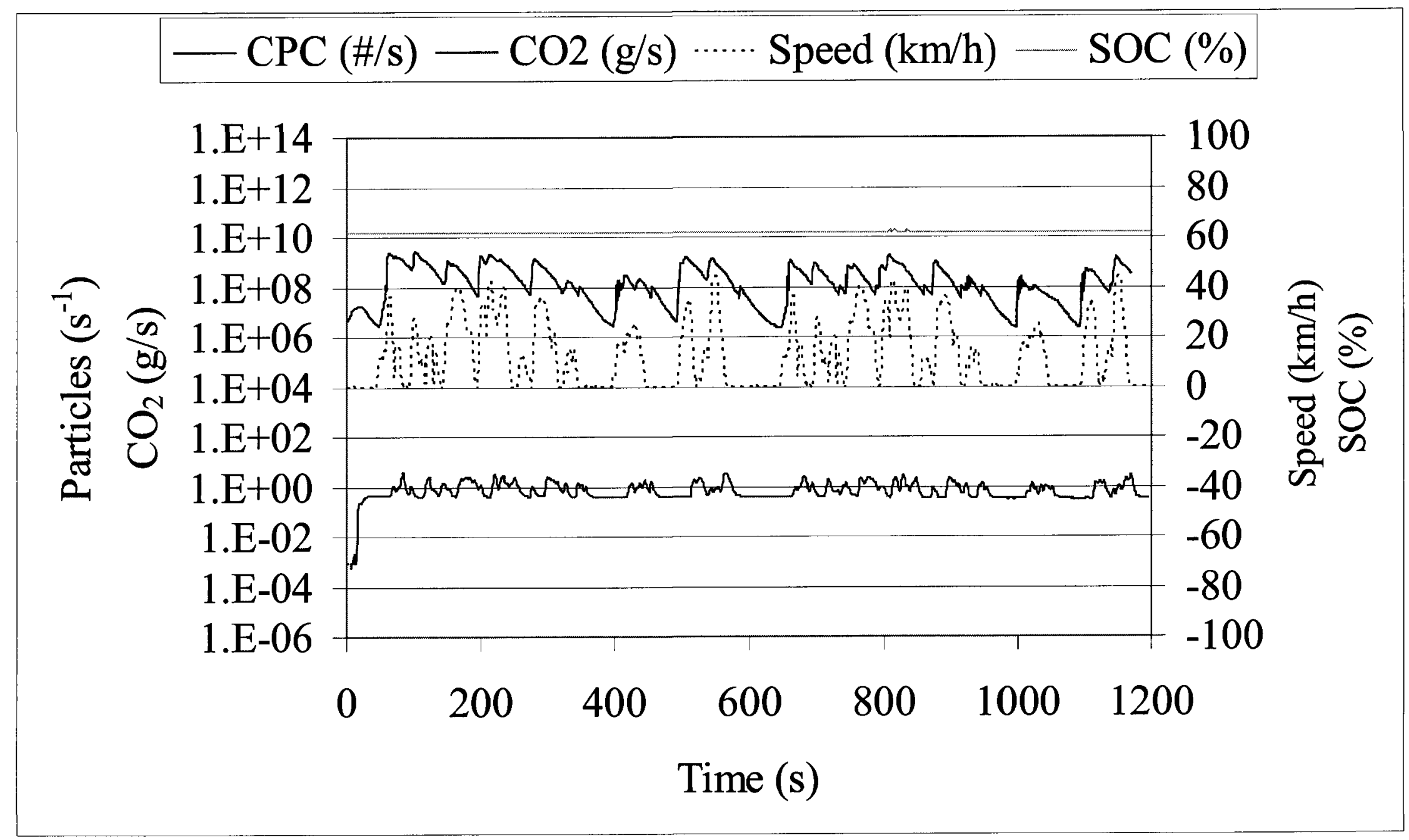

Figure A.6 - Example transient emissions from the Insight on the $\mathrm{NYCC}^{*} 2$ at $-18^{\circ} \mathrm{C}$ 


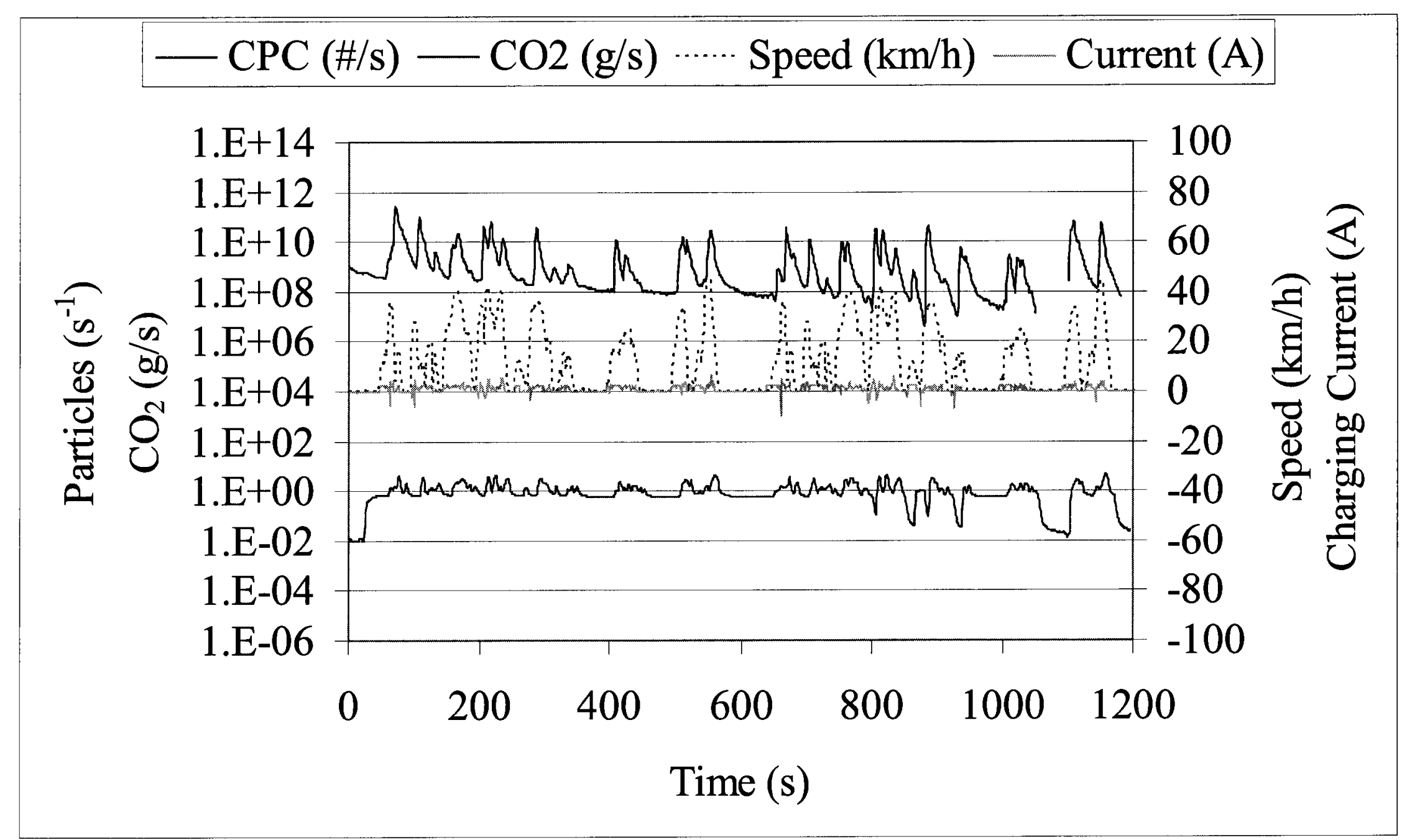

Figure A.7 - Example transient emissions from the Prius on the $\mathrm{NYCC}^{*} 2$ at $-18^{\circ} \mathrm{C}$ 


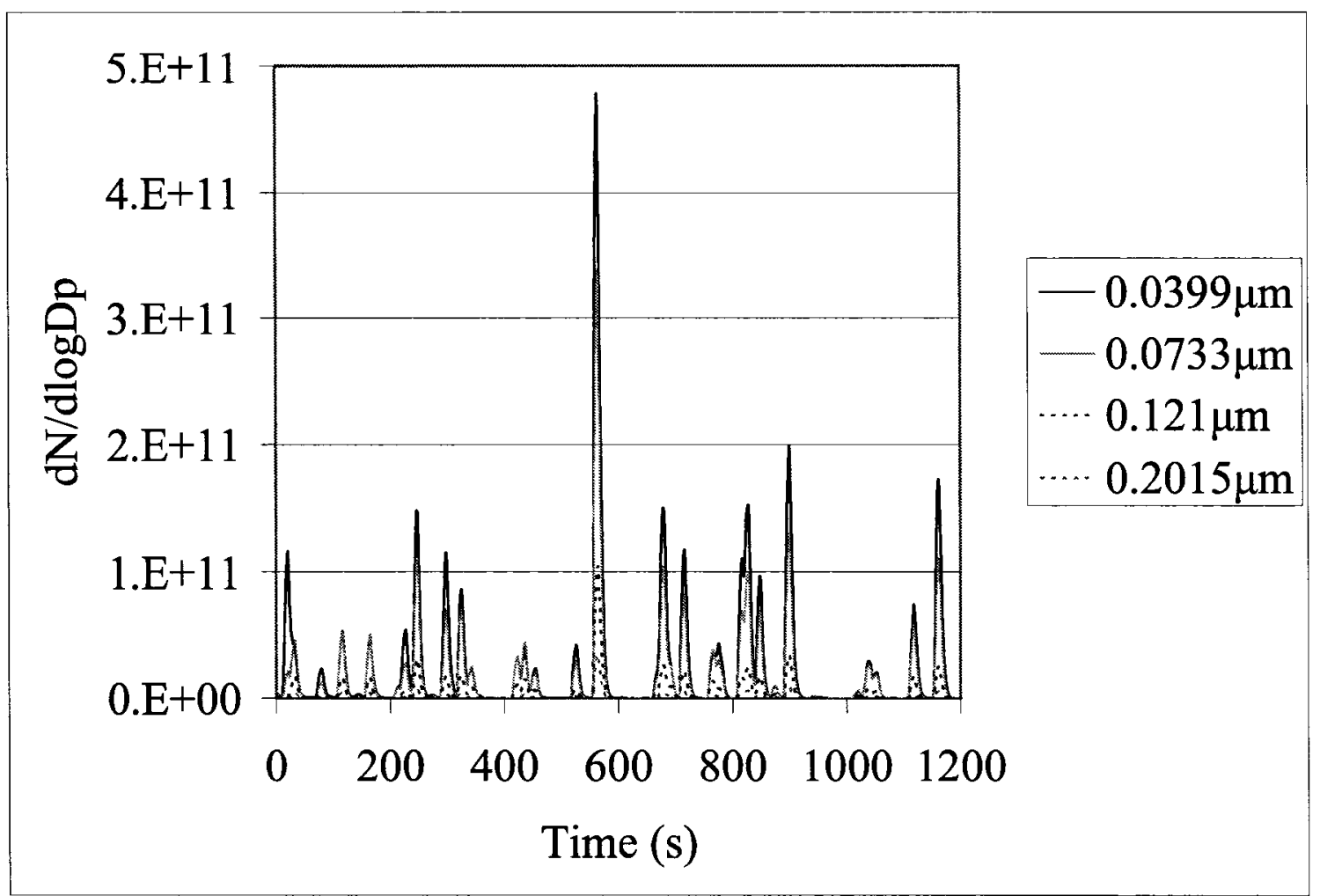

Figure A.8 - Example transient number-weighted size distribution for the Smart on the $\mathrm{NYCC} * 2$ at $20^{\circ} \mathrm{C}$

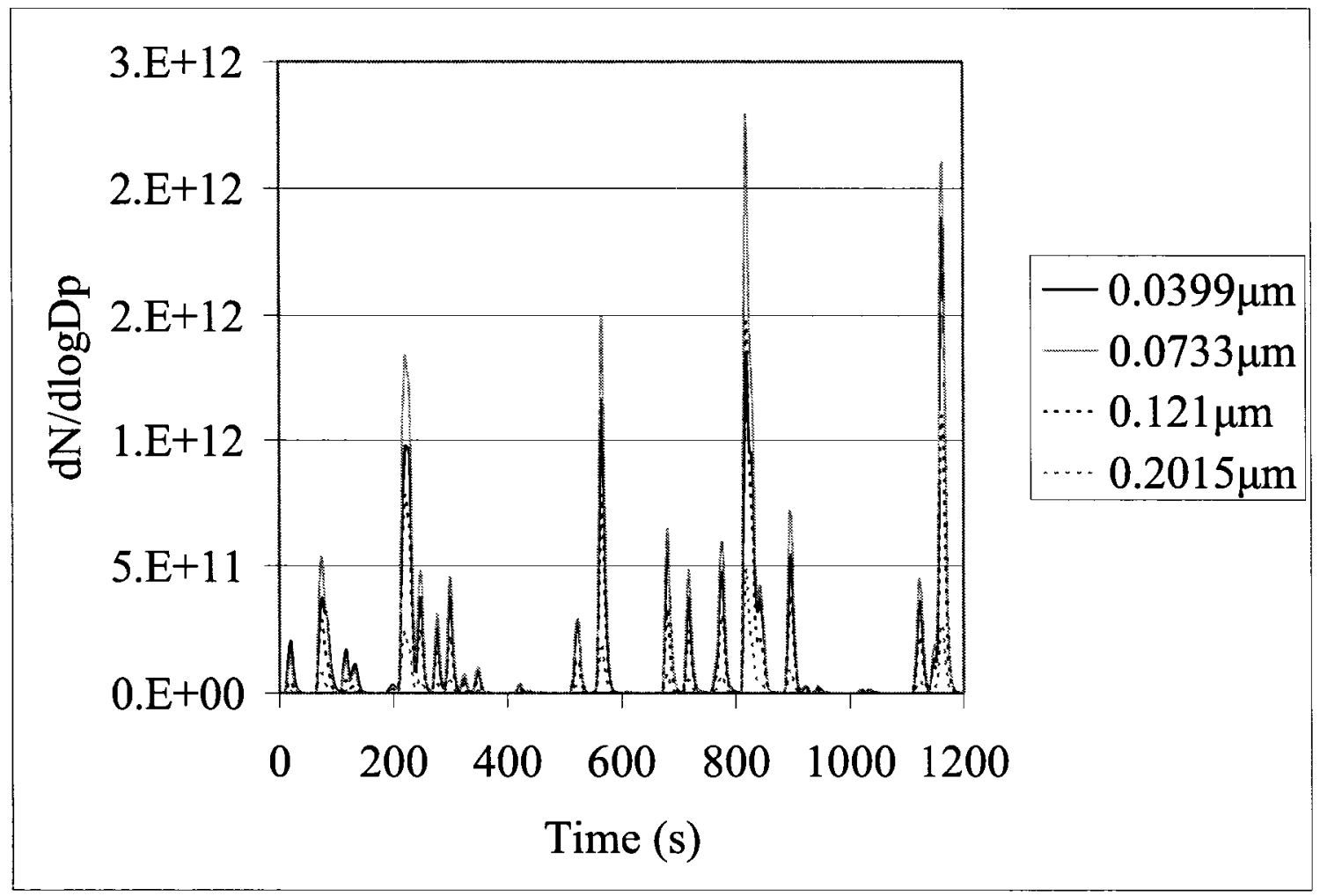

Figure A.9 - Example transient number-weighted size distribution for the Smart on the $\mathrm{NYCC} * 2$ at $-18^{\circ} \mathrm{C}$ 


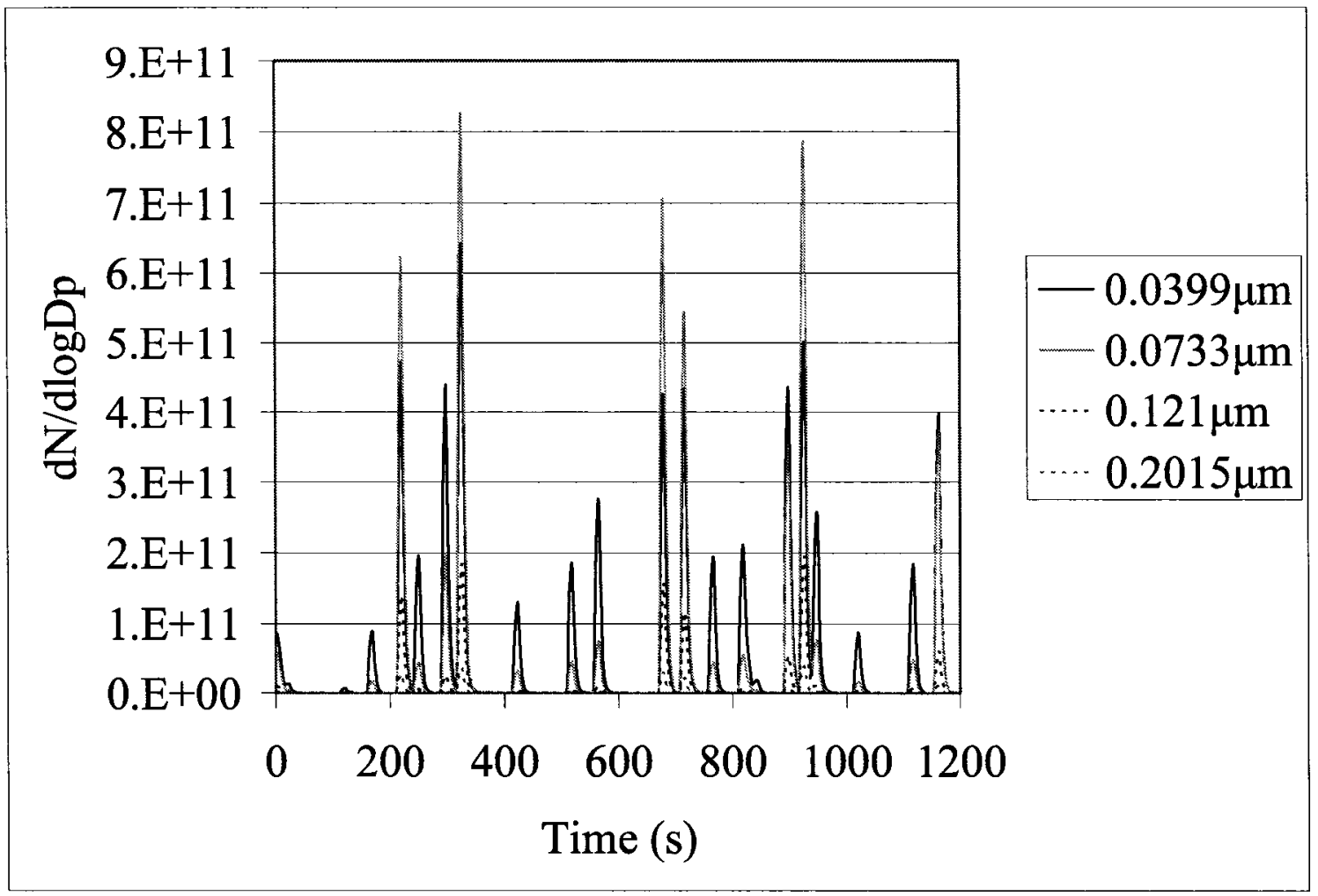

Figure A.10 - Example transient number-weighted size distribution for the Escape on the $\mathrm{NYCC} * 2$ at $20^{\circ} \mathrm{C}$

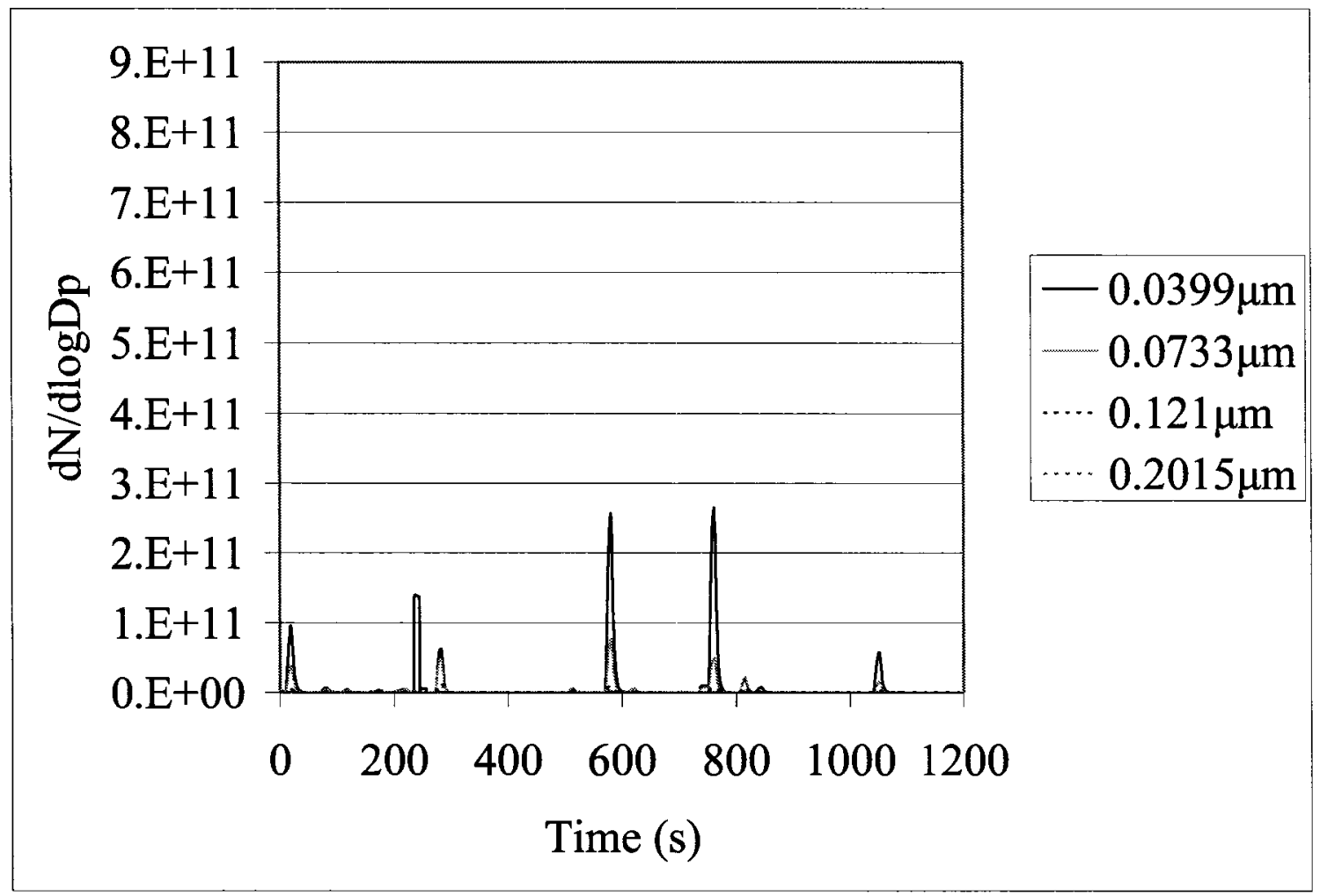

Figure A.11 - Example transient number-weighted size distribution for the Escape on the NYCC $* 2$ at $-18^{\circ} \mathrm{C}$ 


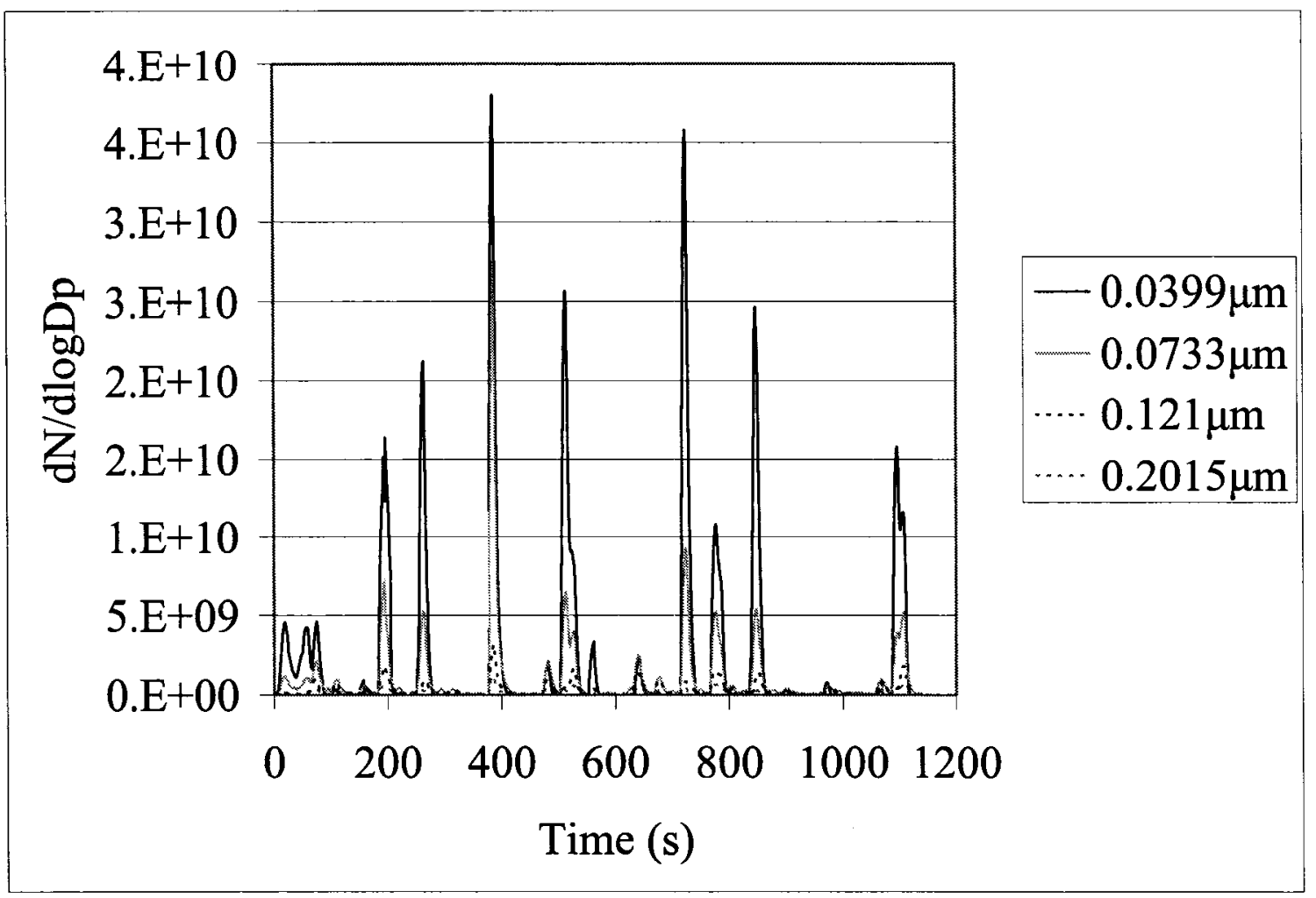

Figure A.12 - Example transient number-weighted size distribution for the Civic on the $\mathrm{NYCC} * 2$ at $20^{\circ} \mathrm{C}$

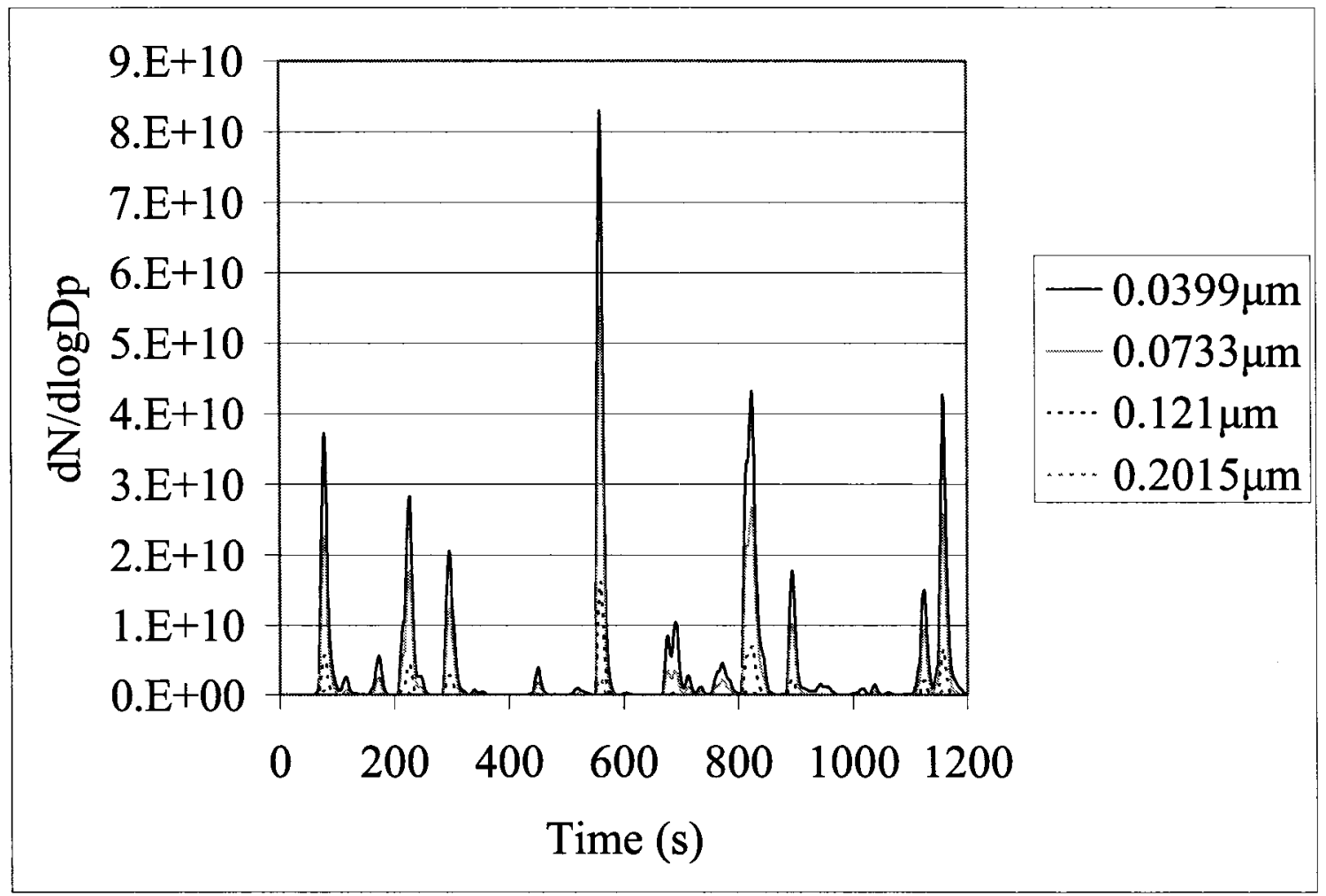

Figure A.13 - Example transient number-weighted size distribution for the Civic on the NYCC $* 2$ at $-18^{\circ} \mathrm{C}$ 


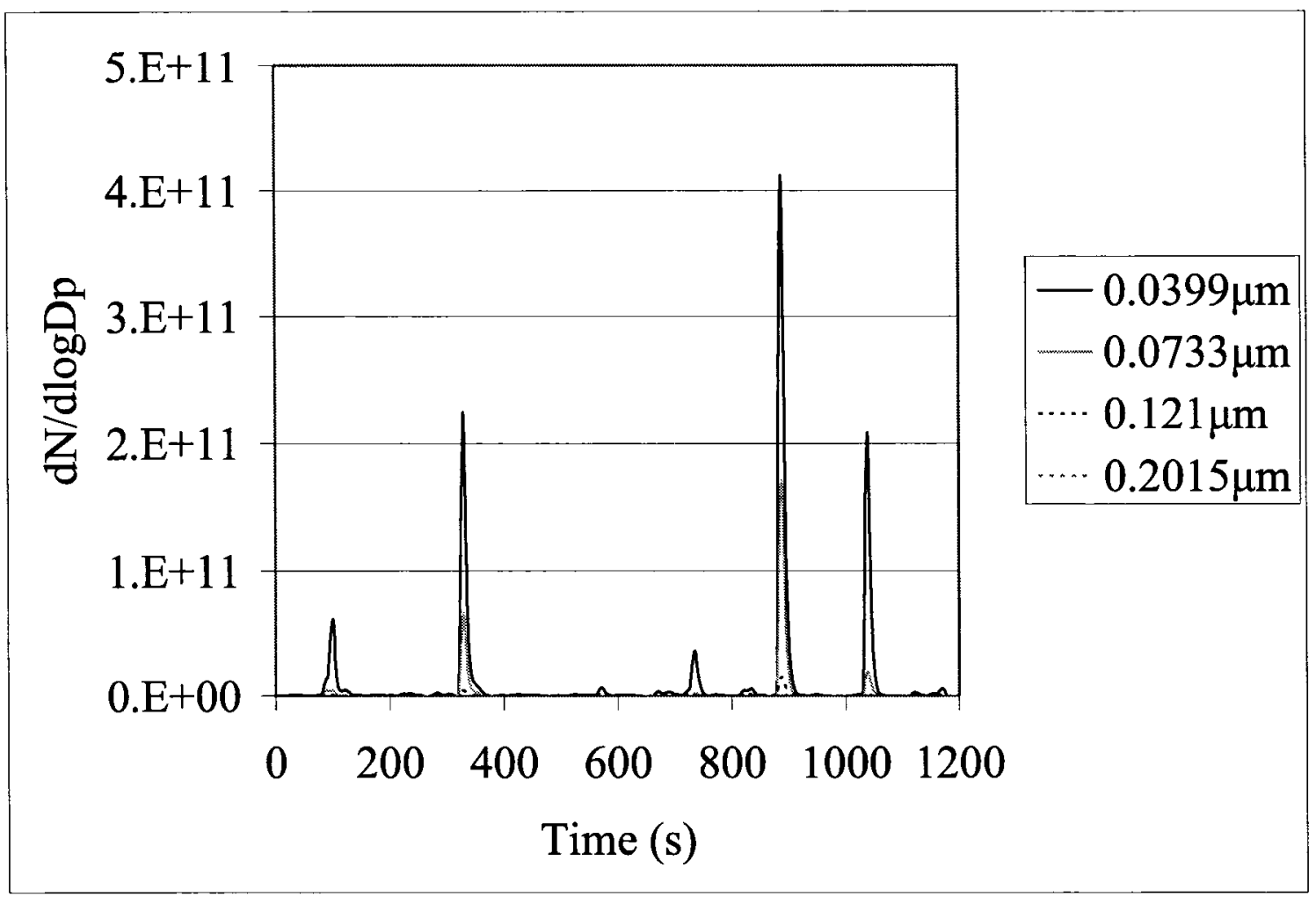

Figure A.14 - Example transient number-weighted size distribution for the Insight on the NYCC* 2 at $20^{\circ} \mathrm{C}$

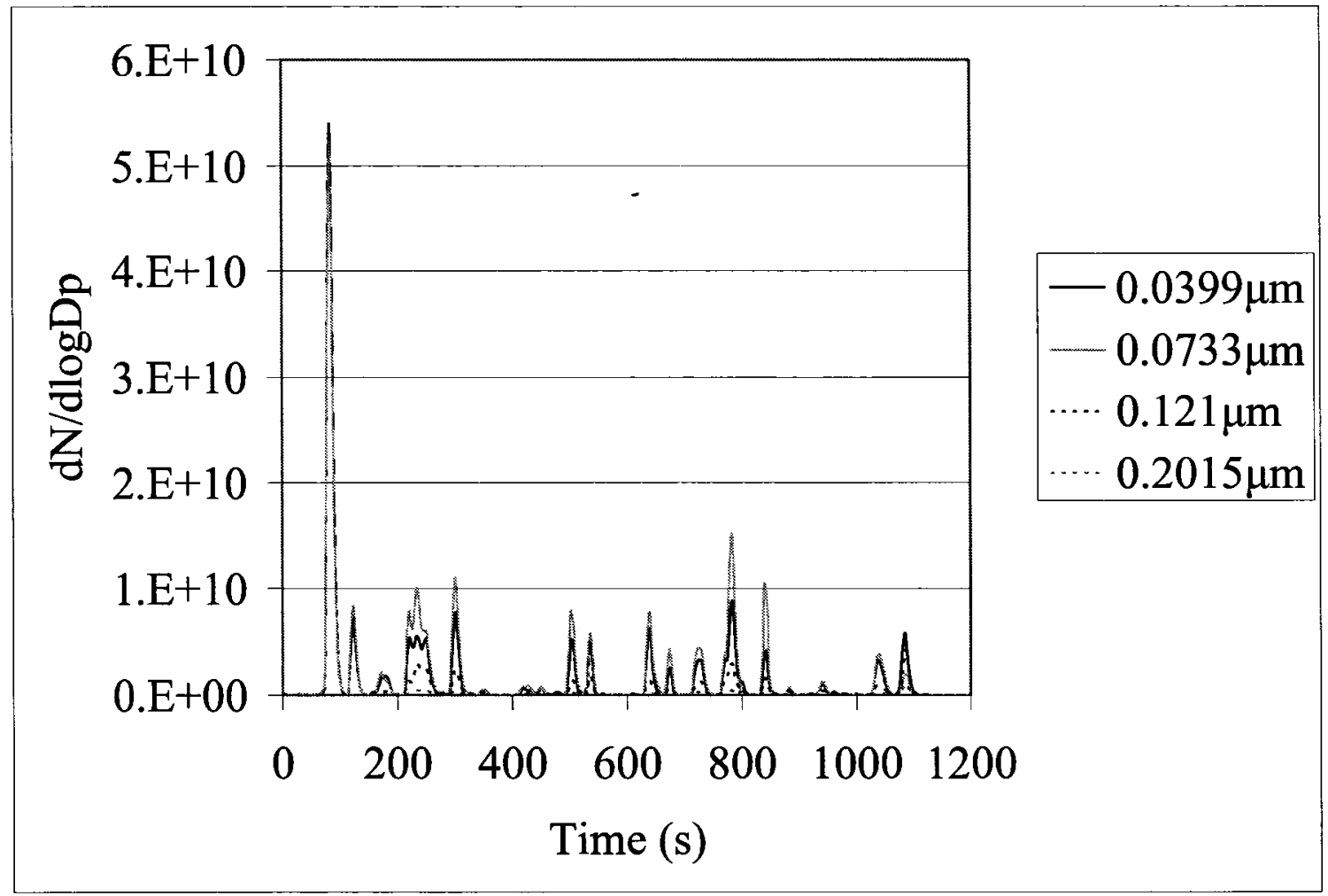

Figure A.15 - Example transient number-weighted size distribution for the Insight on the NYCC* 2 at $-18^{\circ} \mathrm{C}$ 


\section{Appendix 3 - Number Emission Rates}

\section{Contents}

(1) Tabulated average number emission rates based on condensation particle counter (CPC) and electrical low pressure impactor (ELPI) data. CPC counts particles between 0.007 and $3 \mu \mathrm{m}$ in diameter while the ELPI size range is $0.03-10 \mu \mathrm{m}$. Emission rates are distance-based. One standard deviation is shown.

(2) Graphs of CPC and ELPI average emission rates \pm 1 standard deviation $\left(\mathrm{km}^{-1}\right)$ 


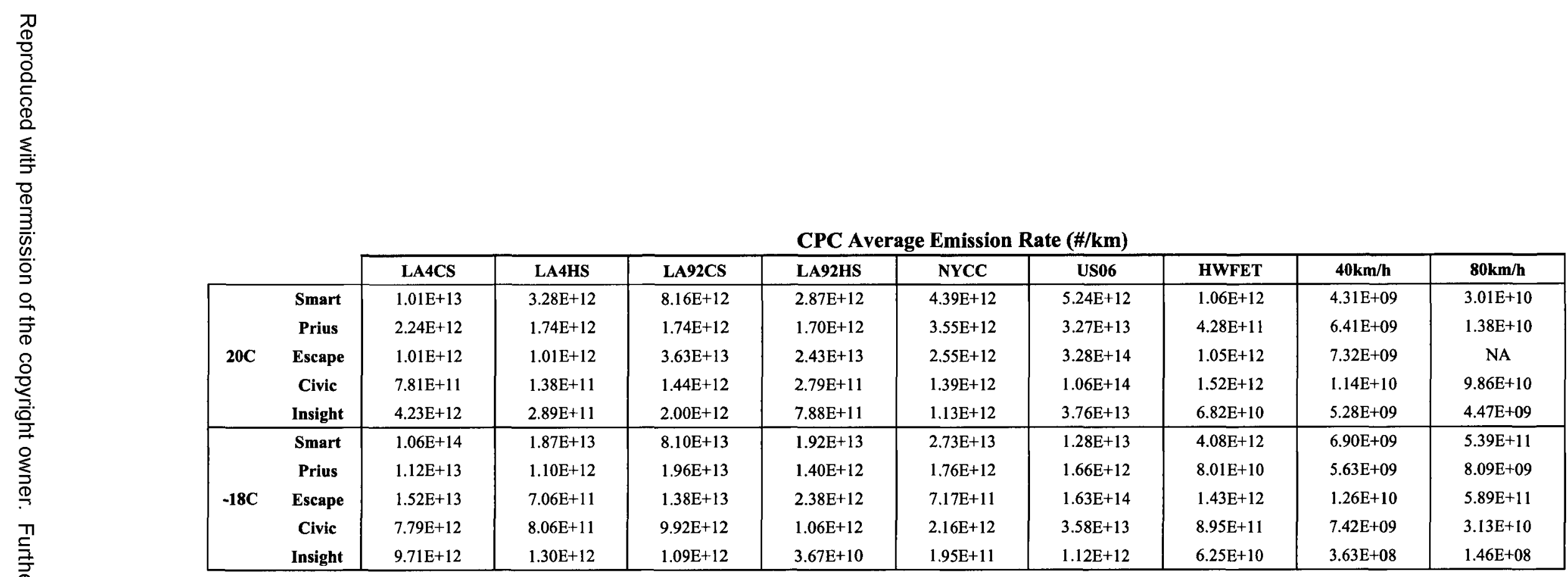

CPC Standard Deviation (\#/km)

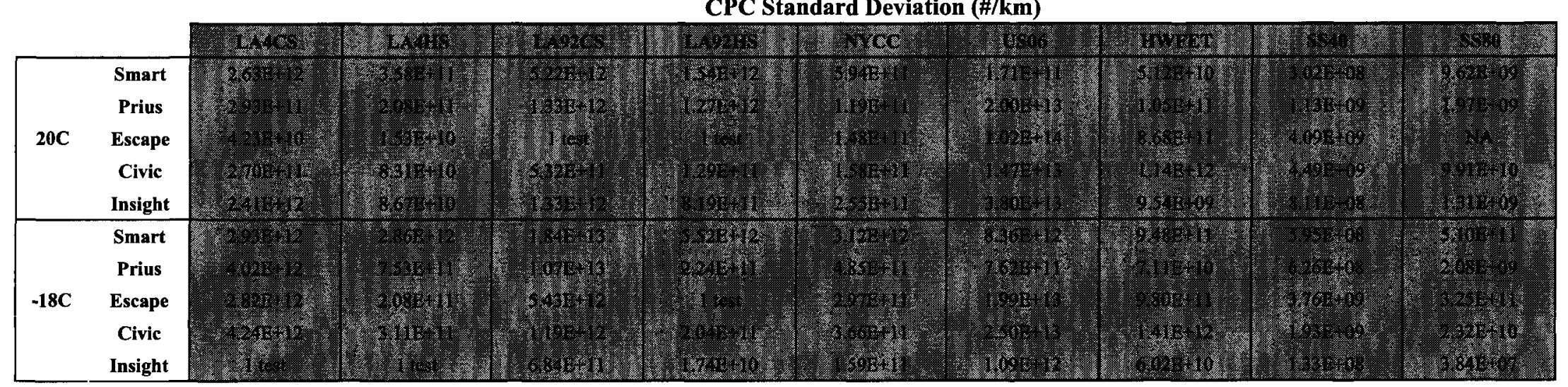


ELPI Emission Rate (\#/km)

\begin{tabular}{|c|c|c|c|c|c|c|c|c|c|c|}
\hline & & LA4CS & LA4HS & LA92CS & LA92HS & NYCC & US06 & HWFET & $40 \mathrm{~km} / \mathrm{h}$ & $80 \mathrm{~km} / \mathrm{h}$ \\
\hline \multirow{5}{*}{$20 \mathrm{C}$} & Smart & $8.67 \mathrm{E}+12$ & $2.62 \mathrm{E}+12$ & $5.51 \mathrm{E}+12$ & $1.58 \mathrm{E}+12$ & $4.08 \mathrm{E}+12$ & $2.08 \mathrm{E}+12$ & $6.28 \mathrm{E}+11$ & $1.58 \mathrm{E}+09$ & $2.86 \mathrm{E}+09$ \\
\hline & Prius & $1.13 \mathrm{E}+12$ & $7.78 \mathrm{E}+11$ & $6.37 \mathrm{E}+11$ & $3.76 \mathrm{E}+11$ & $7.24 \mathrm{E}+11$ & $1.52 \mathrm{E}+12$ & $1.93 \mathrm{E}+11$ & $1.78 \mathrm{E}+09$ & $3.75 \mathrm{E}+08$ \\
\hline & Escape & $3.14 \mathrm{E}+12$ & $4.15 \mathrm{E}+12$ & $3.24 \mathrm{E}+12$ & $4.32 \mathrm{E}+12$ & $9.43 \mathrm{E}+12$ & $1.12 \mathrm{E}+14$ & $7.13 E+09$ & $1.95 \mathrm{E}+09$ & NA \\
\hline & Civic & $5.57 \mathrm{E}+12$ & $1.48 \mathrm{E}+11$ & $1.02 \mathrm{E}+12$ & $6.37 \mathrm{E}+11$ & $9.97 \mathrm{E}+11$ & $2.52 \mathrm{E}+12$ & $5.42 \mathrm{E}+09$ & $1.68 \mathrm{E}+09$ & $1.34 \mathrm{E}+09$ \\
\hline & Insight & $6.19 \mathrm{E}+11$ & $3.44 \mathrm{E}+10$ & $2.83 \mathrm{E}+11$ & $3.67 \mathrm{E}+10$ & $4.31 \mathrm{E}+11$ & $7.49 \mathrm{E}+11$ & $3.70 \mathrm{E}+08$ & $1.26 \mathrm{E}+10$ & $7.12 \mathrm{E}+09$ \\
\hline \multirow{5}{*}{$-18 C$} & Smart & $6.72 \mathrm{E}+13$ & $1.66 \mathrm{E}+13$ & $4.08 \mathrm{E}+13$ & $1.15 \mathrm{E}+13$ & $3.10 \mathrm{E}+13$ & $6.18 \mathrm{E}+12$ & $3.16 \mathrm{E}+12$ & $2.02 \mathrm{E}+09$ & $7.98 \mathrm{E}+11$ \\
\hline & Prius & $1.34 \mathrm{E}+13$ & $1.29 \mathrm{E}+12$ & $1.34 \mathrm{E}+13$ & $1.44 \mathrm{E}+12$ & $1.77 \mathrm{E}+12$ & $1.22 \mathrm{E}+12$ & $1.21 \mathrm{E}+10$ & $4.11 \mathrm{E}+09$ & $3.29 \mathrm{E}+09$ \\
\hline & Escape & $1.16 \mathrm{E}+13$ & $6.01 \mathrm{E}+11$ & $7.49 \mathrm{E}+12$ & $2.11 \mathrm{E}+12$ & $1.08 \mathrm{E}+12$ & $3.35 \mathrm{E}+12$ & $1.89 \mathrm{E}+11$ & $4.37 \mathrm{E}+09$ & NA \\
\hline & Civic & $1.03 \mathrm{E}+13$ & $1.56 \mathrm{E}+12$ & $6.39 \mathrm{E}+12$ & $5.51 \mathrm{E}+11$ & $3.08 \mathrm{E}+11$ & $3.21 \mathrm{E}+12$ & $1.82 \mathrm{E}+10$ & $1.28 \mathrm{E}+09$ & $1.96 \mathrm{E}+09$ \\
\hline & Insight & $3.71 \mathrm{E}+12$ & $1.64 \mathrm{E}+11$ & $5.37 \mathrm{E}+12$ & $2.41 \mathrm{E}+11$ & $7.75 \mathrm{E}+11$ & $7.23 E+11$ & $5.94 \mathrm{E}+09$ & $4.52 \mathrm{E}+09$ & $3.69 E+09$ \\
\hline
\end{tabular}

ELPI Standard Deviation (\#/km)

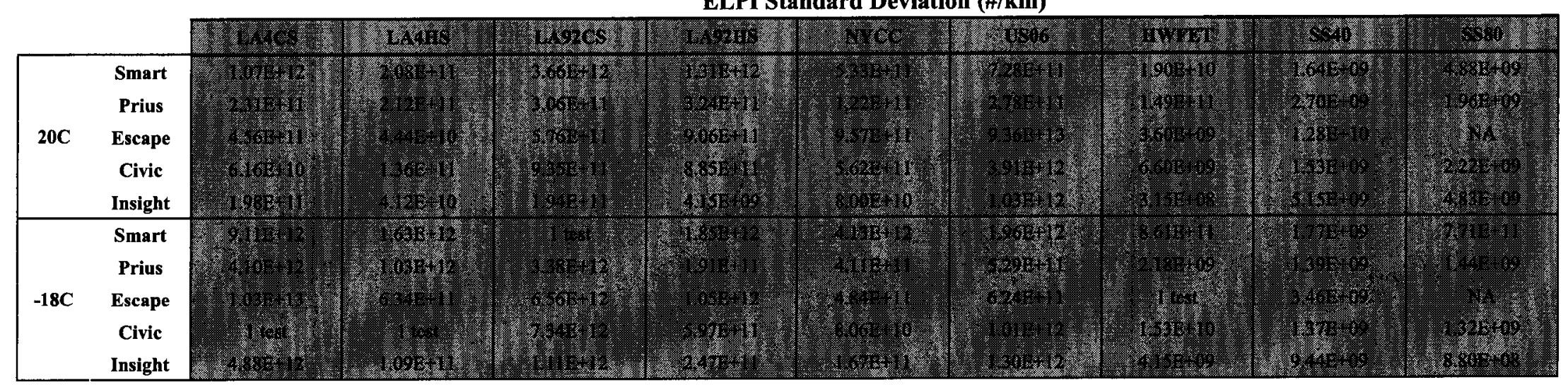



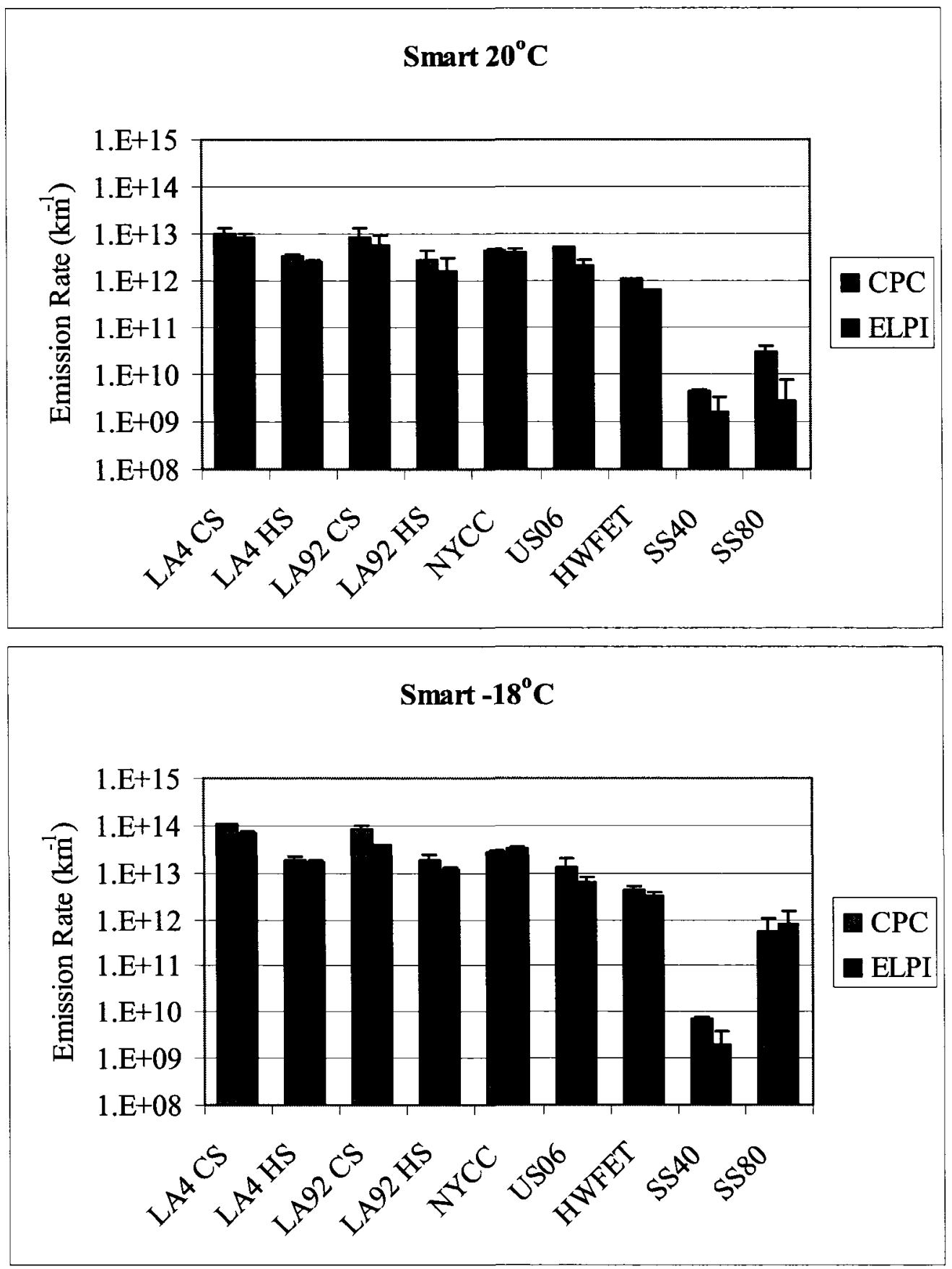

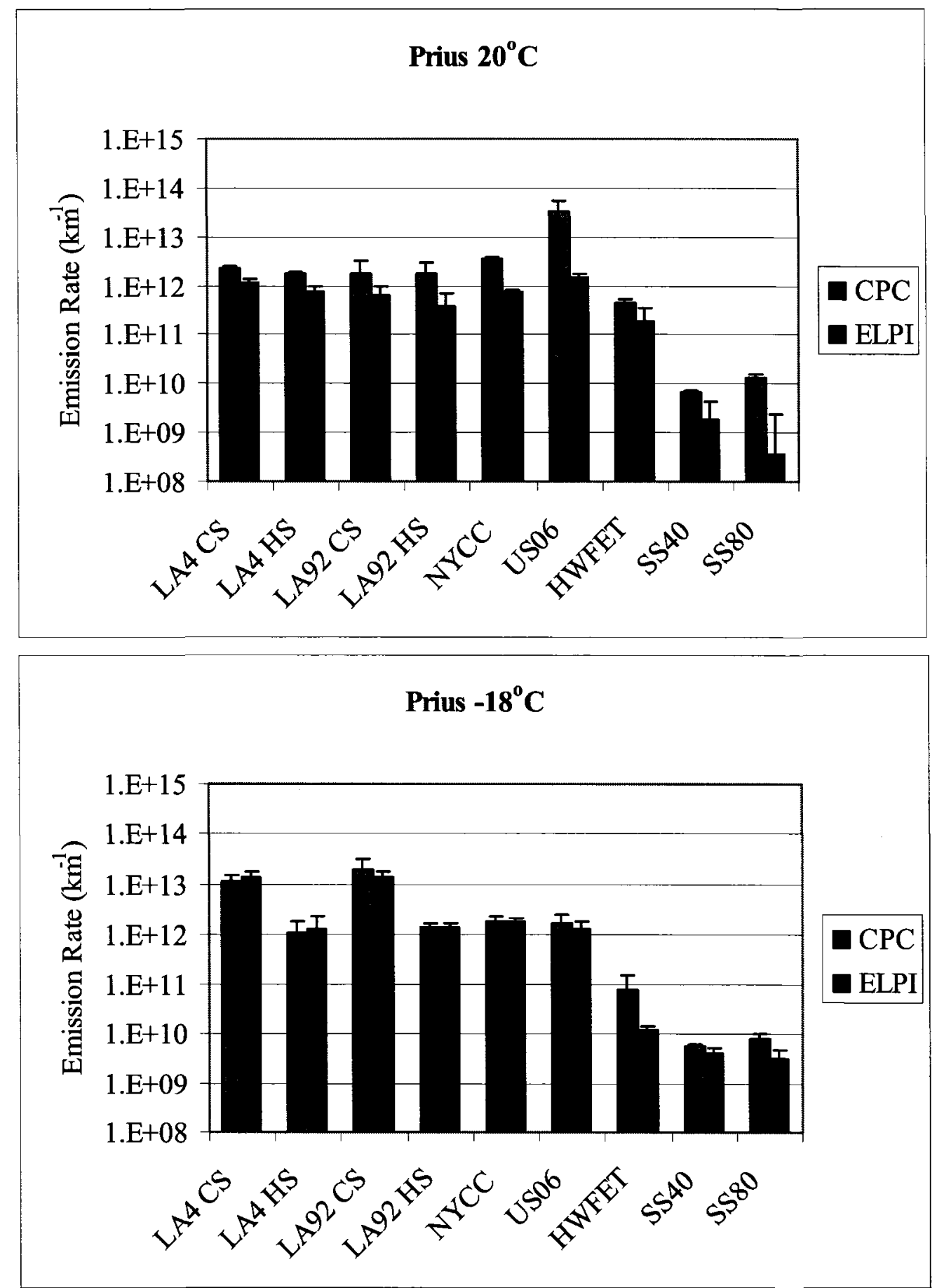

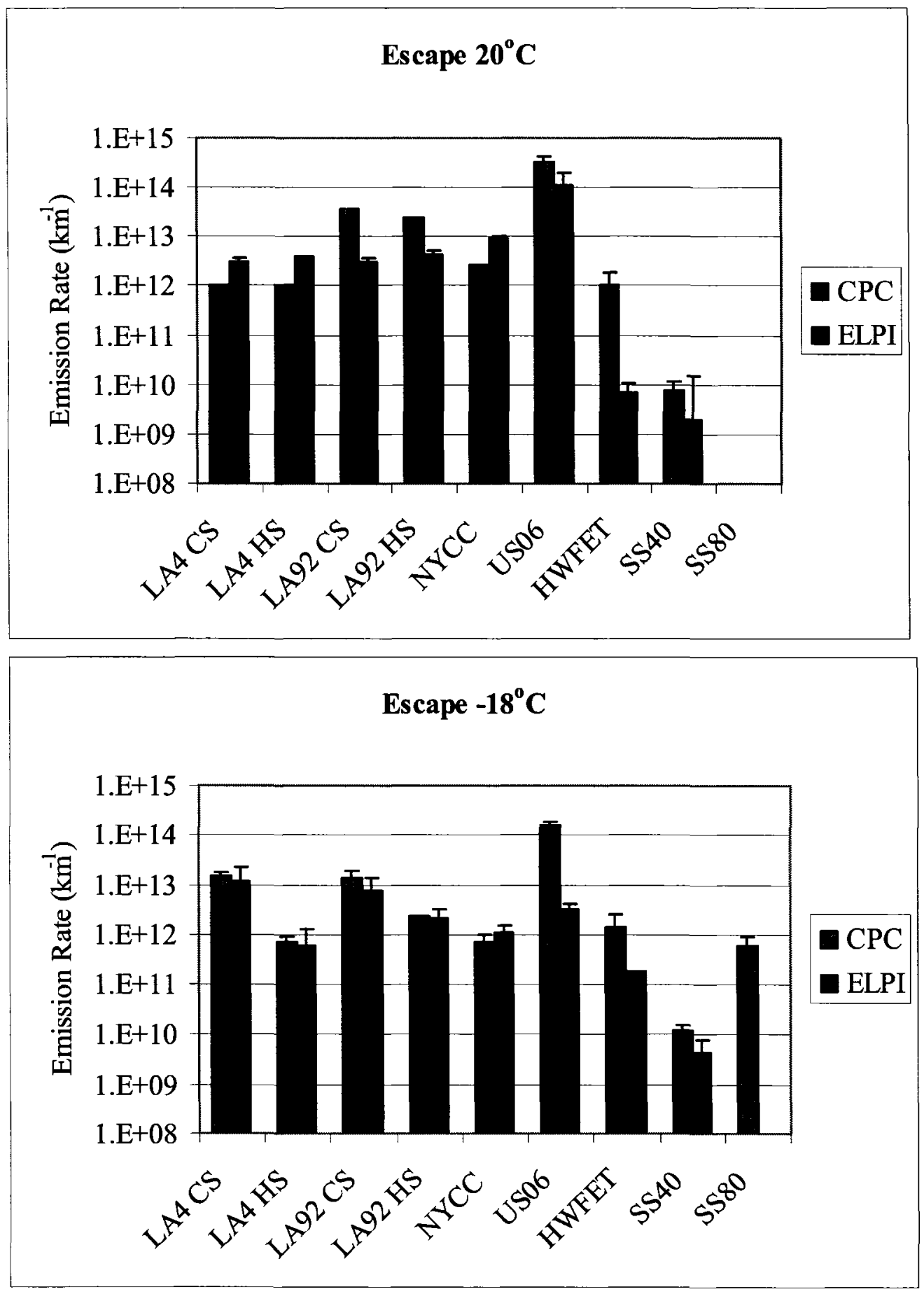

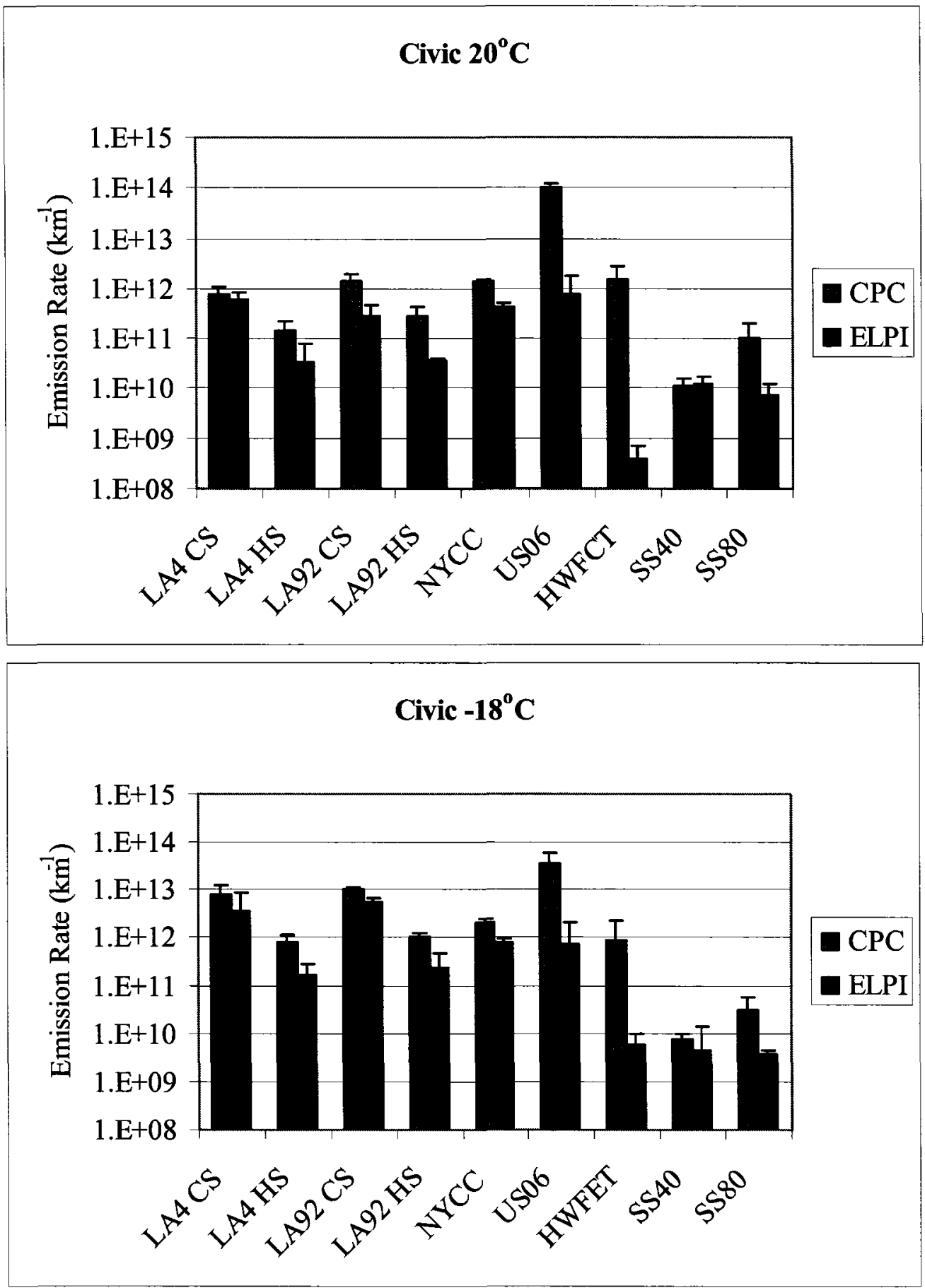

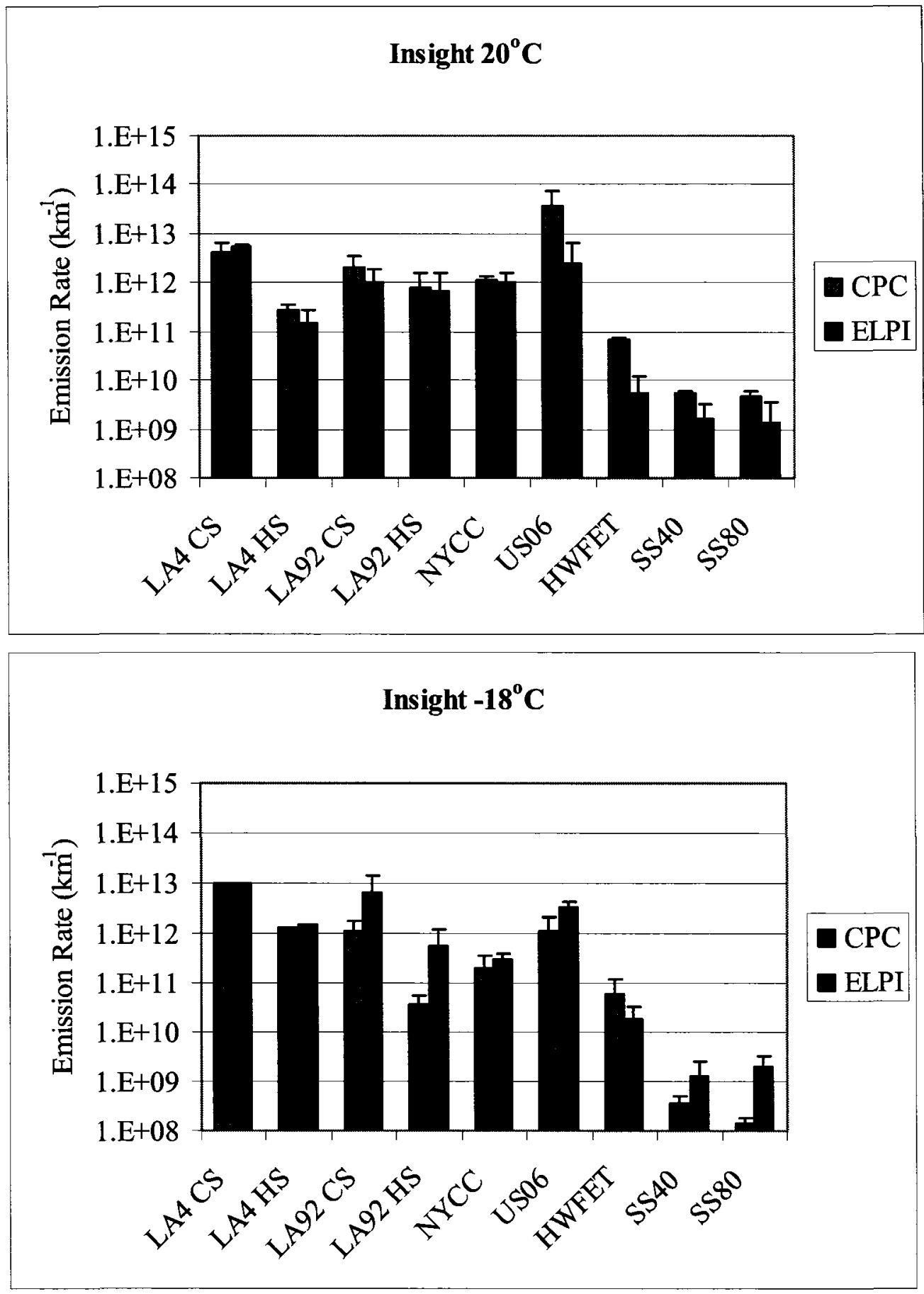


\title{
Appendix 4 - Mass Emission Rates
}

\author{
Contents
}

(1) Tabulated $\mathrm{PM}_{2.5}$, organic carbon (OC), and elemental carbon(EC) average mass emission rates $(\mathrm{mg} / \mathrm{km})$ with standard deviation

(2) Graphs of total $\mathrm{PM}_{2.5}$, organic carbon (OC), and elemental carbon(EC) mass emission rates $(\mathrm{mg} / \mathrm{km}) \pm 1$ standard deviation on the total $\mathrm{PM}_{2.5}$ 


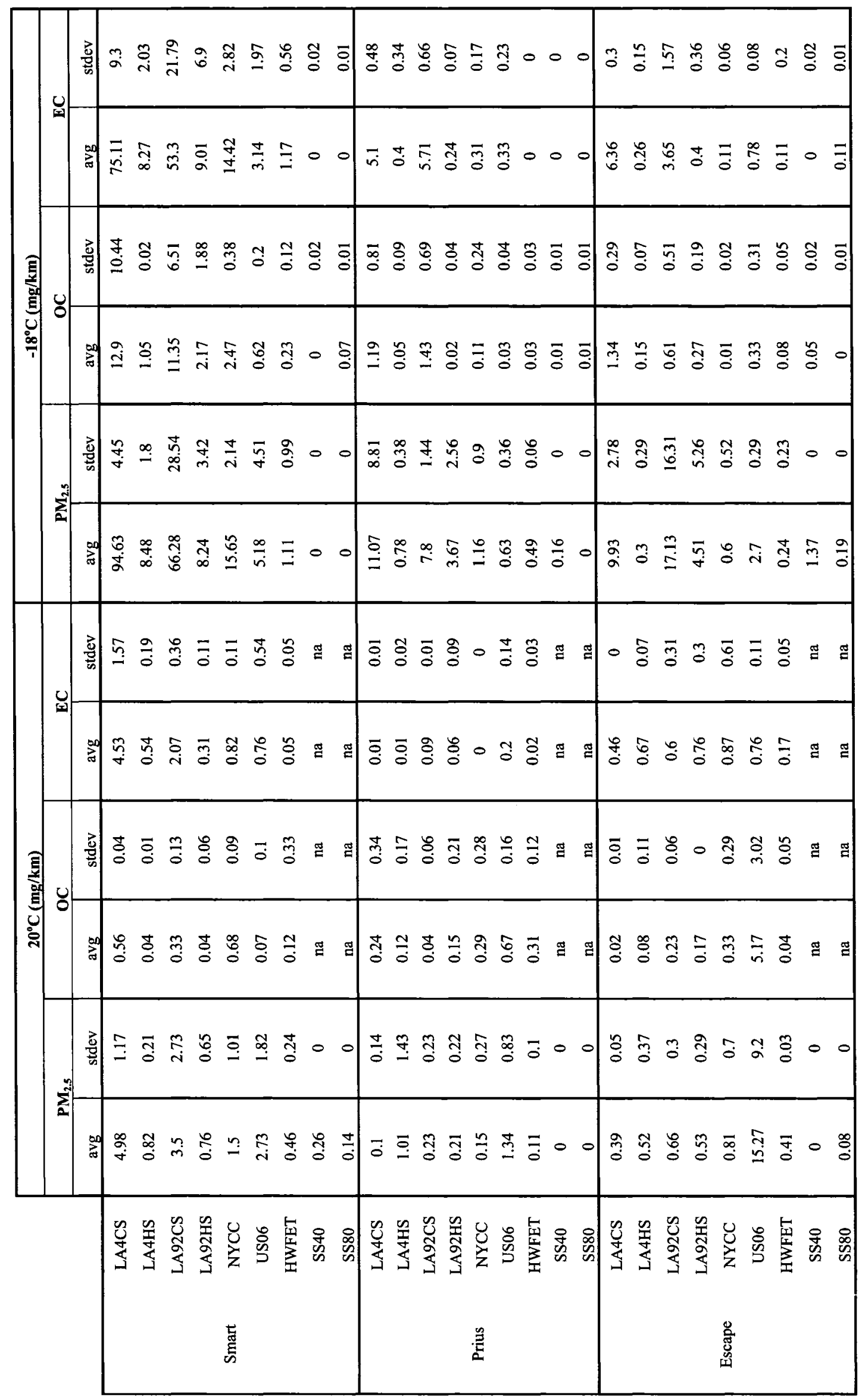




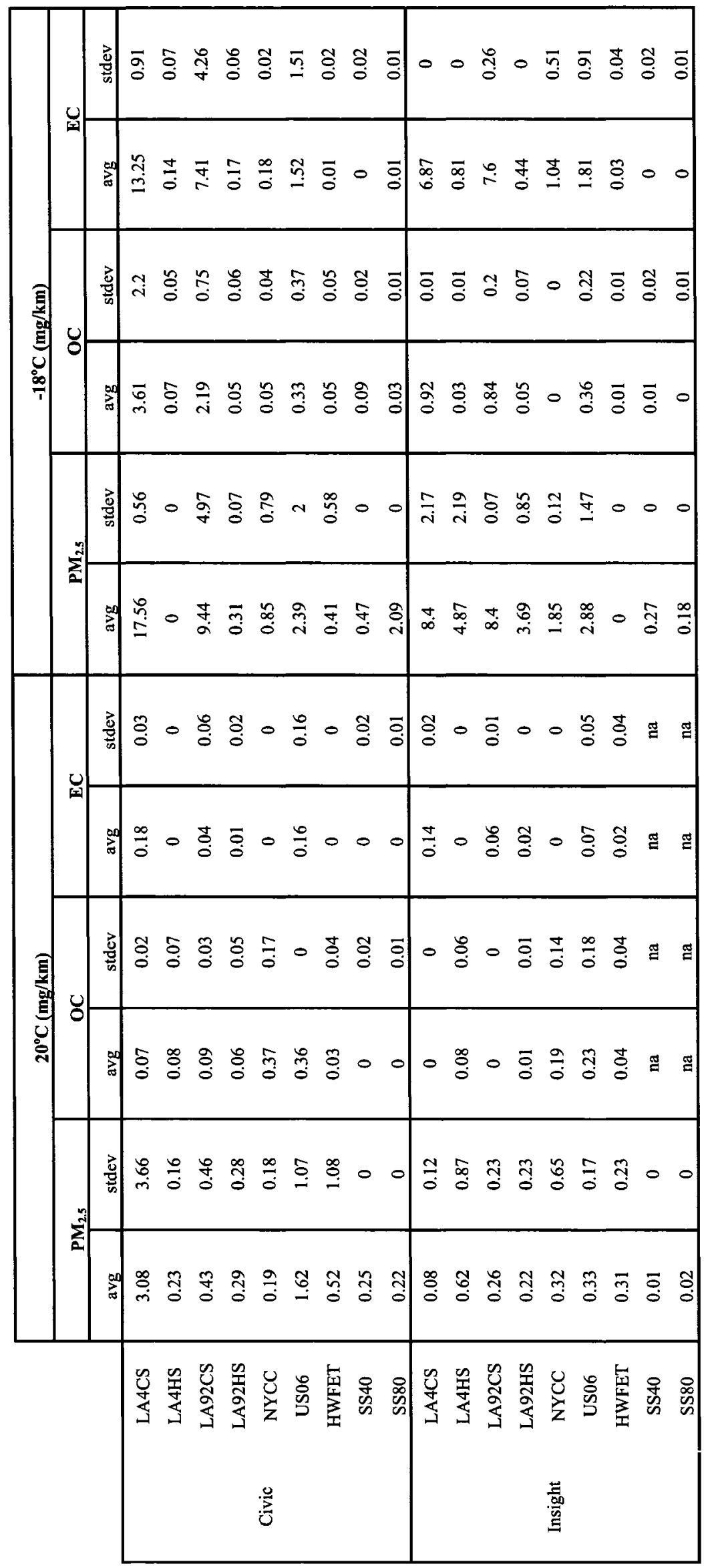



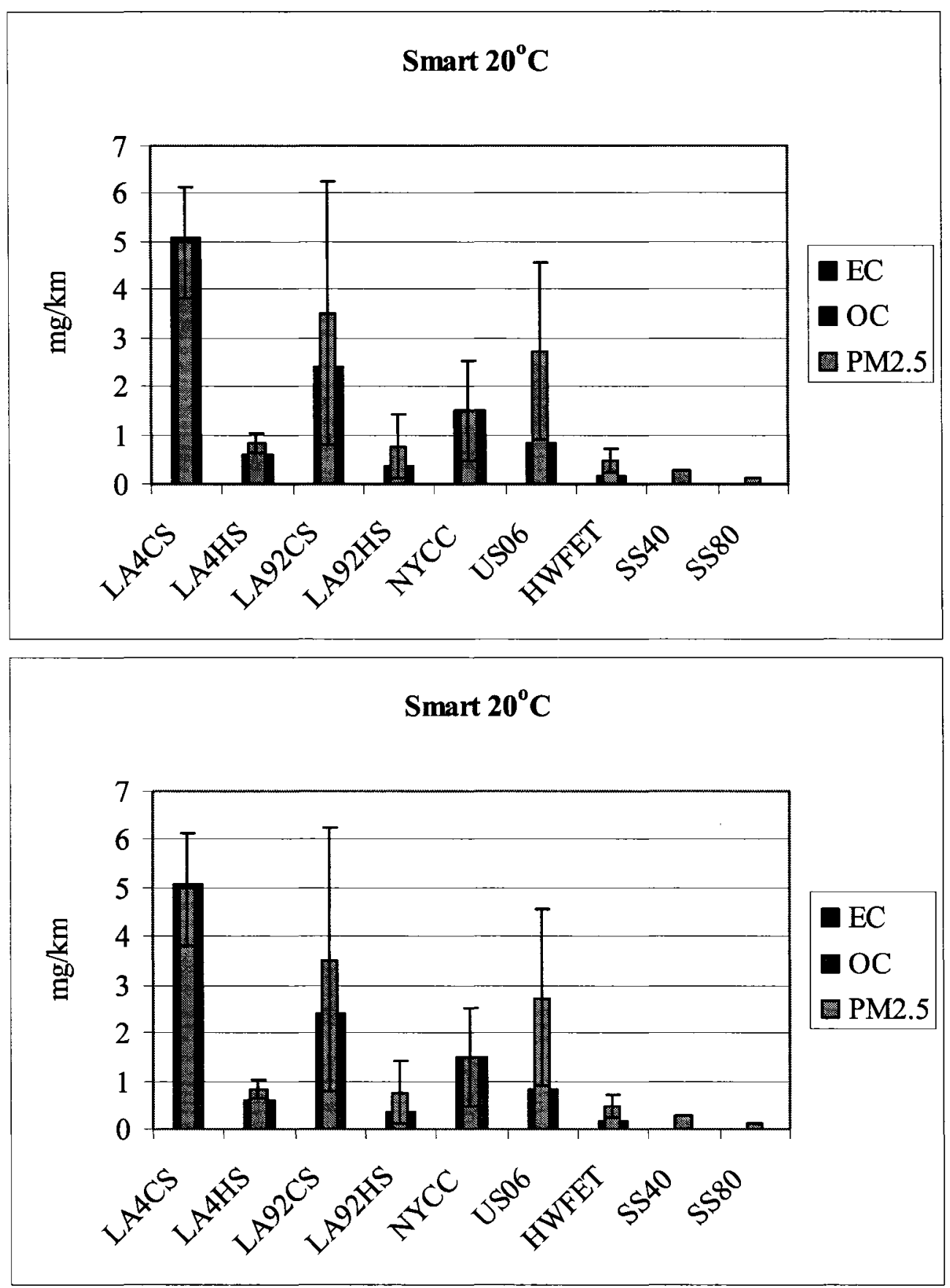

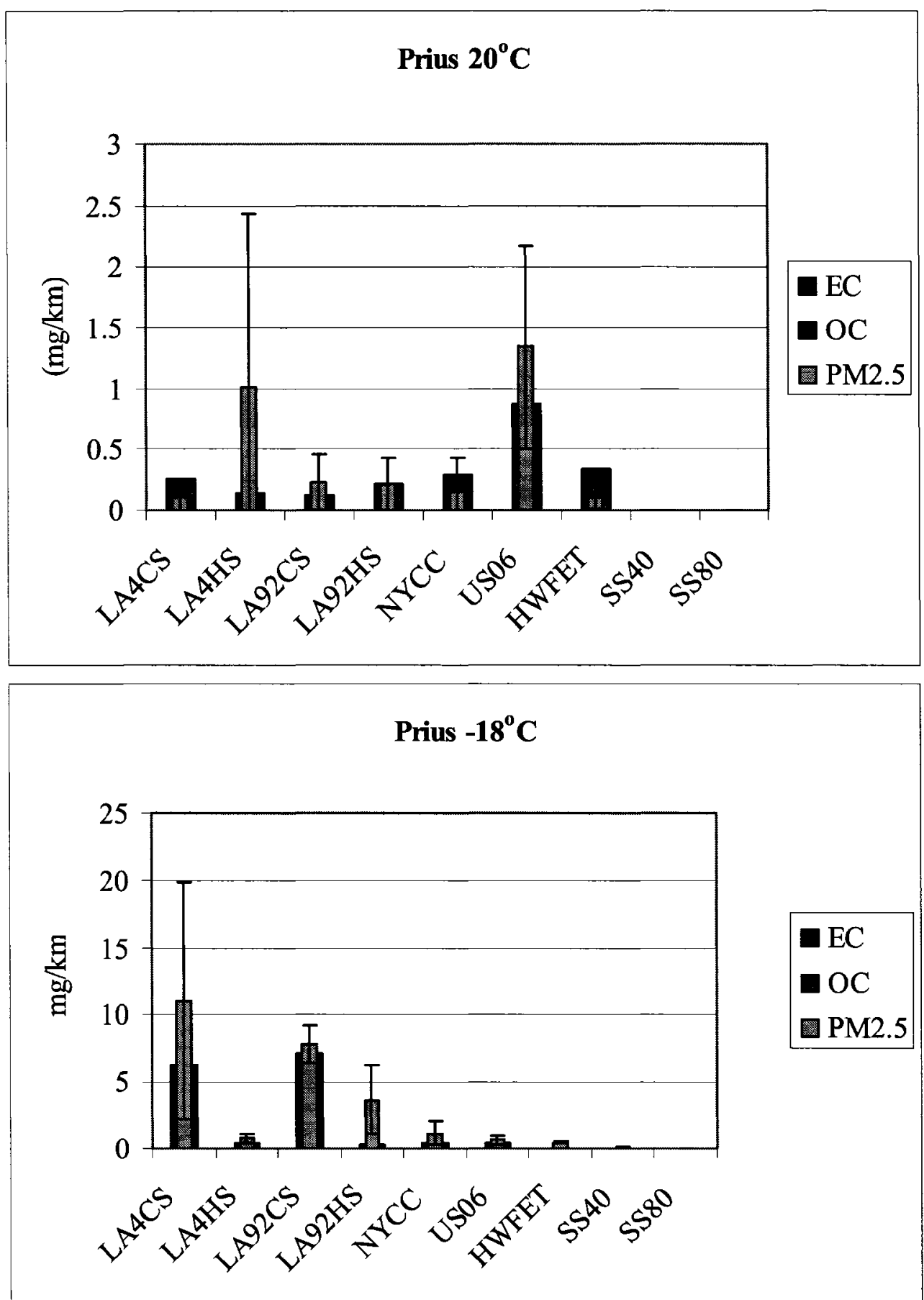

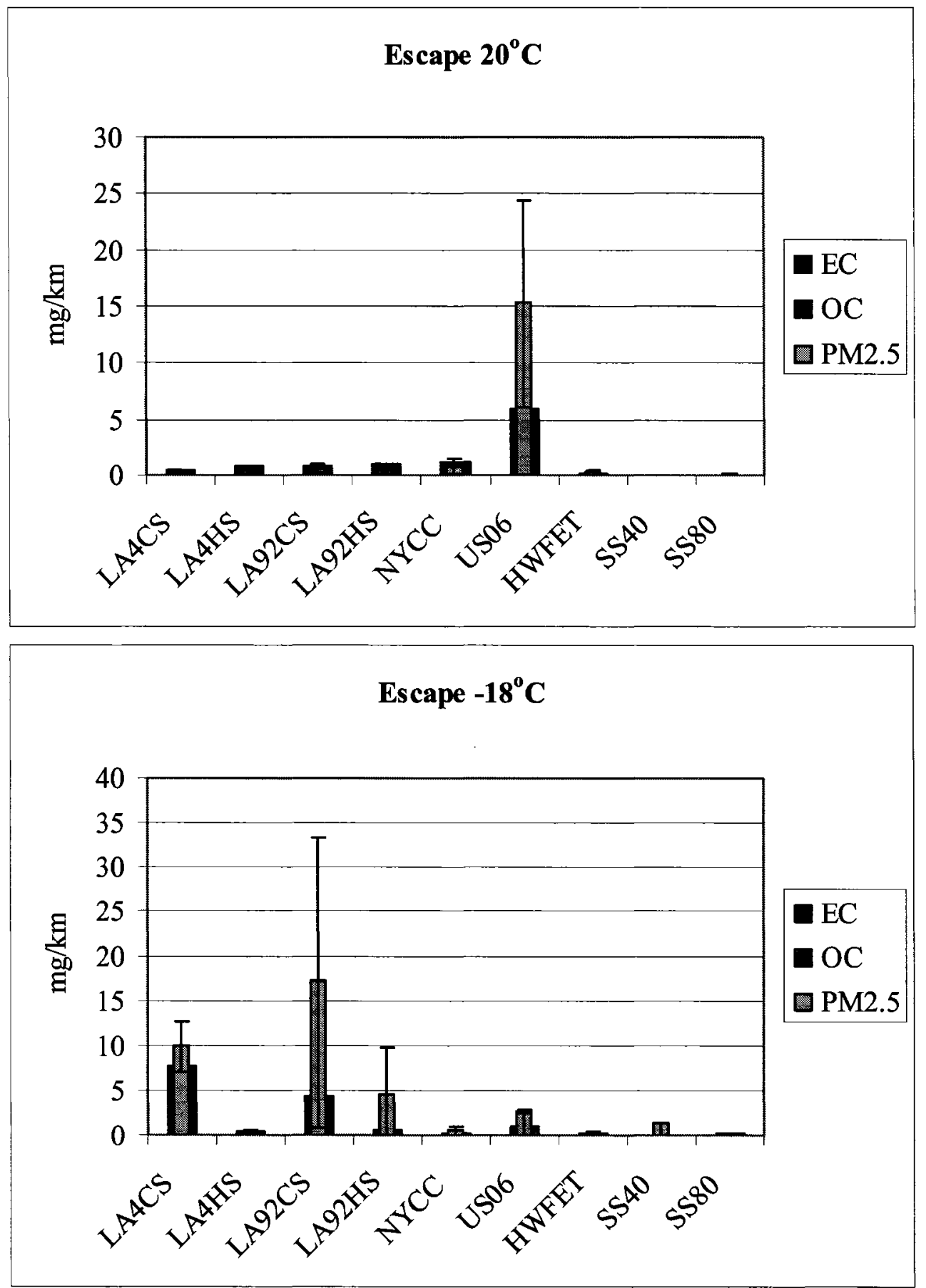

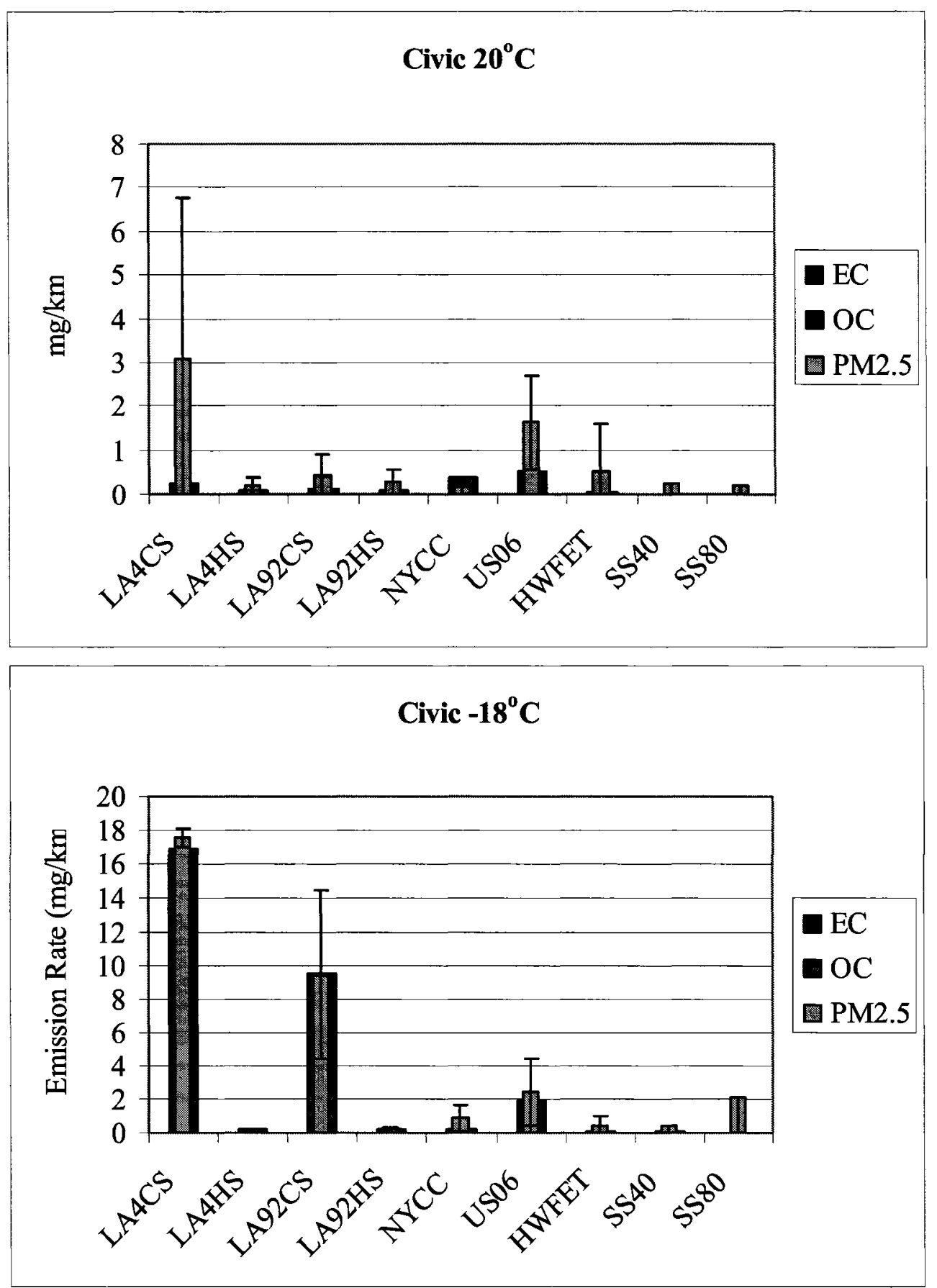

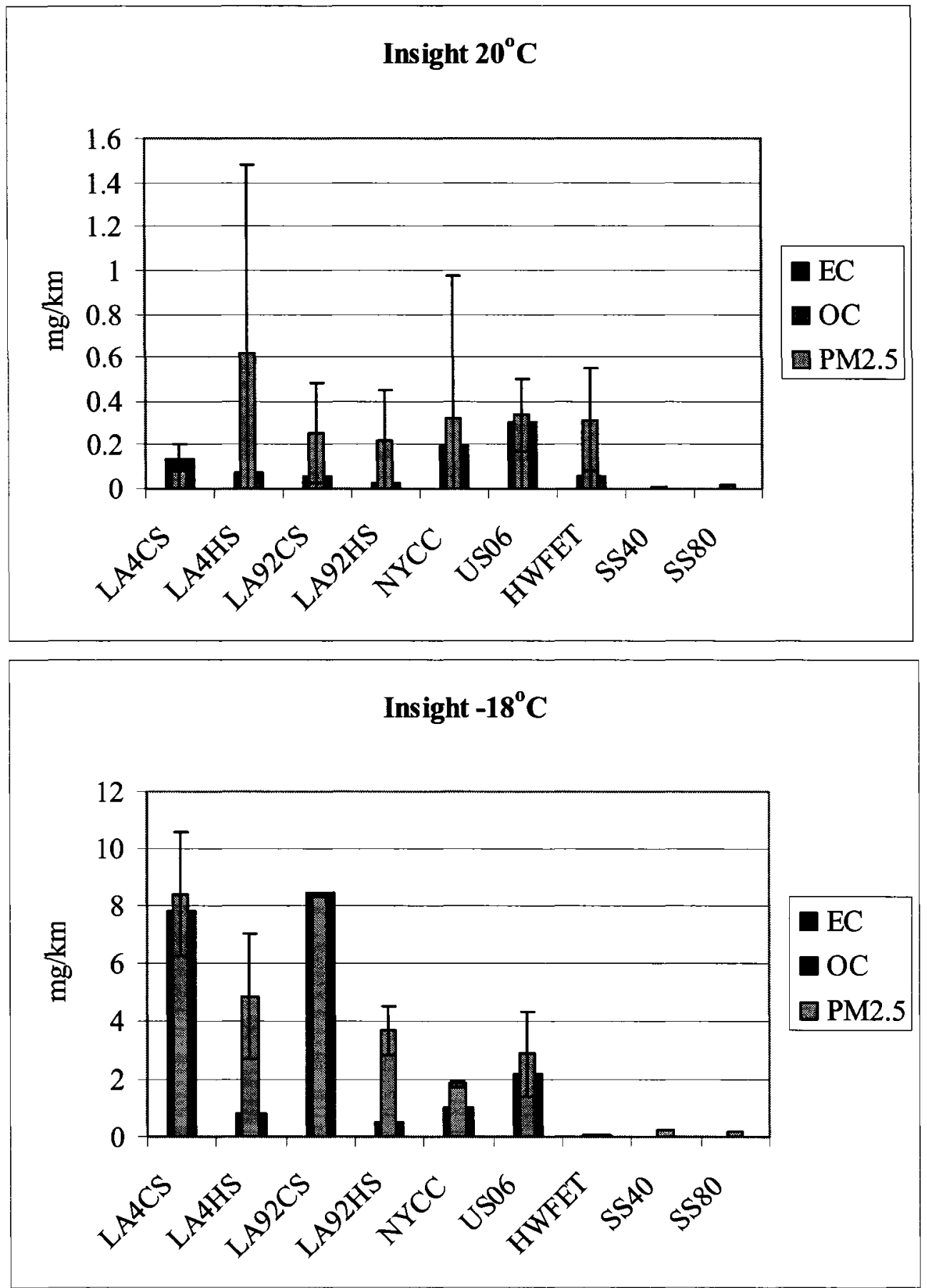


\title{
Appendix 5 - Integrated Size Distributions
}

\author{
Contents
}

(1) Tables of average integrated size distributions based on ELPI data for each driving cycle

(2)Tables of standard deviations for integrated size distributions (grey background) 


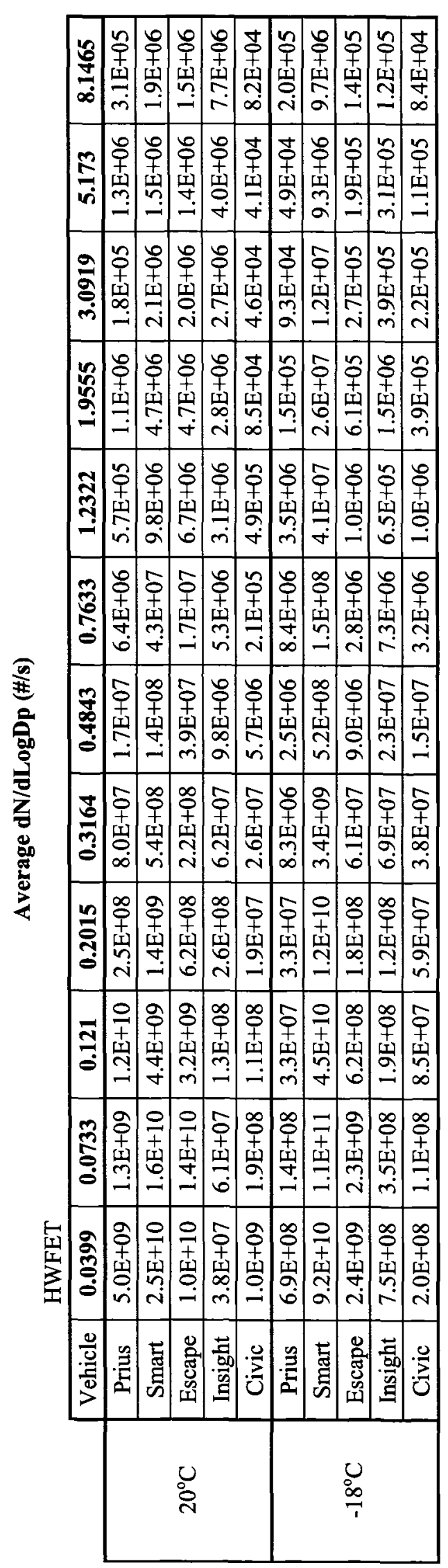

\begin{tabular}{|c|c|c|c|c|c|c|c|c|c|c|}
\hline 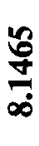 & 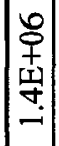 & $\begin{array}{c}5 \\
9 \\
19 \\
9 \\
-1\end{array}$ & 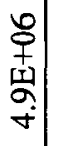 & $\begin{array}{c}0 \\
+ \\
+ \\
\text { 夏 } \\
-1\end{array}$ & 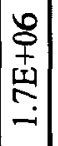 & $\mid \begin{array}{c}0 \\
+ \\
+ \\
\text { บn } \\
m \\
m\end{array}$ & $\mid \begin{array}{c}\infty \\
0 \\
+ \\
\text { 至 } \\
0 \\
-1\end{array}$ & $\begin{array}{l}5 \\
+ \\
1 \\
\infty \\
-1\end{array}$ & $\begin{array}{c}0 \\
+ \\
+ \\
\text { பn } \\
\infty \\
\infty\end{array}$ & 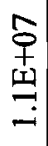 \\
\hline$\underset{n}{\stackrel{m}{r}}$ & 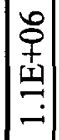 & 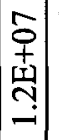 & $\begin{array}{l}0 \\
0 \\
+ \\
\text { जी } \\
0 \\
\forall\end{array}$ & $\begin{array}{c}0 \\
0 \\
+ \\
\text { 至 } \\
0 \\
0\end{array}$ & $\begin{array}{c}0 \\
0 \\
+1 \\
0 \\
0 \\
-1\end{array}$ & $\left|\begin{array}{c}- \\
\mathbf{1} \\
+ \\
\mathbf{m} \\
m \\
m \\
m\end{array}\right|$ & 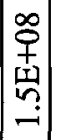 & 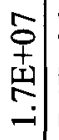 & 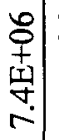 & $\begin{array}{l}8 \\
0 \\
\frac{1}{0} \\
0 \\
9\end{array}$ \\
\hline $\begin{array}{l}\hat{\sigma} \\
\hat{\sigma} \\
\dot{m}\end{array}$ & $\left|\begin{array}{l}n \\
0 \\
+ \\
n \\
n \\
\infty\end{array}\right|$ & $\begin{array}{c}5 \\
+ \\
+1 \\
\text { 至 } \\
-1\end{array}$ & $\begin{array}{c}0 \\
0 \\
+ \\
\text { 竎 } \\
0 \\
0\end{array}$ & 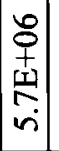 & $\left|\begin{array}{c}0 \\
0 \\
+ \\
\text { c1 } \\
\\
-1\end{array}\right|$ & 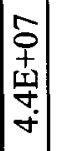 & $\left|\begin{array}{c}\infty \\
0 \\
+ \\
\text { 夏 } \\
\text { N }\end{array}\right|$ & 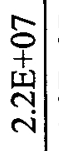 & $\begin{array}{l}5 \\
+ \\
+4 \\
0 \\
-\end{array}$ & $\begin{array}{l}5 \\
0 \\
+ \\
w \\
n\end{array}$ \\
\hline $\begin{array}{l}n \\
\tilde{n} \\
\alpha \\
\alpha \\
\end{array}$ & 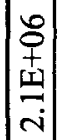 & 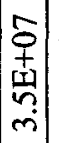 & $\begin{array}{c}5 \\
+ \\
+ \\
+ \\
-\end{array}$ & $\begin{array}{c}0 \\
0 \\
\pm \\
= \\
-1 \\
-1\end{array}$ & $\left|\begin{array}{c}0 \\
0 \\
+ \\
c \\
n \\
\sim \\
\sim\end{array}\right|$ & 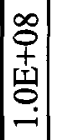 & $\left|\begin{array}{c}\infty \\
0 \\
+ \\
\text { 至 } \\
\dot{v}\end{array}\right|$ & 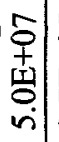 & $\begin{array}{c}5 \\
+ \\
\stackrel{1}{r} \\
\text { i }\end{array}$ & 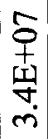 \\
\hline 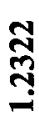 & 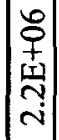 & 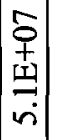 & $\begin{array}{c}5 \\
0 \\
+2 \\
9 \\
-1\end{array}$ & $\left|\begin{array}{c}5 \\
0 \\
1 \\
9 \\
-i\end{array}\right|$ & $\left|\begin{array}{c}0 \\
9 \\
0 \\
0 \\
0 \\
0\end{array}\right|$ & 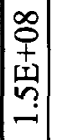 & $\left|\begin{array}{c}\infty \\
0 \\
+ \\
\underline{m} \\
m \\
\infty\end{array}\right|$ & $\begin{array}{c}5 \\
9 \\
\text { 몽 } \\
9 \\
-\end{array}$ & $\begin{array}{c}5 \\
⿱ 亠 䒑 \\
\text { m } \\
m \\
m\end{array}$ & 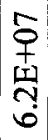 \\
\hline 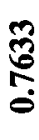 & 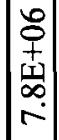 & 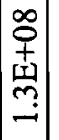 & $\begin{array}{c}5 \\
0 \\
\mathfrak{1} \\
\mathfrak{y} \\
\text { n. }\end{array}$ & 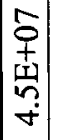 & $\left|\begin{array}{c}0 \\
+ \\
\omega \\
m \\
\infty \\
\infty\end{array}\right|$ & 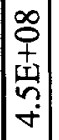 & $\begin{array}{c}g \\
\delta \\
+ \\
\text { ज్ } \\
\sigma \\
m\end{array} \mid$ & $\begin{array}{l}\infty \\
0 \\
+ \\
1 \\
0 \\
ن \\
\text { in }\end{array}$ & $\begin{array}{c}5 \\
+ \\
+ \\
\text { 亗 } \\
\sigma\end{array}$ & 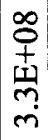 \\
\hline 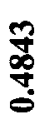 & 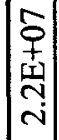 & $\begin{array}{c}\infty \\
0 \\
+ \\
\text { 岁 } \\
\dot{+}\end{array}$ & \begin{tabular}{c}
$\infty$ \\
0 \\
+ \\
9 \\
\hdashline \\
-1 \\
-1
\end{tabular} & 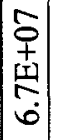 & $\left|\begin{array}{c}\tilde{D} \\
+ \\
w \\
\text { v } \\
\sim\end{array}\right|$ & $\left|\begin{array}{c}9 \\
0 \\
+ \\
\text { 됭 } \\
\text { i }\end{array}\right|$ & $\left|\begin{array}{c}0 \\
\frac{0}{+} \\
\underline{I} \\
\underline{-1}\end{array}\right|$ & $\mid \begin{array}{c}9 \\
9 \\
1 \\
9 \\
-1\end{array}$ & $\begin{array}{c}\infty \\
0 \\
0 \\
\text { 岀 } \\
m \\
m\end{array}$ & 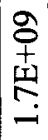 \\
\hline 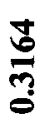 & $\left|\begin{array}{c}5 \\
0 \\
101 \\
0 \\
0\end{array}\right|$ & $\left|\begin{array}{c}9 \\
0 \\
+ \\
1 \\
0 \\
0 \\
ن\end{array}\right|$ & $\begin{array}{c}\infty \\
0 \\
0 \\
\infty \\
\infty \\
\dot{0} \\
\dot{0}\end{array}$ & $\mid$\begin{tabular}{c}
$\infty$ \\
0 \\
+ \\
国 \\
\hdashline$\dot{m}$
\end{tabular} & 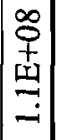 & 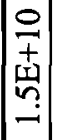 & 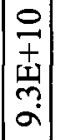 & 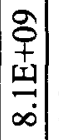 & $\begin{array}{l}8 \\
+ \\
+ \\
\text { 离 } \\
\text { in }\end{array}$ & $\begin{array}{l}\frac{0}{7} \\
\text { 岌 } \\
= \\
-1\end{array}$ \\
\hline 롱 & 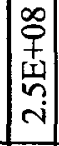 & $\left|\begin{array}{c}0 \\
0 \\
+ \\
\text { II } \\
= \\
-1\end{array}\right|$ & $\begin{array}{l}8 \\
8 \\
+ \\
\text { 됭 } \\
-1\end{array}$ & $\begin{array}{c}g \\
0 \\
+ \\
\text { ț } \\
\\
\text { n. }\end{array}$ & $\mid \begin{array}{c}\infty \\
0 \\
+ \\
\text { cu } \\
\dot{0} \\
\dot{f}\end{array}$ & 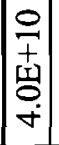 & 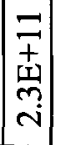 & $\begin{array}{c}0 \\
+1 \\
\text { 吉 } \\
0 \\
\text { i }\end{array} \mid$ & $\begin{array}{c}0 \\
+ \\
\pm \\
\underline{Z} \\
-\end{array}$ & 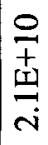 \\
\hline 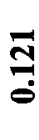 & 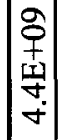 & $\left|\begin{array}{c}0 \\
+ \\
+ \\
1 \\
m \\
m \\
+\end{array}\right|$ & $\begin{array}{c}9 \\
0 \\
+ \\
1 \\
0 \\
0 \\
\infty\end{array}$ & $\left|\begin{array}{c}0 \\
+ \\
\pm \\
\text { II } \\
\text { i }\end{array}\right|$ & $\begin{array}{c}8 \\
\delta \\
+ \\
\text { 至 } \\
0 \\
\text { i }\end{array}$ & 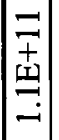 & $\begin{array}{c}7 \\
+ \\
+ \\
\text { 吉 } \\
6\end{array}$ & $\begin{array}{c}0 \\
0 \\
+ \\
\text { 至 } \\
0 \\
\infty\end{array}$ & $\begin{array}{c}0 \\
\stackrel{1}{+} \\
\text { 辛 } \\
\dot{+}\end{array}$ & $\begin{array}{l}\frac{0}{+} \\
\text { 壳 } \\
\frac{8}{t}\end{array}$ \\
\hline$\stackrel{m}{\stackrel{m}{0}}$ & 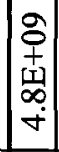 & $\begin{array}{l}= \\
+ \\
\pm \\
\text { ปn } \\
-\end{array}$ & 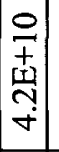 & $\left|\begin{array}{c}0 \\
7 \\
1 \\
0 \\
0 \\
0 \\
0\end{array}\right|$ & $\mid \begin{array}{c}8 \\
+ \\
4 \\
0 \\
0\end{array}$ & 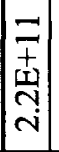 & 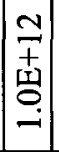 & $\begin{array}{l}7 \\
7 \\
\text { 壳 } \\
-1\end{array}$ & $\begin{array}{c}0 \\
+\underset{7}{+} \\
\text { 岌 } \\
\infty \\
\infty\end{array}$ & 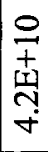 \\
\hline & 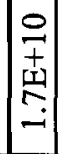 & 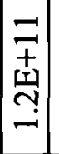 & $\begin{array}{c}0 \\
+1 \\
1 \\
\text { 壳 } \\
n \\
n\end{array} \mid$ & $\left|\begin{array}{c}0 \\
7 \\
+1 \\
\frac{1}{9} \\
\infty\end{array}\right|$ & 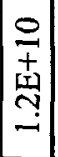 & 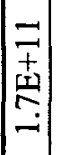 & $\begin{array}{l}= \\
+ \\
\text { and } \\
n \\
n\end{array} \mid$ & $\begin{array}{c}= \\
+ \\
+ \\
\pm \\
-1 \\
-i\end{array}$ & 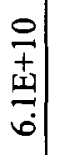 & 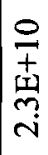 \\
\hline & 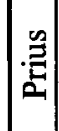 & 鴶 & 吕 & 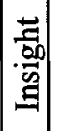 & 号 & $\left|\begin{array}{l}\mathscr{Z} \\
2 \\
2\end{array}\right|$ & 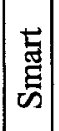 & 总 & 总 & : \\
\hline & & & & & & & & $\frac{\infty}{7}$ & & \\
\hline
\end{tabular}




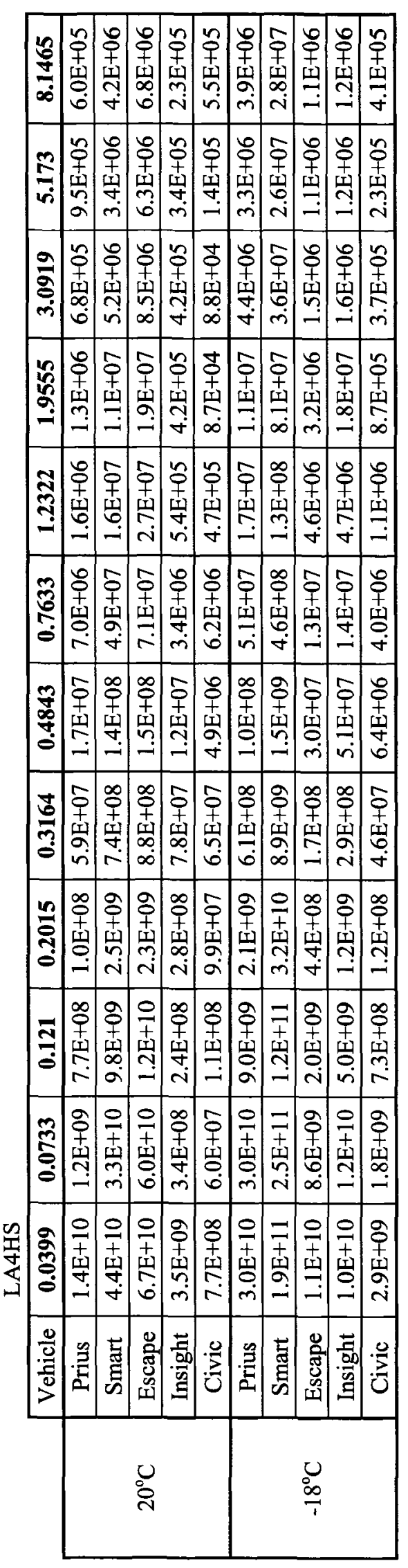

\begin{tabular}{|c|c|c|c|c|c|c|c|c|c|}
\hline & 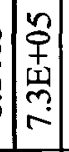 & $\mid \begin{array}{c}0 \\
0 \\
0 \\
0 \\
-1\end{array}$ & 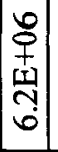 & 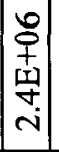 & 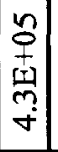 & $\begin{array}{c}0 \\
+ \\
\pm \\
\mathbf{y} \\
i\end{array} \mid$ & $\begin{array}{l}\infty \\
0 \\
+ \\
\text { ज్ } \\
\\
\end{array}$ & 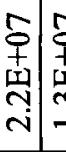 & 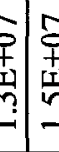 \\
\hline & 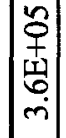 & 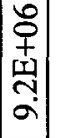 & $\left|\begin{array}{c}0 \\
\vdots \\
0 \\
0 \\
0 \\
ن \\
ن\end{array}\right|$ & $\left|\begin{array}{c}0 \\
+ \\
0 \\
0 \\
0 \\
-1 \\
-1\end{array}\right|$ & 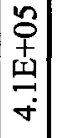 & $\left|\begin{array}{c}0 \\
⿱ \\
1 \\
⿱ 亠 䒑 \\
+ \\
i\end{array}\right|$ & 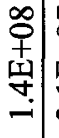 & 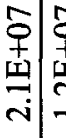 & 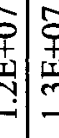 \\
\hline & $\left|\begin{array}{c}0 \\
0 \\
0 \\
\vdots \\
m \\
m\end{array}\right|$ & $\left|\begin{array}{c}0 \\
+ \\
\overline{1} \\
- \\
-1\end{array}\right|$ & 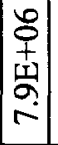 & 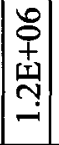 & 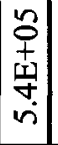 & $\left|\begin{array}{c}0 \\
+ \\
4 \\
y \\
+ \\
m\end{array}\right|$ & $\begin{array}{l}\infty \\
0 \\
+ \\
\vdots \\
\vdots \\
-1\end{array}$ & & 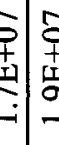 \\
\hline & 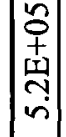 & $\left|\begin{array}{c}0 \\
1 \\
+1 \\
0 \\
0 \\
ن\end{array}\right|$ & 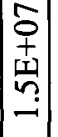 & $\left|\begin{array}{l}8 \\
+ \\
9 \\
0 \\
0 \\
-1\end{array}\right|$ & $\left|\begin{array}{l}0 \\
1 \\
1 \\
\multicolumn{1}{c}{} \\
-2\end{array}\right|$ & 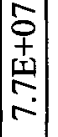 & $\begin{array}{l}\infty \\
0 \\
+ \\
0 \\
0 \\
\dot{\gamma} \\
\dot{\gamma}\end{array}$ & & 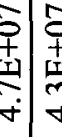 \\
\hline & $\left|\begin{array}{c}0 \\
1 \\
1 \\
y \\
0 \\
\infty \\
0\end{array}\right|$ & $\left|\begin{array}{c}0 \\
⿱ \\
1 \\
y \\
n \\
m\end{array}\right|$ & $\left|\begin{array}{c}0 \\
1 \\
\text { 웜 } \\
-2\end{array}\right|$ & $\left|\begin{array}{c}8 \\
1 \\
1 \\
10 \\
0 \\
\forall \\
\forall\end{array}\right|$ & 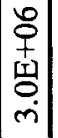 & 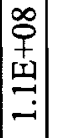 & $\begin{array}{l}\infty \\
0 \\
+ \\
01 \\
0 \\
\end{array}$ & 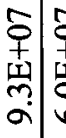 & \begin{tabular}{c|c}
$\mathbf{5}$ & \\
\multicolumn{1}{c}{} & \\
0 & \\
0 &
\end{tabular} \\
\hline & 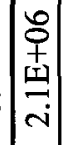 & $\mid \begin{array}{c}\infty \\
0 \\
+ \\
\mathbf{1} \\
= \\
=\end{array}$ & $\left|\begin{array}{c}0 \\
1 \\
\underline{1} \\
\dot{m} \\
.\end{array}\right|$ & $\mid \begin{array}{c}0 \\
0 \\
1 \\
=1 \\
= \\
=\end{array}$ & $\begin{array}{c}0 \\
0 \\
0 \\
0 \\
\infty \\
\infty\end{array}$ & $\left|\begin{array}{c}\infty \\
0 \\
+ \\
9 \\
\\
\dot{m}\end{array}\right|$ & 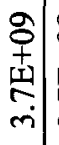 & 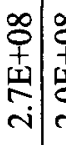 & 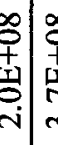 \\
\hline & 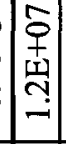 & $\left|\begin{array}{c}\infty \\
0 \\
1 \\
9 \\
\dot{y} \\
\dot{\forall}\end{array}\right|$ & $\left|\begin{array}{c}0 \\
0 \\
1 \\
0 \\
\infty \\
\infty\end{array}\right|$ & $\left|\begin{array}{c}0 \\
0 \\
1 \\
0 \\
0 \\
\end{array}\right|$ & $\left|\begin{array}{c}0 \\
1 \\
9 \\
\\
i\end{array}\right|$ & $\mid \begin{array}{c}0 \\
\vdots \\
\text { ज्ञ } \\
-\dot{-1}\end{array}$ & 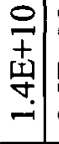 & $\begin{array}{l}\infty \\
\vdots \\
\vdots \\
\vdots \\
\vdots \\
\infty \\
\infty\end{array}$ & \\
\hline J & 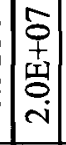 & $\left|\begin{array}{c}0 \\
+ \\
1 \\
\vdots \\
\vdots \\
i\end{array}\right|$ & 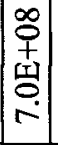 & $\left|\begin{array}{c}\infty \\
\vdots \\
1 \\
9 \\
9 \\
-1\end{array}\right|$ & 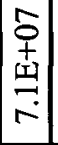 & $\begin{array}{l}0 \\
0 \\
0 \\
4 \\
0 \\
6\end{array}$ & $\begin{array}{l}0 \\
7 \\
9 \\
9 \\
6\end{array}$ & 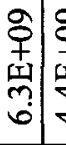 & 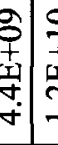 \\
\hline & $\left|\begin{array}{c}0 \\
0 \\
9 \\
0 \\
2 \\
\end{array}\right|$ & $\left|\begin{array}{c}8 \\
0 \\
+ \\
\text { 묑 } \\
\sigma \\
\sigma\end{array}\right|$ & 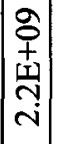 & 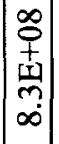 & $\mid \begin{array}{c}\infty \\
0 \\
+ \\
10 \\
0 \\
-1\end{array}$ & $\left|\begin{array}{c}0 \\
+ \\
\pm \\
\infty \\
i\end{array}\right|$ & $\begin{array}{l}= \\
7 \\
\pm \\
\infty \\
-1\end{array}$ & 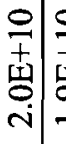 & 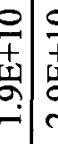 \\
\hline & 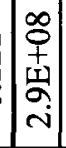 & $\left|\begin{array}{c}0 \\
7 \\
\pm \\
m \\
m \\
m\end{array}\right|$ & $\left|\begin{array}{c}\text { 오 } \\
+ \\
\text { 뚼 } \\
\text { - }\end{array}\right|$ & 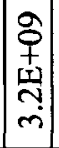 & $\left|\begin{array}{c}\infty \\
0 \\
+ \\
\simeq \\
\infty \\
\sim \\
\sim\end{array}\right|$ & $\mid \begin{array}{c}7 \\
7 \\
\text { 뙹 } \\
-\end{array}$ & 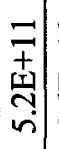 & 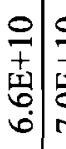 & 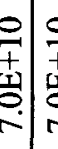 \\
\hline & $\left|\begin{array}{c}2 \\
0 \\
\text { 至 } \\
\end{array}\right|$ & $\left|\begin{array}{c}0 \\
+ \\
+ \\
y \\
\vdots \\
\infty\end{array}\right|$ & $\left|\begin{array}{c}0 \\
1 \\
1 \\
0 \\
0 \\
i\end{array}\right|$ & $\mid \begin{array}{c}0 \\
+ \\
\mathbf{m} \\
m \\
-2\end{array}$ & 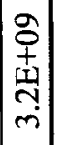 & 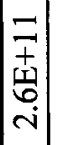 & $\begin{array}{c}\overrightarrow{7} \\
+ \\
\pm \\
m \\
r\end{array}$ & 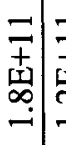 & 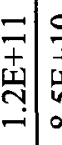 \\
\hline & $\left|\begin{array}{l}8 \\
0 \\
1 \\
5 \\
2 \\
7\end{array}\right|$ & $\left|\begin{array}{c}7 \\
7 \\
\pm \\
= \\
-1\end{array}\right|$ & $\left|\begin{array}{c}0 \\
7 \\
0 \\
1 \\
n \\
0 \\
0\end{array}\right|$ & 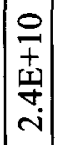 & 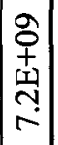 & 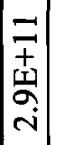 & $\begin{array}{l}= \\
\overrightarrow{7} \\
\text { ज्ञ } \\
\dot{+}\end{array}$ & 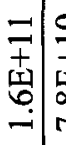 & 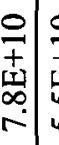 \\
\hline & 统 & 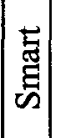 & 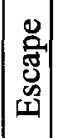 & 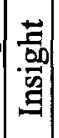 & $\sum_{0}^{0}$ & 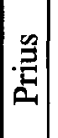 & 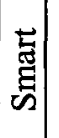 & $\begin{array}{l}0 \\
0 \\
0 \\
0 \\
0\end{array}$ & $\begin{array}{l}\text { 营 } \\
\text { on } \\
\text { on }\end{array}$ \\
\hline & & & & & & & & & \\
\hline
\end{tabular}




\begin{tabular}{|c|c|c|c|c|c|c|c|c|c|}
\hline I & $\left|\begin{array}{l}0 \\
0 \\
1 \\
5 \\
\\
i\end{array}\right|$ & $\left|\begin{array}{c}0 \\
9 \\
1 \\
\vdots \\
\infty \\
\infty\end{array}\right|$ & $\left|\begin{array}{l}0 \\
0 \\
0 \\
0 \\
\vdots \\
-1\end{array}\right|$ & 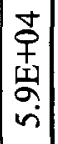 & 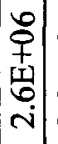 & $\begin{array}{l}\hat{\rho} \\
+ \\
0 \\
0 \\
ن\end{array}$ & 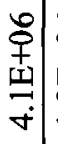 & 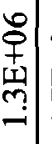 & 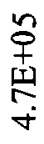 \\
\hline 点 & 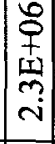 & 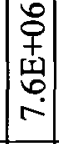 & 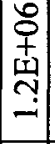 & $\left|\begin{array}{c}0 \\
+ \\
1 \\
\\
-1\end{array}\right|$ & 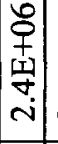 & $\left|\begin{array}{c}0 \\
+ \\
1 \\
0 \\
0 \\
ن\end{array}\right|$ & 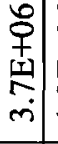 & 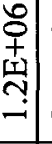 & 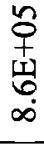 \\
\hline ר & 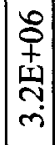 & 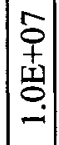 & $\mid \begin{array}{l}8 \\
1 \\
4 \\
4 \\
= \\
=\end{array}$ & 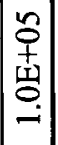 & 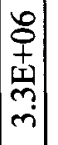 & 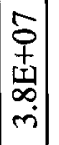 & $\begin{array}{l}8 \\
+ \\
+ \\
n \\
n \\
n\end{array}$ & $\begin{array}{c}0 \\
+ \\
1 \\
0 \\
0 \\
-1\end{array}$ & 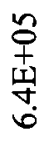 \\
\hline 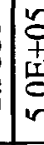 & 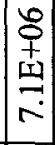 & $\mid \begin{array}{c}0 \\
0 \\
9 \\
0 \\
0 \\
-1 \\
-1\end{array}$ & $\begin{array}{c}8 \\
1 \\
1 \\
4 \\
-1 \\
-1\end{array}$ & $\mid \begin{array}{c}2 \\
0 \\
0 \\
0 \\
0 \\
-1 \\
-1\end{array}$ & $\begin{array}{c}0 \\
0 \\
+ \\
\text { I্工் } \\
\infty \\
\infty\end{array} \mid$ & $\begin{array}{c}5 \\
\vdots \\
+ \\
\text { પ్ } \\
\infty \\
\infty\end{array}$ & $\begin{array}{c}8 \\
+ \\
+ \\
\infty \\
\infty \\
\infty\end{array}$ & 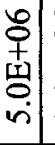 & 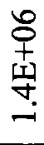 \\
\hline 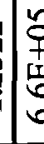 & 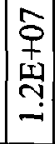 & 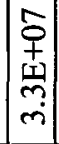 & 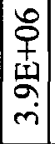 & $\mid \begin{array}{l}0 \\
+ \\
1 \\
0 \\
0 \\
-1 \\
-1\end{array}$ & $\mid \begin{array}{c}0 \\
+ \\
\text { If } \\
0 \\
- \\
-1\end{array}$ & 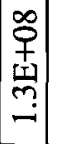 & $\begin{array}{l}0 \\
\vdots \\
9 \\
\infty \\
-1\end{array}$ & $\begin{array}{l}0 \\
\vdots \\
\text { 口. } \\
0 \\
0\end{array}$ & 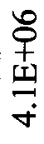 \\
\hline 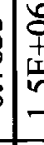 & 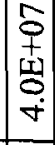 & 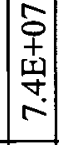 & $\mid \begin{array}{c}8 \\
9 \\
4 \\
0 \\
r\end{array}$ & 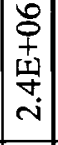 & $\begin{array}{c}5 \\
0 \\
+ \\
\sim 1 \\
\sim \\
\text { m. }\end{array}$ & $\left|\begin{array}{c}\infty \\
0 \\
1 \\
\text { In } \\
0 \\
+\end{array}\right|$ & 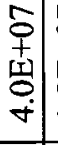 & $\begin{array}{c}\mathbf{0} \\
+ \\
\text { I } \\
\infty \\
- \\
-\end{array}$ & $\begin{array}{l}8 \\
+ \\
1 \\
0 \\
0 \\
\infty \\
\infty\end{array}$ \\
\hline 造 & 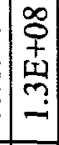 & $\mid$\begin{tabular}{c}
0 \\
0 \\
9 \\
9 \\
\cline { 1 - 1 } \\
\end{tabular} & $\mid \begin{array}{c}0 \\
1 \\
\text { 亲 } \\
-\end{array}$ & 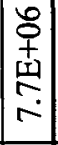 & $\left|\begin{array}{c}0 \\
+ \\
0 \\
0 \\
0 \\
\infty\end{array}\right|$ & 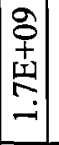 & 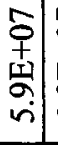 & $\begin{array}{l}0 \\
0 \\
9 \\
0 \\
0 \\
0\end{array}$ & 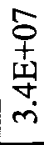 \\
\hline 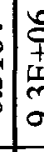 & 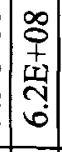 & $\mid \begin{array}{c}8 \\
0 \\
5 \\
0 \\
0 \\
-1\end{array}$ & $\left|\begin{array}{c}0 \\
0 \\
\vdots \\
\text { 妾 } \\
-1\end{array}\right|$ & $\mid \begin{array}{c}5 \\
\vdots \\
\pm \\
\vdots \\
- \\
-1\end{array}$ & $\left|\begin{array}{c}\infty \\
0 \\
+ \\
\text { ty } \\
0 \\
\forall \\
\forall\end{array}\right|$ & $\left|\begin{array}{c}8 \\
0 \\
1 \\
\text { प1 } \\
\infty \\
\infty\end{array}\right|$ & $\begin{array}{c}\infty \\
\vdots \\
+ \\
\frac{T}{\sigma} \\
\dot{m}\end{array}$ & 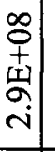 & $\begin{array}{l}\infty \\
0 \\
+ \\
\text { 䛼 } \\
= \\
\end{array}$ \\
\hline $\mid \begin{array}{c}0 \\
\frac{9}{4} \\
\frac{5}{5} \\
a\end{array}$ & 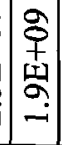 & 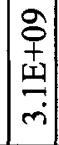 & $\left|\begin{array}{c}\infty \\
0 \\
1 \\
1 \\
0 \\
ن \\
ن\end{array}\right|$ & $\mid \begin{array}{c}0 \\
\vdots \\
1 \\
0 \\
0 \\
i \\
\end{array}$ & $\left|\begin{array}{c}8 \\
0 \\
1 \\
\text { ț } \\
\text { م. } \\
-1\end{array}\right|$ & $\left|\begin{array}{c}0 \\
+ \\
+9 \\
9 \\
\hdashline \\
m\end{array}\right|$ & 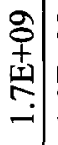 & 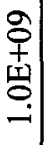 & 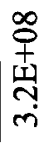 \\
\hline 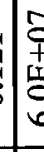 & 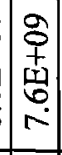 & 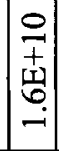 & $\left|\begin{array}{c}0 \\
+ \\
\mathbf{1} \\
ي \\
-1\end{array}\right|$ & 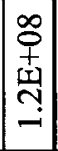 & $\left|\begin{array}{c}8 \\
0 \\
9 \\
=1 \\
\hdashline\end{array}\right|$ & 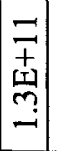 & 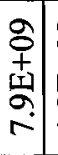 & $\begin{array}{l}0 \\
0 \\
9 \\
9 \\
\text { m. } \\
\forall\end{array}$ & 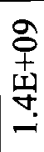 \\
\hline 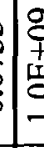 & 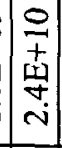 & $\mid \begin{array}{c}0 \\
+ \\
+ \\
\text { 고 } \\
\infty \\
\infty\end{array}$ & 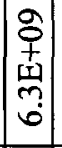 & 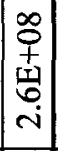 & $\left|\begin{array}{c}0 \\
+ \\
+ \\
\text { y } \\
\sim \\
\sim\end{array}\right|$ & 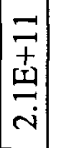 & $\begin{array}{l}0 \\
+ \\
+ \\
\text { ma } \\
\text { m. }\end{array}$ & $\begin{array}{c}8 \\
0 \\
+ \\
\text { ज్ } \\
\text { o. } \\
\end{array}$ & 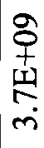 \\
\hline 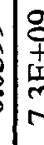 & 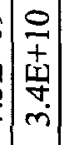 & 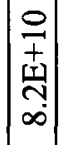 & $\left|\begin{array}{c}0 \\
+ \\
\text { 至 } \\
-2\end{array}\right|$ & 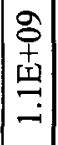 & $\left|\begin{array}{c}0 \\
+ \\
+ \\
\text { ț } \\
\sim \\
\sim\end{array}\right|$ & $\mid \begin{array}{c}= \\
+ \\
+ \\
\text { 贽 } \\
-\end{array}$ & $\begin{array}{l}0 \\
+ \\
\text { 国 } \\
\dot{\sigma} \\
\dot{\nabla}\end{array}$ & $\begin{array}{c}a \\
+ \\
+ \\
\text { 밍 } \\
\sigma\end{array}$ & 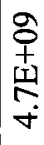 \\
\hline 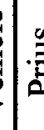 & 惑 & 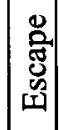 & 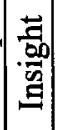 & $\sum_{0}^{2}$ & 急 & 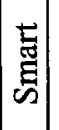 & $\begin{array}{c}\text { : } \\
\text { : } \\
\text {. }\end{array}$ & 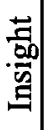 & 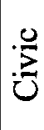 \\
\hline & & : & & & & & $\frac{\infty}{1}$ & & \\
\hline
\end{tabular}

\begin{tabular}{|c|c|c|c|c|c|c|c|c|c|}
\hline & 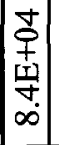 & 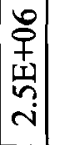 & 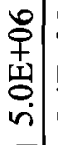 & 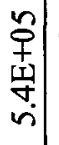 & 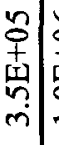 & 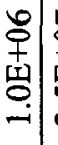 & 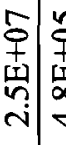 & 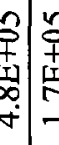 & 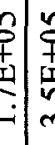 \\
\hline & 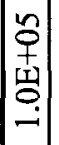 & 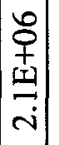 & 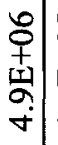 & 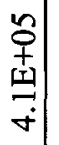 & $\begin{array}{l}2 \\
0 \\
+ \\
\vdots \\
0 \\
\dot{0}\end{array}$ & $\begin{array}{l}0 \\
+ \\
0 \\
\vdots \\
a\end{array}$ & ع & 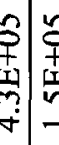 & 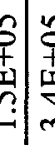 \\
\hline & 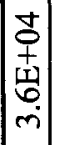 & $\left|\begin{array}{c}0 \\
+ \\
\pm \\
0 \\
\infty \\
\sim\end{array}\right|$ & 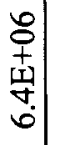 & $\begin{array}{l}n \\
0 \\
\vdots \\
= \\
0 \\
\infty \\
0\end{array} \mid$ & $\begin{array}{l}n \\
+ \\
+ \\
\\
\infty \\
\infty\end{array}$ & 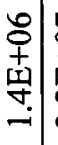 & 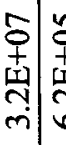 & 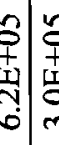 & 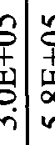 \\
\hline & $\left.\mid \begin{array}{c}n \\
0 \\
5 \\
n \\
- \\
-1\end{array}\right]$ & $\left|\begin{array}{c}0 \\
0 \\
1 \\
\pm \\
0 \\
0 \\
0\end{array}\right|$ & 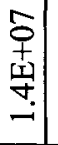 & 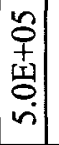 & 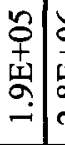 & $\begin{array}{l}8 \\
+ \\
+ \\
0 \\
0 \\
\end{array}$ & 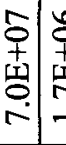 & 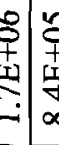 & 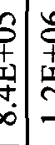 \\
\hline & 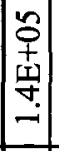 & $\mid \begin{array}{c}0 \\
\vdots \\
1 \\
\text { In } \\
0 \\
\sigma \\
\end{array}$ & $\begin{array}{c}5 \\
+ \\
\pm \\
0 \\
i\end{array}$ & $\left|\begin{array}{c}0 \\
0 \\
0 \\
0 \\
\vdots \\
\dot{\sigma}\end{array}\right|$ & 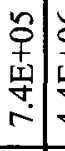 & 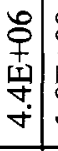 & 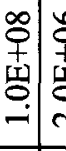 & 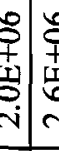 & 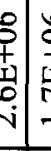 \\
\hline 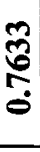 & $\left|\begin{array}{c}n \\
1 \\
1 \\
0 \\
0 \\
m \\
m\end{array}\right|$ & 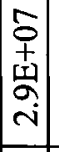 & 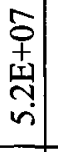 & $\begin{array}{l}0 \\
0 \\
+ \\
\text { t19 } \\
\text { r. } \\
\text { r. }\end{array}$ & 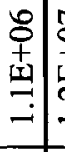 & 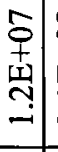 & 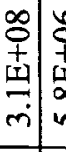 & 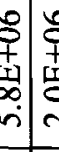 & 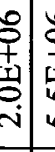 \\
\hline 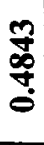 & $\left|\begin{array}{c}0 \\
1 \\
1 \\
\pm \\
\infty \\
\infty\end{array}\right|$ & $\left|\begin{array}{c}0 \\
⿱ \\
વ \\
= \\
0 \\
\infty\end{array}\right|$ & $\begin{array}{c}0 \\
\vdots \\
+ \\
\text { ज్ } \\
\end{array}$ & 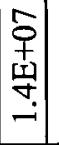 & $\begin{array}{l}8 \\
+ \\
1 \\
0 \\
0 \\
i\end{array}$ & 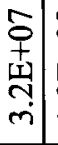 & 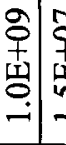 & & 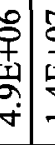 \\
\hline & 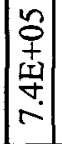 & 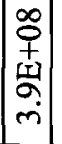 & $\begin{array}{c}0 \\
\vdots \\
+ \\
n \\
\vdots \\
0\end{array}$ & $\left|\begin{array}{c}0 \\
+ \\
w \\
0 \\
0 \\
0\end{array}\right|$ & 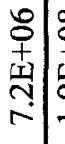 & 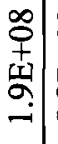 & $\begin{array}{l}2 \\
+ \\
4 \\
n \\
n \\
n\end{array}$ & 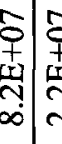 & 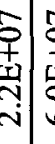 \\
\hline & 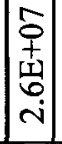 & 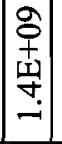 & $\begin{array}{c}\stackrel{9}{0} \\
+ \\
\text { 总 } \\
\stackrel{0}{-}\end{array}$ & $\left|\begin{array}{c}\infty \\
0 \\
+ \\
\sim \\
\sim \\
\sim\end{array}\right|$ & 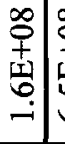 & $\begin{array}{c}\infty \\
0 \\
+ \\
\text { ปn } \\
0\end{array}$ & 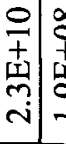 & 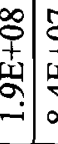 & 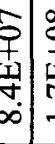 \\
\hline$\frac{\bar{y}}{\dot{y}}$ & 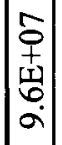 & 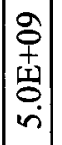 & $\begin{array}{c}9 \\
+ \\
\Phi \\
\oplus \\
\infty \\
\infty\end{array}$ & $\left|\begin{array}{c}\infty \\
0 \\
+ \\
\square \\
n \\
+ \\
+\end{array}\right|$ & 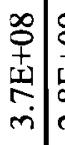 & $\begin{array}{l}9 \\
+ \\
+ \\
\text { 1 } \\
\text { in }\end{array}$ & $\begin{array}{l}0 \\
+ \\
+1 \\
\vdots \\
\infty \\
\infty\end{array}$ & $\begin{array}{l}\infty \\
\vdots \\
\vdots \\
0 \\
\infty \\
\infty \\
\infty\end{array}$ & 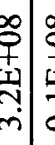 \\
\hline & 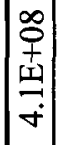 & $\left|\begin{array}{c}0 \\
+ \\
\pm \\
0 \\
0 \\
-1\end{array}\right|$ & $\begin{array}{l}0 \\
7 \\
4 \\
y \\
+ \\
\forall\end{array}$ & 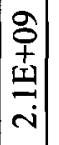 & 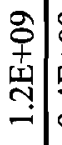 & 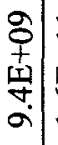 & 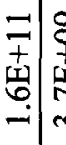 & 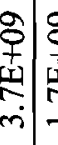 & \begin{tabular}{c|c}
8 \\
+ \\
$\vdots$ \\
$\vdots$ \\
-1
\end{tabular} \\
\hline$\stackrel{\text { }}{\stackrel{8}{8}}$ & $\left|\begin{array}{c}2 \\
0 \\
1 \\
\mathbf{1} \\
0 \\
-1\end{array}\right|$ & $\left|\begin{array}{c}0 \\
+ \\
5 \\
n \\
i\end{array}\right|$ & 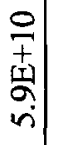 & $\begin{array}{c}0 \\
\vdots \\
\vdots \\
\pm \\
0 \\
\infty\end{array} \mid$ & 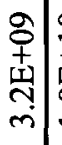 & $\begin{array}{l}\text { 음 } \\
\text { 站 } \\
-\end{array}$ & $\begin{array}{l}7 \\
7 \\
7 \\
\end{array}$ & 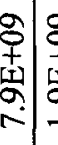 & 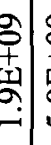 \\
\hline & : & 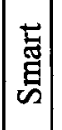 & 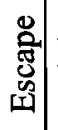 & 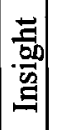 & : & $\cdot \stackrel{n}{n}$ & 苞 & 总 & $\underline{\xi}$ \\
\hline & & & & & & & & & \\
\hline
\end{tabular}




\begin{tabular}{|c|c|c|c|c|c|c|c|c|c|c|}
\hline$\frac{8}{d}$ & 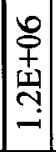 & 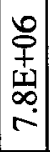 & $\left|\begin{array}{c}\infty \\
0 \\
+ \\
\underline{1} \\
\infty \\
-i\end{array}\right|$ & $\begin{array}{c}0 \\
+ \\
+ \\
\text { 帘 } \\
\infty \\
-1\end{array}$ & $\left|\begin{array}{c}0 \\
+ \\
+ \\
\text { In } \\
n \\
m\end{array}\right|$ & 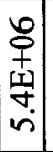 & 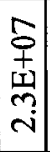 & $\mid \begin{array}{c}5 \\
\frac{1}{1} \\
\text { 되 } \\
\end{array}$ & $\begin{array}{c}5 \\
\text { 畐 } \\
\text { 比 } \\
-i\end{array}$ & 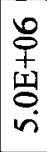 \\
\hline$\stackrel{2}{r}$ & $\left|\begin{array}{l}n \\
+ \\
+1 \\
\infty \\
o \\
0\end{array}\right|$ & \begin{tabular}{c}
0 \\
0 \\
1 \\
\pm \\
\hdashline \\
\end{tabular} & $\left|\begin{array}{c}\infty \\
0 \\
9 \\
\text { 19 } \\
0 \\
-1\end{array}\right|$ & $\left|\begin{array}{c}0 \\
0 \\
+ \\
1 \\
\infty \\
\dot{\tau} \\
\dot{0}\end{array}\right|$ & $\left|\begin{array}{c}0 \\
0 \\
+ \\
\text { 岌 } \\
\text { ن }\end{array}\right|$ & 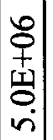 & 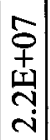 & 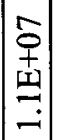 & 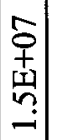 & 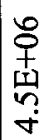 \\
\hline$\frac{\sigma}{\sigma}$ & $\left|\begin{array}{c}n \\
+ \\
n \\
n \\
n \\
-1\end{array}\right|$ & $\begin{array}{c}5 \\
+ \\
+ \\
\text { 突 } \\
-i\end{array}$ & 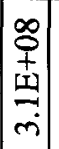 & $\begin{array}{c}0 \\
0 \\
+ \\
\text { 至 } \\
\dot{m}\end{array}$ & $\begin{array}{c}0 \\
0 \\
+ \\
\text { 至 } \\
\dot{m}\end{array}$ & \begin{tabular}{c}
0 \\
0 \\
101 \\
\hdashline \\
0 \\
0
\end{tabular} & $\begin{array}{c}5 \\
+ \\
1 \\
\text { ñ } \\
\text { ñ }\end{array}$ & $\begin{array}{c}5 \\
+ \\
\underline{-1} \\
- \\
-1\end{array} \mid$ & 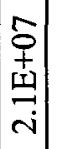 & 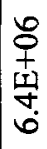 \\
\hline $\begin{array}{l}n \\
\tilde{n} \\
\delta \\
\end{array}$ & $\mid \begin{array}{c}0 \\
0 \\
+ \\
\text { II } \\
\text { J. } \\
-\end{array}$ & 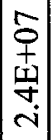 & $\left|\begin{array}{c}\infty \\
0 \\
+ \\
\pm \\
\square \\
\hdashline \\
r\end{array}\right|$ & 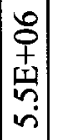 & $\begin{array}{c}0 \\
0 \\
+ \\
01 \\
0 \\
\infty \\
\infty\end{array}$ & 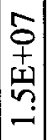 & $\begin{array}{c}5 \\
+ \\
+1 \\
\text { ț } \\
\end{array}$ & $\begin{array}{c}5 \\
+ \\
\text { 岁 } \\
\infty \\
\dot{r}\end{array}$ & $\begin{array}{c}5 \\
+ \\
\pm \\
5 \\
\vdots \\
+\end{array}$ & $\begin{array}{l}5 \\
+ \\
+ \\
\text { 崩 } \\
\text { ? }\end{array}$ \\
\hline 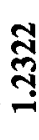 & $\mid \begin{array}{c}0 \\
0 \\
+1 \\
\text { c1 } \\
0 \\
\text { ri }\end{array}$ & 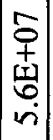 & $\left|\begin{array}{c}8 \\
\Phi \\
\pm \\
0 \\
-1\end{array}\right|$ & 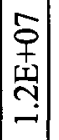 & $\begin{array}{c}5 \\
8 \\
\text { 岁 } \\
-\end{array}$ & 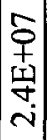 & 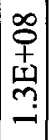 & $\mid \begin{array}{c}5 \\
+ \\
0 \\
0 \\
0 \\
\text { ri }\end{array}$ & $\begin{array}{c}5 \\
+ \\
+ \\
0 \\
0 \\
-\end{array}$ & 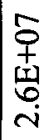 \\
\hline 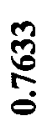 & 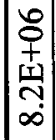 & $\left|\begin{array}{c}\infty \\
0 \\
+ \\
w \\
\\
\sim \\
\sim\end{array}\right|$ & 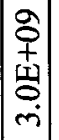 & $\begin{array}{c}0 \\
+ \\
+ \\
\text { 뙹 } \\
\dot{8}\end{array}$ & $\begin{array}{c}5 \\
+ \\
+ \\
1 \\
0 \\
0 \\
0\end{array}$ & $\begin{array}{c}5 \\
+ \\
+1 \\
\text { 亲 } \\
r\end{array}$ & $\begin{array}{c}\infty \\
0 \\
+ \\
\stackrel{+}{\infty} \\
\infty \\
\dot{+}\end{array}$ & $\mid \begin{array}{c}\infty \\
0 \\
+ \\
+1 \\
0 \\
0 \\
-1\end{array}$ & $\begin{array}{c}\infty \\
0 \\
+ \\
4 \\
0 \\
0 \\
\text { î }\end{array}$ & $\begin{array}{l}\hat{0} \\
+ \\
\text { 崩 } \\
\infty \\
\infty\end{array}$ \\
\hline $\begin{array}{l}\stackrel{m}{*} \\
\stackrel{0}{+} \\
\dot{0}\end{array}$ & $\begin{array}{l}5 \\
+ \\
\pm \\
-1 \\
-1\end{array}$ & $\left|\begin{array}{c}\infty \\
0 \\
+ \\
\text { 농 } \\
\infty \\
\infty\end{array}\right|$ & $\begin{array}{c}9 \\
0 \\
+ \\
\text { 묑 } \\
\therefore\end{array}$ & $\left|\begin{array}{c}\infty \\
0 \\
+ \\
1 \\
m \\
n \\
-1\end{array}\right|$ & $\begin{array}{c}0 \\
0 \\
+ \\
\text { 됭 } \\
-1\end{array}$ & $\begin{array}{c}\infty \\
0 \\
+ \\
\text { 列 } \\
\text { ci }\end{array}$ & 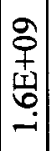 & $\begin{array}{c}\infty \\
0 \\
+ \\
\pm \\
\text { 蒠 } \\
\dot{+}\end{array}$ & $\begin{array}{c}\infty \\
0 \\
+ \\
\pm \\
\vdots \\
0 \\
0\end{array}$ & $\begin{array}{l}\infty \\
0 \\
+ \\
\text { 峁 } \\
\dot{m}\end{array}$ \\
\hline$\frac{\mathbb{H}}{\tilde{m}}$ & \begin{tabular}{c}
5 \\
+ \\
+ \\
\cline { 1 - 1 } \\
ri
\end{tabular} & 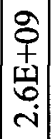 & 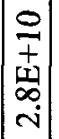 & $\left|\begin{array}{c}\infty \\
0 \\
+ \\
\text { In } \\
n \\
0\end{array}\right|$ & 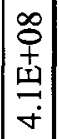 & $\mid \begin{array}{c}\infty \\
0 \\
+ \\
\text { ب } \\
0 \\
0 \\
0\end{array}$ & $\mid \begin{array}{c}9 \\
9 \\
\underline{9} \\
6\end{array}$ & $\left|\begin{array}{c}9 \\
0 \\
+ \\
9 \\
0 \\
0 \\
ن\end{array}\right|$ & $\begin{array}{c}9 \\
0 \\
+ \\
\omega \\
0 \\
\dot{0} \\
m\end{array}$ & 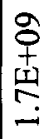 \\
\hline$\stackrel{n}{\stackrel{2}{\rho}}$ & $\mid \begin{array}{c}\infty \\
0 \\
+ \\
\text { 至 } \\
\dot{+}\end{array}$ & 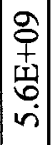 & 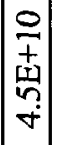 & $\left|\begin{array}{c}9 \\
0 \\
+ \\
1 \\
= \\
= \\
-1\end{array}\right|$ & 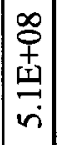 & $\begin{array}{c}8 \\
\dot{1} \\
\mathbf{\omega} \\
\hat{\sigma} \\
\text { ci }\end{array}$ & 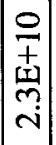 & $\mid \begin{array}{c}g \\
0 \\
+ \\
\text { 岂 } \\
\dot{r i}\end{array}$ & 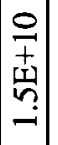 & $\begin{array}{l}g \\
+ \\
+ \\
\text { m } \\
\text { in }\end{array}$ \\
\hline 궁 & 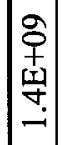 & 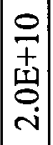 & $\begin{array}{c}-1 \\
\overrightarrow{+} \\
\dot{\omega} \\
\infty \\
-1\end{array}$ & $\left|\begin{array}{c}g \\
9 \\
y \\
\text { II } \\
\dot{v}\end{array}\right|$ & $\begin{array}{c}9 \\
+ \\
+ \\
\text { 岁 } \\
-1\end{array}$ & $\left|\begin{array}{c}0 \\
+\frac{1}{4} \\
m \\
m\end{array}\right|$ & $\begin{array}{c}= \\
+ \\
\underline{I} \\
\sim \\
-\end{array}$ & 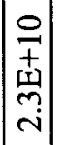 & $\begin{array}{c}0 \\
+ \\
\omega \\
\frac{\omega}{2} \\
\dot{n}\end{array} \mid$ & 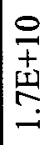 \\
\hline$\stackrel{\mathscr{c}}{\stackrel{0}{\theta}}$ & $\begin{array}{l}8 \\
0 \\
+ \\
\text { 뇡 } \\
\text { n. }\end{array}$ & $\left|\begin{array}{c}0 \\
\dot{y} \\
{[\underline{I}} \\
m \\
6\end{array}\right|$ & 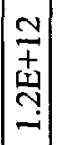 & $\left|\begin{array}{c}0 \\
+1 \\
\text { w } \\
n \\
\sim\end{array}\right|$ & $\begin{array}{c}g \\
\dot{0} \\
+1 \\
g \\
\infty \\
\infty\end{array} \mid$ & $\begin{array}{c}0 \\
+ \\
\pm \\
\underline{+} \\
\dot{f}\end{array} \mid$ & 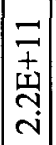 & 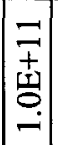 & $\begin{array}{l}= \\
\pm \\
\pm \\
=\end{array}$ & $\begin{array}{l}\frac{0}{+} \\
\text { 章 } \\
\text { vi }\end{array}$ \\
\hline & 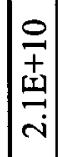 & $\left|\begin{array}{c}0 \\
+1 \\
\text { II } \\
0 \\
\infty\end{array}\right|$ & 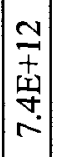 & 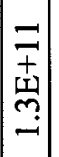 & $\begin{array}{c}0 \\
+ \\
+ \\
\text { บ } \\
\forall\end{array}$ & $\begin{array}{l}0 \\
\dot{y} \\
\text { 殅 } \\
\dot{8}\end{array}$ & $\begin{array}{l}z \\
\pm \\
\underline{I} \\
\underline{-1}\end{array}$ & 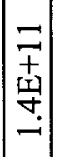 & $\begin{array}{c}0 \\
+ \\
+ \\
0 \\
0 \\
0\end{array} \mid$ & $\begin{array}{l}\frac{0}{7} \\
\text { 至 } \\
\text { ? }\end{array}$ \\
\hline & : & $\mid \begin{array}{c}5 \\
\text { 营 } \\
\text { फ }\end{array}$ & 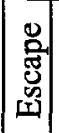 & 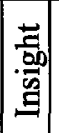 & : & $\mid \begin{array}{c}2 \\
.2 \\
0 \\
0\end{array}$ & 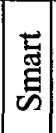 & 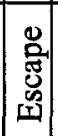 & 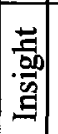 & ن \\
\hline & & & $\begin{array}{l}0 \\
\stackrel{\sim}{\sim}\end{array}$ & & & & & $\stackrel{\infty}{\rightarrow}$ & & \\
\hline
\end{tabular}



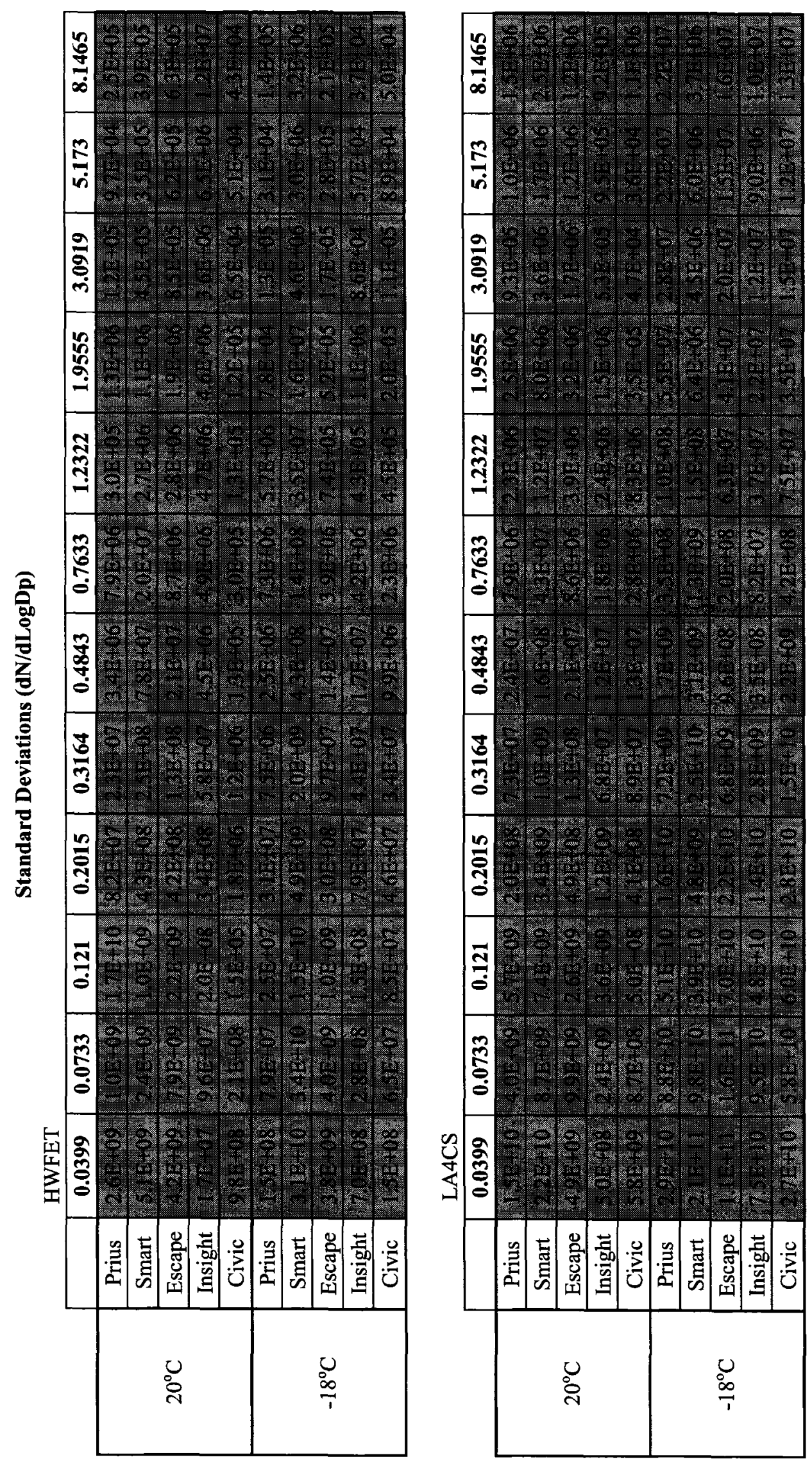

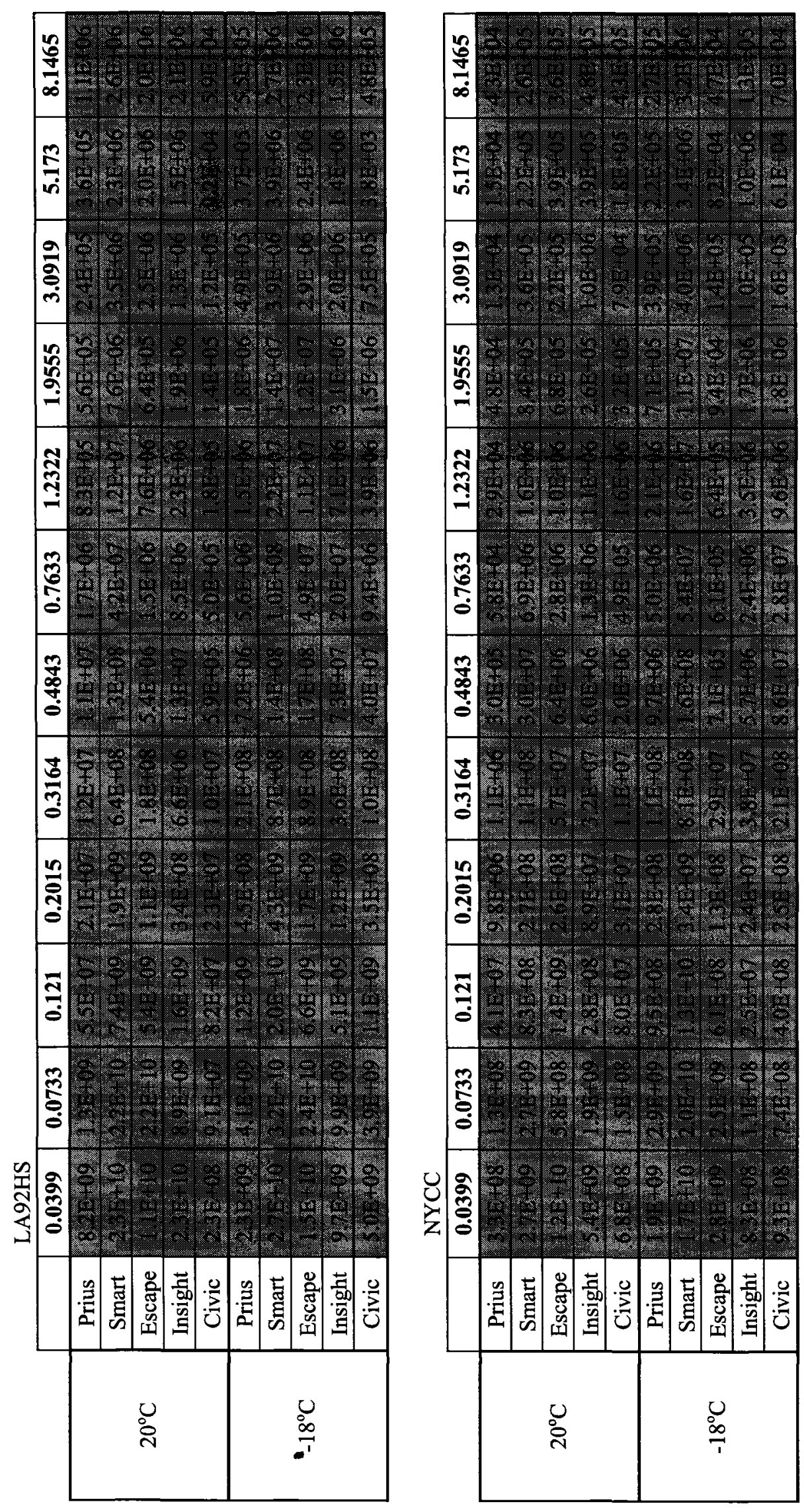


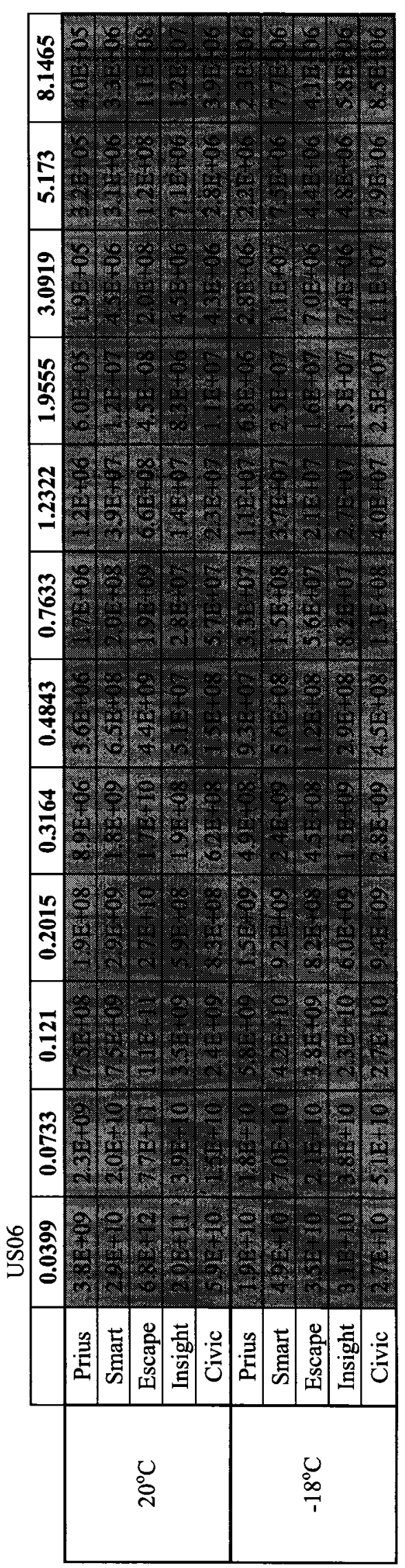

